\title{
2012
}
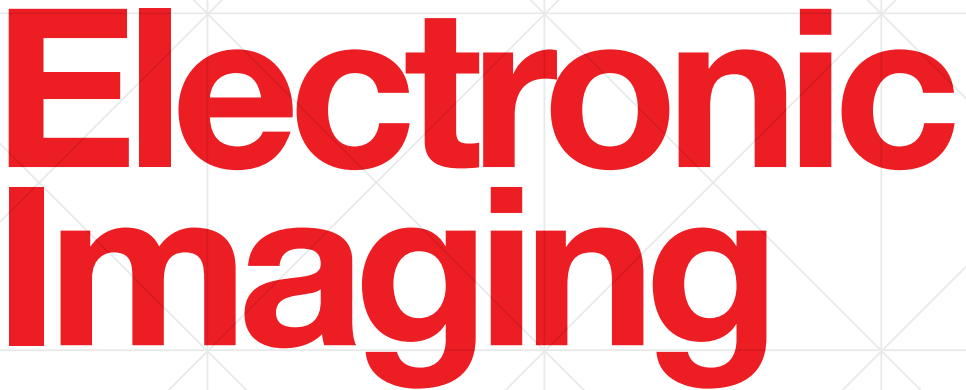

SCIENCE AND TECHNOLOGY 22-26 January 2012

\section{Technical Program}

Conferences and Courses

22-26 January 2012

Hyatt Regency

San Francisco Airport Hotel

Burlingame, California, USA

electronicimaging.org

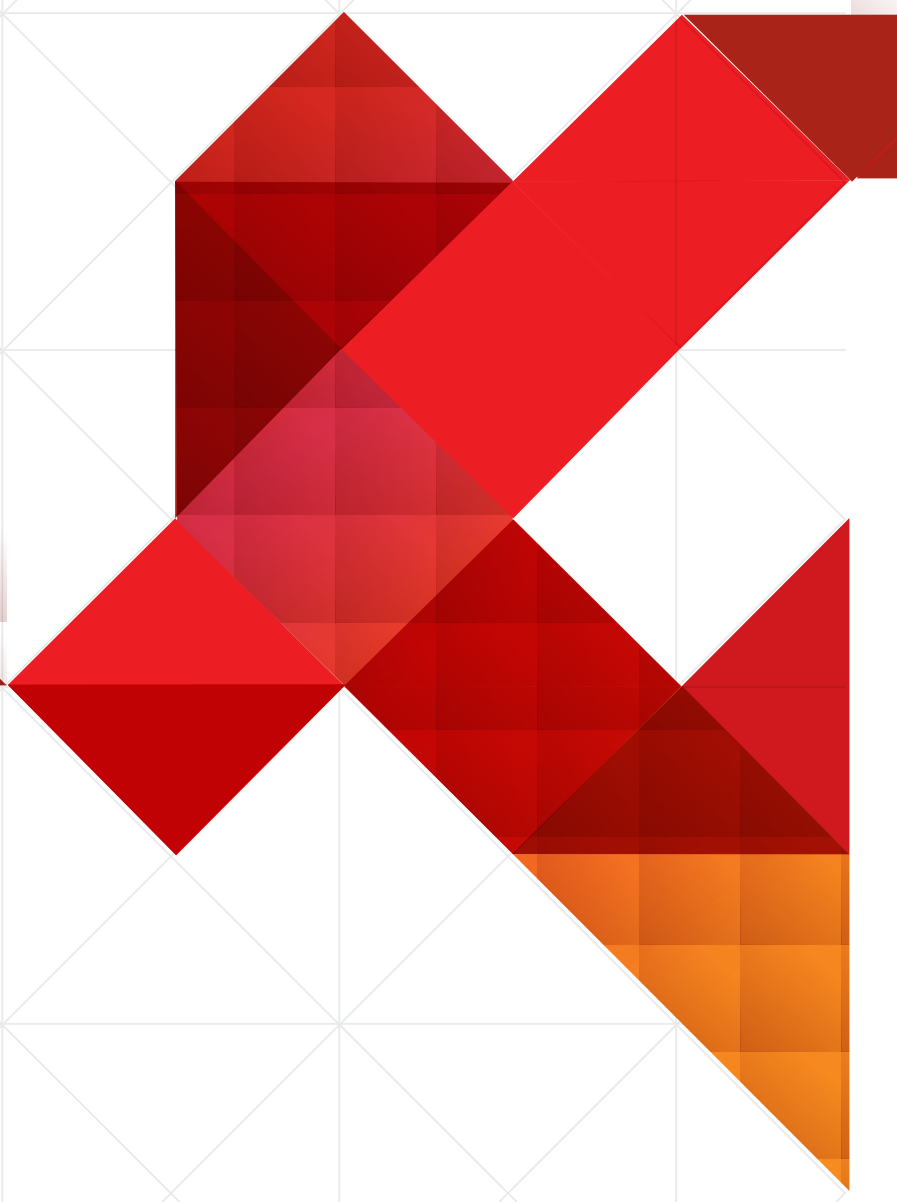




\section{Welcome}

On behalf of IS\&T-The Society for Imaging Science and Technology and SPIE-The International Society for Optics and Photonics, we would like to welcome you to the 24th annual Symposium on Electronic Imaging. Imaging is pervasive in the human experience, be it photographs that we take in our everyday lives to those that are used in space exploration, medical imaging, entertainment, science, or national security.

This week at Electronic Imaging 2012, you will hear the latest research from the world's leading experts in imaging, image processing, sensors, applications, and imaging science and technology. You will also have many opportunities to develop both your career and business by networking with leading researchers and entrepreneurs in the field. Electronic Imaging 2012 is the premier international imaging symposium where you are on the forefront of research and innovation, and we look forward to seeing you this week.

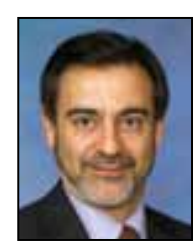

Symposium Chair Majid Rabbani Eastman Kodak Company

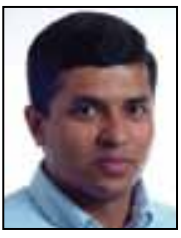

Symposium Cochair

Gaurav Sharma

University of Rochester

Symposium Steering Committee:

Majid Rabbani, Symposium Chair, Eastman Kodak Co.

Gaurav Sharma, Symposium Cochair, Univ. of Rochester

Sabine Süsstrunk, Past Symposium Chair, École Polytechnique Fédérale de Lausanne

Geoff Wolfe, Short Course Chair, Canon Information Systems Research Australia Pty. Ltd.

Nitin Sampat, Technical Advisory Chair, Rochester Institute of Technology

Ron Scotti, SPIE Science and Technology Advisor

Suzanne E. Grinnan, IS\&T Executive Director Rob Whitner, SPIE Event Manager

\section{IS\&T/SPIE}

Electronic

Imaging

SCIENCE AND TECHNOLOGY

22-26 January 2012

\section{Technical Program}

Hyatt Regency San Francisco Airport Hotel

Burlingame, California, USA

IS\&T and SPIE would like to express deep appreciation to the symposium chairs, conference chairs, program committees, and session chairs who have so generously given of their time and advice to make this symposium possible. The symposium, like our other conferences and activities, would not be possible without the dedicated contribution of our participants and members.

This program is based on commitments received up to the time of publication and is subject to change without notice. 


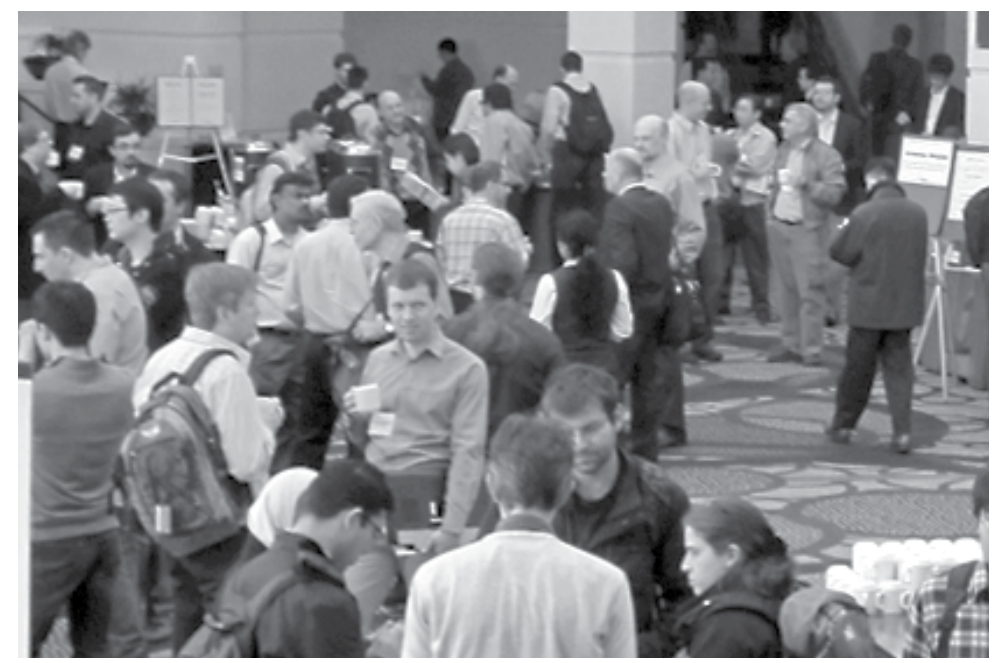

\section{Contents}

Special Events and Plenary Presentations. . . . . . . . 2-3

Meeting Room Locations. . . . . . . . . . . . . 4

General Information . . . . . . . . . . . . . . 5

Organizing Committee .................. 6

Conference Daily Schedule . . . . . . . . . . . . . . 7

Course Daily Schedule $\ldots \ldots \ldots \ldots \ldots \ldots . . . .68$

Technical Conferences. . . . . . . . . . . . . . . . . .10-63

Index of Authors, Chairs, and Committee Members . .64-73

Proceedings ....................... 74

Publication Order Form . . . . . . . . . . . . . . . . . 75

\section{Conferences}

\section{D Imaging, Interaction, and Measurement}

8288 Stereoscopic Displays and Applications XXIII (Woods, Holliman, Favalora) .............. 10-16

8289 The Engineering Reality of Virtual Reality 2012 (McDowall, Dolinsky) ................... 17-18

8290 3D Image Processing (3DIP) and Applications 2012 (Baskurt, Sitnik)..................... 19-21

\section{Imaging, Visualization, and Perception}

8291 Human Vision and Electronic Imaging XVII (Rogowitz, Pappas, de Ridder) . ............. 22-26

8292 Color Imaging XVII: Displaying, Processing, Hardcopy, and Applications (Eschbach, Marcu, Rizzi) . . . . . .................... 27-29

8293 Image Quality and System Performance IX (Gaykema, Burns) .................... 30-32

8294 Visualization and Data Analysis 2012 (Wong, Kao, Hao, Chen) . . . . . . . . . . . . . . . . . . 33-35

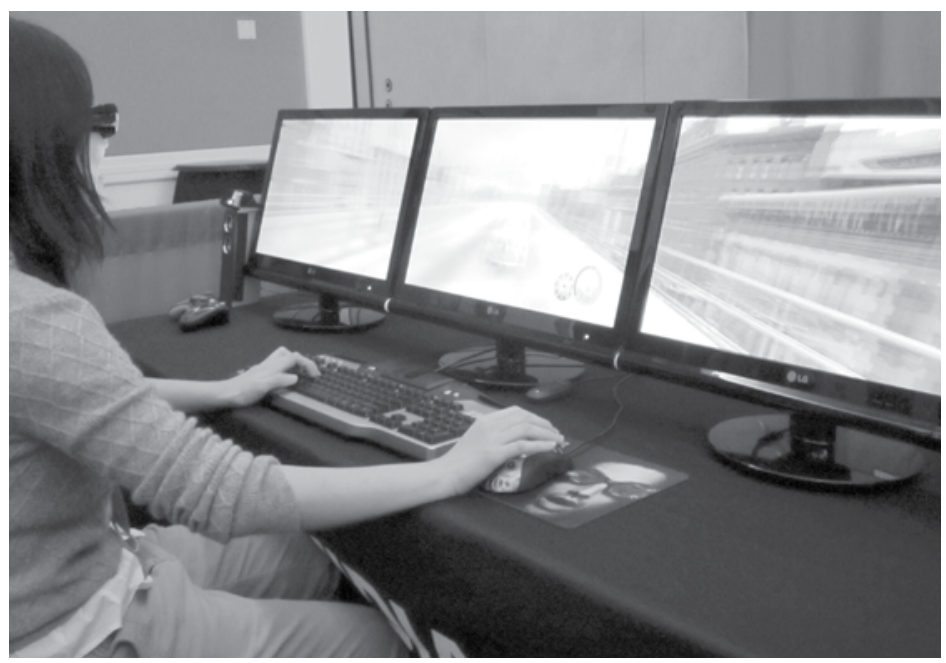

\section{Image Processing}

8295A Image Processing: Algorithms and Systems X (Egiazarian, Agaian, Gotchev) ............. 36-38

8295B Parallel Processing for Imaging Applications II (Recker, Wang) .......................... 39

8296 Computational Imaging X (Bouman, Pollak, Wolfe) . ........................ 40-41

8297 Document Recognition and Retrieval XIX (Viard-Gaudin, Zanibbi) . ................. 42-43

\section{Digital Imaging Sensors and Applications}

8298 Sensors, Cameras, and Systems for Industrial/ Scientific Applications XIII (Widenhorn, Nguyen, Dupret).......................... 44-45

8299 Digital Photography VIII (Battiato, Rodricks, Sampat)....................... 46-47

8300 Image Processing: Machine Vision Applications V (Bingham, Lam)...................... 48-49

8301 Intelligent Robots and Computer Vision XXIX: Algorithms and Techniques (Röning, Casasent) 50-52

\section{Multimedia Processing and Applications}

8302 Imaging and Printing in a Web 2.0 World III (Lin, Allebach, Fan)................... 53-54

8303 Media Watermarking, Security, and Forensics 2012 (Memon, Alattar, Delp) ................. 55-56

8304A Multimedia on Mobile Devices 2012 (Creutzburg, Akopian) ........................ 57-58

8304B Multimedia Content Access: Algorithms and Systems VI (Snoek, Sebe, Kennedy) . . . . . . . . 59-60

\section{Visual Information Processing and Communication}

8305 Visual Information Processing and Communication III (Said, Guleryuz, Stevenson).............. 61-63 


\section{Special Events}
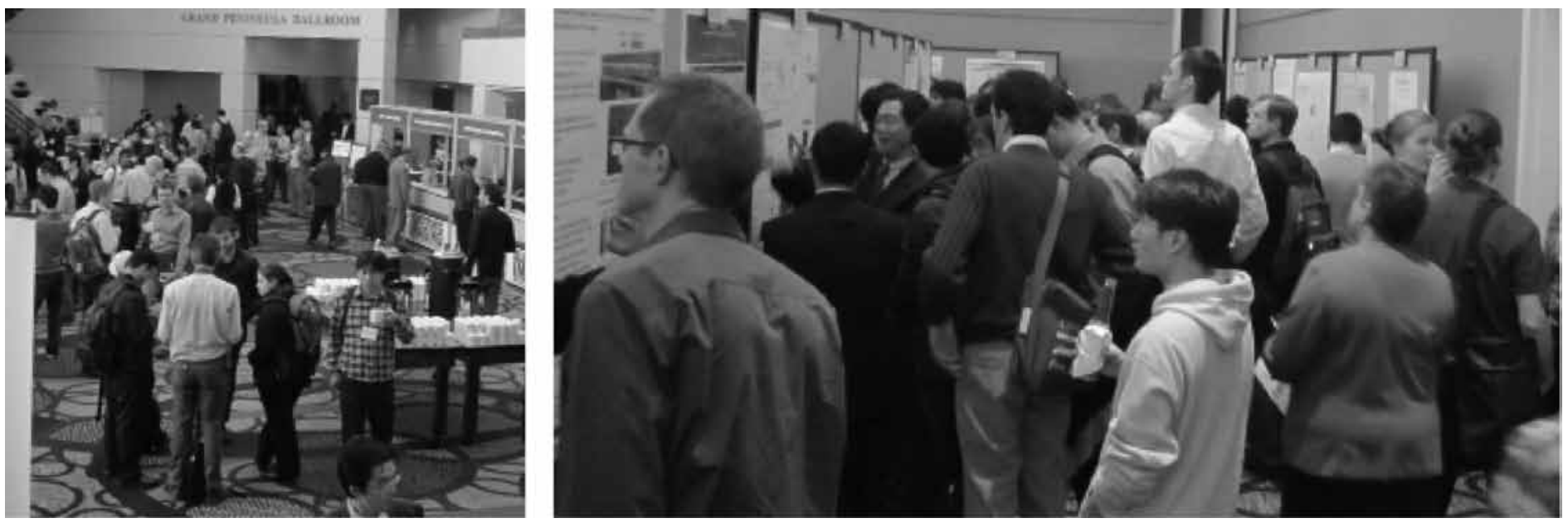

\section{Interactive Paper and Symposium Demonstration Session}

Grand Peninsula Ballroom E

\section{Interactive Paper Set-up, Viewing, and Presentations}

\section{Author Set-up:}

Tuesday 24 January . . . . . . . . . . 7:30 to 10:30 am

\section{General Viewing:}

Tuesday 24 January . . . . . . . . . 10:30 am to 3:00 pm

\section{Interactive Paper Session:}

Tuesday 24 January . . . . . . . . . . 5:30 to 7:00 pm

Conference attendees are encouraged to attend the Interactive Paper and Symposium Demonstration Session where Interactive Paper authors display their posters and are available to answer questions and engage in in-depth discussions about their papers. Light refreshments are provided. Please note that conference registration badges are required for entrance and that posters may be previewed by all attendees on Tuesday from 10:30 am to $3: 00 \mathrm{pm}$.

Authors are asked to set up their poster papers between 7:30 and 10:30 am on Tuesday. Pushpins are provided; other supplies can be obtained at the Conference Registration Desk. Posters will be on display Tuesday.

Authors must remove poster papers at the conclusion of the Interactive Session; posters not removed are considered unwanted and will be removed by staff and discarded. Neither sponsoring Society assumes responsibility for posters left up before or after the Interactive Paper Session.

\section{Symposium Demonstration Session}

Grand Peninsula Ballroom E

Demonstration Set-up:

Tuesday 24 January . . . . . . . . . . . . . . 3:00 to 5:30 pm

Demonstration:

Tuesday 24 January. . . . . . . . . . . . . 5:30 to 8:00 pm

The highly-successful, interactive, hands-on demonstration of hardware, software, display, and research products related to all the topics covered by the Electronic Imaging Symposium will again take place in conjunction with the Interactive Papers session.

This annual demonstration - which traditionally has showcased the largest and most diverse collection of stereoscopic research and products in one location - represents a unique networking opportunity, a time when attendees can see the latest research in action, compare commercial products, ask questions of technically knowledgeable demonstrators, and even make purchasing decisions about a range of El products.

\section{Special JEI booth open for attendees Grand Peninsula Foyer}

Tuesday 24 January . . . . . . . . . . . 5:30 to 7:00 pm

Be sure to check out the Journal of Electronic Imaging booth during the poster demonstration session to learn more about the Journal of Electronic Imaging. This peer-reviewed journal, co-published by IS\&T and SPIE, covers the latest research in electronic imaging technology. JEI representatives will have displays of previous issues and can provide information about how to submit your work for publication.

\section{All-Conference Reception}

Grand Peninsula Ballroom E

Wednesday 25 January. . . . . . . . . . . . 7:00 to 9:00 pm

The All-Conference Reception provides a wonderful opportunity to get to know and interact with Electronic Imaging colleagues. Plan to join us for this relaxing and enjoyable event. 


\section{Special Events}

\section{D Theatre}

Grand Peninsula Ballroom A

Monday 23 January. . . . . . . . . . . . . 5:30 to 7:30 pm

Hosted by Andrew J. Woods, Curtin Univ. (Australia); Chris Ward, Lightspeed Design, Inc. (United States)

The 3D Theatre Session at each year's Stereoscopic Displays and Applications conference showcases the wide variety of 3D content that is being produced and exhibited around the world. All $3 \mathrm{D}$ footage screened at the 3D Theatre Session is shown in highquality, polarized 3D, on a large-screen. The final program will be announced at the conference and 3D glasses will be provided.

\section{Plenary Session and Society Award Presentations}

Grand Peninsula Ballroom A

Tuesday 24 January . . . . . . . . . . . 8:20 to 9:30 am

Welcome . . . . . . . . . . . . . . 8:20 to 8:25 am

Plenary Presentation . . . . . . . . . . . 8:25 to 9:10 am

Society Award Announcements . . . . . . . . 9:10 to 9:20 am

\section{Computational Photography}

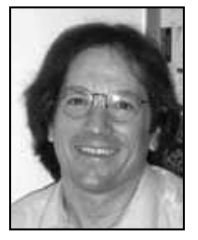

William T. Freeman, Massachusetts Institute of
Technology

Abstract: Computational Photography explores the design space at the interaction of optics, sensing, and computation. l'll review my favorite research projects within this area, most of them by other people, and a few that I was involved with. These projects involve modifications to the camera lens, aperture, shutter, light source or image sensor. By designing algorithms appropriate for each camera modification, novel image capture or manipulation capabilities can be achieved.

Biography: William T. Freeman is Professor and Associate Department Head of the Electrical Engineering and Computer Science Department at the Computer Science and Artificial Intelligence Laboratory (CSAIL) at MIT, joining the faculty in 2001.

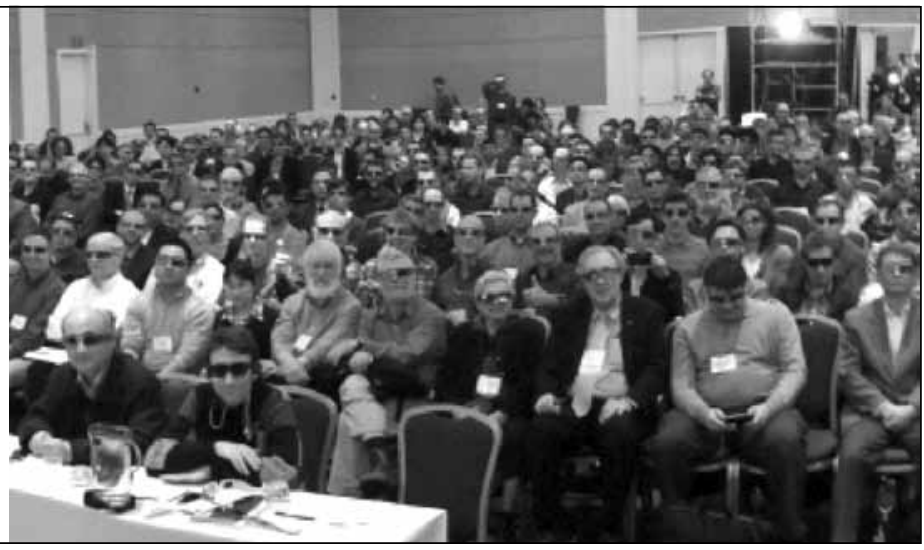

\section{Plenary Session and Conference Award Presentations \\ Grand Peninsula Ballroom A}

Wednesday 25 January. . . . . . . . . . . 8:20 to 9:30 am

Welcome . . . . . . . . . . . . . . . . 8:20 to 8:25 am

Plenary Presentation . . . . . . . . . . . . 8:25 to 9:10 am

Conference Award Announcements . . . . . . 9:10 to 9:20 am

\section{More Words and Bigger Pictures}

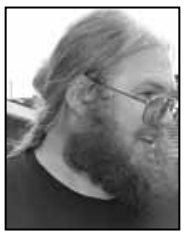

David Forsyth, Univ. of Illinois at Urbana-Champaign

Abstract: I will sketch the current state of the art in object recognition, with a particular emphasis on methods that try to tag images with words, phrases or sentences. Methods are built on two strong ideas: local image descriptors, and classification. Using these tools, the field has built rich technologies for classifying images of objects, detecting objects in images, and describing unfamiliar objects in images. Current methods are moderately accurate. Future methods will have higher accuracy, will produce richer and more conceptual descriptions, and will exploit geometric context to understand spatial relations between objects.

Biography: David Forsyth is currently a full professor at Univ. of Illinois at Urbana-Champaign, where he moved from UC Berkeley and was also full professor. He has published over 130 papers on computer vision, computer graphics and machine learning. Mr. Forsyth has served as program co-chair for IEEE Computer Vision and Pattern Recognition in 2000 and in 2011, general co-chair for CVPR 2006, and program co-chair for the European Conference on Computer Vision 2008. He is a regular member of the program committee of all major international conferences on computer vision. He has served five years on the SIGGRAPH program committee and continues to be a regular reviewer. Mr. Forsyth has received best paper awards at the International Conference on Computer Vision and at the European Conference on Computer Vision. He received an IEEE technical achievement award for 2005 for his research and became an IEEE fellow in 2009. His recent textbook, "Computer Vision: A Modern Approach" (joint with J. Ponce and published by Prentice Hall) is now widely adopted as a course text. A second edition is in press. 


\section{Meeting Room Locations}

\section{Hyatt Regency San Francisco Airport Hotel}

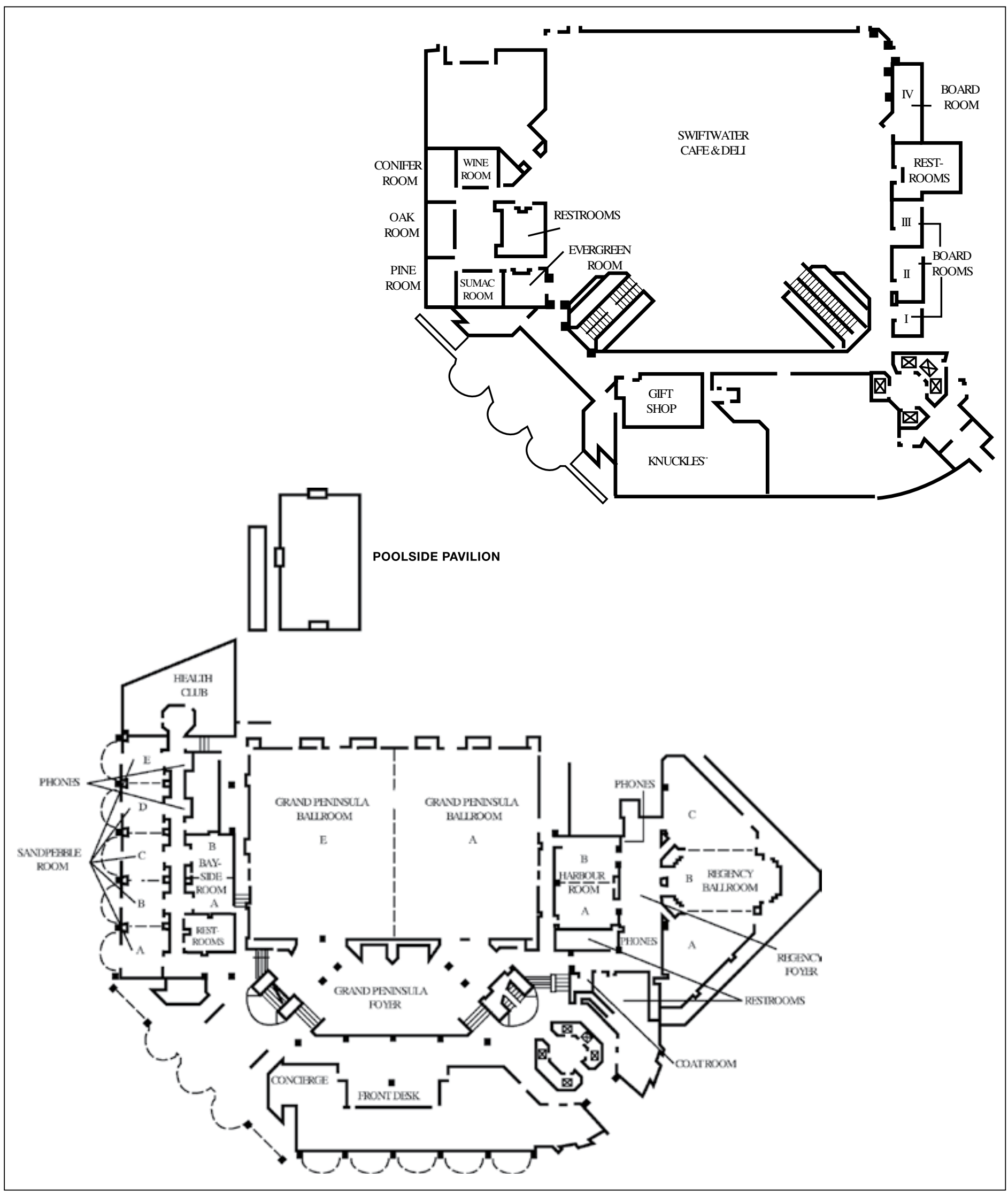




\section{Electronic Imaging 2012}

Hyatt Regency San Francisco Airport Hotel

1333 Bayshore Hwy, Burlingame, CA 94010

\section{Short Course Registration and Course Notes}

\section{Course-only registration}

Sunday 22 January . . . . . . . . . . . 7:00 am to 10:00 am

Courses and workshops are priced separately. Course-only registration includes your selected course(s), course notes, coffee breaks, and admittance to the exhibition.

\section{Short Courses Notes}

Short courses will take place in various meeting rooms at the Hyatt Regency San Francisco Airport Hotel. Room assignments are noted on the course admission tickets and distributed with registration materials.

\section{Onsite Registration Hours}

Hyatt Regency San Francisco Airport Hotel, Grand Peninsula Foyer Conference and course registration

Sunday 22 January . . . . . . . . . . 10:00 am to 4:00 pm Monday 23 January. . . . . . . . . . . 7:00 am to 4:00 pm Tuesday 24 January . . . . . . . . . . . . 7:30 am to 4:00 pm Wednesday 25 January . . . . . . . . 7:30 am to 4:00 pm Thursday 26 January . . . . . . . . . . . . 7:30 am to noon

Conference registration includes: access to all symposium conferences, Interactive Paper and Demonstration Sessions, Exhibition, coffee breaks, All-Conference Reception, and choice of conference proceedings: printed or CD. Courses are not automatically included; you can add a course registration with your conference registration.

\section{Speaker AV Prep Room and Hours}

\section{Open during Registration Hours}

Each conference room has an LCD projector, screen, lapel microphone, and laser pointer. All presenters are encouraged to visit the Speaker AV Prep Room to confirm that their presentation, is compatible with the audiovisual equipment supplied in the conference rooms.

Speakers who have requested special equipment, prior to the request deadline, are asked to report to the AV Prep Room to confirm their requested equipment is available. No shared laptops are provided.

\section{Interactive Paper Set-up}

Authors are asked to set up their poster papers between 7:30 and 10:30 am Tuesday. Pushpins are provided; other supplies can be obtained at the Conference Registration Desk. Posters will be on display Tuesday. Authors must remove poster papers at the conclusion of the Interactive Session; posters not removed are considered unwanted and will be removed by staff and discarded. Neither sponsoring Society assumes responsibility for posters left up before or after the Interactive Paper Session.

\section{Internet Availability}

The Hyatt Regency offers wireless Internet services in each guest room for a charge of $\$ 9.99$ per 24 -hour period. There is no free wireless service in public areas.

A computer dedicated to printing out boarding passes, at no charge, is located next to the Concierge Desk in the lobby.

\section{Business Center}

Hyatt Regency San Francisco Airport Hotel offers a full service 24-hour business center with the following amenities:

Internet access with printers - 20 minutes @ \$5.00

Wireless NIC cards for rent or purchase

Copy services in black and white (Notes: Currently there are no options for color copying) - \$.25 per copy (\$1.25 minimum)

Color copies are available at the local FedEx Office Print \& Ship Computers available for use - 20 minutes @ \$5.00

Facsimile services - no charge

Shipping services and supplies

The business center is located in the lobby of the hotel, adjacent to the registration desk.

\section{Cashier}

IS\&T cashier can assist with registration payments, adding a short course, receipts, and badge corrections.

\section{Message Center}

There will be a message board next to the conference registration desk. Attendees are asked to check the board daily for any messages.

\section{IS\&T Bookstore and Membership Booth} Open Sunday through Thursday during registration hours.

IS\&T publishes and/or distributes technical materials on a broad range of subjects pertinent to the field of electronic imaging. In addition to titles from leading scientific publishers, IS\&T showcases proceedings from its Digital Printing Technologies, Digital Fabrication, Archiving and Color Imaging conferences, as well as selected books on related topics. Information on upcoming meetings and membership, and gratis copies of journals are also available.

\section{SPIE Bookstore}

Open during registration hours.

The SPIE Bookstore is your source for the latest SPIE Press books, Proceedings and educational and professional development materials.

\section{Child Care Services}

American Childcare is the preferred babysitting services for the hotel. They are accredited. Phone: 415-285-2300.

IS\&T/SPIE do not imply an endorsement or recommendation of these services. They are provided on an "information only" basis for your further analysis and decision. Other services may be available. 


\section{IS\&T/SPIE}

\section{Electronic Imaging}

22-26 January 2012

Hyatt Regency San Francisco Airport Hotel Burlingame, California, USA

\section{Technical Organizing Committee}

Sos S. Again, The Univ. of Texas at San Antonio (United States)

David Akopian, The Univ. of Texas at San Antonio (United States)

Adnan M. Alattar, Digimarc Corp. (United States)

Jan P. Allebach, Purdue Univ. (United States)

Atilla M. Baskurt, Univ. of Lyon (France)

Sebastiano Battiato, Univ. degli Studi di Catania (Italy)

Philip R. Bingham, Oak Ridge National Lab. (United States)

Charles A. Bouman, Purdue Univ. (United States)

Peter D. Burns, Consultant (United States)

David P. Casasent, Carnegie Mellon Univ. (United States)

Chaomei Chen, Drexel Univ. (United States)

Reiner Creutzburg, Fachhochschule Brandenburg (Germany)

Huib de Ridder, Technische Univ. Delft (Netherlands)

Edward J. Delp, Purdue Univ. (United States)

Jeffrey M. DiCarlo, Intuitive Surgical, Inc. (United States)

Margaret Dolinsky, Indiana Univ. (United States)

Antoine Dupret, École Supérieure d'Ingénieurs en Electronique et Electrotechnique (France)

Karen O. Egiazarian, Tampere Univ. of Technology (Finland)

Reiner Eschbach, Xerox Corp. (United States)

Zhigang Fan, Xerox Corp. (United States)

Gregg E. Favalora, Optics for Hire (United States)

Frans Gaykema, Océ Technologies B.V. (Netherlands)
Atanas P. Gotchev, Tampere Univ. of Technology (Finland)

Onur G. Guleryuz, DoCoMo Communications Labs. USA, Inc. (United States)

Ming C. Hao, Hewlett-Packard Labs. (United States)

Nicolas S. Holliman, Durham Univ. (United Kingdom)

Francisco H Imai, Canon Development Americas Inc. (United States)

David L. Kao, NASA Ames Research Ctr. (United States) Lyndon Kennedy, Yahoo! Research (United States)

Edmund Y. Lam, The Univ. of Hong Kong (China)

Qian Lin, Hewlett-Packard Labs. (United States)

Gabriel G. Marcu, Apple Inc. (United States)

Ian E. McDowall, Fakespace Labs, Inc. (United States)

Nasir D. Memon, Polytechnic Institute of NYU (United States)

Valérie Nguyen, CEA Leti MINATEC (France)

Thrasyvoulos N. Pappas, Northwestern Univ. (United States)

Ilya Pollak, Purdue Univ. (United States)

John Recker, Hewlett-Packard Labs. (United States)

Alessandro Rizzi, Univ. degli Studi di Milano (Italy)

Brian Rodricks, Fairchild Imaging (United States)

Bernice E. Rogowitz, Visual Perspectives Consulting (United States)

Juha Röning, Univ. of Oulu (Finland)

Amir Said, Hewlett-Packard Labs. (United States)

Nitin Sampat, Rochester Institute of Technology (United States)

Nicu Sebe, Univ. degli Studi di Trento (Italy)

Robert Sitnik, Warsaw Univ. of Technology (Poland)

Cees G. M. Snoek, Univ. van Amsterdam (Netherlands)

Robert L. Stevenson, Univ. of Notre Dame (United States)

Christian Viard-Gaudin, Univ. of Nantes (France)

Guijin Wang, Tsinghua Univ. (China)

Ralf Widenhorn, Portland State Univ. (United States)

Patrick J. Wolfe, Harvard Univ. (United States)

Pak C. Wong, Pacific Northwest National Lab. (United States)

Andrew J. Woods, Curtin Univ. (Australia)

Feng Xiao, Fairchild Imaging (United States)

Richard Zanibbi, Rochester Institute of Technology (United States) 


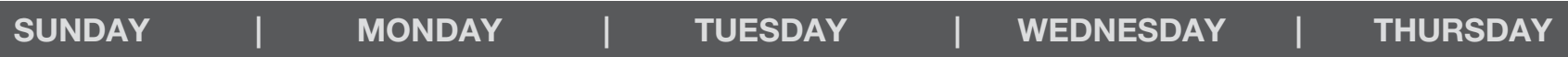

\section{D Imaging, Interaction, and Measurement}

8288 Stereoscopic Displays and Applications XXIII (Woods, Holliman, Favalora) p. 10-16

8289 The Engineering Reality of Virtual Reality 2012

(McDowall, Dolinsky) p. 17-18

8290 3D Image Processing (3DIP) and Applications 2012 (Baskurt, Sitnik) p. 19-21

\section{Imaging, Visualization, and Perception}

8291 Human Vision and Electronic Imaging XVII (Rogowitz, Pappas, de Ridder) p. 22-26

8292 Color Imaging XVII: Displaying, Processing, Hardcopy, and Applications (Eschbach, Marcu, Rizzi) p. 27-29

8293 Image Quality and System Performance IX (Gaykema, Burns) p. 30-32

8294 Visualization and Data Analysis 2012 (Wong, Kao, Hao, Chen) p. 33-35

\section{Image Processing}

8295A Image Processing: Algorithms and Systems X (Egiazarian, Agaian, Gotchev) p. 36-38

8295B Parallel Processing for Imaging Applications II (Recker, Wang) p. 39

8296 Computational Imaging X (Bouman, Pollak, Wolfe)

p. $40-41$

8297 Document Recognition and Retrieval XIX (Viard-Gaudin, Zanibbi) p. 42-43

\section{Digital Imaging Sensors and Applications}

\begin{tabular}{|c|c|}
\cline { 2 - 2 } & \begin{tabular}{|c}
8298 Sensors, Cameras, and Systems for Industrial/Scientific Applications XIII (Widenhorn, \\
Nguyen, Dupret) p. 44-45
\end{tabular} \\
\hline
\end{tabular}

8299 Digital Photography VIII (Battiato, Rodricks, Sampat) p. 46-47

8300 Image Processing: Machine Vision Applications V (Bingham, Lam) p. 48-49

8301 Intelligent Robots and Computer Vision XXIX: Algorithms and Techniques (Röning, Casasent) p. 50-52

\section{Multimedia Processing and Applications}

8302 Imaging and Printing in a Web 2.0 World III (Lin, Allebach, Fan) p. 53-54

8303 Media Watermarking, Security, and Forensics 2012 (Memon, Alattar, Delp) p. 55-56

8304A Multimedia on Mobile Devices 2012 (Creutzburg, Akopian) p. 57-58

8304B Multimedia Content Access: Algorithms and Systems

VI (Snoek, Sebe, Kennedy) p. 59-60

\section{Visual Information Processing and Communication}

8305 Visual Information Processing and Communication II (Said, Guleryuz, Stevenson) p. 61-63 


\section{SUNDAY}

\section{D Imaging, Interaction, and Measurement}

\begin{tabular}{l}
\hline SC060 Stereoscopic Display \\
Application Issues (Merritt, Woods) 8:30 \\
am to 5:30 pm, \$575 / \$685 \\
\hline SC1047 Autostereoscopic and \\
Holographic Display Technologies (Lee) \\
8:30 am to 12:30 pm, \$350 / \$405 \\
\hline SC1046 Video Processing \\
Techniques for 3D Television (Ho) 1:30 \\
to 5:30 pm, \$350 / \$405 \\
\hline SC1045 Evaluation Methodology \\
for 2D and 3D Displays (de Ridder, \\
Heynderickx) 1:30 to 5:30 pm, \$350 / \\
\$405 DLP Projection Technology \\
\hline SC1029 D \\
(Ramanath) 8:30 am to 12:30 pm, \$350 / \\
$\$ 405 \quad$ Multivariate Analysis of \\
\hline SC837 \\
Imaging and Sensor Data (Bajorski) \\
8:30 am to 5:30 pm, \$575 / \$685
\end{tabular}

Digital Imaging Sensors and Applications
SC967 High Dynamic Range

(Darmont) 8:30 am to 5:30 pm, \$575 / $\$ 685$

SC1058 Image Quality and

Evaluation of Cameras In Mobile

Devices (Wüller, Matherson) 8:30 am to

5:30 pm, \$575 / \$685

SC1021 Mobile Computational

Photography (Pulli, Ahonen, Troccoli)

8:30 am to 5:30 pm, \$575 / \$685

SC837 Multivariate Analysis of

Imaging and Sensor Data (Bajorski)

8:30 am to 5:30 pm, \$575 / \$685

SC965 Joint Design of Optics

and Image Processing for Imaging

Systems (Stork) 1:30 to 5:30 pm, \$350 /

$\$ 405$

\section{Image Processing}

SC837 Multivariate Analysis of Imaging and Sensor Data (Bajorski) 8:30 am to $5: 30 \mathrm{pm}, \$ 575 / \$ 685$

SC1058 Image Quality and

Evaluation of Cameras In Mobile

Devices (Wüller, Matherson) 8:30 am to

5:30 pm, \$575 / \$685

SC468 Image Enhancement,

Deblurring and Super-Resolution

(Rabbani) 8:30 am to 5:30 pm, \$575 /

$\$ 685$

SC965 Joint Design of Optics

and Image Processing for Imaging

Systems (Stork) 1:30 to 5:30 pm, \$350 /

$\$ 405$

SC967 High Dynamic Range

Imaging: Sensors and Architectures

(Darmont) 8:30 am to 5:30 pm, \$575 /

$\$ 685$

SC1021 Mobile Computational

Photography (Pulli, Ahonen, Troccoli)

8:30 am to 5:30 pm, \$575 / \$685

SC060 Stereoscopic Display

Application Issues (Merritt, Woods) 8:30

am to 5:30 pm, \$575 / \$685

SC1050 Perception and Cognition

for Emerging Imaging Technologies

(Rogowitz) 8:30 am to 12:30 pm, \$350 /

$\$ 405$
SC927 3D Imaging (Agam)

$8: 30$ am to $12: 30 \mathrm{pm}, \$ 350$ /

$\$ 405$

SC504 Introduction to CCD and CMOS Imaging Sensors and Applications (Janesick) 8:30 am to 5:30 pm, $\$ 715 / \$ 825$

SC1049 Objective and

Subjective Image Quality

Camera Benchmarking

(Hornung, Eliasson, Phillips) 8:30

am to 5:30 pm, \$575 / \$685
SC916 Digital Camera and Sensor Evaluation Using

Photon Transfer (Janesick)

$8: 30$ am to $5: 30 \mathrm{pm}, \$ 630$ /

$\$ 740$

SC1048 Image Processing

for Single-Sensor Imaging

Devices (Battiato) 8:30 am to

12:30 pm, \$350 / \$405

SC927 3D Imaging (Agam)
$8: 30$ am to $12: 30 \mathrm{pm}, \$ 350$ /
$\$ 405$

SC1015 Understanding and Interpreting Images (Rabbani) 1:30 to 5:30 pm, $\$ 350 / \$ 405$
SC1048 Image Processing for Single-Sensor Imaging Devices (Battiato) 8:30 am to 12:30 pm, \$350 / \$405 
Imaging, Visualization, and Perception

\begin{tabular}{|c|}
\hline $\begin{array}{l}\text { SC1045 Evaluation } \\
\text { Methodology for 2D and 3D } \\
\text { Displays (de Ridder, Heynderickx) } \\
\text { 1:30 to } 5: 30 \mathrm{pm}, \$ 350 / \$ 405\end{array}$ \\
\hline $\begin{array}{l}\text { SC1050 Perception and } \\
\text { Cognition for Emerging Imaging } \\
\text { Technologies (Rogowitz) 8:30 am } \\
\text { to } 12: 30 \mathrm{pm}, \$ 350 / \$ 405\end{array}$ \\
\hline $\begin{array}{l}\text { SC468 Image Enhancement, } \\
\text { Deblurring and Super-Resolution } \\
\text { (Rabbani) 8:30 am to 5:30 pm, } \\
\$ 575 / \$ 685\end{array}$ \\
\hline $\begin{array}{l}\text { SC1029 DLP Projection } \\
\text { Technology (Ramanath) 8:30 am to } \\
12: 30 \text { pm, } \$ 350 / \$ 405\end{array}$ \\
\hline $\begin{array}{l}\text { SC967 High Dynamic } \\
\text { Range Imaging: Sensors and } \\
\text { Architectures (Darmont) 8:30 am to } \\
5: 30 \mathrm{pm}, \$ 575 \text { / } \$ 685\end{array}$ \\
\hline $\begin{array}{l}\text { SC1058 Image Quality and } \\
\text { Evaluation of Cameras In Mobile } \\
\text { Devices (Wüller, Matherson) 8:30 } \\
\text { am to 5:30 pm, } \$ 575 / \$ 685\end{array}$ \\
\hline $\begin{array}{l}\text { SC837 Multivariate Analysis } \\
\text { of Imaging and Sensor Data } \\
\text { (Bajorski) 8:30 am to 5:30 pm, \$575 } \\
\text { / \$685 }\end{array}$ \\
\hline $\begin{array}{l}\text { SC060 Stereoscopic Display } \\
\text { Application Issues (Merritt, } \\
\text { Woods) 8:30 am to 5:30 pm, } \$ 575 \text { / } \\
\$ 685\end{array}$ \\
\hline
\end{tabular}
Subjective Image Quality Camera Benchmarking (Hornung, Eliasson, Phillips) $8: 30$ am to 5:30 pm, \$575 / $\$ 685$

SC927 3D Imaging (Agam) 8:30 am to $12: 30 \mathrm{pm}, \$ 350$ $\$ 405$

SC1015 Understanding and Interpreting Images (Rabbani) $1: 30$ to $5: 30 \mathrm{pm}, \$ 350 / \$ 405$

\section{Multimedia Processing and Applications}

\section{SC1058 Image Quality} and Evaluation of Cameras

In Mobile Devices Wüller, Matherson) 8:30 am to 5:30 pm, $\$ 575 / \$ 685$

SC1021 Mobile Computational Photography (Pulli, Ahonen, Troccoli) 8:30 am to $5: 30 \mathrm{pm}$, $\$ 575$ / \$685

SC1046 Video Processing Techniques for 3D Television SC967 High Dynamic Range Imaging: Sensors and Architectures (Darmont) 8:30 am to 5:30 pm, \$575 / \$685

SC468 Image Enhancement, Deblurring and Super-

Resolution (Rabbani) 8:30 am to 5:30 pm, \$575 / \$685 (Ho) 1:30 to 5:30 pm, \$350 / \$405

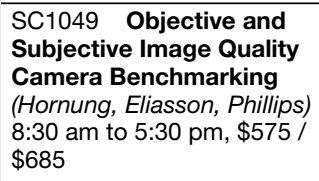

Visual Information Processing and Communication

SC468 Image Enhancement,

Deblurring and Super-Resolution

(Rabbani) 8:30 am to 5:30 pm, \$575

/ \$685

SC1046 Video Processing

Techniques for 3D Television $(\mathrm{Ho})$

1:30 to 5:30 pm, \$350 / \$405

SC1058 Image Quality and

Evaluation of Cameras In Mobile

Devices (Wüller, Matherson) 8:30

am to $5: 30 \mathrm{pm}, \$ 575 / \$ 685$
SC1048 Image Processing

for Single-Sensor Imaging

Devices (Battiato) 8:30 am to

12:30 pm, \$350 / \$405

SC1048 Image Processing

for Single-Sensor Imaging

Devices (Battiato) 8:30 am to

12:30 pm, \$350 / \$405 


\section{Conference 8288}

Monday-Wednesday 23-25 January 2012 • Proceedings of SPIE Vol. 8288

\section{Stereoscopic Displays and Applications XXIII}

Conference Chairs: Andrew J. Woods, Curtin Univ. (Australia); Nicolas S. Holliman, Durham Univ. (United Kingdom); Gregg E. Favalora, Optics for Hire (United States)

Program Committee: Florian Ciurea, Pelican Imaging Corp. (United States); Neil A. Dodgson, Univ. of Cambridge (United Kingdom); Hideki Kakeya, Univ. of Tsukuba (Japan); Takashi Kawai, Waseda Univ. (Japan); John D. Stern, Intuitive Surgical, Retired (United

States); Vivian K. Walworth, StereoJet, Inc. (United States); Chris Ward, Lightspeed Design, Inc. (United States); Michael A. Weissman, Perspective Systems (United States); Samuel Zhou, IMAX Corp. (Canada)

Founding Chair: John O. Merritt, The Merritt Group (United States)

\section{Cosponsors}

Gold Sponsors:

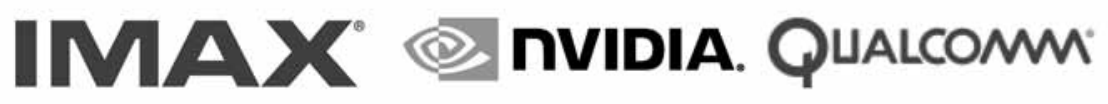

Silver Sponsors:

\section{Depth $(9$ \\ ELDIM}

Projection Sponsors:

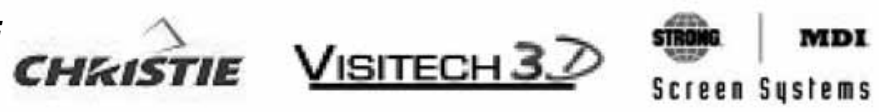

Media Sponsors:
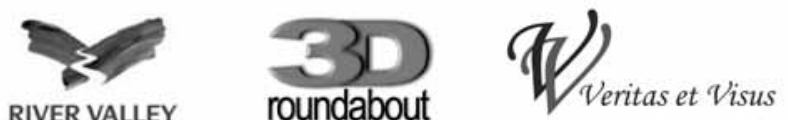

RIVER VALLEY

roundabout

\section{Monday 23 January SESSION 1}

Room: Grand Peninsula Ballroom A... Mon. 8:30 to 9:10 am

\section{D Applications}

Session Chair: Andrew J. Woods, Curtin Univ. (Australia) 8:30 am: Matching stereo 3D reconstructions of CT/MRI data and intraoperative stereo video for medical education and treatment planning, Justus F. Ilgner M.D., Martin Westhofen M.D., Univ. Hospital Aachen (Germany) . . . . . . . . . . . . . . . . . . . [8288-01]

8:50 am: Stereoscopic desktop VR system for tele-maintenance, Michael Kleiber, Fraunhofer FKIE (Germany) . . . . . . . . . [8288-02]

\section{Room: Grand Peninsula \\ Ballroom A . . . . . . . . . . . . . . . . . . Mon. 9:10 to 9:20 am}

Welcome and Opening Remarks

Session Chair: Andrew J. Woods, Curtin Univ. (Australia)

\section{Room: Grand Peninsula}

Ballroom A. . Mon. 9:20 to $10: 20$ am

\section{Keynote Presentation I}

9:20 am: Panasonic's stereoscopic 3D technologies, standardization, and business strategy (Presentation Only), Masayuki Kozuka, Panasonic Corp. (Japan). . . . . . . . . . . . [8288-99]

Coffee Break ........................ 10:20 to 10:50 am 
SESSION 2

Room: Grand Peninsula Ballroom A. . . . Mon. 10:50 am to 12:30 pm

\section{D Cameras and Mobile 3D}

Session Chair: Michael A. Weissman, Consultant (United States)

10:50 am: Angle-sensitive pixels: a new paradigm for low-power, low-cost 2D and 3D sensing, Albert Wang, Sheila S. Hemami, Alyosha Molnar, Cornell Univ. (United States) . . . . . . . . . . . . [8288-03]

11:10 am: Polarizing aperture stereoscopic cinema camera, Lenny Lipton, Leonardo IP (United States) . . . . . . . . . . . . . [8288-04]

11:30 am: Hardware-efficient, real-time 3D image processing for single lens color/depth-unified sensor: from depth noise reduction, depth super-resolution, to stereoscopic image synthesis, Hwasup Lim, Yong Sun Kim, Ouk Choi, Byongmin Kang, Seong-Jin Kim, Keechang Lee, James D.K. Kim, Changyeong Kim, Samsung Advanced Institute of Technology (Korea, Republic of) . . . . . . . . . . . . . . . [8288-05]

11:50 am: Unassisted 3D camera calibration, Kalin Atanassov, Vikas Ramachandra, Sergio Goma, Qualcomm Inc. (United States) . . [8288-06]

12:10 pm: Auto convergence for stereoscopic 3D mobile cameras, Buyue Zhang, Sreeni Kothandaraman, Aziz Umit Batur, Texas Instruments Inc. (United States) . . . . . . . . . . . . . . . . . . . [8288-07]

Lunch Break ................... 12:30 to 2:00 pm

\section{SESSION 5}

Room: Grand Peninsula Ballroom E.....Mon. 10:50 am to 12:30 pm

\section{D Developments}

Session Chair: Neil A. Dodgson, Univ. of Cambridge (United Kingdom) 10:50 am: Stereoscopic-3D display design: a new paradigm with Intel adaptive stable image technology [IA-SIT], Sunil K. Jain, Intel Corp. (United States). . . . . . . . .

11:10 am: A real-time misalignment correction algorithm for stereoscopic 3D cameras, Ibrahim E. Pekkucuksen, Buyue Zhang, Aziz Umit Batur, Texas Instruments Inc. (United States) . . . . . . . . [8288-17]

11:30 am: Full-color stereoscopy with little flicker at low-refresh rate by time-division multiplexing anaglyph, Hideki Kakeya, Hiroaki Kodaira, Univ. of Tsukuba (Japan). . . . . . . . . . . . . . . . . [8288-18]

11:50 am: Supervised disparity estimation, Patrick Vandewalle, Chris Varekamp, Philips Research Nederland B.V. (Netherlands) . . . . [8288-19]

12:10 pm: Analysis of brain activity and response during monoscopic and stereoscopic visualization, Enrico Calore, Raffaella Folgieri, Davide Gadia, Daniele Marini, Univ. degli Studi di Milano (Italy). . . . . . . [8288-20] Lunch Break .................... 12:30 to 2:00 pm

\section{SESSION 3}

\section{Room: Grand Peninsula Ballroom A... Mon. 2:00 to 3:20 pm \\ Autostereoscopic Displays: Multi-Layer and Multi- Projector}

Session Chair: Gregg E. Favalora, Optics for Hire (United States)

2:00 pm: Beyond parallax barriers: applying formal optimization methods to multi-layer automultiscopic displays, Douglas Lanman, Massachusetts Institute of Technology (United States) . . . . . . . [8288-08]

2:20 pm: 3D image quality of 200-inch glasses-free 3D display system, Masahiro Kawakita, NHK Science \& Technical Research Labs. (Japan); Shoichiro Iwasawa, National Institute of Information and Communications Technology (Japan); Masahisa Sakai, Yasuyuki Haino, Masahito Sato, JVC KENWOOD Holdings, Inc. (Japan); Naomi Inoue, National Institute of Information and Communications Technology (Japan). . . . . . . [8288-09]

2:40 pm: Implementation and analysis of an autostereoscopic display using multiple liquid crystal layers, Hironobu Gotoda, National Institute

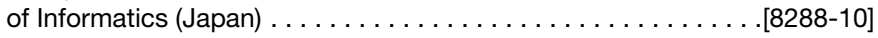

3:00 pm: 360-degree, three-dimensional table-screen display using small array of high-speed projectors, Shigeki Uchida, Yasuhiro Takaki, Tokyo Univ. of Agriculture and Technology (Japan) . . . . . . . . [8288-11] Coffee Break. $3: 20$ to $3: 50 \mathrm{pm}$

\section{SESSION 6}

Room: Grand Peninsula Ballroom E. . . Mon. 2:00 to 3:20 pm

\section{Perception, Quality, and Comfort}

Session Chair: John D. Stern, Intuitive Surgical, Inc., Retired (United States)

2:00 pm: Motion in-depth constancy in stereoscopic displays, Sidrah Laldin, Laurie Wilcox, Carly Hylton, Robert S. Allison, York Univ.

(Canada) ................................. [8288-21]

2:20 pm: Quality evaluation of depth image-based rendering methods for stereoscopic video content, Mattias Eisenbarth, Technische Univ. Wien (Austria) and emotion3D (Austria); Florian H. Seitner, emotion3D (Austria) and Technische Univ. Wien (Austria); Margrit Gelautz, Technische Univ. Wien (Austria) . . . . . . . . . . . . . . . . . . . . .

2:40 pm: Disparity profiles in 3DV applications: overcoming the issue of heterogeneous viewing conditions in stereoscopic delivery, Guillaume Boisson, Technicolor S.A. (France) . . . . . . . . . [8288-23] 3:00 pm: Investigation of object thickness for visual discomfort prediction in stereoscopic images, Hosik Sohn, Yong Ju Jung, Seong-il Lee, Hyun Wook Park, Yong Man Ro, KAIST (Korea, Republic of)[8288-24]

Coffee Break ..................... 3:20 to $3: 50$ pm 


\section{Conference 8288}

\section{SESSION 4}

Sessions 4 and 7 run concurrently

\section{Room: Grand Peninsula Ballroom A... Mon. 3:50 to 5:10 pm}

\section{D Image Processing and Content Adaptation}

Session Chair: Nicolas S. Holliman, Durham Univ. (United Kingdom)

3:50 pm: Focus mis-match detection in stereoscopic content, Frederic Devernay, Sergi Pujades, Vijay Ch.A.V., INRIA Rhône-Alpes

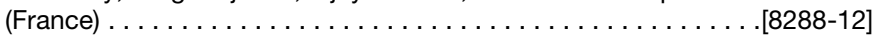

4:10 pm: 2D-to-3D image conversion: leveraging 3D data on the net Janusz Konrad, Geoffrey Brown, Meng Wang, Prakash Ishwar, Boston Univ. (United States) . . . . . . . . . . . . . . . . . . . . . . . . . [8288-13]

4:30 pm: 3D cinema to 3DTV content adaptation, Didier Doyen, Lasith Yasakethu, Laurent Blondé, Quan Huynh-Thu, Technicolor S.A.

(France) . . . . . . . . . . . . . . . . . . . . . . . .

4:50 pm: Video retargeting for stereoscopic content under 3D viewing constraints, Christel Chamaret, Technicolor S.A. (France) . . . . [8288-83]

Session Break. . $5: 10$ to $5: 30 \mathrm{pm}$

\section{SESSION 7}

Room: Grand Peninsula Ballroom E... Mon. 3:50 to 5:10 pm

\section{Autostereoscopy}

Session Chair: Gregg E. Favalora, Optics for Hire (United States) 3:50 pm: History of autostereoscopic cinema, Walter Funk, Hologlyphics (United States).

4:10 pm: Full optical characterization of auto-stereoscopic 3D displays using local viewing angle and imaging measurements, Pierre $\mathrm{M}$. Boher, Thierry Leroux, Thibault Bignon, ELDIM (France) .[8288-26]

4:30 pm: Analysis on monocular accommodation in horizontalparallax-only super-multiview display, Jisoo Hong, Youngmin Kim, Seoul National Univ. (Korea, Republic of); Jae-Hyeung Park, Chungbuk National Univ. (Korea, Republic of); Byoungho Lee, Seoul National Univ. (Korea, Republic of). . . . . . . . . . . . . . . . . . [8288-27] 4:50 pm: A novel time-multiplexed, autostereoscopic, multi-view, fullresolution 3D display, Jian-Chiun Liou, Industrial Technology Research Institute (Taiwan) . . . . . . . . . . . . . . . . . . . . [8288-28] Session Break . $5: 10$ to $5: 30 \mathrm{pm}$

\section{Room: Grand Peninsula Ballroom A....Mon. 5:30 to 7:30 pm \\ 3D Theatre}

Session Chairs: Andrew J. Woods, Curtin Univ. (Australia); Chris Ward, Lightspeed Design, Inc. (United States)

This ever-popular session allows attendees to see large-screen examples of 3D content from around the world. Program announced at the conference. 3D glasses provided.

\section{SD\&A Annual Dinner}

Mon. 7:45 to $10: 00 \mathrm{pm}$

The annual informal dinner for SD\&A attendees. An opportunity to meet with colleagues and discuss the latest advances. There is no host for the dinner. Information on venue and cost will be provided on the day at the conference.

\section{Tuesday 24 January}

\section{Room: Grand Peninsula}

Ballroom A . . . . . . . . . . . Tues. 8:20 to 9:30 am

\section{Plenary Session and Society Award Presentations}

8:25 am: Computational Photography, William T. Freeman, Massachusetts Institute of Technology (United States)

\section{Room: Grand Peninsula \\ Ballroom A . . . . . . . . . . . . . Tues. 9:30 to 10:30 am}

\section{Keynote Presentation II}

9:30 am: The past, present, and future of YouTube3D, Pete Bradshaw, Debargha Mukherjee, Google Inc. (United States)[8288-100]

Coffee Break ..................... 10:30 to $11: 00 \mathrm{am}$ 


\section{SESSION 8}

Room: Grand Peninsula

Ballroom A . . . . . . . . . . . . . . . Tues. 11:00 am to 12:40 pm

\section{D Image Quality: Crosstalk}

Session Chair: John O. Merritt, The Merritt Group (United States)

11:00 am: Crosstalk reduces the amount of depth seen in 3D images of natural scenes, Inna Tsirlin, Robert S. Allison, Laurie M. Wilcox, York Univ. (Canada) . . . . . . . . . . . . . . . . . . . . [8288-29]

11:20 am: Method and simulation to study 3D crosstalk perception, Darya Aleksandrovna Khaustova, Laurent Blondé, Didier Doyen, Quan Huynh-Thu, Technicolor S.A. (France) ............... [8288-30]

11:40 am: Reproducibility of crosstalk measurements on active glasses 3D LCD displays based on temporal characterization, Sylvain Tourancheau, Mid Sweden Univ. (Sweden); Kun Wang, Acreo AB (Sweden) and Mid Sweden Univ. (Sweden); Lucjan Janowski, Jaroslaw Bulat, AGH Univ. of Science and Technology (Poland); Kjell Brunnström, Acreo AB (Sweden); Marcus Barkowsky, Polytech' Nantes (France) . . . . . [8288-31]

12:00 pm: Crosstalk and brightness in projection-based, multiview systems, Roland Blach, Achim Pross, Fraunhofer-Institut für Arbeitswirtschaft und Organisation (Germany); Alexander Kulik, Bauhaus Univ. Weimar (Germany); Oliver Stefani, Fraunhofer-Institut für Arbeitswirtschaft und Organisation (Germany) . . . . . . . . . [8288-32]

12:20 pm: How much crosstalk can be allowed in a stereoscopic system at various grey levels?, Sergey A. Shestak, Dae-Sik Kim, Samsung Electronics Co., Ltd. (Korea, Republic of). . . . . . . . . [8288-33] Lunch Break ..................... 12:40 to 2:00 pm

\section{SESSION 9A}

Room: Grand Peninsula Ballroom A... .Tues. 2:00 to 3:20 pm

\section{Stereoscopic 3D Image Quality: Quantifying Perception and Comfort: Joint Session with Conference 8291}

Session Chairs: Sergio R. Goma, Qualcomm Inc. (United States); John O. Merritt, The Merritt Group (United States); Christopher W. Tyler, The Smith-Kettlewell Eye Research Institute (United States); Lora T. Likova, The Smith-Kettlewell Eye Research Institute (United States)

2:00 pm: Apparent stereo: the Cornsweet illusion can enhance perceived depth, Piotr Didyk, Max-Planck-Institut für Informatik (Germany); Tobias Ritschel, Elmar Eisemann, Telecom ParisTech (France); Karol Myszkowski, Hans-Peter Seidel, Max-Planck-Institut für Informatik (Germany) . . . . . . . . . . . . . . . . . . . [8291-19]

2:20 pm: Perceived depth of multi parallel, overlapping, transparent, stereoscopic surfaces, Saori Aida, Koichi Shimono, Tokyo Univ. of Marine Science and Technology (Japan); Wa James Tam, Communications Research Ctr. Canada (Canada) . . . . . . . . . . . . . [8291-20]

2:40 pm: Diagnosing perceptual distortion present in group stereoscope viewing, Melissa M. Burton, Brice B. Pollock, Jonathan W. Kelly, Stephen B. Gilbert, Eliot Winer, lowa State Univ. (United States); Julio de la Cruz, U.S. Army RDECOM/STTC (United States) . . . .[8291-21] 3:00 pm: Visual discomfort and the timing of vergenceaccommodation conflicts, Joohwan Kim, David Kane, Martin S. Banks, Univ. of California, Berkeley (United States) . . . . . . . . . . . [8288-34] Coffee Break ..................... 3:20 to $3: 50$ pm

\section{SESSION 9B}

Room: Grand Peninsula Ballroom A... Tues. 3:50 to 5:10 pm

\section{Stereoscopic 3D Image Quality: Quantifying Perception and Comfort: Joint Session with Conference 8291}

Session Chairs: Sergio R. Goma, Qualcomm Inc. (United States); John O. Merritt, The Merritt Group (United States); Christopher W. Tyler, The Smith-Kettlewell Eye Research Institute (United States); Lora T. Likova, The Smith-Kettlewell Eye Research Institute (United States)

3:50 pm: Measuring 3D discomfort from vertical and torsional disparities in natural images, Christopher W. Tyler, Lora T. Likova, The Smith-Kettlewell Eye Research Institute (United States); Kalin Atanassov, Vikas Ramachandra, Sergio Goma, Qualcomm (United States) . . [8291-22]

4:10 pm: Visual fatigue versus eye-movements, Cyril Vienne, Laurent Blondé, Didier Doyen, Technicolor S.A. (France) ........... [8288-35]

4:30 pm: Visual comfort: stereoscopic objects moving in the horizontal and mid-sagittal planes, Wa James Tam, Filippo Speranza, Carlos Vázquez, Ron Renaud, Communications Research Ctr. Canada (Canada); Namho Hur, Electronics and Telecommunications Research Institute (Korea, Republic of)....................... [8288-36]

4:50 pm: Visual discomfort with stereo 3D displays when the head is not upright, David Kane, Robin Held, Martin Banks, Univ. of California, Berkeley (United States) . . . . . . . . . . . . . . . . . . [8288-37]

\section{Interactive Paper and Symposium Demonstration Session}

Room: Grand Peninsula Ballroom E. . Tues. 5:30 to 8:00 pm

Demonstrations ................... 5:30 to 8:00 pm

A symposium-wide demonstration session will be open to attendees 5:30 to 8:00 pm Tuesday evening. Demonstrators will provide interactive, hands-on demonstrations of a wide-range of products related to Electronic Imaging.

The session will have a focused "Stereoscopic Displays and Applications" area. The demonstration session hosts a vast collection of stereoscopic products providing a perfect opportunity to witness a wide array of stereoscopic displays with your own two eyes.

Posters . . . . . . . . . . . . . . . . . . . . . . . 5:30 to 7:00 pm

Interactive papers will be placed on display after 10:30 am on Tuesday. An interactive paper session, with authors present at their papers, will be held Tuesday evening, 5:30 to 7:00 pm.

\section{Stereoscopic Perception and Quality}

Correlation between a perspective distortion in a S3D content and the visual discomfort perceived, Didier Doyen, Laurent Blondé, JeanJacques Sacré, Technicolor S.A. (France) .............. [8288-54]

Evaluation of quality of experience in interactive 3D visualization: methodology and results, Sylvain Tourancheau, Mårten Sjöström, Roger Olsson, Mid Sweden Univ. (Sweden); Anders Persson, Ctr. for Medical Image Science and Visualization (Sweden); Thomas Ericson, Setred AB

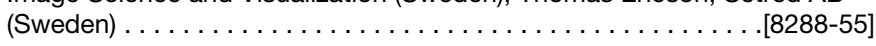

Objective view synthesis quality assessment, Pierre-Henri Conze, Technicolor S.A. (France) and Institut National des Sciences Appliquées de Rennes (France); Robert Philippe, Technicolor S.A. (France); Luce Morin, Institut National des Sciences Appliquées de Rennes (France) . . [8288-56]

Depth enhancement of S3D content and the psychological effects, Masahiro Hirahara, Saki Shiraishi, Takashi Kawai, Waseda Univ.

(Japan). . . . . .

Perception of size and shape in stereoscopic 3D imagery, Michael D. Smith, MDS Consulting (United States); Bradley T. Collar, Warner Bros. Entertainment Inc. (United States). . . . . . . . . . . . . [8288-58] 
Quality of experience model for 3DTV, Wei Chen, France Telecom R\&D (France) and Polytech' Nantes (France); Jérôme Fournier, France Telecom R\&D (France); Marcus Barkowsky, Patrick Le Callet, Polytech' Nantes (France) . . . . . . . . . . . . . . . . . . . . . . . . [8288-59]

New approach on calculating multi-view 3D crosstalk for autostereoscopic displays, Sung-Min Jung, Kyeong-Jin Lee, Ji-Na Kang, Seung-Chul Lee, Kyoung-Moon Lim, LG Display (Korea,

Republic of)

Towards adapting current 3DTV for an improved 3D experience, Laurent Blondé, Didier Doyen, Cédric Thébault, Quan Huynh-Thu, Technicolor S.A. (France); Daniel Stoenescu, Emmanuel Daniel, JeanLouis de Bougrenet de la Tocnaye, TELECOM Bretagne (France); Samir Bentahar, EyesTripleShut (France) . . . . . . . . . . . . . .[8288-61]

\section{D Displays}

Integral volumetric imaging with high-resolution and smooth-motion parallax, Shimpei Sawada, Hideki Kakeya, Univ. of Tsukuba

(Japan) . . . . . . . . . . . . . . . . . . . . . . . . . . .[8288-62]

Enlargement of viewing freedom of reduced-view SMV display, Junya Nakamura, Taichi Takahashi, Yasuhiro Takaki, Tokyo Univ. of Agriculture and Technology (Japan) . . . . . . . . . . . . . . . . . . . [8288-63]

Development of high-speed, phase-modulating spatial light modulators for 3D-holographic displays, Hiroyuki Takagi, Taichi Goto, Alexander Baryshev, Mitsuteru Inoue, Toyohashi Univ. of Technology (Japan). . . . . . . . . . . . . . . . . . . . . . . [8288-64]

Color hologram generation using depth map of real objects with viewing-zone-angle expansion, Kosuke Nomura, Tokyo Univ. of Science (Japan) and National Institute of Information and Communications Technology (Japan); Ryutaro Oi, Taiichiro Kurita, National Institute of Information and Communications Technology (Japan); Takayuki Hamamoto, Tokyo Univ. of Science (Japan). . . . . . . . . . . . . . [8288-65]

Stereoscopic surround displays using interference filters, Silvio Peikert, Jérémie Gerhardt, Fraunhofer FIRST (Germany). . . . . . . . . . . [8288-66]

Design of extended viewing zone at autostereoscopic 3D display based on diffusing optical element, Min-Chang Kim, Yong Seok Hwang, Eun-Soo Kim, Kwangwoon Univ. (Korea, Republic of) . . . . . . . . [8288-67]

Floating image device with auto-stereoscopic display and viewertracking technology, Chang-Ying Chen, Kun-Lung Tseng, Chy-Lin Wang, Chao-Hsu Tsai, Industrial Technology Research Institute (Taiwan)[8288-68]

A time-sequential, mutli-view, autostereoscopic display without resolution loss using a multi-directional backlight unit and an LCD panel, Hyunkyung Kwon, Hee-Jin Choi, Sejong Univ. (Korea,

Republic of) . . . . . . . . . . . . . . . . . . . . . . . . . . . . . . [8288-69]

Full-resolution autostereoscopic display with all-electronic tracking system, Jean-Etienne Gaudreau, PolarScreens, Inc. (Canada) . .[8288-70]

Design of crossed-mirror array to form floating 3D LED signs, Hirotsugu Yamamoto, Univ. of Tokushima (Japan) and JST CREST (Japan); Hiroki Bando, Shiro Suyama, Univ. of Tokushima (Japan) . . . . . [8288-98]

\section{Multiview Image Methods}

Novel multi-view generation framework for 3D displays, Kyuyoung Hwang, Yangho Cho, Hoyoung Lee, Dusik Park, ChangYeong Kim, Samsung Advanced Institute of Technology (Korea, Republic of) [8288-71]

Calibration of multiview camera with parallel and decentered image sensors, Mohamed Ali-Bey, Saïd Moughamir, Noureddine Manamanni, Univ. de Reims Champagne-Ardenne (France). . . . . . . . [8288-72]

Inversion-free multiview subpixel rendering for natural 3D presentation, Yun-Tae Kim, Gee-Young Sung, Ju-Yong Park, DongKyung Nam, Du-Sik Park, Samsung Advanced Institute of Technology (Korea, Republic of). . . . . . . . . . . . . . . . . . . . [8288-73]

Wide-viewing angle three-dimensional display based on the ray reconstruction method using multiple micro-projectors, Hideya Takahashi, Kenta Hirooka, Osaka City Univ. (Japan); Kenji Yamada, Osaka Univ. (Japan) . . . . . . . . . . . . . . . . . . . . [8288-74]

Multi-layered, see-through movie in diminished reality, Yuko Uematsu, Takanori Hashimoto, Takuya Inoue, Naoki Shimizu, Hideo Saito, Keio Univ. (Japan). [8288-75]

An independent motion and disparity vector prediction method for multiview video coding, Seungchul Ryu, Jungdong Seo, Yonsei Univ. (Korea, Republic of); Jin Young Lee, Samsung Advanced Institute of Technology (Korea, Republic of); Dong Hyun Kim, Yonsei Univ. (Korea, Republic of); Ho-Cheon Wey, Samsung Advanced Institute of Technology (Korea, Republic of); Kwanghoon Sohn, Yonsei Univ. (Korea,

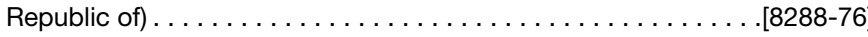

Geometry compensation using depth and camera parameters for three-dimensional video coding, Dong-Hyun Kim, Jungdong Seo,

Seungchul Ryu, Yonsei Univ. (Korea, Republic of); Jin Young Lee, Hocheon Wey, Samsung Advanced Institute of Technology (Korea, Republic of); Kwanghoon Sohn, Yonsei Univ. (Korea, Republic of) . . . . . . . [8288-77]

Converting conventional stereo pairs to multi-view sequences using morphing, Roger Olsson, Vamsi Kiran Adhikarla, Sebastian Schwarz, Mårten Sjöström, Mid Sweden Univ. (Sweden). . . . . . . . . . [8288-78]

Multiview video and depth compression for free-view navigations, Yuta Higuchi, Mehrdad Panahpour Tehrani, Tomohiro Yendo, Toshiaki Fujii, Masayuki Tanimoto, Nagoya Univ. (Japan) . . . . . . . . [8288-79]

A layered inpainting method for virtual view synthesis, Seona Kim, Kyoung Joon Lee, Seoul National Univ. (Korea, Republic of); II Dong Yun, Hankuk Univ. of Foreign Studies (Korea, Republic of); Sang Uk Lee, Seoul National Univ. (Korea, Republic of) . . . . . . . . . . . . . . . . . . . [8288-80]

Analysis on ray reconstruction characteristics of multi-view and integral imaging display, Hee-Seung Kim, Hyun-Eui Kim, Kyeong-Min Jeong, Jae-Hyeung Park, Chungbuk National Univ. (Korea,

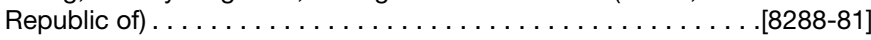

A content-based method for perceptually driven joint color/depth compression, Emilie Bosc, Luce Morin, Muriel Pressigout, Institut National des Sciences Appliquées de Rennes (France) . . . . . . . . . . [8288-82] 


\section{Stereoscopic Image Methods}

Efficient panoramic sampling of real-world environments for imagebased stereoscopic telepresence, Luis E. Gurrieri, Eric Dubois, Univ. of Ottawa (Canada) . . . . . . . . . . . . . . . . . . . . . [8288-84]

Partial 2D-to-S3D conversion and the cognitive characteristics, Yoshihisa Koido, Takashi Kawai, Waseda Univ. (Japan) . . . . . . [8288-85]

Disparity-compensated view synthesis for S3D content correction, Robert Philippe, Cédric Thébault, Valter Drazic, Pierre-Henri Conze, Technicolor S.A. (France) . . . . . . . . . . . . . . . . . [8288-86]

Virtual view interpolation at arbitrary view points for mixed-resolution 3D videos, Seungsin Lee, Seok Lee, Ho-Cheon Wey, Du-Sik Park, Samsung Advanced Institute of Technology (Korea, Republic of) [8288-87]

Efficient dense blur map estimation for automatic 2D-to-3D conversion, Luc Vosters, Technische Univ. Eindhoven (Netherlands) and Axon Digital Design (Netherlands); Gerard de Haan, Philips Research Nederland B.V. (Netherlands) and Technische Univ. Eindhoven

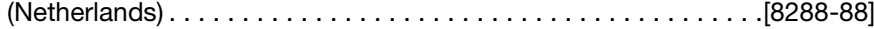

ROI-based transmission method for stereoscopic video to maximize rendered 3D video quality, Chaminda T. E. R. Hewage, Maria G. Martini, Kingston Univ. (United Kingdom) . . . . . . . . . . . . . . . . [8288-89]

Stereoscopic image-inpainting-based, view-synthesis algorithm for glasses-based and glasses-free 3D displays, Chang Yuan, Sharp Labs. of America, Inc. (United States); Chris Huei Hung Liao, The Univ. of Southern California (United States); Hao Pan, Sharp Labs. of America, Inc. (United States). . . . . . . . . . . . . . . . . . . . . . . . . . [8288-90]

Towards a real-time, high-definition depth sensor with hardwareefficient stereo matching, Ke Zhang, IMEC (Belgium) and Katholieke Univ. Leuven (Belgium); Guanyu Yi, Chao-Kang Liao, Christine Lin, Hsiu-Chi Yeh, IMEC (Belgium); Rudy Lauwereins, IMEC (Belgium) and Katholieke Univ. Leuven (Belgium); Luc J. Van Gool, Katholieke Univ. Leuven (Belgium) and ETH Zurich (Switzerland); Gauthier Lafruit, IMEC (Belgium) . . . . . . . . . . . . . . . . . . . . . . .

Interactive floating windows: a new technique for stereoscopic video games, Andrew Hogue, Bill Kapralos, Chris Zerebecki, Mina Tawadrous, Brodie Stanfield, Univ. of Ontario Institute of Technology

(Canada) . . . . . . . . . . . . . . . . . . . . . . [8288-92]

Stereoscopic reconfiguration for 3D displays, Jean-Christophe Houde, Pierre-Marc Jodoin, Univ. de Sherbrooke (Canada); François Deschênes, Univ. du Québec à Rimouski (Canada) . . . . . . . . . . . . . . . [8288-93]

Single lens dual-aperature 3D imaging system: color modeling to reduce the difference between two viewpoints, Sam Youngsam Bae, Jet Propulsion Lab. (United States) and The Univ. of Southern California (United States); Allen Ream, Montana State Univ. (United States); Ronald Korniski, Michael Shearn, Jet Propulsion Lab. (United States); Hrayr Shahinian, Skull Base Institute (United States); Harish Manohara, Jet Propulsion Lab. (United

\section{Stereoscopic Applications}

A simultaneous 2D/3D autostereo workstation, Dennis Chau, Bradley McGinnis, Jonas Talandis, Jason Leigh, Univ. of Illinois at Chicago (United States); Tom Peterka, Aaron Knoll, Aslihan Sumer, Michael Papka, Julius Jellinek, Argonne National Lab. (United States) . . . . . . . . . [8288-95] Interactive stereoscopic visualization of large-scale astrophysical simulations, Ralf Kaehler, SLAC National Accelerator Lab. (United States) . . . . . . . . . . . . . . . . . . . . . . . . .

Designing stereoscopic information visualization for 3D-TV: what can we can learn from S3D gaming?, Jonas Schild, Maic Masuch, Univ. Duisburg-Essen (Germany) . . . . . . . . . . . . . . . . . . [8288-97]

A stereoscopic movie player with real-time content adaptation to the display geometry, Sylvain Duchene, INRIA Rhône-Alpes (France); Martin Lambers, Univ. Siegen (Germany); Frederic Devernay, INRIA Rhône-Alpes

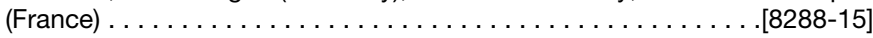

\section{Wednesday 25 January}

Room: Grand Peninsula

Ballroom A . Wed. 8:20 to 9:30 am

\section{Plenary Session and Conference Award Presentations}

8:25 am: More Words and Bigger Pictures, David A. Forsyth, Univ. of Illinois at Urbana-Champaign (United States)

\section{SESSION 10}

Room: Grand Peninsula Ballroom A. . Wed. 9:30 to 10:30 am

\section{D Games}

Session Chair: Chris Ward, Lightspeed Design, Inc. (United States)

9:30 am: Case study: the introduction of stereoscopic games on the Sony PlayStation 3, Ian H. Bickerstaff, Sony Computer Entertainment Europe Ltd. (United Kingdom). . . . . . . . . . . . . . . . . [8288-38]

9:50 am: Stereoscopic 3D video games and their effects on engagement, Andrew Hogue, Bill Kapralos, Chris Zerebecki, Mina Tawadrous, Brodie Stanfield, Univ. of Ontario Institute Of Technology (Canada) . . . . . . . . . . . . . . . . . . . . . . . [8288-39]

10:10 am: Stereoscopic display in a slot machine, Mikko Laakso, Finland's Slot Machine Association (RAY) (Finland) .......... . [8288-40] Coffee Break . . . . . . . . . . . . . . . . 10:30 to 11:10 am 


\section{SESSION 11}

Sessions 11 and 12 run concurrently

Room: Grand Peninsula

Ballroom A

Wed. 11:10 am to $12: 20 \mathrm{pm}$

\section{D Cinema}

Session Chair: Samuel Zhou, IMAX Corp. (Canada)

11:10 am: YouDash3D: exploring stereoscopic 3D gaming for 3D movie theaters, Jonas Schild, Univ. Duisburg-Essen (Germany); Sven Seele, Hochschule Bonn-Rhein-Sieg (Germany); Maic Masuch, Univ. Duisburg-Essen (Germany) . . . . . . . . . . . . . . . . [8288-42]

11:30 am: 3D storytelling: a case study (Invited Paper), Kasimir Lehto, 4th Wall Productions (Finland). . . . . . . . . . . . . . . . . . . [8288-43]

11:50 pm: Thinking in z-space: flatness and spatial narrativity, Ray Zone, The 3-D Zone (United States) . . . . . . . . . . . . . . . . . . . [8288-44] Lunch Break $12: 20$ to $2: 00 \mathrm{pm}$

\section{SESSION 13}

Room: Grand Peninsula Ballroom A. . . Wed. 2:00 to 4:20 pm

\section{Stereoscopic Displays}

Session Chair: Takashi Kawai, Waseda Univ. (Japan)

2:00 pm: Investigating the cross-compatibility of IR-controlled active shutter glasses, Andrew J. Woods, Jesse Helliwell, Curtin Univ. (Australia). . . . . . . . . . . . . . . . . . . . . . . [8288-49]

2:20 pm: New high-brightness interference filter developments, Helmut Jorke, Arnold Simon, Infitec GmbH (Germany) . . . . . . . . . [8288-50]

2:40 pm: Real-world stereoscopic performance in multiple-focalplanes displays: how far apart should the image planes be?, Simon J. Watt, Kevin J. MacKenzie, Louise C. Ryan, Bangor Univ. (United

Kingdom). . . . . . . . . . . . . . . . . . . . . . . [8288-51]

3:00 pm: An eyeglass-like, eye-tracked, optical see-through, headmounted display using freeform optics, Hong Hua, College of Optical Sciences, The Univ. of Arizona (United States). . . . . . . . . . . [8288-52]

Coffee Break

3:20 to $4: 00 \mathrm{pm}$

4:00 pm: Optimization of a multi-view system based on pulsed LEDLCD projectors, Achim Pross, Roland Blach, Matthias Bues, Roman Reichel, Oliver Stefani, Fraunhofer-Institut für Arbeitswirtschaft und

Organisation (Germany). . . . . . . . . . . . . . . . . . . . [8288-53]
Room: Grand Peninsula

Ballroom E . . . . . . . . . . . . . W Wed. 11:10 am to 12:30 pm

Autostereoscopic Displays: Advances and Analysis Session Chair: Hideki Kakeya, Univ. of Tsukuba (Japan)

11:10 am: Floating three-dimensional display with 360-degree viewing angle, Daisuke Miyazaki, Kenta Okoda, Yuki Maeda, Takaaki Mukai, Osaka City Univ. (Japan). . . . . . . . . . . . . . . . . . . . . . . . [8288-45]

11:30 am: A novel 3D display system using combined integral imaging and Fresnel hologram, Jhen-Si Chen, Neil Collings, Daping Chu, Univ. of Cambridge (United Kingdom)

11:50 am: Analysis and management of geometric distortions on multi-view displays with only horizontal parallax, Amir Said, Bruce Culbertson, Hewlett-Packard Labs. (United States) . . . . . . . . . [8288-47]

12:10 pm: Mixed-resolution view synthesis using non-local means refined image merging, Thomas Richter, Michael Schöberl, Jürgen Seiler, Tobias Tröger, André Kaup, Friedrich-Alexander-Univ. Erlangen-Nürnberg

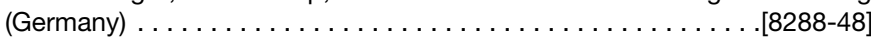
Lunch Break . . . . . . . . . . . . . . . . . . . 12:30 to 2:00 pm

\section{Room: Grand Peninsula \\ Ballroom A . . . . . . . . . . . . . . . Wed. 4:20 to 5:20 pm}

Discussion Forum: 3D Moving Images: Will They Become Ubiquitous?

Advances in technology have enabled filmmakers to create a new stereoscopic cinema that has established itself with several dozen films in release each year that are shown on tens of thousands of theater screens all over the world. Millions of TV sets are now 3D capable and there promises to be an onslaught of eyewear-free single-user devices in the coming year or two. Will all films and video become stereoscopic, in the way that color became a standard modality? Our panel will discuss the technological, aesthetic, and business aspects of the question.

Room: Grand Peninsula Ballroom A... Wed. 5:20 to 5:30 pm

\section{SD\&A Closing Remarks}

Session Chair: Andrew J. Woods, Curtin Univ. (Australia)

Please visit www.stereoscopic.org for more information about the Stereoscopic Displays and Applications conference.

\section{Room: Grand Peninsula}

Ballroom E . . . . . . . . . . . . . . . Wed. 7:00 to 9:00 pm

\section{All-Conference Reception}

The annual Electronic Imaging All-Conference Reception provides a wonderful opportunity to get to know and interact with new and old SD\&A colleagues. Plan to join us for this relaxing and enjoyable event. 


\section{Conference 8289}

Tuesday 24 January 2012 • Proceedings of SPIE Vol. 8289

\section{The Engineering Reality of Virtual Reality 2012}

Conference Chairs: Ian E. McDowall, Fakespace Labs, Inc. (United States); Margaret Dolinsky, Indiana Univ. (United States)

\section{Tuesday 24 January}

Room: Grand Peninsula
Ballroom A . . . . . . . . . . Tues. 8:20 to 9:30 am
Plenary Session and Society Award Presentations
8:25 am: Computational Photography, William T. Freeman,
Massachusetts Institute of Technology (United States)

\section{SESSION 1}

Room: Sumac Room Tues. 9:30 to $10: 30$ am

\section{Context Awareness and Immersion}

Session Chair: Ian E. McDowall, Fakespace Labs, Inc. (United States) 9:30 am: Foreign language learning in immersive virtual environments, Benjamin Chang, Lee Sheldon, Mei Si, Rensselaer Polytechnic Institute (United States). .

9:50 am: Virtual reality technology prevents accidents in extreme situations, Yehuda Badihi, Jerusalem College of Technology (Israel); Motti Reiff, Jerusalem College of Technology (Korea, Republic of) . . . [8289-02]

10:10 am: Motion parallax in immersive cylindrical display systems, Nicolas Filliard, Gilles Reymond, Renault Technocentre (France); Andras Kemeny, Renault Technocentre (France) and Arts et Métiers ParisTech (France); Alain Berthoz, Collège de France (France). . . . . . . . [8289-03]

Coffee Break $10: 30$ to $11: 10$ am

\section{SESSION 2}

Room: Sumac Room . . . . . . . . . . Tues. 11:10 am to 12:30 pm

\section{Communicating Perspective through VR}

Session Chair: Margaret Dolinsky, Indiana Univ. (United States)

11:10 am: Meta!Blast computer game: a pipeline from science to 3D art to education, Eve Syrkin Wurtele, P. J. Campbell, William Schneller, Diane Bassham, lowa State Univ. (United States) . . . . . . . . . [8289-04] 11:30 am: Learning immersion without getting wet, Julieta C. Aguilera, Adler Planetarium \& Astronomy Museum (United States). . . . . . [8289-05]

11:50 am: Byte me, Diane Gromala, Meehae Song, Andrea Zeffiro, Simon Fraser Univ. (Canada) . . . . . . . . . . . . . . . . . . . . . [8289-06]

12:10 pm: Female artists and the VR crucible: expanding the aesthetic vocabulary, Jacquelyn F. Morie, The Univ. of Southern California (United States) . . . . . . . . . . . . . . . . . . . [8289-07]

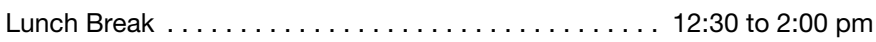

\section{SESSION 3}

Room: Sumac Room .............Tues. 2:00 to 3:20 pm

\section{Refacing VR}

Session Chair: Ian E. McDowall, Fakespace Labs, Inc. (United States) 2:00 pm: Markerless 3D facial motion capture system, Youngkyoo Hwang, Jung-Bae Kim, Won-Chul Bang, James D.K. Kim, Chang-Yeong Kim, Samsung Advanced Institute of Technology (Korea,

Republic of) . . . . . . . . [8289-08.

2:20 pm: Capturing geometry in real-time using a tracked Microsoft Kinect, Daniel Tenedorio, Marlena Fecho, Jorge Schwartzhaupt, Robert Pardridge, James Lue, Jurgen P. Schulze, Univ. of California, San Diego (United States)........................... [8289-09] 2:40 pm: An example-based face relighting, Hyunjung Shim, Samsung Advanced Institute of Technology (Korea, Republic of) ....... . [8289-10] 3:00 pm: Heteronyms and avatars: a self-reflective system for artistic activity, Elif E. Ayiter, Sabanci Univ. (Turkey) . . . . . . . . . . . . [8289-11] Coffee Break ....................... 3:20 to 4:00 pm

\section{SESSION 4}

Room: Sumac Room ..............Tues. 4:00 to 5:20 pm

\section{VR Hybrids: Augmented Reality}

Session Chair: Todd Margolis, Univ. of California, San Diego (United States)

4:00 pm: ManifestAR: an augmented reality manifesto, John Craig Freeman, Emerson College (United States) ............. [8289-12]

4:20 pm: Invisible waves and hidden realms: augmented reality and experimental art, Silvia P. Ruzanka, Rensselaer Polytechnic Institute

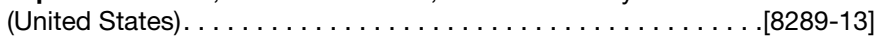

4:40 pm: Immersive realities: articulating the shift from VR to AR through artistic practice, Tracy Cornish, Todd Margolis, Univ. of California, San Diego (United States) . . . . . . . . . . . . . [8289-14] 5:00 pm: MetaTree: augmented reality narrative explorations of urban forests, Ruth G. West, Todd Margolis, Univ. of California, San Diego (United States); Jarlath O'Neil-Dunne, The Univ. of Vermont (United States); Eitan Mendelowitz, Smith College (United States). . . . . . [8289-15] 
Room: Grand Peninsula Ballroom E . . . Tues. 5:30 to 8:00 pm

\section{Interactive Paper and Symposium Demonstration Session}

Demonstrations.

5:30 to $8: 00 \mathrm{pm}$

A symposium-wide demonstration session will be open to attendees 5:30 to 8:00 pm Tuesday evening. Demonstrators will provide interactive, hands-on demonstrations of a wide-range of products related to Electronic Imaging.

\section{Posters} 5:30 to 7:00 pm

Interactive papers will be placed on display after 10:30 am on Tuesday. An interactive paper session, with authors present at their papers, will be held Tuesday evening, 5:30 to 7:00 pm.

Prediction of visually perceived location using reaching action and effect of reaching distance on it, Masahiro Suzuki, Keigo Takazawa, Kazutake Uehira, Kanagawa Institute of Technology (Japan). . . . [8289-23]

An innovative multimodal virtual platform for communication with devices in a natural way, Chhayarani R. Kinkar, Richa Golash, Akhilesh R. Upadhyay, Sagar Institute of Research, Technology \& Science

(India) . . . . . . . . . . . . . . . . . . . . . . . . . . . . . . . . [8289-24]

Composite lay-up process with application of elements of augmented reality, Jozef Novak-Marcincin, Jozef Barna, Miroslav Janak, Ludmila Novakova-Marcincinova, Veronika Fecova, Technical Univ. of Kosice (Slovakia) . . . . . . . . . . . . . . . . . . . . . . . . [8289-25]

\section{Wednesday 25 January}

\section{Room: Grand Peninsula}

Ballroom A . . . . . . . . . . . . . .Wed. 8:20 to 9:30 am

\section{Plenary Session and Conference Award Presentations}

8:25 am: More Words and Bigger Pictures, David A. Forsyth, Univ. of Illinois at Urbana-Champaign (United States)

\section{SESSION 5}

Room: Sumac Room

Wed. 9:30 to $10: 10$ am

\section{Viewing Virtual Experiences}

Session Chair: Ian E. McDowall, Fakespace Labs, Inc. (United States) 9:30 am: Reordering virtual reality: recording and recreating real-time experiences, Margaret Dolinsky, William R. Sherman, Chris Eller, Eric A. Wernert, Yi-Chen Chi, Indiana Univ. (United States).

.[8289-16]

9:50 am: The cognitive implications of virtual locomotion with a restricted field of view, William E. Marsh, Jonathan W. Kelly, Veronica J. Dark, James H. Oliver, lowa State Univ. (United States). . . . . . . [8289-18] Coffee Break . . . . . . . . . . . . . . . . . . . . 10:10 to 10:50 am

\section{SESSION 6}

Room: Sumac Room ......... Wed. 10:50 am to 12:10 pm

\section{Educational Pathways in VR}

Session Chair: Margaret Dolinsky, Indiana Univ. (United States)

10:50 am: Use of a simulator based on virtual reality to assess the application of economic driving techniques by truck drivers, Tales N. Bogoni, Univ. Estadual do Mato Grosso Sul (Brazil); Márcio Sarroglia Pinho, PUCRS-IPCT (Brazil) . . . . . . . . . . . . . . . . . . . . [8289-19]

11:10 am: LVC interaction within a mixed-reality training system, Brice B. Pollock, lowa State Univ. (United States) and Virtual Reality Application Ctr. (United States); Eliot Winer, Stephen Gilbert, lowa State Univ. (United States); Julio de la Cruz, U.S. Army RDECOM/STTC

(United States).

11:30 am: Immersive volume rendering of blood vessels, Gregory Long, Han Suk Kim, Alison Marsden, Yuri Bazilevs, Jurgen Schulze, Univ. of California, San Diego (United States) . . . . . . . . . . . . . . [8289-21]

11:50 am: A virtual reality interface for pre-planning of surgical operations based on a customized model of the patient, Marcin Witkowski, Robert Sitnik, Janusz Lenar, Warsaw Univ. of Technology (Poland) . . . . . . . . . . . . . . . . . . . . . . . . [8289-22] 


\section{D Image Processing (3DIP) and Applications 2012}

Conference Chairs: Atilla M. Baskurt, Univ. of Lyon (France); Robert Sitnik, Warsaw Univ. of Technology (Poland)

Program Committee: Mongi A. Abidi, The Univ. of Tennessee (United States); Hugues Benoit-Cattin, INSERM (France); Adrian G. Bors, The Univ. of York (United Kingdom); Saida Bouakaz, Univ. of Lyon (France); Mohamed Daoudi, TELECOM Lille 1 (France); Eduardo da Silva, Univ. Federal do Rio de Janeiro (Brazil); Jean-Luc E. Dugelay, EURECOM (France); Florent Dupont, Univ. of Lyon (France); Afzal Godil, National Institute of Standards and Technology (United States); Benoît M. Macq, Univ. Catholique de Louvain (Belgium); Serge Miguet, Univ. of Lyon (France); Levent Onural, Bilkent Univ. (Turkey); Eric Paquet, National Research Council Canada (Canada); Marc Pollefeys, The Univ. of North Carolina at Chapel Hill (United States); William Puech, Lab. d'Informatique de Robotique et de Microelectronique de Montpellier (France); Bülent Sankur, Bogaziçi Üniv. (Turkey); Peter Schelkens, Vrije Univ. Brussel (Belgium); Michela Spagnuolo, Consiglio Nazionale delle Ricerche (Italy); Frédéric Truchetet, Univ. de Bourgogne (France); Stefano Tubaro, Politecnico di Milano (Italy)

\section{Tuesday 24 January}

Room: Grand Peninsula

Ballroom A . . . . . . . . . . . . Tues. 8:20 to 9:30 am

\section{Plenary Session and Society Award Presentations}

8:25 am: Computational Photography, William T. Freeman,

Massachusetts Institute of Technology (United States)

\section{SESSION 1}

Room: Sandpebble Room A. . . . . . . . Tues. 2:00 to 3:20 pm

\section{Stereo and Multiview Imaging I}

Session Chair: Afzal Godil, National Institute of Standards and Technology (United States)

2:00 pm: Edge-aware stereo matching with $\mathbf{O}(1)$ complexity, Cevahir Cigla, Middle East Technical Univ. (Turkey) and Vestek (Turkey); A. Aydin Alatan, Middle East Technical Univ. (Turkey) . . . . . . . . . . [8290-01]

2:20 pm: Establishing eye contact for home video communication using stereo analysis and free viewpoint synthesis, Christian Weigel, Technische Univ. IImenau (Germany); Niklas Treutner, Humboldt-Univ. zu Berlin (Germany) . . . . . . . . . . . . . . . . . . . . . [8290-02]

2:40 pm: Depth adaptive hierarchical hole filling for DIBR-based 3D videos, Mashhour Solh, Ghassan Al-Regib, Georgia Institute of Technology (United States) . . . . . . . . . . . . . . . . . . . [8290-03]

3:00 pm: Space carving MVD sequences for modelling natural 3D scenes, Youssef Alj, Technicolor S.A. (France) and Institut National des Sciences Appliquées de Rennes (France); Guillaume Boisson, Technicolor S.A. (France); Luce Morin, Muriel Pressigout, Institut National des Sciences Appliquées de Rennes (France); Philippe Bordes, Technicolor S.A.

(France) . . . . . . . . . . . . . . . . . . . . . [8290-04]

Coffee Break .................... 3:20 to $4: 00 \mathrm{pm}$

\section{SESSION 2}

Room: Sandpebble Room A. ......... Tues. 4:00 to 4:40 pm

\section{Poster Pops}

Session Chair: Robert Sitnik, Warsaw Univ. of Technology (Poland)

In addition to their interactive paper presentations, the interactive paper authors will provide short oral presentations during the conference.

\section{SESSION 3}

Room: Sandpebble Room A......... . Tues. 4:40 to 5:20 pm

\section{Stereo and Multiview Imaging II}

Session Chair: Afzal Godil, National Institute of Standards and Technology (United States)

4:40 pm: A locally content-dependent filter for inter-perspective antialiasing, Mårten Sjöström, Sylvain Tourancheau, Xusheng Wang, Roger Olsson, Mid Sweden Univ. (Sweden) . . . . . . . . . . . . . . . [8290-05]

5:00 pm: Photometric and geometric rectification for stereoscopic images, Seung-Ryong Han, Jongsul Min, Taesung Park, Yongje Kim, Samsung Electronics Co., Ltd. (Korea, Republic of). . . . . . . . . .[8290-06]

\section{Interactive Paper and Symposium Demonstration Session}

Room: Grand Peninsula Ballroom E.. .Tues. 5:30 to 8:00 pm

Demonstrations 5:30 to $8: 00 \mathrm{pm}$

A symposium-wide demonstration session will be open to attendees 5:30 to 8:00 pm Tuesday evening. Demonstrators will provide interactive, hands-on demonstrations of a wide-range of products related to Electronic Imaging

Posters 5:30 to 7:00 pm

Interactive papers will be placed on display after 10:30 am on Tuesday. An interactive paper session, with authors present at their papers, will be held Tuesday evening, 5:30 to 7:00 pm.

Novel time- and depth-stamped imaging for 3D-PIV (particle image velocimetry) using correlation image sensor, Kenji Komiya, Toru Kurihara, Shigeru Ando, The Univ. of Tokyo (Japan) . . . . . . . [8290-40] 3D imaging for ballistics analysis using chromatic white-light sensor, Andrey Makrushin, Mario Hildebrandt, Jana Dittmann, Eric Clausing, Otto-von-Guericke-Univ. Magdeburg (Germany); Robert Fischer, Claus Vielhauer, Univ. of Applied Sciences Brandenburg (Germany). . . [8290-41]

Computer-aided 3D-shape construction of hearts from CT images for rapid prototyping, Yutaro Kato, Masayuki Fukuzawa, Nobuyuki Nakamori, Kyoto Institute of Technology (Japan); Seiichiro Ozawa, Kyoto Prefectural Univ. of Medicine (Japan); Isao Shiraishi, National Cardiovascular Ctr. Research Institute (Japan). . . . . . . . . . . . . . . . . . . [8290-42]

Operation-free 3D visualization of pulsatile tissues in freehand ultrasonic diagnosis, Kazumasa Kawata, Masayuki Fukuzawa, Nobuyuki Nakamori, Kyoto Institute of Technology (Japan); Yoshiki Kitsunezuka, Saiseikai Hyogo-ken Hospital (Japan). . . . . . . . . . . . . . . . [8290-43] 
Semiautomatic generation of semantic building models from image series, Stefan Wirtz, Peter Decker, Denes Weiß, Dietrich W. Paulus, Univ. Koblenz-Landau (Germany). . . . . . . . . . . . . . . . . . . . . . . . [8290-44]

Complex virtual urban environment modeling from CityGML data and OGC web services: application to the SIMFOR project, Jean-Christophe Chambealland, Gilles Gesquière, Lab. des Sciences de l'Information et des Systèmes (France) . . . . . . . . . . . . . . . . . . . . . . [8290-45]

Liquid crystal materials and structures for image processing and 3D shape acquisition, Katarzyna Garbat, Military Univ. of Technology (Poland); Piotr Garbat, Warsaw Univ. of Technology (Poland) . . .[8290-46]

Piece-wise linear function estimation for platelet-based depth maps coding using edge detection, Dorsaf Sebai, The Univ. of Manouba

(Tunisia) . . . . . . . . . . . . . . . . . . . . . . . . . . . . . . .[8290-47]

Source modeling for effective 3D video delivery, Chaminda T.E.R. Hewage, Maria G. Martini, Kingston Univ. (United Kingdom) . . . [8290-48]

New technique for capturing images containing invisible depth information on object using brightness modulated right, Sae Isaka, Kazutake Uehira, Kanagawa Institute of Technology (Japan). . . .[8290-49]

Interactive 3D segmentation by tubular envelope model for thoracic aorta treatment, Pawel J. Lubniewski, Univ. d'Auvergne Clermont-Ferrand I (France) and Univ. Kardynala Stefana Wyszynskiego w Warszawie (Poland); Bruno Miguel M.D., Vincent Sauvage, Christophe Lohou, Univ. d'Auvergne Clermont-Ferrand I (France). . . . . . . . . . . . . . . [8290-50]

A parallel stereo reconstruction algorithm with applications in entomology (APSRA), Rajesh Bhasin, Univ. of Illinois at Urbana Champaign (United States); Won Jun Jang, John C. Hart, Univ. of Illinois at Urbana-Champaign (United States) . . . . . . . . . . . . . . [8290-51]

\section{Wednesday 25 January}

\section{Room: Grand Peninsula Ballroom A . . . . . . . . . . . . . . . . Wed. 8:20 to 9:30 am Plenary Session and Conference Award Presentations}

8:25 am: More Words and Bigger Pictures, David A. Forsyth, Univ. of Illinois at Urbana-Champaign (United States)

\section{SESSION 4}

Room: Sandpebble Room A. . . . . .Wed. 9:30 am to 12:30 pm

\section{Time-Of-Flight Data, Depth Maps Analysis}

Session Chair: Eric Paquet, National Research Council Canada (Canada)

9:30 am: Depth map upscaling through edge-weighted optimization, Sebastian Schwarz, Mårten Sjöström, Roger Olsson, Mid Sweden Univ. (Sweden) . . . . . . . . . . . . . . . . . . . . . . . . . . . . . . . . [8290-07]

9:50 am: Adaptive switching filter for noise removal in highly corrupted depth maps from time-of-flight image sensors, Seunghee Lee, Kwanghyuk Bae, Kyu-Min Kyung, Tae-Chan Kim, SAMSUNG Electronics Co., Ltd. (Korea, Republic of) . . . . . . . . . . . . . . . . . [8290-08]

10:10 am: Parametric model-based noise reduction for ToF depth sensors, Yong Sun Kim, Byongmin Kang, Hwasup Lim, Ouk Choi, Keechang Lee, James D. K. Kim, Chang-Yeong Kim, Samsung Advanced Institute of Technology (Korea, Republic of) . . . . . . . . . . . . . . [8290-09]

Coffee Break . . . . . . . . . . . . . . . . . . . . 10:30 to 11:10 am

11:10 am: Silhouette extraction using color and depth information, Ekaterina V. Tolstaya, Victor Bucha, Samsung Electronics Co., Ltd.

(Russian Federation) . . . . . . . . . . . . . . . . . [8290-10]
11:30 am: Discrete and continuous optimizations for depth image super-resolution, Ouk Choi, Hwasup Lim, Yong Sun Kim, Byongmin Kang, Keechang Lee, James D. K. Kim, Chang-Yeong Kim, Samsung Advanced Institute of Technology (Korea, Republic of) . . . . . . [8290-11]

11:50 am: A line-based approach for depth superresolution, Yongseok Soh, Seoul National Univ. (Korea, Republic of); Jae-Young Sim, Ulsan National Institute of Science and Technology (Korea, Republic of); ChangSu Kim, Korea Univ. (Korea, Republic of); Sang Uk Lee, Seoul National Univ. (Korea, Republic of) . . . . . . . . . . . . . . . . . . . . [8290-12]

12:10 pm: Efficient spatio-temporal hole filling strategy for Kinect depth maps, Massimo Camplani, Luis Salgado, Univ. Politécnica de Madrid (Spain) . . . . . . . . . . . . . . . . . . . . . . . . [8290-13]

Lunch Break $12: 30$ to $2: 00 \mathrm{pm}$

\section{SESSION 5}

Room: Sandpebble Room A........ Wed. 2:00 to 5:40 pm

\section{D Shape Modeling, Retrieval}

Session Chair: Mohamed Daoudi, TELECOM Lille 1 (France)

2:00 pm: Experimental results of bispectral invariants discriminative power, Karol Kubicki, Jagiellonian Univ. (Poland); Ramakrishna Kakarala, Nanyang Technological Univ. (Singapore) . . . . . . . . . . . . . . [8290-14]

2:20 pm: Evaluation of surface reconstruction from point clouds by shape parameters, Lu Cao, Fons J. Verbeek, Leiden Univ.

(Netherlands) . . . . . . . . . . . . . . . . . . . . . . . . . . . . . [8290-15]

2:40 pm: 3D mesh Reeb graph computation using commute-time and diffusion distances, Rachid EL Khoury, Jean Philippe Vandeborre, Mohamed Daoudi, Institut TELECOM (France) and TELECOM Lille 1 (France) . . . . . . . . . . . . . . . . . . . . . . . . [8290-16]

3:00 pm: Geometric modeling of pelvic organs with thickness, Thierry Bay, Lab. des Sciences de l'Information et des Systèmes (France); Zhuo Wei Chen, Univ. d'Evry-Val d'Essonne (France); Romain Raffin, Marc Daniel, Lab. des Sciences de l'Information et des Systèmes (France); Pierre Joli, Univ. d'Evry-Val d'Essonne (France); Zhi Qiang Feng, MarcEmmanuel Bellemare, Lab. des Sciences de l'Information et des Systèmes (France) . . . . . . . . . . . . . . . . . . . . . . . . [8290-17] Coffee Break . . . . . . . . . . . . . . . . 3:20 to 4:00 pm 4:00 pm: Refined facial disparity maps for automatic creation of 3D avatars, Rafael Pagés, Francisco Morán, Luis Salgado, Daniel Berjón, Univ. Politécnica de Madrid (Spain) . . . . . . . . . . . . . . . . [8290-18]

4:20 pm: Fast human pose estimation using 3D Zernike descriptors, Daniel Berjón, Francisco Morán, Univ. Politécnica de Madrid (Spain) . . . . . . . . . . . . . . . . . . . . . . . . . . . [8290-19] 4:40 pm: Analysis of binning of normals for spherical harmonic crosscorrelation, Robert Larkins, Michael J. Cree, Adrian A. Dorrington, The Univ. of Waikato (New Zealand) . . . . . . . . . . . . . . . . . [8290-20]

5:00 pm: Topology reconstruction for B-Rep modeling from 3D mesh in reverse engineering applications, Roseline Bénière, Lab. d'Informatique de Robotique et de Microelectronique de Montpellier (France) and C4W (France); Gérard Subsol, Lab. d'Informatique de Robotique et de Microelectronique de Montpellier (France); Gilles Gesquière, Lab. des Sciences de l'Information et des Systèmes (France); François Le Breton, C4W (France); William Puech, Lab. d'Informatique de Robotique et de Microelectronique de Montpellier (France). . . . .[8290-21] 5:20 pm: An evaluation of local shape descriptors for 3D shape retrieval, Sarah Y. Tang, Princeton Univ. (United States); Afzal Godil, National Institute of Standards and Technology (United States) .[8290-22] 


\section{Thursday 26 January SESSION 6}

Room: Sandpebble Room A....... . Thurs. 8:30 to 10:10 am

\section{D Analysis, Feature Extraction, Segmentation} Session Chair: Atilla M. Baskurt, Univ. of Lyon (France)

8:30 am: Fractal geometry and multimedia retrieval: a theoretical framework, Eric Paquet, National Research Council Canada (Canada); Herna L. Viktor, Univ. of Ottawa (Canada) . . . . . . . . . . . . . . [8290-23]

8:50 am: Spatial modeling of bone microarchitecture, Hui Li, Kang Li, Taehyong Kim, Aidong Zhang, Murali Ramanathan, Univ. at Buffalo (United States). .[8290-24]

9:10 am: A new affine invariant method for image matching, Philippe Montesinos, Ecole des Mines d'Alès (France) . . . . . . . . . . . . [8290-25]

9:30 am: 2D-3D feature association via projective transform invariants for model-based 3D pose estimation, Osman S. Gedik, A. Aydin Alatan, Middle East Technical Univ. (Turkey) . . . . . . . . . . . . . . . [8290-26] 9:50 am: Reprocessing anaglyph images, Henry G. Dietz, Univ. of Kentucky (United States). . . . . . . . . . . . . . . . . . . . . . . [8290-27] Coffee Break . . . . . . . . . . . . . . . . . 10:10 to 10:50 am

\section{SESSION 7}

Room: Sandpebble Room A. . . . Thurs. 10:50 am to 12:10 pm

\section{D Metrology}

Session Chair: Robert Sitnik, Warsaw Univ. of Technology (Poland) 10:50 am: X-ray stereo imaging for micro 3D motions within nontransparent objects, Wasil H. M. Salih, Jan A. N. Buytaert, Joris J. J. Dirckx, Univ. Antwerpen (Belgium) . . . . . . . . . . . [8290-28]

11:10 am: A stereoscopic imaging system for laser back scatter-based trajectory measurement in ballistics: part 2, Uwe Chalupka, Hendrik Rothe, Helmut-Schmidt-Univ. (Germany) . . . . . . . . . . . . [8290-29] 11:30 am: Single frame coaxial 3D measurement using depth from defocus of projection system, Toru Kurihara, Shigeru Ando, The Univ. of Tokyo (Japan) . . . . . . . . . . . . . . . . . . . . . . . . . . . . .88290-30]

11:50 am: Multidirectional four-dimensional shape measurement system, Janusz Lenar, Robert Sitnik, Marcin Witkowski, Warsaw Univ. of Technology (Poland) . . . . . . . . . . . . . . . . . . . [8290-31]

Lunch Break $12: 10$ to $1: 50 \mathrm{pm}$

\section{SESSION 8}

Room: Sandpebble Room A........ Thurs. 1:50 to 3:30 pm

\section{D Imaging Systems}

Session Chair: Frédéric Truchetet, Univ. de Bourgogne (France)

1:50 pm: Estimation of surface normal vectors based on 3D scanning from heating approach, Olivier Aubreton, Univ. de Bourgogne (France); Gonen Eren, Galatasaray Üniv. (Turkey); Frederic Truchetet, Univ. de Bourgogne (France) . . . . . . . . . . . . . . . . . . . . . [8290-32] 2:10 pm: First topographical features for the age determination of latent biometric fingerprint traces using a 3D optical and contact-less chromatic white light (CWL) sensor, Ronny Merkel, Otto-von-GuerickeUniv. Magdeburg (Germany); Stefan Gruhn, Fachhochschule Brandenburg (Germany); Jana Dittmann, Otto-von-Guericke-Univ. Magdeburg (Germany); Claus Vielhauer, Fachhochschule Brandenburg (Germany) . . . . . . . . . . . . . . . . . . . . . . . . [8290-33]

2:30 pm: A single-imager, single-lens video camera prototype for 3D imaging, Lauren Christopher, Weixu Li, Indiana Univ.-Purdue Univ. Indianapolis (United States). . . . . . . . . . . . . . . . [8290-34]

2:50 pm: 3D multimodal data fusion system, Piotr Garbat, Warsaw Univ. of Technology (Poland) . . . . . . . . . . . . . . . . . [8290-35]

3:10 pm: Fully automatic 3D digitization of unknown objects using progressive data bounding box, Antoine Aigueperse, Souhaiel Khalfaoui, Lab. d'Electronique, Informatique et Image (France); Ralph Seulin, Yohan Fougerolle, David Fofi, Univ. de Bourgogne (France) . . . . . . . . .88290-36] Coffee Break .................... 3:30 to $4: 00$ pm

\section{SESSION 9}

Room: Sandpebble Room A. . . . . . . . Thurs. 4:00 to 5:00 pm

\section{D Compression and Watermarking}

Session Chair: William Puech, Lab. d'Informatique de Robotique et de Microelectronique de Montpellier (France)

4:00 pm: 3D video compression with the H.264 codec, Nikolaus L. Karpinsky, Song Zhang, lowa State Univ. (United States) . . . . . [8290-37]

4:20 pm: 3D multiresolutions synchronization scheme based on feature point selection, Nicolas Tournier, Lab. d'Informatique de Robotique et de Microelectronique de Montpellier (France) and Stratégies S.A. (France); William Puech, Gérard Subsol, Lab. d'Informatique de Robotique et de Microelectronique de Montpellier (France); Jean-Pierre Pedeboy, Stratégies S.A. (France) . . . . . . . . . . . . . [8290-38]

4:40 pm: A content-adaptive scheme for reduced-complexity, multiview video coding, Aykut Avci, Jan De Cock, Roel Beernaert, Jelle De Smet, Univ. Gent (Belgium); Youri Meuret, Vrije Univ. Brussel (Belgium); Peter Lambert, Herbert De Smet, Univ. Gent (Belgium) . . . . . . . [8290-39] 


\section{Human Vision and Electronic Imaging XVII}

Conference Chairs: Bernice E. Rogowitz, Visual Perspectives Consulting (United States); Thrasyvoulos N. Pappas, Northwestern Univ. (United States); Huib de Ridder, Technische Univ. Delft (Netherlands)

Program Committee: Albert J. Ahumada, Jr., NASA Ames Research Ctr. (United States); Jan P. Allebach, Purdue Univ. (United States); Erhardt Barth, Univ. zu Lübeck (Germany); Walter R. Bender, MIT Media Lab. (United States); Michael H. Brill, Datacolor (United States); John C. Dalton, Synthetik Software (United States); Scott J. Daly, Dolby Labs., Inc. (United States); Tiarna Doherty, Smithsonian American Art Museum (United States); Elena A. Fedorovskaya, Eastman Kodak Co. (United States); James Fewerda, Rochester Institute of Technology (United States); Jennifer Gille, Qualcomm Inc. (United States); Sheila S. Hemami, Cornell Univ. (United States); Laurent Itti, The Univ. of Southern California (United States); Stanley A. Klein, Univ. of California, Berkeley (United States); Patrick Le Callet, Univ. de Nantes (France); Lora T. Likova, The Smith-Kettlewell Eye Research Institute (United States); John J. McCann, McCann Imaging (United States); Jeffrey B. Mulligan, NASA Ames Research Ctr. (United States); Karol Myszkowski, Max-Planck-Institut für Informatik (Germany); Adar Pelah, The Univ. of York (United Kingdom); Eliezer Peli, Schepens Eye Research Institute (United States); Sylvia C. Pont, Technische Univ. Delft (Netherlands); Hawley K. Rising III, Consultant (United States); David M. Stone, Univ. of Delaware (United States); Sabine Süsstrunk, Ecole Polytechnique Fédérale de Lausanne (Switzerland); Christopher W. Tyler, The Smith-Kettlewell Eye Research Institute (United States); Andrew B. Watson, NASA Ames Research Ctr. (United States)

Cosponsored by:

CARDIFF SCHOOL

Of ART \& DESIGN

\section{Monday 23 January}

\section{Room: Regency Ballroom B ......... Mon. 9:30 to 9:40 am \\ Conference Welcome}

Session Chair: Bernice E. Rogowitz, Visual Perspectives Consulting (United States)

Room: Regency Ballroom B .......Mon. 9:40 am to 12:10 pm

\section{Keynote Session}

Session Chairs: Bernice E. Rogowitz, Visual Perspectives Consulting (United States); Thrasyvoulos N. Pappas, Northwestern Univ. (United States); Huib de Ridder, Technische Univ. Delft (Netherlands)

9:40 am: The general solution to HDR rendering, John J. McCann, McCann Imaging (United States) . . . . . . . . . . . . . . . . [8291-60]

Coffee Break . . . . . . . . . . . . . . . . 10:20 to 10:50 am

10:50 am: Measuring material perception, Laurence T. Maloney, New

York Univ. (United States) . . . . . . . . . . . . . . . . . [8291-61]

11:30 am: Computational photography and the Stanford

Frankencamera (Presentation Only), Marc S. Levoy, Stanford Univ.

(United States). . . . . . . . . . . . . . . . . . . . . [8291-62]

Lunch Break .................... 12:10 to 2:00 pm

\section{SESSION 1}

Room: Regency Ballroom B Mon. 2:00 to $3: 40 \mathrm{pm}$

\section{Computational Photography}

Session Chair: Erhardt Barth, Univ. zu Lübeck (Germany)

2:00 pm: Image representations learned for natural images and a non-linear maximum synthesis rule with applications in computational photography, Jens Hocke, Erhardt Barth, Thomas Martinetz, Univ. zu Lübeck (Germany) . . . . . . . . . . . . . . . . .

2:20 pm: How to make a small phone camera shoot like a big DSLR: creating and fusing multi-modal exposure series, Thomas Binder, Florian Kriener, Christian Wichner, Manuel Wille, Nik Software GmbH (Germany); Mike Wellner, Thomas Kaester, Erhardt Barth, Pattern Recognition Lab. (Germany) . . . . . . . . . . . . . . . . [8291-02] 2:40 pm: Metric image mosaics with bounded error, Dev Ghosh, John Tumblin, Northwestern Univ. (United States) . . . . . . . . . . [8291-03]

3:00 pm: Single-lens 3D camera with extended depth-of-field, Christian Perwass, Lennart Wietzke, Raytrix GmbH (Germany). . . . . . . . [8291-04]

3:20 pm: 3D holoscopic video imaging system, Johannes H. Steurer, Arri Cine Technik (Germany) . . . . . . . . . . . . . . . . . [8291-05] Coffee Break ..................... 3:40 to 4:10 pm

\section{SESSION 2}

Room: Regency Ballroom B ......... Mon. 4:10 to 5:50 pm

\section{Material Perception}

Session Chairs: Sylvia C. Pont, Technische Univ. Delft (Netherlands); James A. Ferwerda, Rochester Institute of Technology (United States) 4:10 pm: Predictive rendering for accurate material perception, Kavita Bala, Cornell Univ. (United States) . . . . . . . . . . . . . [8291-06]

4:30 pm: From color to appearance in the real world, Francis Lamy, X-Rite, Inc. (United States) . . . . . . . . . . . . . . . [8291-07]

4:50 pm: Towards material literacy: making perception and knowledge of materials explicit through visual and verbal documentation of material engagement, Ann-Sophie Lehmann, Utrecht Univ.

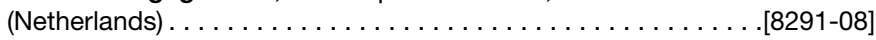
5:10 pm: Mixing material modes, Sylvia C. Pont, Technische Univ. Delft (Netherlands) . . . . . . . . . . .

5:30 pm: Tangible display systems: bringing virtual objects into the real world, James A. Ferwerda, Rochester Institute of Technology (United

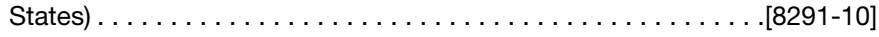


Room: Regency Ballroom B. . . . . Mon. 7:00 to 10:30 pm Human Vision and Electronic Imaging Banquet Banquet Speaker: Carol O'Sullivan, Trinity College Dublin

Style over substance?: What biological motion perception tells us about animating virtual characters

Abstract: What is it about a person's motion that is distinctive, to the point that their friends can recognise them from a distance, or even from a simple cloud of moving points? What kinds of moves are attractive and appealing, and others not so much? How is it that body language can instantly signal a person's emotional state, and what brain areas are involved in this processing?

Biological motion and emotional body language are important topics in perception and cognitive neuroscience, and many researchers are actively trying to answer these questions. In the field of computer animation, a major goal is to create virtual humans with emotion, personality and individual style using a variety of methods. What insights can we use about biological motion perception to help with this task? And in return, how can realistic virtual humans be used to study the perception of real humans in motion?

\section{Tuesday 24 January}

\section{Room: Grand Peninsula Ballroom A . . . . . . . . . . . . Tues. 8:20 to 9:30 am Plenary Session and Society Award Presentations}

8:25 am: Computational Photography, William T. Freeman, Massachusetts Institute of Technology (United States)

\section{SESSION 3}

Room: Regency Ballroom B........ Tues. 9:30 to 10:50 am

\section{Perceptual Image Quality}

Session Chair: Thrasyvoulos N. Pappas, Northwestern Univ. (United States)

9:30 am: Quality estimation for images and video with different spatial resolutions, A. Murat Demirtas, Univ. of California, Irvine (United States); Amy R. Reibman, AT\&T Labs. Research (United States) . . . . . . [8291-11]

9:50 am: Automatic parameter prediction for image denoising algorithms using perceptual quality features, Anish Mittal, Anush Krishna Moorthy, Alan Conrad Bovik, The Univ. of Texas at Austin (United States) . . . . . . . . . [8291-12]

10:10 am: Viewer preferences for classes of noise removal algorithms for high-definition content, Sachin G. Deshpande, Sharp Labs. of America, Inc. (United States). . . . . . . . . . . . . . . . [8291-13] 10:30 am: Image quality assessment in the low-quality regime, Guilherme O. Pinto, Sheila S. Hemami, Cornell Univ. (United States) . . . . . . . . . . . . . . . . . . . . . . . . . [8291-14] Coffee Break..................... 10:50 to 11:10 am

\section{SESSION 4}

\section{Room: Regency Ballroom B ..... Tues. 11:10 am to 12:30 pm}

\section{Multisensory Integration and Brain Plasticity}

Session Chair: Lora T. Likova, The Smith-Kettlewell Eye Research Institute (United States)

11:10 am: The question of simultaneity in multisensory integration, Mark E. McCourt, Lynnette Leone, North Dakota State Univ. (United States) . . . . . . . . . . . . . . . . . . . . . . . . . . [8291-15]

11:30 am: Multisensory integration deficits in children with autism spectrum disorders: a behavioral and ERP investigation, Clifford D. Saron, Yukari Takarae, Margarita Beransky, David M. Horton, Ashley Stark, Andrea Schneider, Fernanda Vieira, Susan M. Rivera, Univ. of California, Davis (United States) . . . . . . . . . . . . . . . . . . [8291-16]

11:50 am: The spatiotopic 'visual' cortex of the blind, Lora T. Likova, The Smith-Kettlewell Eye Research Institute (United States) . . . [8291-17]

12:10 pm: Acoustic-tactile rendering of visual information, Pubudu Madhawa Silva, Thrasyvoulos N. Pappas, Northwestern Univ. (United States); Joshua Atkins, James E. West, The Johns Hopkins Univ. (United States) ................................. [8291-18] Lunch Break ..................... 12:30 to $2: 00 \mathrm{pm}$

\section{SESSION 5A}

Room: Grand Peninsula Ballroom A. . . Tues. 2:00 to 3:20 pm

\section{Stereoscopic 3D Image Quality: Quantifying Perception and Comfort: Joint Session with Conference 8288}

Session Chairs: Sergio R. Goma, Qualcomm Inc. (United States); John O. Merritt, The Merritt Group (United States); Christopher W. Tyler, The Smith-Kettlewell Eye Research Institute (United States); Lora T.

Likova, The Smith-Kettlewell Eye Research Institute (United States)

2:00 pm: Apparent stereo: the Cornsweet illusion can enhance perceived depth, Piotr Didyk, Max-Planck-Institut für Informatik (Germany); Tobias Ritschel, Elmar Eisemann, Telecom ParisTech (France); Karol Myszkowski, Hans-Peter Seidel, Max-Planck-Institut für Informatik (Germany) . . . . . . . . . . . . . . . . . . . [8291-19]

2:20 pm: Perceived depth of multi parallel, overlapping, transparent, stereoscopic surfaces, Saori Aida, Koichi Shimono, Tokyo Univ. of Marine Science and Technology (Japan); Wa James Tam, Communications Research Ctr. Canada (Canada) . . . . . . . . . . . . . . . . . [8291-20]

2:40 pm: Diagnosing perceptual distortion present in group stereoscope viewing, Melissa M. Burton, Brice B. Pollock, Jonathan W. Kelly, Stephen B. Gilbert, Eliot Winer, lowa State Univ. (United States); Julio de la Cruz, U.S. Army RDECOM/STTC (United States) . . . . [8291-21]

3:00 pm: Visual discomfort and the timing of vergenceaccommodation conflicts, Joohwan Kim, David Kane, Martin S. Banks, Univ. of California, Berkeley (United States) . . . . . . . . . . . [8288-34] Coffee Break ..................... 3:20 to $3: 50 \mathrm{pm}$ 


\section{SESSION 5B}

Room: Grand Peninsula Ballroom A. . . Tues. 3:50 to 5:10 pm

\section{Stereoscopic 3D Image Quality: Quantifying Perception and Comfort: Joint Session with Conference 8288}

Session Chairs: Sergio R. Goma, Qualcomm Inc. (United States); John O. Merritt, The Merritt Group (United States); Christopher W. Tyler, The Smith-Kettlewell Eye Research Institute (United States); Lora T. Likova, The Smith-Kettlewell Eye Research Institute (United States)

3:50 pm: Measuring 3D discomfort from vertical and torsional disparities in natural images, Christopher W. Tyler, Lora T. Likova, The Smith-Kettlewell Eye Research Institute (United States); Kalin Atanassov, Vikas Ramachandra, Sergio Goma, Qualcomm (United States). .[8291-22]

4:10 pm: Visual fatigue versus eye-movements, Cyril Vienne, Laurent Blondé, Didier Doyen, Technicolor S.A. (France) . . . . . . . . [8288-35]

4:30 pm: Visual comfort: stereoscopic objects moving in the horizontal and mid-sagittal planes, Wa James Tam, Filippo Speranza, Carlos

Vázquez, Ron Renaud, Communications Research Ctr. Canada (Canada); Namho Hur, Electronics and Telecommunications Research Institute (Korea, Republic of) .[8288-36]

4:50 pm: Visual discomfort with stereo 3D displays when the head is not upright, David Kane, Robin Held, Martin Banks, Univ. of California, Berkeley (United States) . . . . . . . . . . . . . . . . . .

\section{Interactive Paper and Symposium Demonstration Session}

\section{Room: Grand Peninsula Ballroom E... Tues. 5:30 to 8:00 pm}

\section{Demonstrations}

A symposium-wide demonstration session will be open to attendees 5:30 to 8:00 pm Tuesday evening. Demonstrators will provide interactive, hands-on demonstrations of a wide-range of products related to Electronic Imaging.

\section{Posters} $.5: 30$ to $7: 00 \mathrm{pm}$

Interactive papers will be placed on display after 10:30 am on Tuesday. An interactive paper session, with authors present at their papers, will be held Tuesday evening, 5:30 to 7:00 pm.

\section{Art and Perception}

5:30 pm: Structural analysis of digital sculptures and artefacts to guide heritage conservation, J. C. Podany, J. Paul Getty Museum (United States); V. Shapiro, Univ. of Wisconsin-Madison (United

States) . . . . . . . . . . . . . . . . . . . . . . . . . [8291-49]

Tracking of aging process by multiple 3D scans analysis, Eryk Bunsch, The Wilanów Palace Museum (Poland); Robert Sitnik, Warsaw Univ. of Technology (Poland) . . . . . . . . . . . . . . . . . [8291-50]

Aesthetics and entropy: optimization of brightness distribution, Melville R. V. Sahyun, Consultant (United States) . . . . . . . . . . [8291-51]

A novel visualization tool for art history: a method for automated colorization of black and white archival photographs of works of art, Sotirios Tsaftaris, Institute for Advanced Studies Lucca (Italy) and Northwestern Univ. (United States); Francesca Casadio, Kristin Lister, Inge Fiedler, Gwénaëlle Gautier, The Art Institute of Chicago (United States); Jean-Louis Andral, Musée Picasso (France); Stephanie D'Alessandro, The Art Institute of Chicago (United States); Aggelos Katsaggelos, Northwestern Univ. (United States) . . . . . . . . . . . . . . . . . [8291-52]

PHOG analysis of self-similarity in aesthetic images, Seyed Ali Amirshahi, Michael Koch, Joachim Denzler, Christoph Redies, FriedrichSchiller-Univ. Jena (Germany). . . . . . . . . . . . . . . . [8291-53]

\section{Perception and Image Quality}

Influence of the source contact and encoding configuration on the preceived quality for scalable video coding, Yohann Pitrey, Univ. de Nantes (France); Marcus Barkowsky, Polytech' Nantes (France); Romuald Pepion, Univ. de Nantes (France); Patrick Le Callet, Polytech' Nantes (France) . . . . . . . . . . . . . . . . . . . . . . . . . . . [8291-54]

Evaluation of desktop interface displays for $\mathbf{3 6 0}$-degree video, Stephen B. Gilbert, Wutthigrai Boonsuk, Jonathan W. Kelly, lowa State Univ. (United States) [8291-55]

An evaluation of different setups for simulating lighting characteristics, Bart A. Salters, Michael J. Murdoch, Dragan Sekulovksi, Pieter Seuntiens, Shih-Han Chen, Philips Research Nederland B.V. (Netherlands) . . . . . . . . . . . . . . . . . . . . [8291-56]

Biological visual attention guided automatic image segmentation with application in satellite imaging, Md I. Sina, Ana-Maria Cretu, Pierre Payeur, Univ. of Ottawa (Canada) . . . . . . . . . . . . . . . . . . [8291-57]

A neurobiologically-based, two-stage model for human color vision, Charles Q. Wu, Stanford Univ. (United States) . . . . . . . . . [8291-58]

The oscillatory activities and its synchronization in auditory-visual integration as revealed by event-related potentials to bimodal stimuli, Jia Guo, Beijing Normal Univ. (China); Peng Xu, General Hospital Armed Police Forces (China); Xiaojie Zhao, Beijing Normal Univ. (China) [8291-59]

Quality assessment of images illuminated by dim LCD backlight, TaiHsiang Huang, Homer H. Chen, National Taiwan Univ. (Taiwan) .[8291-63]

Parallax scanning methods for stereoscopic three-dimensional imaging, Christopher A. Mayhew, Craig M. Mayhew, Vision III Imaging, Inc. (United States) . . . . . . . . . . . . . . . . . [8291-64]

Reduced reference image quality assessment via sub-image similarity-based redundancy measurement, Xuanqin Mou, Wufeng Xue, Xi'an Jiaotong Univ. (China); Lei Zhang, The Hong Kong Polytechnic Univ.

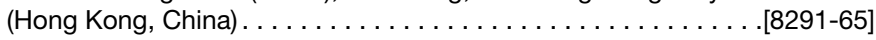

Color impact in visual attention deployment considering emotional images, Christel Chamaret, Technicolor S.A. (France) . . . . . . [8291-66] 


\section{Wednesday 25 January}

\section{Room: Grand Peninsula \\ Ballroom A . . . . . . . . . . . . . Wed. 8:20 to 9:30 am \\ Plenary Session and Conference Award Presentations}

8:25 am: More Words and Bigger Pictures, David A. Forsyth, Univ. of Illinois at Urbana-Champaign (United States)

\section{SESSION 6}

Room: Regency Ballroom B . . . . . Wed. 9:30 am to 12:10 pm

\section{Medical Image Quality: Features, Tasks and Semantics}

Session Chair: Patrick Le Callet, Univ. de Nantes (France)

9:30 am: On the development of expertise in interpreting medical images (Invited Paper), Elizabeth Krupinsky, The Univ. of Arizona (United States) .[8291-23]

10:00 am: Modeling observer performance for optimizing image acquisition and processing, Craig K. Abbey, Miguel Eckstein, Univ. of California, Santa Barbara (United States) . . . . . . . . . . . . . [8291-24]

10:20 am: Evaluation of HVS models in the application of medical image quality assessment, Lu Zhang, Christine Cavaro-Ménard, Univ. of Angers (France); Patrick Le Callet, Polytech' Nantes (France) . . .[8291-25] Coffee Break . . . . . . . . . . . . . . . . . 10:40 to 11:10 am 11:10 am: Perceptual challenges to computer-aided diagnosis, Yulei Jang, The Univ. of Chicago (United States) . . . . . . . . . . . . . [8291-26]

11:30 am: Satisfaction of search experiments in advanced imaging, Kevin S. Berbaum, The Univ. of lowa Hospitals and Clinics (United States) . . . . . . . . . . . . . . . . . . . . . . . . . . . . . . [8291-27]

11:50 am: Integrating human- and computer-based approaches to feature extraction and analysis, Bernice E. Rogowitz, Visual Perspectives (United States); Alyssa Goodman, Harvard-Smithsonian Ctr. for Astrophysics (United States) . . . . . . . . . . . . . . . . . . [8291-28] Lunch Break $12: 10$ to $2: 20 \mathrm{pm}$

\section{SESSION 7A}

Room: Regency Ballroom B .........Wed. 2:20 to 3:20 pm

\section{Visual Attention: Task and Image Quality: Joint Session with Conference 8293}

Session Chair: Bernice E. Rogowitz, Visual Perspectives Consulting (United States)

2:20 pm: How do we watch images?: a case of change detection and quality estimation, Jenni Radun, Tuomas Leisti, Toni Virtanen, Göte Nyman, Univ. of Helsinki (Finland). . . . . . . . . . . . . . . . . . [8293-20]

2:40 pm: Examining the effect of task on viewing behavior in videos using saliency maps, Hani Alers, Judith A. Redi, Technische Univ. Delft (Netherlands); Ingrid Heynderickx, Philips Research (Netherlands)[8291-29]

3:00 pm: Measuring saliency in images: which experimental parameters for the assessment of image quality?, Clement Fredembach, Geoff Woolfe, Jue Wang, Canon Information Systems Research Australia Pty. Ltd. (Australia) . . . . . . . . . . . . . . . . [8293-21] Coffee Break $3: 20$ to $3: 50 \mathrm{pm}$

\section{SESSION 7B}

Room: Regency Ballroom B .........Wed. 3:50 to 5:50 pm

\section{Visual Attention: Task and Image Quality: Joint Session with Conference 8293}

Session Chair: Susan P. Farnand, Rochester Institute of Technology (United States)

3:50 pm: Investigations of the tone reproduction curves on the perceived image quality for fine art reproductions, Jun Jiang, Franziska Frey, Susan Farnand, Rochester Institute of Technology (United States) . . . . . . . . . . . . . . . . . . . . . . . . . . . . . . . . . . . [8293-23]

4:10 pm: Characterizing eye movements during temporal- and global-quality assessment of h.264 compressed video sequences, Claire Mantel, Nathalie Guyader, Patricia Ladret, Gelu Ionescu, Gipsa-lab (France); Thomas Kunlin, STMicroelectronics (France). . . . . . . [8291-30]

4:30 pm: A compressed sensing model of crowding in peripheral vision, Jens Hocke, Univ. zu Lübeck (Germany); Michael Dorr, Schepens Eye Research Institute (United States); Erhardt Barth, Univ. zu Lübeck (Germany) . . . . . . . . . . . . . . . . . . . . . [8291-31]

4:50 pm: Foveated self-similarity in nonlocal image filtering, Alessandro Foi, Tampere Univ. of Technology (Finland); Giacomo Boracchi, Politecnico di Milano (Italy) . . . . . . . . . . . . . . . . . . . . . . [8291-32]

5:10 pm: A statistical study of the correlation between interest points and gaze points, Michael Nauge, Mohamed-Chaker Larabi, Univ. de Poitiers (France). . . . . . . . . . . . . . . . . . . . . . . . [8291-33]

5:30 pm: Interest point analysis as a model for the Poggendorff illusion, Fred W. M. Stentiford, Univ. College London (United Kingdom). . . . . . . . . . . . . . . . . . . . . . . . . . . [8291-34]

\section{Thursday 26 January SESSION 8}

\section{Room: Regency Ballroom B . . . . . . . Thurs. 8:30 to 11:40 am \\ Art Theory, Perception, and Rendering}

Session Chair: Huib de Ridder, Technische Univ. Delft (Netherlands) 8:30 am: The perception of art and the science of perception (Invited Paper), Robert Pepperell, Cardiff School of Art \& Design (United Kingdom). . . . . . . . . . . . . . . . . . . . . . . [8291-35]

9:00 am: Paintings, photographs, and computer graphics are calculated appearances, John J. McCann, McCann Imaging (United States) . . . . . . . . . . . . . . . . . . . . . . . . . . . . . . [8291-36] 9:20 am: Image integrity and aesthetics: towards a more encompassing definition of visual quality, Judith $A$. Redi, Technische Univ. Delft (Netherlands); Ingrid Heynderickx, Philips Research (Netherlands) and Delft Univ. of Technology (Netherlands) . . . . [8291-37] 9:40 am: Depicting 3D shape using lines (Invited Paper), Doug DeCarlo, Rutgers, The State Univ. of New Jersey (United States). . . . . . . [8291-38] Coffee Break . . . . . . . . . . . . . . . . . . . . . . 10:10 to 10:40 am

10:40 am: Box spaces in pictorial space: linear perspective versus templates, Huib de Ridder, Sylvia C. Pont, Technische Univ. Delft (Netherlands) . . . . . . . . . . . . . . . . . . . [8291-39]

11:00 am: Warping realist art to ensure consistent perspective: a new software tool for art investigations, Yu-Sung Chang, Wolfram Research (United States); David G. Stork, Ricoh Innovations, Inc. (United

States) . . . . . . . . . . . . . . . . . . . . . . . . . . . . . . [8291-40]

11:20 am: Sound meets image: freedom of expression in texture description, Reinier J. Jansen, René van Egmond, Huib de Ridder, Technische Univ. Delft (Netherlands); Thrasyvoulos N. Pappas,

Northwestern Univ. (United States). . . . . . . . . . . . . . . [8291-41] Lunch Break .................... 11:40 am to 1:00 pm 


\section{SESSION 9}

Room: Regency Ballroom B........ Thurs. 1:00 to 3:20 pm

\section{Computer Vision and Image Analysis of Art}

Session Chairs: Christopher W. Tyler, The Smith-Kettlewell Eye Research Institute (United States); Tiarna Doherty, J. Paul Getty Museum (United States); David M. Stone, Univ. of Delaware (United States)

1:00 pm: On the dynamics of aesthetic appreciation (Invited Paper), Claus-Christian Carbon, Otto-Friedrich-Univ. Bamberg (Germany)[8291-42]

1:40 pm: Museum as an integrated imaging device: visualization of ancient Kyoto cityscape from folding screen artifact, Kimiyoshi Miyata, Umi Oyabu, Michihiro Kojima, National Museum of Japanese History (Japan)............................... [8291-46]

2:00 pm: An experimental and theoretical analysis of the merits of 'virtual cleaning' of paintings, John Delaney, National Gallery of Art (United States); Andrea Casini, Istituto di Fisica Applicata Nello Carrara (Italy); Lionel Simonot, Univ. de Poitiers (France); M. Thoury, National Gallery of Art (United States); Marcello Picollo, Lorenzo Stefani, Istituto di Fisica Applicata Nello Carrara (Italy); Marco Poggesi, Consiglio Nazionale delle Ricerche (Italy); D. Conover, K. Fleisher, E. René de la Rie, National Gallery of Art (United States).

2:20 pm: In search of Leonardo: computer-based facial image analysis of Renaissance artworks for identifying Leonardo as subject Christopher W. Tyler, The Smith-Kettlewell Eye Research Institute (United States); William Smith, The Univ. of York (United Kingdom); David G. Stork, Ricoh Innovations, Inc. (United States). .[8291-44]

2:40 pm: Non-destructive analytical imaging of metallic surfaces using spectral measurements and ultrahigh-resolution scanning for cultural heritage investigation, Jun Kaneko, Yusuke Murayama, Jay Arre Toque, Ari Ide-Ektessabi, Kyoto Univ. (Japan) . . . . . . . . . . . . . [8291-45]

3:00 pm: Mapping colors from paintings to tapestries: rejuvenating the faded colors in tapestries based on colors in reference paintings, Eija Johansson, Marie Strom, Chalmers Univ. of Technology (Sweden); David G. Stork, Ricoh Innovations, Inc. (United States) . . . . . . . . .[8291-47]

Coffee Break....................... 3:20 to $3: 40 \mathrm{pm}$

Excursion . . . . . . . . . . . . . . . Thurs. 3:40 to 9:00 pm

Museum Visit: San Francisco Museum of Modern Art: Exhibition and Discussion

3:40 to $5: 00$ pm: Travel to San Francisco

5:00 to 7:00 pm: Museum Tour

7:00 pm: No-Host Group Dinner

We will be visiting an exhibition at the San Francisco Museum of Modern Art and explore the current exhibit with the curator. Participants will leave the conference hotel at 3:40 pm. Transportation, fee details, restaurant, and exhibit information to be provided at the conference. 


\section{Color Imaging XVII: Displaying, Processing, Hardcopy, and Applications}

Conference Chairs: Reiner Eschbach, Xerox Corp. (United States); Gabriel G. Marcu, Apple Inc. (United States); Alessandro Rizzi, Univ. degli Studi di Milano (Italy)

Program Committee: Jan P. Allebach, Purdue Univ. (United States); Scott J. Daly, Dolby Labs., Inc. (United States); Phil J. Green, London College of Communication (United Kingdom); Roger D. Hersch, Ecole Polytechnique Fédérale de Lausanne (Switzerland); Choon-Woo Kim, Inha Univ. (Korea, Republic of); Michael A. Kriss, Consultant (United States); Fritz Lebowsky, STMicroelectronics (France); Nathan Moroney, Hewlett-Packard Labs. (United States); Carinna E. Parraman, Univ. of the West of England (United Kingdom); Shoji Tominaga, Chiba Univ. (Japan); Stephen Westland, Univ. of Leeds (United Kingdom)

\section{Tuesday 24 January}

\section{Room: Grand Peninsula Ballroom A . . . . . . . . . . . . . . . Tues. 8:20 to 9:30 am Plenary Session and Society Award Presentations \\ 8:25 am: Computational Photography, William T. Freeman, Massachusetts Institute of Technology (United States)}

\section{SESSION 1}

Room: Regency Ballroom C . . . . . . . . . Tues. 9:30 to 10:50 am

\section{Vision and HDR I}

Session Chair: Reiner Eschbach, Xerox Corp. (United States) 9:30 am: Spatiochromatic detection, appearance, and motivations for wide-gamut color (Invited Paper), Scott J. Daly, Dolby Labs., Inc. (United States) . . . . . . . . . . . . . . . . . . . . . . . . 292-01]

10:00 am: Color assimilation and contrast near absolute threshold (Invited Paper), John J. McCann, McCann Imaging (United

States) . . . . . . . . . . . . . . . . . . . . . . . . . . . . . . . [8292-02]

10:30 am: Multi-illuminant color constancy for HDR images through exposure segmentation, Heng Zhang, Huaping Liu, Oregon State Univ. (United States); Shuxue Quan, Broadcom Corp. (United States) .[8292-03] Coffee Break . . . . . . . . . . . . . . . . . . 11:20 am

\section{SESSION 2}

Room: Regency Ballroom C.... . Tues. 11:20 am to 12:20 pm

\section{Vision and HDR II}

Session Chair: Alessandro Rizzi, Univ. degli Studi di Milano (Italy) 11:20 am: Tone mapping for HDR images with dimidiate luminance and spatial distributions of bright and dark regions, Masaki Kitaura, Fumio Okura, Masayuki Kanbara, Naokazu Yokoya, Nara Institute of Science and Technology (Japan) .................. [8292-04]

11:40 am: Color universal design: analysis of color category dependency on color vision type, Natsuki Kojima, Yasuyo G. Ichihara, Kogakuin Univ. (Japan); Kei Ito, The Univ. of Tokyo (Japan); Miyuki G. Kamachi, Kogakuin Univ. (Japan) . . . . . . . . . . . . . . [8292-05]

12:00 pm: Colour perception with changes in levels of illumination, Kwame F. Baah, Dept. of Health (United Kingdom) and Univ. of the Arts London (United Kingdom) . . . . . . . . . . . . . . . . . . . [8292-06] Lunch Break ................... 12:20 to $1: 50 \mathrm{pm}$

\section{SESSION 3}

Room: Regency Ballroom C......... Tues. 1:50 to 3:30 pm

\section{Color Management}

Session Chair: Gabriel G. Marcu, Apple Inc. (United States)

1:50 pm: Reducing the number of calibration patterns for the twoby-two dot centering model, Vahid Babaei, Romain Rossier, Roger D. Hersch, Ecole Polytechnique Fédérale de Lausanne (Switzerland)[8292-07] 2:10 pm: Spatial gamut mapping for preserving the details of an image, In-Yong Song, Ho-Gun Ha, Wang-Jun Kyung, Yeong-Ho Ha, Kyungpook National Univ. (Korea, Republic of) . . . . . . . . . [8292-08]

2:30 pm: Evaluating color calibration kits with virtual display, WeiChung Cheng, Hugo Caceres, Aldo Badano, U.S. Food and Drug

Administration (United States). . . . . . . . . . . . . . . . . [8292-09]

2:50 pm: Optimizing color fidelity in wide-gamut-display devices when processing images compressed by block-based DCT transforms, Fritz Lebowsky, STMicroelectronics (France) . . . . . . . . . . . [8292-10]

3:10 pm: Optimal gamut volume design for three primary and multiprimary display systems, Carlos Eduardo Rodriguez-Pardo, Gaurav Sharma, Univ. of Rochester (United States); Xiao-Fan Feng, Jon Speigle, Ibrahim Sezan, Sharp Labs. of America, Inc. (United States) . . . . [8292-11] Coffee Break ......................... 3:30 to 4:00 pm

\section{SESSION 4}

Room: Regency Ballroom C.........Tues. 4:00 to 5:30 pm

The Dark Side of the Color

Session Chair: Reiner Eschbach, Xerox Corp. (United States)

4:00 pm: The dark side of CIELAB, Gaurav Sharma, Carlos Eduardo Rodriguez-Pardo, Univ. of Rochester (United States). . . . . . . . [8292-12]

4:15 pm: Complexitites of complex contrast, Eliezer Peli, Schepens Eye Research Institute (United States). . . . . . . . . . . . . . . [8292-13] 4:30 pm: It's not the pixel count, you fool, Michael A. Kriss, MAK Consultants (United States). . . . . . . . . . . . . . . . . . . . . . . [8292-14] 4:45 pm: Color imaging and aesthetics: is there the cheshire cat?, Elena A. Fedorovskaya, Eastman Kodak Co. (United States). . . . [8292-15] 5:00 pm: Dark texture in artworks, Carinna E. Parraman, Univ. of the West of England (United Kingdom) . . . . . . . . . . . . . . [8292-16]

5:15 pm: Harmonious colors: from alchemy to science, Giordano B. Beretta, Nathan M. Moroney, Hewlett-Packard Labs. (United

States) . . . . . . . . . . . . . . . . . . . . . . . [8292-17] 


\section{Conference 8292}

\section{Interactive Paper and Symposium Demonstration Session}

\section{Room: Grand Peninsula Ballroom E . .Tues. 5:30 to 8:00 pm}

\section{Demonstrations .} 5:30 to $8: 00 \mathrm{pm}$

A symposium-wide demonstration session will be open to attendees 5:30 to 8:00 pm Tuesday evening. Demonstrators will provide interactive, hands-on demonstrations of a wide-range of products related to Electronic Imaging.

\section{Posters} 5:30 to 7:00 pm

Interactive papers will be placed on display after 10:30 am on Tuesday. An interactive paper session, with authors present at their papers, will be held Tuesday evening, 5:30 to 7:00 pm.

Characterization of color scanners based on SVR, Bin Li, Yixin Zhang, Jiangnan Univ. (China). . . . . . . . . . . . . . . . . . [8292-44]

Deducing ink thickness variations of fluorescent print by a spectral prediction model, Juan Qing Wang, Yixin Zhang, Jiangnan Univ.

(China) . . . . . . . . . . . . . . . . . . . . . . . . . . [8292-46]

Bio-inspired color sketch for eco-friendly printing, llia V. Safonov, Ekaterina Tolstaya, Michael N. Rychagov, Samsung Electronics Co., Ltd. (Russian Federation); Ho Keun Lee, SangHo Kim, Donchul Choi, Samsung Electronics Co., Ltd. (Korea, Republic of) . . . . . . . . . . . . . . . [8292-48]

Reflectance model for recto-verso color halftone images, Juan Wang, Zhang Yi Xin, Tian Dong Wen, Jiangnan Univ. (China) . . . . . . . [8292-49]

The study on physical dot gain of second order FM halftone based on ink spreading in all ink superposition conditions, Shikun $\mathrm{Xi}$, Yixin Zhang, Jiangnan Univ. (China) . . . . . . . . . . . . . . [8292-50]

Tensor decomposition for color printer model lookup table, Vishal Monga, The Pennsylvania State Univ. (United States); Marty Maltz, Zhigang Fan, Xerox Corp. (United States). . . . . . . . . . . . . . . [8292-51]

Genetic algorithm for segmentation and classification of colony images automatically, Weisheng Li, Henan Polytechnic Univ. (China) . . . . . . . . . . . . . . . . . . . . . . . [8292-52]

Color edge detection using edge density, Weixing Wang, Henan Polytechnic Univ. (China) . . . . . . . . . . . . . . . . . . . . .88292-53]

Spectral prediction model for variable dot-size ink jet presswork (Invited Paper), Weiyong Xing, Yixin Zhang, Yangtze Univ. (China)[8292-54]

\section{Wednesday 25 January}

\section{Room: Grand Peninsula Ballroom A . . . . . . . . . . . . . . . Wed. 8:20 to 9:30 am \\ Plenary Session and Conference Award Presentations}

8:25 am: More Words and Bigger Pictures, David A. Forsyth, Univ. of Illinois at Urbana-Champaign (United States)

\section{SESSION 5}

Room: Regency Ballroom C........ Wed. 9:30 to 10:10 am

\section{Image Processing I}

Session Chair: Alessandro Rizzi, Univ. degli Studi di Milano (Italy) 9:30 am: Detection and compensation of backlight images using chrominance, Hyung Jun Park, Seong Wook Han, Samsung Electronics Co., Ltd. (Korea, Republic of) . . . . . . . . . . . . . . . . . . [8292-18] 9:50 am: A new method for skin color enhancement, Huan Zhao Zeng, Hewlett-Packard Co. (United States); Ronnier Luo, Univ. of Leeds (United Kingdom) . . . . . . . . . . . . . . . . . . . . . . . . . . . . .88292-20] Coffee Break $10: 10$ to $10: 50 \mathrm{am}$

\section{SESSION 6}

Room: Regency Ballroom C..... Wed. 10:50 am to 12:10 pm

\section{Image Processing II}

Session Chair: Fritz Lebowsky, STMicroelectronics (France)

10:50 am: CIE chromaticity, Planckian locus, and correlated color temperature estimation from raw-image data using colorchecker training images, Touraj Tajbakhsh, Technische Univ. Hamburg-Harburg (Germany) ............................. [8292-21]

11:10 am: Comparative performance analysis of mobile displays, Reza Safaee-Rad, Qualcomm Inc. (Canada); Milivoje Aleksic, Qualcomm Inc. (United States). . . . . . . . . . . . . . . . . . . . . . . . . . . [8292-22]

11:30 am: Termites: a Retinex implementation based on a colony of agents, Gabriele Simone, Gjøvik Univ. College (Norway); Giuseppe Audino, Univ. degli Studi di Milano (Italy); Ivar Farup, Gjøvik Univ. College (Norway); Alessandro Rizzi, Univ. degli Studi di Milano (Italy) . . . [8292-23]

11:50 am: A color quantization algorithm based on minimization of $\mathbf{L} \mathbf{p}$ norm error in a modified CIELAB space, Haitao Xue, Jan P. Allebach, Charles A. Bouman, Purdue Univ. (United States) . . . . . . . . [8292-24] Lunch Break ................... 12:10 to $2: 10 \mathrm{pm}$

\section{SESSION 7}

Room: Regency Ballroom C......... Wed. 2:10 to 3:10 pm

\section{Applications}

Session Chair: Jan P. Allebach, Purdue Univ. (United States) 2:10 pm: Human skin imaging using three-phase spectral matching imager, Akira Kimachi, Osaka Electro-Communication Univ. (Japan); Shigeru Ando, The Univ. of Tokyo (Japan); Motonori Doi, Shogo Nishi, Osaka Electro-Communication Univ. (Japan) . . . . . . . . . . . . [8292-25]

2:30 pm: Appearance analysis of human skin with cosmetic foundation, Rie Ohtsuki, Kanebo Cosmetics Inc. (Japan) and Chiba Univ. (Japan); Shoji Tominaga, Chiba Univ. (Japan); Rie Hikima, Kanebo Cosmetics Inc. (Japan) . . . . . . . . . . . . . . . . . . . . [8292-27]

2:50 pm: Color analysis and image rendering of woodblock prints with oil-based ink, Takahiko Horiuchi, Tetsushi Tanimoto, Shoji Tominaga, Chiba Univ. (Japan) . . . . . . . . . . . . . . . . . . . . . . [8292-28] Coffee Break .................... 3:10 to $3: 40$ pm

\section{SESSION 8}

Room: Regency Ballroom C.........Wed. 3:40 to 5:00 pm

\section{Printing and Halftoning I}

Session Chair: Carinna E. Parraman, Univ. of the West of England (United Kingdom)

3:40 pm: Pre-RIP color management for soft proofing, Ingeborg Tastl, Kok-Wei Koh, Hewlett-Packard Labs. (United States) . . . . . . . [8292-30]

4:00 pm: Parametrically controlled, stochastically seeded clustered halftones, Edgar Andres Bernal, Shen-ge Wang, Robert P. Loce, Xerox Corp. (United States) . . . . . . . . . . . . . . . . . . . . . [8292-31] 4:20 pm: Assessing color reproduction tolerances in commercial print workflow, Giordano B. Beretta, Eric Hoarau, Sunil Kothari, I-Jong Lin, Jun Zeng, Hewlett-Packard Labs. (United States). . . . . . . . . . . . [8292-32]

4:40 pm: Investigation of the paper dependency of laser-printed colors for uncoated papers, Saeideh Gorji Kandi, Institute for Color Science \& Technology (Iran, Islamic Republic of) . . . . . . . . . . . [8292-33] 


\section{Thursday 26 January SESSION 9}

Room: Regency Ballroom C....... Thurs. 8:30 to 10:30 am

\section{Printing and Halftoning II}

Session Chair: Shoji Tominaga, Chiba Univ. (Japan)

8:30 am: Color-dependent banding characterization and simulation on natural images, Sirui Hu, Jia Zhang, Purdue Univ. (United States); Hila Nachlieli, Doron Shaked, Hewlett-Packard Labs. Israel Ltd. (Israel); Smadar Shiffman, Indigo Ltd. (Israel); Jan P. Allebach, Purdue Univ. (United States).

8:50 am: Modeling large-area influence in digital halftoning for electrophotographic printers, Yanling Ju, Xujie Zhang, Dhruv Saxena, Purdue Univ. (United States); Tamar Kashti, Dror Kella, Indigo Ltd. (Israel); Doron Shaked, Mani Fischer, Hewlett-Packard Labs. Israel Ltd. (Israel); Robert A. Ulichney, Hewlett-Packard Co. (United States); Jan P. Allebach, Purdue Univ. (United States) . . . . . . . . . . . . . . . . . . . . [8292-35]

9:10 am: The octagon screen set: a square N-color, high-order, Moiréfree screen set, Yung-Yao Chen, Purdue Univ. (United States); Mani Fischer, Hewlett-Packard Labs. Israel Ltd. (Israel); Tamar Kashti, Indigo Ltd. (Israel); Doron Shaked, Hewlett-Packard Labs. Israel Ltd. (Israel); Jan P. Allebach, Purdue Univ. (United States). . . . . . . . . . . . . . [8292-36]

9:30 am: Colour print workflow and methods for multi-layering of colour and decorative inks using UV inkjet for fine-art printing, Carinna E. Parraman, Paul Laidler, Univ. of the West of England (United

Kingdom) . . . . . . . . . . . . . . . . . . . . . . . . . . . . [8292-38]

9:50 am: Halftone blending between smooth- and detail-screens to improve print quality with electrophotographic printers, Seong Jun Park, Purdue Univ. (United States); Mark Q. Shaw, George Kerby, Terry Nelson, Di-Yuan Tzeng, Victor Loewen, Kurt Bengtson, Hewlett-Packard Co. (United States); Jan P. Allebach, Purdue Univ. (United States)[8292-39]

10:10 am: Ink-saving strategy based on document content characterization and halftone textures, Maria V. Ortiz Segovia, Purdue Univ. (United States) and Océ Print Logic Technologies (France); Nicolas Bonnier, Océ Print Logic Technologies (France); Jan P. Allebach, Purdue Univ. (United States) . . . . . . . . . . . . . . . . . . . . . . . [8292-37]

Coffee Break $10: 30$ to $11: 00$ am

\section{SESSION 10}

\section{Room: Regency Ballroom C . . . . Thurs. 11:00 am to 12:20 pm}

\section{Spectral and Display}

Session Chair: Reiner Eschbach, Xerox Corp. (United States)

11:00 am: Spectral transmittance model for piles of transparencies printed in halftone, Jacques Machizaud, Mathieu Hébert, Lab. Hubert Curien (France) and Univ. Jean-Monnet Saint-Etienne (France) and CNRS (France) . . . . . . . . . . . . . . . . . . . . . . . . . . [8292-40]

11:20 am: Optimal estimation of spectral reflectance based on metamerism, Tzren-Ru Chou, Wei-Ju Lin, National Taiwan Normal Univ. (Taiwan) . . . . . . . . . . . . . . . . . . . . . . . . . . . [8292-41]

11:40 am: Hue-shift model for DLP projector with the white peaking function, II-Su Park, Ho-Gun Ha, Dae-Chul Kim, Yeong-Ho Ha, Kyungpook National Univ. (Korea, Republic of) . . . . . . . . . . . [8292-42]

12:00 pm: Content-dependent noise reduction for mobile displays, Ga-Hee Kim, Yoon-Gyoo Lee, Han-Eol Kim, Choon-Woo Kim, Inha Univ. (Korea, Republic of). . . . . . . . . . . . . . . . . . . . . . . . [8292-43] 


\section{Image Quality and System Performance IX}

Conference Chairs: Frans Gaykema, Océ Technologies B.V. (Netherlands); Peter D. Burns, Burns Digital Imaging (United States)

Program Committee: Majed Chambah, Univ. de Reims Champagne-Ardenne (France); Luke C. Cui, Lexmark International, Inc. (United States); Mark D. Fairchild, Rochester Institute of Technology (United States); Susan P. Farnand, Rochester Institute of Technology (United States); Dirk W. Hertel, E Ink Corp. (United States); Robin B. Jenkin, Aptina Imaging Corp. (United States); Sang Ho Kim, Samsung Digital City (Korea, Republic of); Chaker Larabi, Univ. de Poitiers (France); Lindsay W. MacDonald, London College of Communication (United Kingdom); Yoichi Miyake, Chiba Univ. (Japan); Göte S. Nyman, Univ. of Helsinki (Finland); D. René Rasmussen, Qi Analytics LLC (United States); Sophie Triantaphillidou, Univ. of Westminster (United Kingdom); Eric K. Zeise, Kodak's Graphic Communications Group (United States); Hongqin Zhang, Apple Inc. (United States)

\section{Tuesday 24 January}

Room: Grand Peninsula

\section{Plenary Session and Society Award Presentations}

8:25 am: Computational Photography, William T. Freeman,

Massachusetts Institute of Technology (United States)

\section{SESSION 1}

Room: Regency Ballroom A........ Tues. 9:30 to 10:30 am

\section{Image Quality and Mobile Imaging I: Joint Session with Conference 8299}

Session Chairs: Peter D. Burns, Burns Digital Imaging (United States); Sebastiano Battiato, Univ. degli Studi di Catania (Italy)

9:30 am: Development of the I3A CPIQ spatial metrics, Henrik Eliasson, Sony Ericsson Mobile Communications AB (Sweden); Donald Baxter, STMicroelectronics (R\&D) Ltd. (United Kingdom); Frédéric Cao, DxO Labs (France); Jonathan Phillips, Eastman Kodak Co. (United States) .[8293-01] 9:50 am: A functional-design approach to lens shading correction issues on mobile camera system, Seunghun Yoo, SAMSUNG Electronics Co., Ltd. (Korea, Republic of); TaeChan Kim, SAMSUNG Electronics Co., Ltd. (United States) . . . . . . . . . . . . . . . . . . . . . . . [8299-18]

10:10 am: Rethinking user interfaces for cameraphones, Stephen A. Brewster, Christopher McAdam, Univ. of Glasgow (United

Kingdom) . . . . . . . . . . . . .

Coffee Break ...................... 10:30 to 11:10 am

\section{SESSION 2}

Room: Regency Ballroom A . . . . . Tues. 11:10 am to 12:30 pm

Image Quality and Mobile Imaging II: Joint Session with Conference 8299

Session Chairs: Peter D. Burns, Burns Digital Imaging (United States); Sebastiano Battiato, Univ. degli Studi di Catania (Italy)

11:10 am: Calibration and adaptation of ISO visual noise for camera phone image quality assessment, Donald J. Baxter, Andrew Murray, STMicroelectronics (R\&D) Ltd. (United Kingdom) . . . . . . . . . . . [8293-02]

11:30 am: An objective method for evaluating the texture-preserving capability of digital camcorders, Kongfeng Zhu, Shujun Li, Dietmar Saupe, Univ. Konstanz (Germany) . . . . . . . . . . . . . . [8293-03]
11:50 am: Improving texture loss measurement: spatial frequency response based on a colored target, Uwe Artmann, Dietmar Wueller, Image Engineering GmbH \& Co. KG (Germany) . . . . . . . . . . [8293-04]

12:10 pm: On the performances of computer vision algorithms on mobile platforms, Sebastiano Battiato, Giovanni M. Farinella, Enrico Messina, Giovanni Puglisi, Daniele Ravì, Univ. degli Studi di Catania (Italy); Alessandro Capra, Valeria Tomaselli, STMicroelectronics (Italy) .[8299-20] Lunch Break .................... 12:30 to 2:00 pm

\section{SESSION 3}

Room: Harbour Room B ...........Tues. 2:00 to 3:20 pm

\section{Image Acquisition Performance: Characterization and Measurement}

Session Chair: Robin B. Jenkin, Aptina Imaging Corp. (United States) 2:00 pm: The uncertainty of scanner illumination II, Luke C. Cui, Lexmark International, Inc. (United States).

2:20 pm: Measuring the modulation transfer function of image capture devices: what do the numbers really mean?, Xujie Zhang, Yanling Ju, Purdue Univ. (United States); Tamar Kashti, Dror Kella, Tal Frank, Indigo Ltd. (Israel); Doron Shaked, Hewlett-Packard Labs. Israel Ltd. (Israel); Robert A. Ulichney, Hewlett-Packard Co. (United States); Mani Fischer, Hewlett-Packard Labs. Israel Ltd. (Israel); Jan P. Allebach, Purdue Univ. (United States). . . . . . . . . . . . . . . . . . . . . . [8293-06]

2:40 pm: A fast, automatic camera image stabilization benchmarking scheme, Jun Yu, Scott Craver, Binghamton Univ. (United States)[8293-07] 3:00 pm: A comparison of signal-to-noise ratio (SNR) of linear CCD sensors for optical payload, Mahmood Waqas, Pakistan Space and Upper Atmospheric Research Commission (SUPARCO)

(Pakistan). . . . . . . . . . . . . . . . . . . . . . . . . . . . . . . [8293-08]

Coffee Break . . . . . . . . . . . . . . . . . . . 3:20 to $3: 50$ pm

\section{SESSION 4}

Room: Harbour Room B ............ Tues. 3:50 to 5:30 pm

\section{Image Processing Performance: Characterization and Measurement}

Session Chair: Sangho Kim, Samsung Digital City (Korea, Republic of) 3:50 pm: A sharpness measure on automatically selected edge segments, Francesca Gasparini, Fabrizio Marini, Silvia Corchs, Schettini Raimondo, Univ. degli Studi di Milano-Bicocca (Italy) . . . . . . . [8293-09]

4:10 pm: Selecting the proper window for SSIM, Steven McFadden, Univ. of Waterloo (Canada) and Christie Digital Systems Canada, Inc (Canada); Paul A. S. Ward, Univ. of Waterloo (Canada) . . . . . . . [8293-10] 
4:30 pm: Measurement of texture loss for JPEG 2000 compression, Peter D. Burns, Burns Digital Imaging (United States); Don Williams, Image Science Associates (United States) . . . . . . . . . . . . . . . . [8293-11]

4:50 pm: A no-reference image quality metric for blur and ringing distortions based on weighting process, Aladine Chetouani, Azeddine Beghdadi, Univ. Paris-Nord (France). . . . . . . . . . . . . . . . . . [8293-12]

5:10 pm: A new method to identify and quantify image distortion based on Gabor filter bank and multiple regression analysis, Benhur Ortiz Jaramillo, Univ. Nacional de Colombia (Colombia) and Univ. Gent (Belgium); Julio Cesar Garcia Alvarez, Univ. Nacional de Colombia (Colombia); Hartmut Führ, RWTH Aachen (Germany); Sergio Alejandro Orjuela Vargas, Univ. Gent (Belgium); German Castellanos Dominguez, Univ. Nacional de Colombia (Colombia); Wilfried Philips, Univ. Gent (Belgium) . . . . . . . . . . . . . . . . . . . . . . . . [8293-36]

\section{Interactive Paper and Symposium Demonstration Session}

Room: Grand Peninsula Ballroom E . . Tues. 5:30 to 8:00 pm

\section{Demonstrations}

A symposium-wide demonstration session will be open to attendees 5:30 to 8:00 pm Tuesday evening. Demonstrators will provide interactive, hands-on demonstrations of a wide-range of products related to Electronic Imaging.

Posters 5:30 to 7:00 pm

Interactive papers will be placed on display after 10:30 am on Tuesday. An interactive paper session, with authors present at their papers, will be held Tuesday evening, 5:30 to 7:00 pm.

Optimal patch code design via device characterization, Wencheng $\mathrm{Wu}$ Edul N. Dalal, Xerox Corp. (United States) . .[8293-37]

Influence of viewing device and soundtrack in HDTV on subjective video quality, Arne Redl, Christian Keimel, Klaus Diepold, Technische Univ. München (Germany). . . . . . . . . . . . . . . . . . . . . [8293-38] Influence of viewing experience and stabilization phase in subjective video testing, Christian Keimel, Arne Redl, Klaus Diepold, Technische Univ. München (Germany). . . . . . . . . . . . . . . . . . . . . . [8293-39]

Perceptual visual image sharpness metric for image-based imager stabilization, Fabien F. G. Gavant, Laurent Alacoque, Antoine Dupret, Tien Ho-Phuoc, Dominique David, CEA-LETI (France) . . . . . . . . . . .[8293-40]

A unified method for comparison of algorithms of saliency extraction, Tien Ho-Phuoc, Laurent Alacoque, Antoine Dupret, CEA-LETI (France); Anne Guérin-Dugué, Gipsa-lab (France); Arnaud Verdant, CEA-LETI

(France) . . . . . . . . . . . . . . . . . . . . . . . . . [8293-41]

\section{Wednesday 25 January}

\section{Room: Grand Peninsula \\ Ballroom A . . . . . . . . . . . . . Wed. 8:20 to 9:30 am \\ Plenary Session and Conference Award Presentations}

8:25 am: More Words and Bigger Pictures, David A. Forsyth, Univ. of Illinois at Urbana-Champaign (United States)

\section{SESSION 5}

Room: Harbour Room B . . . . . . . . . . Wed. 9:30 to 10:30 am

Image Display Performance: Color Adjustment

Session Chair: Sophie Triantaphillidou, Univ. of Westminster (United Kingdom)

9:30 am: Comparative performance analysis of two picture adjustment methods: HSV versus YCbCr, Reza Safaee-Rad, Milivoje Aleksic,

Qualcomm Inc. (Canada). . . . . . . . . . . . . . . . . . . . . . [8293-13]

9:50 am: Evaluation of preferred lightness rescaling methods for color reproduction, Yerin Chang, Phil Green, London College of Communication (United Kingdom) . . . . . . . . . . . . . . . . [8293-14]

10:10 am: Investigations of the display white point on the perceived image quality, Jun Jiang, Farhad Abed, Joseph Voelkel, Rochester Institute of Technology (United States) . . . . . . . . . . . . . . . [8293-15] Coffee Break . . . . . . . . . . . . . . . . . . . 10:30 to 11:10 am

\section{SESSION 6}

Room: Harbour Room B . . . . . . . Wed. 11:10 am to 12:30 pm

Perceptual Image Quality Experimentation

Session Chair: Mohamed-Chaker Larabi, Univ. de Poitiers (France)

11:10 am: The mobile image quality survey game, D. René Rasmussen, Qi Analytics LLC (United States) . . . . . . . . . . . . . . . . . . . [8293-16]

11:30 am: Evaluation of perceived image sharpness with changes in the displayed image size, Jae-Young Park, Sophie Triantaphillidou, Ralph E. Jacobson, Univ. of Westminster (United Kingdom) . . . . . . . [8293-17]

11:50 am: Towards a perceptual metric for computer-generated images, Pierre Boulenguez, Boris Airieau, Mohamed-Chaker Larabi, Daniel Meneveaux, Univ. de Poitiers (France) . . . . . . . . . . . . . . . [8293-18]

12:10 pm: Assessing product image quality for online shopping, Anjan Goswami, Sung H. Chung, Naren Chittar, Atiq Islam, eBay Inc. (United States) . . . . . . . . . . . . . . . . . . . . . . . . [8293-19] Lunch Break . . . . . . . . . . . . . . . . . . . . . . 12:30 to 2:20 pm

\section{SESSION 7A}

Room: Regency Ballroom B . . . . . . . . . Wed. 2:20 to 3:20 pm

Visual Attention: Task and Image Quality: Joint Session with Conference 8291

Session Chair: Bernice E. Rogowitz, Visual Perspectives Consulting (United States)

2:20 pm: How do we watch images?: a case of change detection and quality estimation, Jenni Radun, Tuomas Leisti, Toni Virtanen, Göte Nyman, Univ. of Helsinki (Finland). . . . . . . . . . . . . . . . . [8293-20]

2:40 pm: Examining the effect of task on viewing behavior in videos using saliency maps, Hani Alers, Judith A. Redi, Technische Univ. Delft (Netherlands); Ingrid Heynderickx, Philips Research (Netherlands)[8291-29]

3:00 pm: Measuring saliency in images: which experimental parameters for the assessment of image quality?, Clement Fredembach, Geoff Woolfe, Jue Wang, Canon Information Systems Research Australia Pty. Ltd. (Australia) . . . . . . . . . . . . . . . [8293-21] Coffee Break . . . . . . . . . . . . . . . . 3:20 to 3:50 pm 


\section{SESSION 7B}

Room: Regency Ballroom B Wed. 3:50 to 5:50 pm

\section{Visual Attention: Task and Image Quality: Joint Session with Conference 8291}

Session Chair: Susan P. Farnand, Rochester Institute of Technology (United States)

3:50 pm: Investigations of the tone reproduction curves on the perceived image quality for fine art reproductions, Jun Jiang, Franziska Frey, Susan Farnand, Rochester Institute of Technology (United States) . . . . . . . . . . . . . . . . . . . . . . . . . . . [8293-23]

4:10 pm: Characterizing eye movements during temporal- and global-quality assessment of h.264 compressed video sequences, Claire Mantel, Nathalie Guyader, Patricia Ladret, Gelu lonescu, Gipsa-lab (France); Thomas Kunlin, STMicroelectronics (France). . . . . . . [8291-30]

4:30 pm: A compressed sensing model of crowding in peripheral vision, Jens Hocke, Univ. zu Lübeck (Germany); Michael Dorr, Schepens Eye Research Institute (United States); Erhardt Barth, Univ. zu Lübeck (Germany) . . . . . . . . . . . . . . . . . . . . [8291-31]

4:50 pm: Foveated self-similarity in nonlocal image filtering, Alessandro Foi, Tampere Univ. of Technology (Finland); Giacomo Boracchi, Politecnico di Milano (Italy) [8291-32]

5:10 pm: A statistical study of the correlation between interest points and gaze points, Michael Nauge, Mohamed-Chaker Larabi, Univ. de Poitiers (France). . . . . . . . . . . . . . . . . . . . . . [8291-33]

5:30 pm: Interest point analysis as a model for the Poggendorff illusion, Fred W. M. Stentiford, Univ. College London (United

Kingdom) . . . . . . . . . . . . . . . . . . . . . . . . . . . . . .[8291-34]

\section{Thursday 26 January SESSION 8}

\section{Room: Harbour Room B . . ........ Thurs. 8:50 to 10:10 am \\ Image Quality in Print}

Session Chair: Frans Gaykema, Océ Technologies B.V. (Netherlands) 8:50 am: A method of detecting changes in image quality via sensing on customer documents, Wencheng Wu, Beilei Xu, John C. Handley, Xerox Corp. (United States). . . . . . . . . . . . . . . . . . . . [8293-24] 9:10 am: Print quality analysis for ink-saving algorithms, Maria V. Ortiz Segovia, Purdue Univ. (United States) and Océ Print Logic Technologies (France); Nicolas Bonnier, Océ Print Logic Technologies (France); Jan P. Allebach, Purdue Univ. (United States) . . . . . . . . . . . . . . [8293-25] 9:30 am: Masking mediated print defect visibility predictor, Xiaochen Jing, Purdue Univ. (United States); Hila Nachieli, Doron Shaked, Smadar Shiffman, Hewlett-Packard Labs. Israel Ltd. (Israel); Jan P. Allebach, Purdue Univ. (United States) . . . . . . . . . . . . . . . . . . [8293-26] 9:50 am: Psychophysical evaluation of banding visibility in the presence of print content, Jia Zhang, Purdue Univ. (United States); Doron Shaked, Hila Nachlieli, Smadar Shiffman, Hewlett-Packard Labs. Israel Ltd. (Israel); Jan P. Allebach, Purdue Univ. (United States) . . . . . . . [8293-27] Coffee Break . . . . . . . . . . . . . . . . . 10:10 to 10:50 am

\section{SESSION 9}

Room: Harbour Room B ..... Thurs. 10:50 am to 12:30 pm

System Performance: Video

Session Chair: Luke C. Cui, Lexmark International, Inc. (United States)

10:50 am: No-reference video quality assessment of $\mathbf{H . 2 6 4}$ video streams based on semantic saliency maps, Hugo Boujut, Jenny BenoisPineau, Toufik Ahmed, Bordeaux Univ. (France); Ofer Hadar, Ben-Gurion Univ. of the Negev (Israel); Patrick Bonnet, Audemat Worldcast Systems (France) . .[8293-28]

11:10 am: Linking quality assessment of free-viewpoint video objects up with algorithm development, Sara Kepplinger, Technische Univ. IImenau (Germany) . . . . . . . . . . . . . . . . . . . . . . [8293-29]

11:30 am: A perceptual optimization of H.264/AVC bit allocation at the frame and macroblock levels, Miryem Hrarti, Hakim Saadane, MohamedChaker Larabi, XLIM-SIC (France). . . . . . . . . . . . . . . [8293-30]

11:50 am: QoE assessment method for mobile video services based on user motivation, Fumiya Kobayashi, Masataka Masuda, Takanori Hayashi, NTT Network Innovation Labs. (Japan) . . . . . . . . . [8293-31]

12:10 pm: Quality rules for detection, recognition, and identification in video-surveillance applications, Mohamed-Chaker Larabi, Didier Nicholson, Univ. de Poitiers (France) . . . . . . . . . . . . [8293-32] Lunch Break ................... 12:30 to 2:00 pm

\section{SESSION 10}

Room: Harbour Room B ........... Thurs. 2:00 to 3:00 pm

\section{Image Quality Evaluation: New Developments} Session Chair: Göte S. Nyman, Univ. of Helsinki (Finland)

2:00 pm: A learning-based approach for automated quality assessment of computer-rendered images, Xi Zhang, Gady Agam, Illinois Institute of Technology (United States) . . . . . . . . . . . [8293-33] 2:20 pm: A comparison of techniques for superresolution evaluation, Monica A. Trifas, Jacksonville State Univ. (United States) . . . . . [8293-34] 2:40 pm: Detection of image quality metamers based on the metric for unified image quality, Kimiyoshi Miyata, National Museum of Japanese History (Japan); Norimichi Tsumura, Chiba Univ. (Japan). . . . . . .88293-35] 


\section{Visualization and Data Analysis 2012}

Conference Chairs: Pak Chung Wong, Pacific Northwest National Lab. (United States); David L. Kao, NASA Ames Research Ctr. (United States); Ming C. Hao, Hewlett-Packard Labs. (United States); Chaomei Chen, Drexel Univ. (United States)

Conference Co-Chairs: Robert Kosara, The Univ. of North Carolina at Charlotte (United States); Mark A. Livingston, U.S. Naval Research Lab. (United States); Jinah Park, Korea Advanced Institute of Science and Technology (Korea, Republic of); lan Roberts, Pacific Northwest National Lab. (United States)

Program Committee: Madjid Allili, Bishop's Univ. (Canada); Guoning Chen, The Univ. of Utah (United States); Yi-Jen Chiang, Polytechnic Institute of NYU (United States); George Chin, Pacific Northwest National Lab. (United States); Scott E. Dillard, Pacific Northwest National Lab. (United States); Marian Dörk, Univ. of Calgary (Canada); Sussan Einakian, The Univ. of Alabama in Huntsville (United States); Matti T. Gröhn, Ctr. for Scientific Computing (Finland); Halldor Janetzko, Univ. Konstanz (Germany); Ming Jiang, Lawrence Livermore National Lab. (United States); Alark Joshi, Boise State Univ. (United States); Dan Keefe, Univ. of Minnesota (United States); Daniel A. Keim, Univ. Konstanz (Germany); Bongshin Lee, Microsoft Corp. (United States); Bob Lewis, Washington State Univ. (United States); Guo-Shi Li, ExxonMobil Upstream Research Company (United States); Peter Lindstrom, Lawrence Livermore National Lab. (United States); Lars Linsen, Jacobs Univ. Bremen gGmbH (Germany); Zhanping Liu, Kentucky State Univ. (United States); Lucille T. Nowell, U.S. Dept. of Energy (United States); Harald Obermaier, Univ. of Kaiserslautern (Germany); Donald A. Pellegrino, Jr., Drexel Univ. (United States); William Pike, Pacific Northwest National Lab. (United States); Theresa-Marie Rhyne, Computer Graphics and E-Learning (United States); Tobias Schreck, Univ. Konstanz (Germany); Han-Wei Shen, The Ohio State Univ. (United States); Chad A. Steed, Oak Ridge National Lab. (United States); Kalpathi R. Subramanian, The Univ. of North Carolina at Charlotte (United States); Soon Tee Teoh, San José State Univ. (United States); Matthew O. Ward, Worcester Polytechnic Institute (United States); Yingcai Wu, Univ. of California, Davis (United States); Caixia Zhang, Google (United States); Jian Zhang, Drexel Univ. (United States); Song Zhang, Mississippi State Univ. (United States)

Cosponsored by:

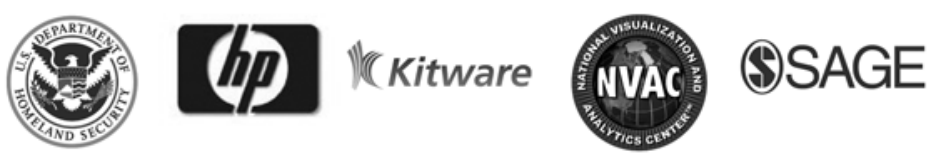

\section{Monday 23 January}

Room: Sandpebble Room E.... . . . . Mon. 8:30 to 8:45 am

Opening Remarks

Session Chair: Pak Chung Wong, Pacific Northwest National Lab. (United States)

Room: Sandpebble Room E. . . . . . . . Mon. 8:45 to 9:00 am

Information Visualization (IVS) Introduction

Chaomei Chen, Drexel Univ. (United States)

\section{SESSION 1}

Room: Sandpebble Room E . . . . . . . . Mon. 9:00 to 10:00 am

\section{Interactive Visualization}

Session Chair: Pak Chung Wong, Pacific Northwest National Lab. (United States)

9:00 am: StreamSqueeze: a dynamic stream visualization for monitoring of event data, Florian Mansmann, Milos Krstajic, Fabian Fischer, Enrico Bertini, Univ. Konstanz (Germany) . . . . . . . . . [8294-01] 9:20 am: Interactive data-centric viewpoint selection, Han Suk Kim, Didem Unat, Scott B. Baden, Jurgen P. Schulze, Univ. of California, San Diego (United States) . . . . . . . . . . . . . . . . . . [8294-02] 9:40 am: Interactive analysis of situational awareness metrics, Derek R. Overby, James A. Wall, John Keyser, Texas A\&M Univ. (United States) . . . . . . . . . . . . . . . . . . . . . . . . . Coffee Break . $.10: 00$ to $10: 30 \mathrm{am}$

\section{SESSION 2}

Room: Sandpebble Room E . . . . . . . Mon. 10:30 to 11:10 am

\section{Visual Analytics}

Session Chair: Chaomei Chen, Drexel Univ. (United States) 10:30 am: Incremental visual text analytics of news story development, Milos Krstajic, Univ. Konstanz (Germany) . . . . . . . . . . . . [8294-04]

10:50 am: Guided text analysis using adaptive visual analytics, Chad A. Steed, Christopher T. Symons, Frank A. DeNap, Thomas E. Potok, Oak Ridge National Lab. (United States) . . . . . . . . . . . . . . . . . .8294-05]

Session Break . . . . . . . . . . . . . . . . . . 11:10 to 11:20 am

\section{SESSION 3}

Room: Sandpebble Room E. . . . . Mon. 11:20 am to 12:20 pm

\section{Visualization Techniques and Applications}

Session Chair: Chad A. Steed, Oak Ridge National Lab. (United States) 11:20 am: Designing a better weather display, Colin Ware, Matthew Plumlee, The Univ. of New Hampshire (United States). . . . . . . . [8294-06]

11:40 am: Visualization feedback for musical ensemble practice: a case study on phrase articulation and dynamics, Trevor Knight, Nicolas Boulliot, Jeremy Cooperstock, McGill Univ. (Canada) . . . . . . . . [8294-07]

12:00 pm: Exploring ensemble visualization, Christopher G. Healey, Madhura N. Phadke, Lifford Pinto, North Carolina State Univ. (United States); Femi Alabi, Jonathan M. Harter, Russell M. Taylor II, The Univ. of North Carolina at Chapel Hill (United States); Xunlei Wu, Renaissance Computing Institute (United States); Hannah Petersen, Steffen A. Bass, Duke Univ. (United States) . . . . . . . . . . . . . . . . . [8294-08]

Lunch Break .. $12: 20$ to $1: 50 \mathrm{pm}$ 
Room: Sandpebble Room E. . . . . . . . . Mon. 1:50 to 2:40 pm

\section{Keynote Presentation I}

Session Chair: Mark A. Livingston, U.S. Naval Research Lab. (United States)

1:50 pm: Data analysis using R, Patrick Hanrahan, Stanford Univ.

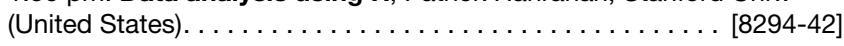

Session Break .................... 2:40 to 3:00 pm

\section{SESSION 4}

Room: Sandpebble Room E. Mon. 3:00 to 3:40 pm

\section{Large Data Visualization}

Session Chair: Mark A. Livingston, U.S. Naval Research Lab. (United States)

3:00 pm: Parallel large-data visualization with display walls, Luiz Scheidegger, Facebook Inc. (United States); Huy Vo, Polytechnic Institute of New York Univ. (United States); Jens Kruger, Univ. des Saarlandes (Germany); Claudio T. Silva, Polytechnic Institute of New York Univ. (United States); Joao L. D. Comba, Univ. Federal do Rio Grande do Sul (Brazil) . . . . . . . . . . . . . . . . . . . . . . . . . . . . . .88294-09]

3:20 pm: Visual exploratory analysis of a large volume of SQL log data with the SDSS log viewer, Jian Zhang, Chaomei Chen, Michael Vogeley, Danny Pan, Drexel Univ. (United States); Ani Thakar, Jordan Raddick, The Johns Hopkins Univ. (United States). . . . . . . . . . . . . . . . . [8294-10]

Coffee Break $3: 40$ to $4: 10 \mathrm{pm}$

\section{SESSION 5}

Room: Sandpebble Room E. Mon. 4:10 to 5:10 pm

\section{Evaluations}

Session Chair: Christopher G. Healey, North Carolina State Univ. (United States)

4:10 pm: Comparison of open-source visual analytics toolkits, John R. Harger, Sandia National Labs. (United States) and The Univ. of New Mexico (United States); Patricia J. Crossno, Sandia National Labs. (United States) . . . . . . . . . . . . . . . . . . . . . . . . [8294-11] 4:30 pm: Evaluation of progressive treemaps to convey tree and node properties, René Rosenbaum, Bernd Hamann, Univ. of California, Davis (United States). . . . . . . . . . . . . . . . . . . . . . [8294-12]

4:50 pm: Evaluation of multivariate visualizations: a case study of refinements and user experience, Mark A. Livingston, Jonathan Decker, U.S. Naval Research Lab. (United States). . . . . . . . . . . . . . . .88294-13]

\section{Tuesday 24 January}

\section{Room: Grand Peninsula}

Ballroom A . . . . . . . . . . . . . . . . . Tues. 8:20 to 9:30 am

\section{Plenary Session and Society Award Presentations}

8:25 am: Computational Photography, William T. Freeman,

Massachusetts Institute of Technology (United States)

\section{SESSION 6}

Room: Sandpebble Room E. . . . . . . . Tues. 10:00 to 10:40 am

\section{Geo-Temporal Visualizations}

Session Chair: Chaomei Chen, Drexel Univ. (United States)

10:00 am: Integrating sentiment analysis and term associations with geo-temporal visualizations on customer feedback streams, Ming C. Hao, Hewlett-Packard Labs. (United States); Christian Rohrdantz, Halldór Janetzko, Daniel A. Keim, Univ. Konstanz (Germany); Umeshwar Dayal, Hewlett-Packard Labs. (United States); Lars-Erik Haug, Hewlett-Packard Co. (United States); Meichun Hsu, Hewlett-Packard Labs. (United

States) . . . . . . . . . . . . . . . . . . . . . . . . . . . . .[8294-14] 10:20 am: A self-adaptive technique for visualizing geospatial data in 3D with minimum occlusion, Abon Chaudhuri, Han-Wei Shen, The Ohio State Univ. (United States) . . . . . . . . . . . . . . . . . . [8294-15] Coffee Break ....................... 10:40 to 11:10 am

\section{SESSION 7}

Room: Sandpebble Room E. . . . . Tues. 11:10 am to 12:30 pm

\section{Visualization Algorithms}

Session Chair: Han-Wei Shen, The Ohio State Univ. (United States) 11:10 am: Space/error tradeoffs for lossy wavelet reconstruction, Jonathan Frain, R. Daniel Bergeron, The Univ. of New Hampshire (United States) . . . . . . . . . . . . . . . . . . . . . . . . . . . [8294-16]

11:30 am: A configurable data prefetching scheme for interactive visualization of large-scale volume data, Byungil Jeong, Schlumberger (United States); Paul Navratil, Kelly Gaither, Gregory Abram, Gregory P. Johnson, The Univ. of Texas at Austin (United States). . . . . . . [8294-17]

11:50 am: A general approach for similarity-based linear projections using a genetic algorithm, James A. Mouradian, Bernd Hamann, René Rosenbaum, Univ. of California, Davis (United States) . . . . . . . . [8294-18]

12:10 pm: Image space adaptive volume rendering, Andrew Corcoran, John Dingliana, Trinity College Dublin (Ireland). . . . . . . . . . . [8294-19] Lunch Break . . . . . . . . . . . . . . . . . . . . 12:30 to 2:00 pm

Room: Sandpebble Room E. . . . . . . . .Tues. 2:00 to 2:50 pm Keynote Presentation II

Session Chair: Ming C. Hao, Hewlett-Packard Labs. (United States) 2:00 pm: Imaging the Antikythera Mechanism, Thomas Malzbender, Hewlett-Packard Labs. (United States) . . . . . . . . . . . [8294-43]

Session Break .................... 2:50 to $3: 10 \mathrm{pm}$

\section{SESSION 8}

Room: Sandpebble Room E.......... Tues. 3:10 to 3:40 pm

\section{Poster Fast Forward I}

Session Chair: Robert F. Erbacher, Utah State Univ. (United States) In addition to their interactive paper presentations, the interactive paper authors will provide short oral presentations during the conference.

Coffee Break $3: 40$ to $4: 10 \mathrm{pm}$ 


\section{SESSION 9}

Room: Sandpebble Room E. . . . . . . . Tues. 4:10 to 4:40 pm

\section{Poster Fast Forward II}

Session Chair: Robert F. Erbacher, Utah State Univ. (United States)

In addition to their interactive paper presentations, the interactive paper authors will provide short oral presentations during the conference.

\section{Interactive Paper and Symposium Demonstration Session}

\section{Room: Grand Peninsula Ballroom E . . Tues. 5:30 to 8:00 pm}

\section{Demonstrations . . . . . . . . . . . . . . 5:30 to 8:00 pm}

A symposium-wide demonstration session will be open to attendees 5:30 to 8:00 pm Tuesday evening. Demonstrators will provide interactive, hands-on demonstrations of a wide-range of products related to Electronic Imaging.

\section{Posters} 5:30 to 7:00 pm

Interactive papers will be placed on display after 10:30 am on Tuesday. An interactive paper session, with authors present at their papers, will be held Tuesday evening, 5:30 to 7:00 pm.

X3DBio1: a visual analysis tool for biomolecular structure exploration Hong Yi, Renaissance Computing Institute (United States); Abhishek Singh, Yaroslava G. Yingling, North Carolina State Univ. (United States) . . . . . . . . . . . . . . . . . . . . . . .

Increasing the perceptual salience of relationships in parallel coordinate plots, Jonathan M. Harter, Xunlei Wu, The Univ. of North Carolina at Chapel Hill (United States); Daniel Dougherty, Michigan State Univ. (United States); Hannah Petersen, Steffen Bass, Duke Univ. (United States); Russell M. Taylor II, The Univ. of North Carolina at Chapel Hill (United States); Madhura N. Phadke, Lifford Pinto, North Carolina State Univ. (United States); Oluwafemi S. Alabi, The Univ. of North Carolina at Chapel Hill (United States) . . . . . . . . . . . . . . . . . . . [8294-26]

Comparative visualization of ensembles using ensemble surface slicing, Oluwafemi S. Alabi, The Univ. of North Carolina at Chapel Hill (United States); Xunlei Wu, Renaissance Computing Institute (United States); Hannah Petersen, Steffen Bass, Duke Univ. (United States); Sharon Zhong, Michigan State Univ. (United States); Madhura N. Phadke, Lifford Pinto, Christopher G. Healey, North Carolina State Univ. (United States); Russell M. Taylor II, The Univ. of North Carolina at Chapel Hill (United States). . . . . . . . . . . . . . . . . . . . . . . . . . . . . [8294-27]

A performance assessment on the effectiveness of digital image registration methods, Steve T. Kacenjar, Lockheed Martin Corp. (United States); Bing Li, Lockheed Martin Systems Integration-Owego (United States); Alan Ostrow, Lockheed Martin Maritime Systems \& Sensors (United States). . . . . . . . . . . . . . . . . . . . . . . . . .88294-29]

An evaluation of rendering and interactive methods for volumetric data exploration in virtual reality environments, Nan Wang, Alexis Paljic, Philippe Fuchs, Mines ParisTech (France) . . . . . . . . . . . . . [8294-30]

Efficient, dynamic data visualization with persistent data structures, Joseph A. Cottam, Andrew Lumsdaine, Indiana Univ. (United

States) . . . . . . . . . . . . . . . . . . . . . . . . . . . . . [8294-32]

Radial visualizations for comparative data analysis, Geoffrey Draper, Matthew G. Styles, Brigham Young Univ.-Hawaii (United States); Richard F. Riesenfeld, Brigham Young Univ. (United States). . . . . . . . . [8294-33]

Exploiting major trends in subject hierarchies for large-scale collection visualization, Charles-Antoine Julien, Pierre Tirilly, Univ. of Wisconsin-Milwaukee (United States); John E. Leide, Catherine Guastavino, McGill Univ. (Canada) . . . . . . . . . . . . . . . . [8294-36] Visualization of multidimensional time, Luther A. Tychonievich, Brigham Young Univ. (United States) and Univ. of Virginia (United States); Robert P. Burton, Brigham Young Univ. (United States). . . . . . . . . . . . [8294-37]
Degeneracy-aware interpolation of 3D diffusion tensor fields, Chongke $\mathrm{Bi}$, Shigeo Takahashi, The Univ. of Tokyo (Japan); Issei Fujishiro, Keio Univ. (Japan) . . . . . . . . . . . . . . . . . . . . . . . . . . . . . . . . [8294-38]

Visualization and analysis of 3D gene expression patterns in zebrafish using web services, Dome Potikanond, Fons J. Verbeek, Leiden Univ. (Netherlands) . . . . . . . . . . . . . . . . . . . . . . . [8294-39]

Vortex core detection: back to basics, Allen Van Gelder, Univ. of California, Santa Cruz (United States). . . . . . . . . . . . . . . . [8294-40]

\section{Wednesday 25 January}

\section{Room: Grand Peninsula Ballroom A . . . . . . . . . . . . . . Wed. 8:20 to 9:30 am Plenary Session and Conference Award Presentations}

8:25 am: More Words and Bigger Pictures, David A. Forsyth, Univ. of Illinois at Urbana-Champaign (United States)

\section{SESSION 10}

Room: Sandpebble Room E. . . . . . . . Wed. 9:50 to 10:30 am

\section{Bioinformatics Visualizations}

Session Chair: Mark A. Livingston, U.S. Naval Research Lab. (United States)

9:50 am: Visualization of mappings between the gene ontology and cluster trees, Ilir Jusufi, Andreas Kerren, Vladyslav Aleksakhin, Linnaeus Univ. (Sweden); Falk Schreiber, Leibniz Institute of Plant Genetics and Crop Plant Research (Germany) and Martin-Luther Univ. Halle-Wittenberg (Germany) . . . . . . . . . . . . . . . . . . . . . . . . . . . . . [8294-20]

10:10 am: Visualizing uncertainty in biological expression data, Clemens Holzhüter, Univ. Rostock (Germany); Alexander Lex, Dieter Schmalstieg, Hans-Jörg Schulz, Technische Univ. Graz (Austria); Heidrun Schumann, Univ. Rostock (Germany); Marc Streit, Technische Univ. Graz (Austria) . . . . . . . . . . . . . . . . . . . . . . [8294-21] Coffee Break . . . . . . . . . . . . . . . . . . . . .10:30 to 11:00 am

\section{SESSION 11}

Room: Sandpebble Room E . . . . .Wed. 11:00 am to 12:00 pm

\section{Flow Visualization}

Session Chair: David L. Kao, NASA Ames Research Ctr. (United States)

11:00 am: Instant visitation maps for interactive visualization of uncertain particle trajectories, Kai Bürger, Roland Fraedrich, Technische Univ. München (Germany); Dorit Merhof, Univ. Konstanz (Germany); Rüdiger Westermann, Technische Univ. München (Germany) . . . [8294-22]

11:20 am: Motion visualization in large particle simulations, Roland Fraedrich, Rüdiger Westermann, Technische Univ. München

(Germany) . . . . . . . . . . . . . . . . . . . . . . . . [8294-23]

11:40 am: Animating streamlines with repeated asymmetric patterns for steady flow visualization, Chih-Kuo Yeh, National Cheng Kung Univ. (Taiwan); Zhanping Liu, Univ. of Pennsylvania (United States); Tong-Yee Lee, National Cheng Kung Univ. (Taiwan). . . . . . . . . . . . . . . . [8294-24]

Room: Sandpebble Room E. . . . . . . Wed. 12:00 to 12:15 pm Closing Remarks

Session Chair: David L. Kao, NASA Ames Research Ctr. (United States) 


\section{Image Processing: Algorithms and Systems X}

Conference Chairs: Karen O. Egiazarian, Tampere Univ. of Technology (Finland); Sos S. Agaian, The Univ. of Texas at San Antonio (United States); Atanas P. Gotchev, Tampere Univ. of Technology (Finland)

Program Committee: Til Aach, RWTH Aachen (Germany); Gözde Bozdagi Akar, Middle East Technical Univ. (Turkey); Junior Barrera, Univ. de São Paulo (Brazil); Jenny Benois-Pineau, Bordeaux Univ. (France); Reiner Creutzburg, Fachhochschule Brandenburg (Germany); Paul Gader, Univ. of Florida (United States); John C. Handley, Xerox Corp. (United States); Vladimir Vasilyevich Lukin, National Aerospace Univ. (Ukraine); Stephen Marshall, Univ. of Strathclyde (United Kingdom); Alessandro Neri, Univ. degli Studi di Roma Tre (Italy); Françoise Prêteux, Mines ParisTech (France); Gianni Ramponi, Univ. degli Studi di Trieste (Italy); Eli Saber, Rochester Institute of Technology (United States); Jagath K. Samarabandu, The Univ. of Western Ontario (Canada); Ivan W. Selesnick, Polytechnic Institute of NYU (United States); Damir Sersic, Univ. of Zagreb (Croatia); Akira Taguchi, Musashi Kogyo Univ. (Japan)

\section{Monday 23 January SESSION 1}

Room: Evergreen Room Mon. 8:50 to $10: 10$ am

\section{Image Analysis}

Session Chair: Atanas P. Gotchev, Tampere Univ. of Technology (Finland)

8:50 am: Analysis of different image-based biofeedback models for improving cycling performances, Daniele Bibbo, Silvia Conforto, Ivan Bernabucci, Marco Carli, Maurizio Schmid, Tommaso D’Alessio, Univ. degli Studi di Roma Tre (Italy) . . . . . . . . . . . . . . . . . [8295A-01]

9:10 am: Textured areas detection and segmentation in circular harmonic functions domain, Luca Costantini, Licia Capodiferro, Fondazione Ugo Bordoni (Italy); Marco Carli, Alessandro Neri, Univ. degli Studi di Roma Tre (Italy) . . . . . . . . . . . . . . . . . . . . [8295A-02] 9:30 am: Searching for streamer trajectories on synoptic maps of the sun corona, Antoine Llebaria, Observatoire Astronomique de MarseilleProvence (France) . . . . . . . . . . . . . . . . . . . . . [8295A-03] 9:50 am: Performance evaluation for 2D and 3D filtering methods of noise removal in color images, Vladimir Vasilyevich Lukin, Alexander A. Zelensky, Nikolay N. Ponomarenko, National Aerospace Univ. (Ukraine); Karen O. Egiazarian, Jaakko T. Astola, Tampere Univ. of Technology

(Finland). . . . . . . . . . . . . . . . . . . . . . [8295A-04]

Coffee Break.

$10: 10$ to $10: 50$ am

\section{SESSION 2}

Room: Evergreen Room ........Mon. 10:50 am to 12:10 pm

\section{Image Classification and Recognition}

Session Chair: Sos S. Agaian, The Univ. of Texas at San Antonio (United States)

10:50 am: Integrated text detection and recognition in natural images, Nadejda S. Roubtsova, Technische Univ. Eindhoven (Netherlands) and ViNotion B.V. (Netherlands); Rob Wijnhoven, ViNotion B.V. (Netherlands) and Technische Univ. Eindhoven (Netherlands); Peter H. N. de With, Technische Univ. Eindhoven (Netherlands). . . . . . . . . . . [8295A-05]

11:10 am: Ear recognition based on edge potential function, Federica Battisti, Marco Carli, Univ. degli Studi di Roma Tre (Italy); Francesco G. B. De Natale, Univ. degli Studi di Trento (Italy); Alessandro Neri, Univ. degli Studi di Roma Tre (Italy) . . . . . . . . . . . . . . . . . . . [8295A-06] 11:30 am: Feature extraction from ladar data using modified GPCA, Peter F. Stiller, Texas A\&M Univ. (United States) . . . . . . . [8295A-07] 11:50 am: Recognition of rotated images using the multi-valued neuron and rotation-invariant 2D Fourier descriptors, Evgeni Aizenberg, Irving J. Bigio, Eladio Rodriguez-Diaz, Boston Univ. (United

States) . . . . . . . . . . . . . . . . . . . . . . . . . . [8295A-08]

Lunch Break $12: 10$ to $2: 20 \mathrm{pm}$

\section{SESSION 3}

Room: Evergreen Room

Mon. 2:20 to 3:20 pm

\section{Image Representation I}

Session Chair: Karen O. Egiazarian, Tampere Univ. of Technology (Finland)

2:20 pm: Amoeba-based superpixel partitioning of multispectral images into elementary, uniform, connected units, Jacopo Grazzini, Lakshman Prasad, Los Alamos National Lab. (United States) . [8295A-10] 2:40 pm: Smooth partition of unity with Hermite interpolation: applications to image processing, Lubomir T. Dechevsky, Peter Zanaty, Arne Lakså, Børre Bang, Narvik Univ. College (Norway) .... . [8295A-11]

3:00 pm: An algorithm for GPGPU-computing of multidimensional DWTs based on bijective mapping of tensor-product wavelet bases of different number of variables, Lubomir T. Dechevsky, Jostein Bratlie, Børre Bang, Arne Lakså, Narvik Univ. College (Norway) . . . . [8295A-12] Coffee Break ..................... 3:20 to 4:00 pm

\section{SESSION 4}

Room: Evergreen Room ............Mon. 4:00 to 5:00 pm

\section{Image Representation II}

Session Chair: Karen O. Egiazarian, Tampere Univ. of Technology (Finland)

4:00 pm: Quantitative evaluation of image mosaicing in multiple scene categories, Debabrata Ghosh, Sangho Park, Naima Kaabouch, William Semke, Ronald Fevig, The Univ. of North Dakota (United States)[8295A-13]

4:20 pm: Curvelet transform with adaptive tiling, Hasan Al-Marzouqi, Ghassan Al-Regib, Georgia Institute of Technology (United States) . . . . . . . . . . . . . . . . . . . . . . . . . [8295A-14]

4:40 pm: Tetrachromatic colour space, Alfredo Restrepo, Univ. de Los Andes (Colombia) . . . . . . . . . . . . . . . . . . . [8295A-15] 


\section{Tuesday 24 January}

\section{Room: Grand Peninsula \\ Ballroom A . . . . . . . . . . . . . . Tues. 8:20 to 9:30 am \\ Plenary Session and Society Award Presentations}

8:25 am: Computational Photography, William T. Freeman,

Massachusetts Institute of Technology (United States)

\section{SESSION 5}

Room: Evergreen Room ........... Tues. 9:30 to 10:30 am

\section{Image Synthesis and Reconstruction I}

Session Chair: Karen O. Egiazarian, Tampere Univ. of Technology (Finland)

9:30 am: Smooth image inpainting by least square oriented edge prediction, Emiliano Pallotti, Licia Capodiferro, Federica Mangiatordi, Fondazione Ugo Bordoni (Italy); Paolo Sità, Univ. degli Studi di Roma Tre

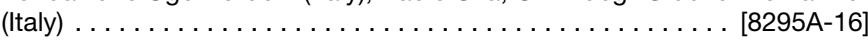

\section{9:50 am: Image inpainting using cubic spline-based edge} reconstruction, Viatcheslav Voronin, Vladimir I. Marchuk, South-Russian State Univ. of Economics and Service (Russian Federation); Karen O. Egiazarian, Tampere Univ. of Technology (Finland); Alexandr Sherstobitov, South-Russian State Univ. of Economics and Service (Russian

Federation) . . . . . . . . . . . . . . . . . . . . . . . . [8295A-17]

10:10 am: Global registration and stabilization of jittered and noisy airborne image sequences, Nader M. Namazi, The Catholic Univ. of America (United States); William Scharpf, U.S. Naval Research Lab. (United States); Jerome Obermark, DCS Corp. (United States); James Caron, Research Support Instruments, Inc. (United States). . . [8295A-18]

Coffee Break . . . . . . . . . . . . . . . . . . . . 10:30 to 11:10 am

\section{SESSION 6}

\section{Room: Evergreen Room ........ Tues. 11:10 am to 12:10 pm}

\section{Image Synthesis and Reconstruction II}

Session Chair: Karen O. Egiazarian, Tampere Univ. of Technology (Finland)

11:10 am: Image and video restoration via Ising-like models, Ofer Hadar, Ben-Gurion Univ. of the Negev (Israel); Eliahu Cohen, Tel Aviv Univ. (Israel) . . . . . . . . . . . . . . . . . . . . [8295A-19] 11:30 am: Region adaptive correction method for radial distortion of fish-eye image, Ki Sun Song, Young Seok Han, Moon Gi Kang, Yonsei Univ. (Korea, Republic of) . . . . . . . . . . . . . . . . . . [8295A-20]

11:50 am: Super-resolution image reconstruction with edge adaptive weight in video sequence, Ji Yong Kwon, Du Sic Yoo, Moon Gi Kang, Yonsei Univ. (Korea, Republic of) . . . . . . . . . . . . . . [8295A-21] Lunch Break

$12: 10$ to $2: 00 \mathrm{pm}$
SESSION 7

Room: Evergreen Room ............Tues. 2:00 to 3:20 pm

Image Filtering and Enhancement I

Session Chair: Atanas P. Gotchev, Tampere Univ. of Technology (Finland)

2:00 pm: Color image enhancement based on genetic algorithm and ensemble empirical mode decomposition, Somayeh Bakhtiari, Sos Agaian, Mo Jamshidi, The Univ. of Texas at San Antonio (United States) . . . . . . . . . . . . . . . . . . . . . [8295A-22]

2:20 pm: Image classification and interpolation, Animesh Khemka, KLATencor Corp. (United States); Charles A. Bouman, Purdue Univ. (United

States) . . . . . . . . . . . . . . . . . . . . . . [8295A-23]

2:40 pm: Optimal fractional filter for image segmentation, Amir Nakib, Yohanna Schulze M.D., Eric Petit, Univ. Paris 12 - Val de Marne

(France) . . . . . . . . . . . . . . . . . . . . . . [8295A-24]

3:00 pm: Multi-scale image enhancement using a second derivativelike measure of contrast, Shahan C. Nercessian, Karen Panetta, Tufts Univ. (United States); Sos Agaian, The Univ. of Texas at San Antonio (United States)........................ [8295A-25] Coffee Break ....................... 3:20 to 4:00 pm

\section{SESSION 8}

Room: Evergreen Room ...........Tues. 4:00 to 5:00 pm Image Filtering and Enhancement II

Session Chair: Atanas P. Gotchev, Tampere Univ. of Technology (Finland)

4:00 pm: A new denoising method in high-dimensional PCA space, Quoc Bao Do, Azeddine Beghdadi, Marie Luong, Univ. Paris 13 (France) . . . . . . . . . . . . . . . . . . . . . [8295A-26] 4:20 pm: Intelligent detection of impulse noise using multilayer neural network with multi-valued neurons, Igor Aizenberg, Glen Wallace, Texas A\&M Univ.-Texarkana (United States). . . . . . . . . . . . . . . [8295A-27]

4:40 pm: An homomorphic filtering and expectation maximization approach for the point spread function estimation in ultrasound imaging, Said Benameur, Eiffel Medtech, Inc. (Canada); Max Mignotte, Univ. de Montréal (Canada); Frederic Lavoie, Eiffel Medtech, Inc.

(Canada) ............................ [8295A-28]

\section{Interactive Paper and Symposium Demonstration Session}

Room: Grand Peninsula Ballroom E .. Tues. 5:30 to 8:00 pm

Demonstrations .................. 5:30 to 8:00 pm

A symposium-wide demonstration session will be open to attendees $5: 30$ to 8:00 pm Tuesday evening. Demonstrators will provide interactive, hands-on demonstrations of a wide-range of products related to Electronic Imaging

Posters 5:30 to 7:00 pm

Interactive papers will be placed on display after 10:30 am on Tuesday. An interactive paper session, with authors present at their papers, will be held Tuesday evening, 5:30 to 7:00 pm.

Intensity-constrained, flat-kernel filter for local dark feature suppression: application to removal of hair artifacts in dermatoscopic images, Alex A. Gutenev, Retiarius Pty Ltd. (Australia) . . . . . [8295A-35]

New decision support tool for acute lymphoblastic leukemia classification, Monica Madhukar, Sos Agaian, Anthony Chronopoulos, The Univ. of Texas at San Antonio (United States) . . . . . . . . [8295A-36]

Sharpness metric for no-reference image visual quality assessment, Vladimir Vasilyevich Lukin, Nikolay N. Ponomarenko, Oleg Eremeev, National Aerospace Univ. (Ukraine); Karen O. Egiazarian, Jaakko T. Astola Tampere Univ. of Technology (Finland). . . . . . . . . . [8295A-37] 
A new system of computer-aided diagnosis of skin lesions, Isaac A. Sanchez, Sos Agaian, The Univ. of Texas at San Antonio (United

States) . . . . . . . . . . . . . . . . . . . . . . . . . . . . . . . [8295A-38]

Image denoising using a combined criterion, Evgeny Semenishchev, Vladimir I. Marchuk, South-Russian State Univ. of Economics and Service (Russian Federation); Karen O. Egiazarian, Tampere Univ. of Technology (Finland); Viatcheslav Voronin, South-Russian State Univ. of Economics and Service (Russian Federation) . . . . . . . . . . . . . . . . . [8295A-39]

Non-cooperative stationary ground targets detection based on IRST, Degui Yang, Yuliang Qin, Xufeng Zhang, Xizhang Wei, Hongqiang Wang, National Univ. of Defense Technology (China) . . . . . . . . . . [8295A-40]

Motion-compensated spatial-temporal filtering for noisy color filter array sequence, Min Seok Lee, Yonsei Univ. (Korea,

Republic of) . . . . . . . . . . . . . . . . . . . . . . . . . . . . [8295A-41]

Application of 1D FIR filter methods to 3D polygonal meshes, William S. Ward, The Univ. of Texas at San Antonio (United States) . . [8295A-42]

An automatic approach for 3D registration of CT scans, Yang $\mathrm{Hu}$, Eli Saber, Sohail Dianat, Sreenath Rao Vantaram, Rochester Institute of Technology (United States); Vishwas Abhyankar, DataPhysics Research, Inc. (United States)

Boundary handling mechanism for lifting-based spatial adaptation of filter banks, Dakala Jayachandra, Anamitra Makur, Nanyang

Technological Univ. (Singapore) . . . . . . . . . . . . . . . . . [8295A-44]

A simple and efficient algorithm for connected-component labeling in color images, M. Emre Celebi, Louisiana State Univ. Shreveport (United

States) . . . . . . . . . . . . . . . . . . . . . . . . . . . . . . [8295A-45]

An adaptive and deterministic method for initializing the Lloyd-Max algorithm, Jared Vicory, M. Emre Celebi, Louisiana State Univ. Shreveport (United States) 8295A-46]

Multi-resolution analysis for region of interest extraction in thermographic, nondestructive evaluation, Benhur Ortiz Jaramillo, Hermes Alexander Fandino Toro, Univ. Nacional de Colombia (Colombia); Hernan Darío Benitez Restrepo, Pontificia Univ. Javeriana, Cali (Colombia); Sergio Alejandro Orjuela Vargas, Univ. Gent (Belgium); German Castellanos Dominguez, Univ. Nacional de Colombia (Colombia); Wilfried Philips, Univ. Gent (Belgium). . . . . . . . . . . . . . . . . . . . . . . . . . . [8295A-47]

Estimation of deformations in ultrasound images using dynamic programming, Sérgio S. Furuie, Fernando M. Cardoso, Escola Politécnica da Univ. de São Paulo (Brazil)

Combining skin texture and facial structure for face identification, Rachel E. Manoni, Photon Research Associates, Inc. (United States); Roxanne L. Canosa, Rochester Institute of Technology (United States) . . . . . . . . . . . . . . . . . . . . . . . . [8295A-49]

Development of a human vision simulation camera and its application Hiroshi Okumura, Mai Fukusaki, Shoichiro Takubo, Kohei Arai, Saga Univ. (Japan) . . . . . . . . . . . . . . . . . . . . . . . . . . . . [8295A-50]

Reconstruction from divergent ray projections, Challa Subrahmanya Sastry, International Institute of Information Technology (India); Santosh Singh, Siemens Information Systems Ltd. (India) . . . . . . . . [8295A-51]

Fusing electro-optic and infrared signals for high-resolution night images, Xiaopeng Huang, Stevens Institute of Technology (United States); Ravi Netravali, Columbia Univ. (United States); Hong Man, Victor B. Lawrence, Stevens Institute of Technology (United States) . . [8295A-52]

Texture and color descriptors as a tool for context-aware patchbased image inpainting, Tijana Ruzic, Aleksandra Pižurica, Wilfried Philips, Univ. Gent (Belgium). . . . . . . . . . . . . . . . . [8295A-53]
Wednesday 25 January

\section{Room: Grand Peninsula \\ Ballroom A . . . . . . . . . . . . . . . Wed. 8:20 to 9:30 am \\ Plenary Session and Conference Award Presentations}

8:25 am: More Words and Bigger Pictures, David A. Forsyth, Univ. of Illinois at Urbana-Champaign (United States)

\section{SESSION 9}

Room: Evergreen Room ..........Wed. 9:30 to 10:30 am

\section{Image Processing Systems I}

Session Chair: Sos S. Agaian, The Univ. of Texas at San Antonio (United States)

9:30 am: Hybrid gesture recognition system for short-range use, Akihiro Minagawa, Fujitsu Labs. (Japan); Wei Fan, Fujitsu Research and Development Center Co., Ltd. (China); Yutaka Katsuyama, Hiroaki Takebe, Noriaki Ozawa, Yoshinobu Hotta, Fujitsu Labs. (Japan); Jun Sun, Fujitsu Research and Development Center Co., Ltd. (China). . . . . . . [8295A-29] 9:50 am: Tracking white road line by particle filter from the video sequence acquired by the camera attached to a walking human body Shohei Takahashi, Jun Ohya, Waseda Univ. (Japan) . . . . . . . [8295A-30]

10:10 am: Driver/passenger discrimination for the interaction with the dual-view touch screen integrated to the automobile centre consol, Enrico Herrmann, Andrey Makrushin, Jana Dittmann, Otto-vonGuericke-Univ. Magdeburg (Germany); Claus Vielhauer, Fachhochschule Brandenburg (Germany) . . . . . . . . . . . . . . [8295A-31] Coffee Break . . . . . . . . . . . . . . . . . . . . . 10:30 to 11:10 am

\section{SESSION 10}

Room: Evergreen Room . . . . . . . Wed. 11:10 am to 12:10 pm

\section{Image Processing Systems II}

Session Chair: Sos S. Agaian, The Univ. of Texas at San Antonio (United States)

11:10 am: A linear filter design technique for equalizing document scanners, Ahmed Hamad Eid, Lexmark International, Inc. (United States) . . . . . . . . . . . . . . . . . . . . [8295A-32]

11:30 am: Application of spatial contrast techniques on satellite imagery for cloud shape differentiation, Jules R. Dim, Hiroshi Murakami, Japan Aerospace Exploration Agency (Japan) . . . . . . . . . . [8295A-33]

11:50 am: A multi-step system for screening and localization of hard exudates in retinal images, Ajit S. Bopardikar, Vishal Bhola, Raghavendra B. S., Rangavittal Narayanan, Samsung Electronics, India Software Operations Ltd. (India). . . . . . . . . . . . . . . . . . [8295A-34] 


\section{Parallel Processing for Imaging Applications II}

Conference Chairs: John Recker, Hewlett-Packard Labs. (United States); Guijin Wang, Tsinghua Univ. (China)

Program Committee: Jiansheng Chen, Tsinghua Univ. (China); Justin Hensley, Advanced Micro Devices, Inc. (United States); Wen-Mei Hwu, Univ. of Illinois at Urbana-Champaign (United States); Constantine Kreatsoulas, Merck \& Co., Inc. (United States); I-Jong Lin, Hewlett-Packard Labs. (United States); Thomas Malzbender, Hewlett-Packard Labs. (United States); Richard J. Moore, 3M Co. (United States); Sung W. Park, Samsung Electronics Co., Ltd. (Korea, Republic of); William Pratt, Pixelsoft, Inc (United States); Norman Rubin, AMD (United States); Huachun Tan, Beijing Institute of Technology (China); Chung M. Wong, Northrop Grumman Aerospace Systems (United States)

\section{Monday 23 January SESSION 11}

Room: Bayside Room B. . . . . . . Mon. 11:10 am to 12:20 pm

\section{Parallel Systems}

Session Chair: William Pratt, PixelSoft, Inc. (United States)

11:10 am: GPGPU-based surface inspection from structured white light (Invited Paper), Miguel Bordallo Lopez, Univ. of Oulu (Finland); Karri Niemelä, VTT Technical Research Ctr. of Finland (Finland); Olli Johannes Silvén, Univ. of Oulu (Finland) . . . . . . . . . . . . . . . [8295B-52] 11:40 am: IMPAIR-GPU: massively parallel deconvolution algorithm for GPUs, Michael Sherry, Andrew Shearer, National Univ. of Ireland, Galway (Ireland) . . . . . . . . . . . . . . . . . . . . . [8295B-54] 12:00 pm: Parallel processing architectures for H.264 deblocking filter on multicore platforms, Durga P. Prasad, Sekar Sonachalam, Mangesh Kumar Kunchamwar, Nageswara Rao Gunupudi, Parallel Prisms (United States) . . . . . . . . . . . . . . . . . . . . . . . . . . . [8295B-55]

Room: Bayside Room B . . . . . Mon. 12:20 to 12:50 pm

\section{Keynote Presentation}

Session Chair: William Pratt, Pixel Soft, Inc. (United States)

12:20 pm: Compute infrastructure challenges of commercial digital print, I-Jong Lin, Hewlett-Packard Labs. (United States). . . [8295B-56]

Lunch Break $12: 50$ to $2: 00 \mathrm{pm}$

\section{SESSION 12}

Room: Bayside Room B. ............ Mon. 2:00 to 3:30 pm

\section{Parallel Algorithms}

Session Chair: Robert A. Ulichney, Hewlett-Packard Co. (United States)

2:00 pm: Interactive plenoptic rendering with GPUs, Andrew Lumsdaine, Georgi N. Chunev, Indiana Univ. (United States); Todor G. Georgiev, Adobe Systems Inc. (United States). . . . . . . . . [8295B-57] 2:20 pm: Three-level GPU accelerated Gaussian mixture model for background subtraction, Yin Li, Guijin Wang, Xinggang Lin, Tsinghua Univ. (China) . . . . . . . . . . . . . . . . . [8295B-58] 2:40 pm: Plane-dependent error diffusion on a GPU, Yao Zhang, Univ. of California, Davis (United States); John L. Recker, Hewlett-Packard Labs. (United States); Robert A. Ulichney, Ingeborg Tastl, Hewlett-Packard Co. (United States); John D. Owens, Univ. of California, Davis (United

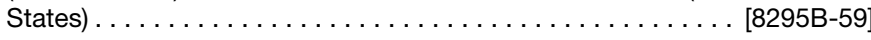
3:00 pm: An analysis of OpenCL for portable imaging (Invited Paper), Richard J. Moore, 3M Co. (United States); Ben Zimmer, 3M Co. (United States) and Univ. of Wisconsin-Eau Claire (United States). . . [8295B-60]

\section{Tuesday 24 January}

Room: Grand Peninsula

Ballroom A . . . . . . . . . . . Tues. 8:20 to 9:30 am

Plenary Session and Society Award Presentations

8:25 am: Computational Photography, William T. Freeman,

Massachusetts Institute of Technology (United States)

\section{Interactive Paper and Symposium Demonstration Session}

Room: Grand Peninsula Ballroom E . . Tues. 5:30 to 8:00 pm

Demonstrations 5:30 to 8:00 pm

A symposium-wide demonstration session will be open to attendees 5:30 to 8:00 pm Tuesday evening. Demonstrators will provide interactive, hands-on demonstrations of a wide-range of products related to Electronic Imaging.

Posters 5:30 to $7: 00 \mathrm{pm}$

Interactive papers will be placed on display after 10:30 am on Tuesday. An interactive paper session, with authors present at their papers, will be held Tuesday evening, 5:30 to 7:00 pm

Speed-up on GPU in Bayesian image reconstruction, Shuma Horiuchi, Shuhei Yoshida, Zenta Ushiyama, Manabu Yamamoto, Tokyo Univ. of Science (Japan) . . . . . . . . . . . . . . . . . [8295B-61]

\section{Wednesday 25 January}

Room: Grand Peninsula

Ballroom A . . . . . . . . . . . . . Wed.20 to 9:30 am

Plenary Session and Conference Award Presentations

8:25 am: More Words and Bigger Pictures, David A. Forsyth, Univ. of Illinois at Urbana-Champaign (United States) 


\section{Computational Imaging $X$}

Conference Chairs: Charles A. Bouman, Purdue Univ. (United States); llya Pollak, Purdue Univ. (United States); Patrick J. Wolfe, Harvard Univ. (United States)

Program Committee: Samit Basu, GE Security (United States); Thomas S. Denney, Jr., Auburn Univ. (United States); Maya R. Gupta, Univ. of Washington (United States); Eric L. Miller, Tufts Univ. (United States); Joseph A. O'Sullivan, Washington Univ. in St. Louis (United States); Zygmunt Pizlo, Purdue Univ. (United States); Stanley J. Reeves, Auburn Univ. (United States); Yongyi Yang, Illinois Institute of Technology (United States)

Monday 23 January

\section{SESSION 1}

\section{Room: Harbour Room A ........ Mon. 8:30 am to 12:10 pm \\ Special Session on Micropscopy and Information Modeling}

8:30 am: Imaging with electrons: a review of modern modalities (Keynote Presentation), Marc DeGraef, United States (United

States) . . . . . . . . . . . . . . . . . . . . . . . . [8296-01]

9:00 am: Improving boundary localization in the statistical image segmentation of materials micrographs, Mary L. Comer, Purdue Univ. (United States) . . . . . . . . . . . . . . . . . . . [8296-02]

9:20 am: Scanning transmission electron tomography and applications to materials science, Lawrence F. Drummy, Air Force Research Lab. (United States) . . . . . . . . . . . . . . . . . . . . . . [8296-03] 9:40 am: Combining global labeling and local relabeling for metallic image segmentation, Jarrell W. Waggoner, Univ. of South Carolina (United States); Jeff Simmons, Air Force Research Lab. (United States); Song Wang, Univ. of South Carolina (United States). . . . . . . . . . . . [8296-04]

10:00 am: Towards automated detection of active colitis in images of H\&E-stained tissue samples, Michael McCann, Ramu Bhagavatula, Carnegie Mellon Univ. (United States); Matthew Fickus, Air Force Institute of Technology (United States); Jelena Kovacevic, Carnegie Mellon Univ. (United States). . . . . . . . . . . . . . . . . . . . . . . . . . . [8296-05]

Coffee Break . . . . . . . . . . . . . . . . . . . . 10:20 to 10:50 am

10:50 am: Computer-aided fiber analysis for crime scene forensics, Mario Hildebrandt, Andrey Makrushin, Jana Dittmann, Christian Arndt, Ottovon-Guericke-Univ. Magdeburg (Germany) . . . . . . . . . . [8296-06]

11:10 am: An automated diagnostic aid for otitis media, Anupama Kuruvilla, Carnegie Mellon Univ. (United States); Pablo H. Hennings Yeomans, Ontario Institute for Cancer Research (Canada); Pedro Quelhas, Instituto de Engenharia Biomédica (Portugal); Alejandro Hoberman, Univ. of Pittsburgh (United States); Jelena Kovacevic, Carnegie Mellon Univ. (United States) . . . . . . . . . . . . . . . . . . . . . . . . . .

11:30 am: 3D reconstruction based on single-particle cryo electron microscopy images as a random signal in noise problem, Qiu Wang, Cornell Univ. (United States); Yili Zheng, Lawrence Berkeley National Lab. (United States); Peter C. Doerschuk, Cornell Univ. (United States)[8296-08] 11:50 am: Highly scalable methods for exploiting a label with unknown location in order to orient a set of single-particle cryo electron microscopy images, Cory J. Prust, Milwaukee School of Engineering (United States); Peter C. Doerschuk, Cornell Univ. (United States); John E. Johnson, The Scripps Research Institute (United States). . . . . . [8296-09] Lunch Break .................... 12:10 to $1: 40 \mathrm{pm}$

\section{SESSION 2}

Room: Harbour Room A ........... Mon. 1:40 to 3:50 pm

\section{Reconstruction}

1:40 pm: Plenoptic camera with freely movable microlenses, Todor G. Georgiev, Adobe Systems Inc. (United States); Sergio Goma, Qualcomm Inc. (United States) . . . . . . . . . . . . . . . . . . . . [8296-10] 2:00 pm: Image reconstruction using projections from a few views by discrete steering combined with DART, Junghyun Kwon, Samuel M. Song, Brian Kauke, Douglas P. Boyd, TeleSecurity Sciences, Inc. (United States) . . . . . . . . . . . . . . . . . . . . . . . . . [8296-11]

2:20 pm: One-dimensional control grid interpolation-based demosaicing and color image interpolation, Christine M. Zwart, David H. Frakes, Arizona State Univ. (United States) . . . . . . . . . . [8296-12] 2:40 pm: Limited view angle iterative CT reconstruction for transportation security application, Sherman J. Kisner, Charles A. Bouman, Purdue Univ. (United States) . . . . . . . . . . . . . . . [8296-13] Coffee Break ..................... 3:00 to $3: 30$ pm 3:30 pm: Variational semi-blind sparse image reconstruction with application to MRFM, Se Un Park, Alfred O. Hero, Univ. of Michigan (United States); Nicolas Dobigeon, Univ. de Toulouse (France) . .[8296-15]

\section{SESSION 3}

Room: Harbour Room A ........... Mon. 3:50 to 5:10 pm

\section{Classification and Detection}

3:50 pm: Moon search algorithms for NASA's Dawn mission to asteroid Vesta, Nargess Memarsadeghi, Lucy A. McFadden, David R. Skillman, NASA Goddard Space Flight Ctr. (United States); Brian McLean, Max Mutchler, Space Telescope Science Institute (United States)[8296-16]

4:10 pm: CLEAN: a false alarm reduction method for SAR CCD,

Rhonda Phillips, MIT Lincoln Lab. (United States) . . . . . . . . . [8296-17]

4:30 pm: Insertion of synthetic features in SAR CCD imagery, Eric

Turner, Rhonda Phillips, Miriam Cha, MIT Lincoln Lab. (United

States) . . . . . . . . . . . . . . . . . . . . . . .

4:50 pm: Multichannel hierarchical image classification using multivariate copulas, Aurelie Voisin, Vladimir Krylov, INRIA Sophia Antipolis - Méditerranée (France); Gabriele Moser, Sebastiano B. Serpico, Univ. degli Studi di Genova (Italy); Josiane Zerubia, INRIA Sophia Antipolis - Méditerranée (France) . . . . . . . . . . . . . . . . . . [8296-19]

\section{Tuesday 24 January}

Room: Grand Peninsula

Ballroom A . . . . . . . . . . . . Tues. 8:20 to 9:30 am

Plenary Session and Society Award Presentations

8:25 am: Computational Photography, William T. Freeman, Massachusetts Institute of Technology (United States) 


\section{Keynote Presentation}

Room: Harbour Room A . . . . . . . Tues. 9:30 to 10:00 am

9:30 am: Definition of shape, Zygmunt Pizlo, Purdue Univ. (United

States) . . . . . . . . . . . . . . . . . . . . . [8296-43]

\section{SESSION 4}

Room: Harbour Room A . . . . . . Tues. 10:00 am to 12:10 pm

Enhancement, Denoising, and Restoration I

10:00 am: Denoising and deblurring of Fourier-trasform infrared spectroscopic imaging, Tan H. Nguyen, Rohith K. Reddy, Michael J. Walsh, Matthew Schulmerich, Gabriel Popescu, Minh N. Do, Rohit Bhargava, Univ. of Illinois at Urbana-Champaign (United States) [8296-20]

Coffee Break . . . . . . . . . . . . . . . . . . . . . . 10:20 to 10:50 am

10:50 am: Iterative weighted risk estimation for nonlinear image restoration with analysis priors, Jeffrey Rosen, Zhihao Liu, Sathish Ramani, Jeffrey A. Fessler, Univ. of Michigan (United States) . . . [8296-21]

11:10 am: Nonlocal transform-domain denoising of volumetric data with groupwise adaptive variance estimation, Matteo T. Maggioni, Alessandro Foi, Tampere Univ. of Technology (Finland). . . . . . . [8296-22]

11:30 am: Non-uniform contrast correction for coded source neutron imaging, Hector J. Santos-Villalobos, Philip R. Bingham, Oak Ridge National Lab. (United States). . . . . . . . . . . . . . . . . . . . . . . [8296-23]

11:50 am: Image enhancement and quality measures for dietary assessment using mobile devices, Chang $\mathrm{Xu}$, Fengqing Zhu, Nitin Khanna, Carol J. Boushey, Edward J. Delp III, Purdue Univ. (United States) . . . . . . . . . . . . . . . . . . . . . . . [8296-24] Lunch Break $12: 10$ to $1: 40 \mathrm{pm}$

\section{SESSION 5}

Room: Harbour Room A ........... Tues. 1:40 to 2:40 pm

\section{Enhancement, Denoising, and Restoration II}

1:40 pm: Risk estimates for MRI denoising, Patrick J. Wolfe, Harvard Univ. (United States)

2:00 pm: Subjective evaluations of example-based, total variation, and joint regularization for image processing, Hyrum S. Anderson, Maya R. Gupta, Univ. of Washington (United States); Jon Hardeberg, Gjøvik Univ. College (Norway) . . . . . . . . . . . . . . . . . . . . . . . . [8296-26]

2:20 pm: Removal of haze and noise from a single image, Erik Matlin, Peyman Milanfar, Univ. of California, Santa Cruz (United States).[8296-27]

\section{SESSION 6}

Room: Harbour Room A ............Tues. 2:40 to 5:50 pm

\section{Computer Vision and 3D Modeling}

2:40 pm: Finding saliency in noisy images, Chelhwon Kim, Peyman Milanfar, Univ. of California, Santa Cruz (United States). . . . . . . [8296-28]

3:00 pm: Automatic loop closure detection using multiple cameras for 3D indoor localization, Nicholas Corso, John Kua, Jacky Chen, Avideh Zakhor, Univ. of California, Berkeley (United States) . . . . . . . [8296-29]

Coffee Break $3: 20$ to $3: 50 \mathrm{pm}$

3:50 pm: An information theoretic trackability measure, Scott T. Acton, Alla Aksel, Univ. of Virginia (United States) . . . . . . . . . . . . . [8296-30]

4:10 pm: Text replacement on cylindrical surfaces: a semi-automatic approach, Hengzhou Ding, Raja Bala, Zhigang Fan, Xerox Corp. (United States); Charles A. Bouman, Jan P. Allebach, Purdue Univ. (United

States) . . . . . . . . . . . . . . . . . . . . . . [8296-31]

4:30 pm: Figure-ground organization is easier than previously thought, Yunfeng Li, Taekyu Kwon, Purdue Univ. (United States); Longin Jan Latecki, Temple Univ. (United States); Zygmunt Pizlo, Purdue Univ.

(United States) . . . . . . . . . . . . . . . . . . . . . [8296-32]
4:50 pm: An efficient and iterative two-step depth camera selfcalibration technique using depth measurements, R. S. Pahwa, D. Babacan, M. N. Do, Univ. of Illinois at Urbana-Champaign (United

States) . . . . . . . . . . . . . . . . . . . . . . [8296-41] 5:10 pm: Registration and integration of multiple depth images using signed distance function, D. Kubacki, H. Q. Bui, D. Babacan, M. N. Do, Univ. of Illinois at Urbana-Champaign (United States) . . . . . . . [8296-42] 5:30 pm: Image reconstruction from nonuniformly spaced samples in Fourier domain optical coherence tomography, Jun Ke, Edmund $Y$. Lam, Rui Zhu, The Univ. of Hong Kong (Hong Kong, China) ... . [8296-14]

\section{Interactive Paper and Symposium Demonstration Session}

Room: Grand Peninsula Ballroom E . .Tues. 5:30 to 8:00 pm

Demonstrations 5:30 to 8:00 pm

A symposium-wide demonstration session will be open to attendees 5:30 to 8:00 pm Tuesday evening. Demonstrators will provide interactive, hands-on demonstrations of a wide-range of products related to Electronic Imaging.

Posters 5:30 to $8: 00 \mathrm{pm}$

Interactive papers will be placed on display after 10:30 am on Tuesday. An interactive paper session, with authors present at their papers, will be held Tuesday evening, 5:30 to 8:00 pm.

Analysis of practical coverage of uniform motions for approximating real camera shakes, Hojin Cho, Sunghyun Cho, Pohang Univ. of Science and Technology (Korea, Republic of); Young Su Moon, Junguk Cho, Shihwa Lee, Samsung Electronics Co., Ltd. (Korea, Republic of); Seungyong Lee, Pohang Univ. of Science and Technology (Korea,

Republic of) .

[8296-33]

Real-time computational camera system for high-sensitivity imaging by using combined long/short exposure, Satoshi Sato, Yusuke Okada, Takeo Azuma, Panasonic Corp. (Japan).

[8296-34]

Color correction with edge preserving and minimal SNR decrease using multi-layer decomposition, Byung Kwan Park, Wonhee Choe, JaeGuyn Lim, SeongDeok Lee, ChangYeong Kim, Samsung Electronics Co., Ltd. (Korea, Republic of) . . . . . . . . . . . . . . . . . . . [8296-35]

Bayesian image superresolution for hyperspectral image reconstruction, Yusuke Murayama, Ari Ide-Ektessabi, Kyoto Univ. (Japan). . . . . . . . . . . . . . . . . . . . . . [8296-36] ToF depth image deblurring using 3D blur shape models and motion blur saliency map (MBSM), Seungkyu Lee, Kate Shim, James D. K. Kim, Chang yeong Kim, Samsung Advanced Institute of Technology (Korea,

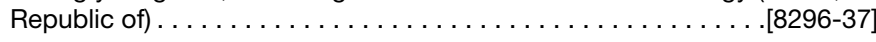

Computational imaging of defects in commercial substrates for electronic and photonic devices, Ryo Kashiwagi, Masayuki Fukuzawa, Masayoshi Yamada, Kyoto Institute of Technology (Japan) . . . . [8296-38]

Nondestructive three-dimensional measurement of gas temperature distribution by phase tomography, Satoshi Tomioka, Shusuke Nishiyama, Hokkaido Univ. (Japan). . . . . . . . . . . . . . . . [8296-39]

Closed-form inverses for the mixed pixel/multpath interference problem in AMCW lidar, John P. Godbaz, Michael J. Cree, Adrian Dorrington, The Univ. of Waikato (New Zealand) . . . . . . . . . [8296-40]

\section{Wednesday 25 January}

Room: Grand Peninsula

Ballroom . . . . . . . . . . . . . . .Wed. 8:20 to 9:30 am

\section{Plenary Session and Conference Award Presentations}

8:25 am: More Words and Bigger Pictures, David A. Forsyth, Univ. of Illinois at Urbana-Champaign (United States) 


\section{Document Recognition and Retrieval XIX}

Conference Chairs: Christian Viard-Gaudin, Univ. de Nantes (France); Richard Zanibbi, Rochester Institute of Technology (United States)

Program Committee: Gady Agam, Illinois Institute of Technology (United States); Elisa H. Barney Smith, Boise State Univ. (United States); Bill Barrett, Brigham Young Univ. (United States); Kathrin Berkner, Ricoh Innovations, Inc. (United States); Bertrand Coüasnon, Institut National des Sciences Appliquées de Rennes (France); Hervé Déjean, Xerox Research Ctr. Europe Grenoble (France); Xiaoqing Ding, Tsinghua Univ. (China); David Scott Doermann, Univ. of Maryland, College Park (United States); Oleg D. Golubitsky, Google Waterloo (Canada); Jianying Hu, IBM TJ Watson Research Ctr. (United States); Laurence Likforman-Sulem, Telecom ParisTech (France); Xiaofan Lin, Vobile, Inc. (United States); Marcus Liwicki, Deutsches Forschungszentrum für Künstliche Intelligenz GmbH (Germany); Daniel P. Lopresti, Lehigh Univ. (United States); Hiroshi Sako, Hosei Univ. (Japan); Sargur N. Srihari, Univ. at Buffalo (United States); Venkata Subramaniam, IBM India Research Lab. (India); Kazem Taghva, Univ. of Nevada, Las Vegas (United States); George R. Thoma, National Library of Medicine (United States); Berrin Yanikoglu, Sabanci Univ. (Turkey); Jie Zou, National Library of Medicine (United States)

\section{Tuesday 24 January}

\section{Room: Grand Peninsula \\ Ballroom A . . . . . . . . . . . . . Tues. 8:20 to 9:30 am \\ Plenary Session and Society Award Presentations}

8:25 am: Computational Photography, William T. Freeman,

Massachusetts Institute of Technology (United States)

\section{Interactive Paper and Symposium} Demonstration Session

Room: Grand Peninsula Ballroom E . . Tues. 5:30 to 8:00 pm

\section{Demonstrations}

A symposium-wide demonstration session will be open to attendees 5:30 to 8:00 pm Tuesday evening. Demonstrators will provide interactive, hands-on demonstrations of a wide-range of products related to Electronic Imaging.

\section{Posters} 5:30 to 7:00 pm

Interactive papers will be placed on display after 10:30 am on Tuesday. An interactive paper session, with authors present at their papers, will be held Tuesday evening, 5:30 to 7:00 pm.

Bleed-through removal in degraded documents, Róisín F. RowleyBrooke, Anil Kokaram, Trinity College Dublin (Ireland) . . . . . . . [8297-28]

Clustering document fragments using background color and texture information, Sukalpa Chanda, Katrin Franke, Gjøvik Univ. College (Norway); Umapada Pal, Indian Statistical Institute (India) . . . . . [8297-29] Lecture video segmentation and indexing, Di Ma, Gady Agam, Illinois Institute of Technology (United States) . . . . . . . . . . . . [8297-30]

Unsupervised categorization method of graphemes on handwritten manuscripts: application to style recognition, Hani Daher, Djamel Gaceb, Veronique Eglin, Stephane Bres, Nicole Vincent, Institut National des Sciences Appliquées de Lyon (France) . . . . . . . . . [8297-31]

Retrieving handwriting by combining word spotting and manifold ranking, Sebastian Peña Saldarriaga, Synchromedia (Canada); Emmanuel Morin, Christian Viard-Gaudin, Univ. de Nantes (France) . . . . . . [8297-32]

The A2iA French handwriting recognition system at the RimesICDAR2011 competition, Farès Menasri, Jérôme Louradour, Anne-Laure Bianne-Bernard, Christopher Kermorvant, A2iA SA (France) . . . . [8297-33]

Using connected component decomposition to detect straight line segments in documents, Xiaofan Feng, Abdou Youssef, The George Washington Univ. (United States) . . . . . . . . . . . . . . . [8297-34]

A synthetic document image dataset for developing and evaluating historical document processing methods, Daniel D. Walker IV, William B. Lund, Eric K. Ringger, Brigham Young Univ. (United States) . .[8297-35]

\section{Wednesday 25 January}

\author{
Room: Grand Peninsula \\ Ballroom A . . . . . . . . . . . . . . Wed. 8:20 to 9:30 am

\section{Plenary Session and Conference Award} \\ Presentations
}

8:25 am: More Words and Bigger Pictures, David A. Forsyth, Univ. of Illinois at Urbana-Champaign (United States)

\section{SESSION 1}

Room: Harbour Room A .......... Wed. 9:30 to 10:30 am

\section{Invited Presentation I}

Session Chair: Christian Viard-Gaudin, Univ. de Nantes (France)

9:30 am: Large scale visual semantic extraction (Invited Paper, Presentation Only), Samy Bengio, Google Inc. (United States). . . [8297-01]

Coffee Break . . . . . . . . . . . . . . . . . . . . . 10:30 to 11:00 am

\section{SESSION 2}

Room: Harbour Room A ........Wed. 11:00 am to 12:20 pm

\section{Region Labeling \\ Session Chair: Gady Agam, Illinois Institute of Technology (United States)}

11:00 am: Graphical image classification combining an evolutionary algorithm and binary particle swarm optimization, Beibei Cheng, Renzhong Wang, Missouri Univ. of Science and Technology (United States); Sameer K. Antani, National Library of Medicine (United States); R. Joe Stanley, Missouri Univ. of Science and Technology (United States); George R. Thoma, National Library of Medicine (United States) .[8297-02] 11:20 am: Combining SVM classifiers to identify investigator name zones in biomedical articles, Jongwoo Kim, Daniel X. Le, George R. Thoma, National Library of Medicine (United States) . . . . . . . . [8297-03] 11:40 am: Comprehensive color segmentation system for noisy digitized documents to enhance text extraction, Asma Ouji, Yann Leydier, Frank LeBourgeois, Institut National des Sciences Appliquées de Lyon (France). . . . . . . . . . . . . . . . . . . . . . . . . . . . [8297-04] 12:00 pm: Ensemble methods with simple features for document zone classification, Tayo Obafemi-Ajayi, Gady Agam, Bingqing Xie, Illinois Institute of Technology (United States) . . . . . . . . . . . . . [8297-05] Lunch Break . . . . . . . . . . . . . . . . . . . 12:20 to 1:50 pm 


\section{Conference 8297}

\section{SESSION 3}

Room: Harbour Room A . . . . . . . . . . Wed. 1:50 to 3:30 pm

\section{Handwriting Recognition}

Session Chair: Xiaoqing Ding, Tsinghua Univ. (China)

1:50 pm: A robust omnifont open-vocabulary arabic OCR system using pseudo-2D-HMM, Abdullah M. Rashwan, Cairo Univ. (Egypt) and RDI (Egypt); Mohsen A. Rashwan, Sherif Abdou, Ahmed Abdel-Hameed, Cairo Univ. (Egypt) . . . . . . . . . . . . . . . . . . . . . . . . [8297-06]

2:10 pm: Variable length and context-dependent HMM letter form models for Arabic handwritten word recognition, Anne-Laure BianneBernard, A2iA SA (France) and Telecom ParisTech (France); Farès Menasri, A2iA SA (France); Laurence Likforman-Sulem, Telecom ParisTech (France); Chafic Mokbel, Univ. of Balamand (Lebanon); Christopher Kermorvant, A2iA SA (France) . . . . . . . . . . . . . . . . . . . [8297-07]

2:30 pm: Post-processing for offline Chinese handwritten character string recognition, Yanwei Wang, Xiaoqing Ding, Changsong Liu,

Tsinghua Univ. (China). . . . . . . . . . . . . . . . . . [8297-08]

2:50 pm: Complexity reduction with recognition rate maintained for online handwritten Japanese text recognition, Jinfeng Gao, Tokyo Univ. Agriculture and Technology (Japan) . . . . . . . . . . . . [8297-09]

3:10 pm: Improving isolated and in-context classication of handwritten characters, Vadim Mazalov, Stephen M. Watt, The Univ. of Western

Ontario (Canada) . . . . . . . . . . . . . . . . . . . . . . .[8297-10]

Coffee Break .................... 3:30 to $4: 00$ pm

\section{SESSION 4}

Room: Harbour Room A . . . . . . . . . . . Wed. 4:00 to 5:20 pm

\section{Graphics Recognition}

Session Chair: Bertrand Coüasnon, Institut National des Sciences Appliquées de Rennes (France)

4:00 pm: Using specific evaluation for comparing and combining competing algorithms: applying it to table column detection, Ana Costa C. Silva, Univ. do Porto (Portugal) . . . . . . . . . . . [8297-11] 4:20 pm: Identification of embedded mathematical formulas in PDF documents using SVM, Xiaoyan Lin, Liangcai Gao, Zhi Tang, Peking Univ. (China); Xuan Hu, BeiHang Univ. (China); Xiaofan Lin, Vobile, Inc. (United States) . . . . . . . . .

4:40 pm: Chemical structure recognition: a rule-based approach, Noureddin M. Sadawi, Alan P. Sexton, Volker Sorge, The Univ. of Birmingham (United Kingdom) . . . . . . . . . . . . . . . . . [8297-13]

5:00 pm: Quantify spatial relations to discover handwritten graphical symbols, Jinpeng Li, Harold Mouchère, Christian Viard-Gaudin, Univ. de Nantes (France) . . . . . . . . . . . . . . . . . . . . [8297-14]

\section{Thursday 26 January SESSION 5}

Room: Harbour Room A .......... Thurs. 8:30 to 9:30 am

\section{Invited Presentation II}

Session Chair: Richard Zanibbi, Rochester Institute of Technology (United States)

8:30 am: Language modeling for information retrieval (Invited Paper, Presentation Only), Christopher Manning, Stanford Univ. (United States) . . . . . . . . . . . . . . . . . . . . . . . .

\section{SESSION 6}

Room: Harbour Room A .......... Thurs. 9:30 to 10:10 am

Information Retrieval

Session Chair: Richard Zanibbi, Rochester Institute of Technology (United States)

9:30 am: Automatic indexing of scanned documents: a layout-based approach, Daniel Esser, Daniel Schuster, Klemens Muthmann, Alexander Schill, Technische Univ. Dresden (Germany) ............. [8297-16] 9:50 am: Layout-based substitution tree indexing and retrieval for mathematical expressions, Thomas Schellenberg, Richard Zanibbi, Bo Yuan, Rochester Institute of Technology (United States) . . . . . . [8297-17] Coffee Break ..........................10:10 to 10:40 am

\section{SESSION 7}

Room: Harbour Room A ..... Thurs. 10:40 am to 12:20 pm

\section{Human-Computer Interaction}

Session Chair: Xiaofan Lin, Vobile, Inc. (United States)

10:40 am: Efficient cost-sensitive human-machine collaboration for off-line signature verification, Johannes Coetzer, Jacques Swanepoel, Stellenbosch Univ. (South Africa); Robert Sabourin, Ecole de Technologie Supérieure (Canada) . . . . . . . . . . . . . . . . . . [8297-18]

11:00 am: Questioned document workflow for handwriting with automated tools, Sargur N. Srihari, Krishnanand Das, Harish Srinivasan, Univ. at Buffalo (United States) . . . . . . . . . . . . . . . . . [8297-19]

11:20 am: Iterative analysis of document collections enables efficient human-initiated interaction, Joseph Chazalon, Bertrand Coüasnon, Institut National des Sciences Appliquées de Rennes (France) . . [8297-20]

11:40 am: VeriClick: an efficient tool for table format verification, George Nagy, Mangesh Tamhankar, Rensselaer Polytechnic Institute (United States). . . . . . . . . . . . . . . . . . . . [8297-21]

12:00 pm: Asymptotic cost in document conversion, Dorothea Blostein, Queen's Univ. (Canada); George Nagy, Rensselaer Polytechnic Institute (United States) . . . . . . . . . . . . . . . . . . . . . . . [8297-22] Lunch Break ..................... 12:20 to $1: 50 \mathrm{pm}$

\section{SESSION 8}

Room: Harbour Room A .......... Thurs. 1:50 to 3:30 pm

\section{Style or Writer Identification}

Session Chair: Daniel P. Lopresti, Lehigh Univ. (United States)

1:50 pm: Style comparisons in calligraphy, Xiafen Zhang, Shanghai Maritime Institute (China); George Nagy, Rensselaer Polytechnic Institute (United States). . . . . . . . . . . . [8297-23]

2:10 pm: An Oracle-based co-training framework for writer identification in offline handwriting, Utkarsh Porwal, Univ. at Buffalo (United States); Sreeranga Rajan, Fujitsu Labs. of America, Inc. (United States); Venu Govindaraju, Univ. at Buffalo (United States) . . . . . [8297-24] 2:30 pm: Handwritten document age classification based on handwriting styles, Chetan Ramaiah, Gaurav Kumar, Venu Govindaraju, Univ. at Buffalo (United States) . . . . . . . . . . . . . . . [8297-25] 2:50 pm: Handwriting individualization using distance and rarity, $\mathrm{Yi}$ Tang, Sargur N. Srihari, Univ. at Buffalo (United States); Harish Srinivasan, Janya Inc. (United States) . . . . . . . . . . . . . . . . . . [8297-26]

$3: 10 \mathrm{pm}$ : Construction of language models for an handwritten mail reading system, Olivier Morillot, Laurence Likforman-Sulem, Telecom ParisTech (France); Emmanuèle Grosicki, Direction Générale de

L'armement (France) . . . . . . . . . . . . . . . . . [8297-27] 


\section{Sensors, Cameras, and Systems for Industrial/Scientific Applications XIII}

Conference Chairs: Ralf Widenhorn, Portland State Univ. (United States); Valérie Nguyen, CEA LETI MINATEC (France); Antoine Dupret, CEA LETI MINATEC (France)

Program Committee: Morley M. Blouke, Portland State Univ. (United States); Erik Bodegom, Portland State Univ. (United States); Glenn H. Chapman, Simon Fraser Univ. (Canada); James A. DiBella, Sr., Eastman Kodak Co. (United States); Terrence S. Lomheim, The Aerospace Corp. (United States); Pierre Magnan, Institut Supérieur de l'Aéronautique et de l'Espace (France); Kevin J. Matherson, Hewlett-Packard Co. (United States); Alice L. Reinheimer, e2v (United States); Nobukazu Teranishi, Panasonic Corp. (Japan); Xinyang Wang, CMOSIS nv (Belgium)

\section{Tuesday 24 January}

Room: Grand Peninsula
Ballroom A ............. Tues. 8:20 to 9:30 am

\section{Plenary Session and Society Award Presentations}

8:25 am: Computational Photography, William T. Freeman,

Massachusetts Institute of Technology (United States)

\section{Interactive Paper and Symposium Demonstration Session}

Room: Grand Peninsula Ballroom E .. Tues. 5:30 to 8:00 pm

\section{Demonstrations}

$5: 30$ to $8: 00 \mathrm{pm}$

A symposium-wide demonstration session will be open to attendees 5:30 to 8:00 pm Tuesday evening. Demonstrators will provide interactive, hands-on demonstrations of a wide-range of products related to Electronic Imaging.

\section{Posters} 5:30 to 7:00 pm

Interactive papers will be placed on display after 10:30 am on Tuesday. An interactive paper session, with authors present at their papers, will be held Tuesday evening, 5:30 to 7:00 pm.

The embedded network infrared video monitoring system based on Linux OS, Lei Liu, Nanjing Univ. of Science \& Technology (China); Ning Chen, Nanjing Normal Univ. (China); Xiaojun Zhou, Tao Pan, Nanjing Univ. of Science \& Technology (China) .[8298-27]

Motion blur-free time-of-flight range sensor, Seungkyu Lee, Byongmin Kang, James D.K. Kim, Chang Yeong Kim, Samsung Advanced Institute of Technology (Korea, Republic of) . . . . . . . . . . . . . . . . [8298-28]

CMOS buried double junction (BDJ) photodiode for trichromatic sensing, Lien Tu, Swetadri Vasan Setlur Nagesh, Univ. at Buffalo (United States); ZhenHong Fu, OmniVision Technologies, Inc. (United States); Albert H. Titus, Univ. at Buffalo (United States) . . . . . . . . . . . [8298-29]

On image sensor dynamic range utilized by security cameras, Anders Johannesson, Axis Communications AB (Sweden) . . . . . . . [8298-30]

Design of low-noise output amplifier for $p$-channel: fully depleted charge-coupled devices, Sufia Haque, Stephen E. Holland, Armin Karcher, William Kolbe, Natalie Roe, Lawrence Berkeley National Lab. (United States); Robert Groulx, Raymond Frost, Francois Dion, Teledyne DALSA Semiconductor (Canada); Guobin Wang, Lawrence Berkeley National Lab. (United States). . . . . . . . . . . . . . . . . . . . . [8298-31]

S/N improvement for the optical-multiplex image-acquisition system, Tadakuni Narabu, Sony Corp. (Japan) . . . . . . . . . . . . .88298-32]

Fully integrated system-on-chip for pixel-based 3D depth and scene mapping, Martin Popp, Beat De Coi, Markus Thalmann, Radoslav Gancarz, Pascal Ferrat, Martin Dürmüller, Florian Britt, Marco Annese, Markus Ledergerber, Gion-Pol Catregn, ESPROS Photonics AG (Switzerland) . . . . . . . . . . . . . . . . . . . . . .

\section{Wednesday 25 January}

\author{
Room: Grand Peninsula \\ Ballroom A . . . . . . . . . . . . . . . Wed. 8:20 to 9:30 am
}

\section{Plenary Session and Conference Award Presentations}

8:25 am: More Words and Bigger Pictures, David A. Forsyth, Univ. of Illinois at Urbana-Champaign (United States)

\section{SESSION 1}

Room: Regency Ballroom A........ Wed. 9:30 to 10:30 am

\section{High Speed Sensors}

Session Chair: Morley M. Blouke, Portland State Univ. (United States) 9:30 am: High-speed VGA resolution CMOS image sensor with global shutter, Pieter Willems, Guido Vanhorebeek, Cheng Ma, CMOSIS nv (Belgium) . . . . . . . . . . . . . . . . . . . . . [8298-01]

9:50 am: High-speed global shutter CMOS machine vision sensor with high-dynamic range image acquisition and embedded intelligence, Ángel B. Rodríguez-Vázquez, Univ. de Sevilla (Spain); Rafael DominguezCastro, Fernando Medeiro, Francisco Jimenez-Garrido, Anafocus (Spain) . . . . . . . . . . . . . . . . . . . . . . . . . . . [8298-02]

10:10 am: High-speed CMOS image sensor for high-throughput lensless microfluidic imaging system with point-of-care application, Mei Yan, Xiwei Huang, Revanth Nadipalli, Yang Shang, Hao Yu, Nanyang Technological Univ. (Singapore); Minkyu Je, A*STAR Institute of Microelectronics (Singapore); Chen Xu, OmniVision Technologies, Inc. (United States); Kiatseng Yeo, Nanyang Technological Univ.

(Singapore) ............................. [8298-03]

Coffee Break . . . . . . . . . . . . . . . . . . 11:10:30 am

\section{SESSION 2}

Room: Regency Ballroom A ..... Wed. 11:10 am to $12: 30 \mathrm{pm}$

\section{Smart Sensors}

Session Chair: Alice L. Reinheimer, e2v (United States)

11:10 am: Smart image sensor with adaptive correction of brightness Michel Paindavoine, Auguste Ngoua, Olivier Brousse, Cedric Clerc, Univ. de Bourgogne (France) . . . . . . . . . . . . . . . . . . [8298-04]

11:30 am: Algorithm architecture co-design for ultra low-power image sensor, Timothé Laforest, Antoine Dupret, Arnaud Verdant, Didier Lattard, Patrick Villard, CEA-LETI (France). . . . . . . . . . . . . . . . . . . [8298-05]

11:50 am: A CMOS imager using focal-plane pinhole effect for confocal multi-beam scanning microscopy, Min-Woong Seo, An Wang, Zhuo Li, Keita Yasutomi, Keiichiro Kagawa, Shoji Kawahito, Shizuoka Univ. (Japan). . . . . . . . . . . . . . . . . . . . . . . . [8298-06] 
12:10 pm: Time-to-impact sensors in robot vision applications based on the near-sensor image processing concept, Anders Astrom, Combitech AB (Sweden); Robert Forchheimer, Linköping Univ.

(Sweden) . . . . . . . . . . . . . . . . . . . . . . . . . [8298-07] Lunch Break $12: 30$ to $1: 30 \mathrm{pm}$

\section{SESSION 3}

Room: Regency Ballroom A......... Wed. 1:30 to 3:00 pm

\section{High Performance Sensors}

Session Chair: Valérie Nguyen, Commissariat à l'Énergie Atomique (France)

1:30 pm: Diffusion dark current in front-illuminated CCDs and CMOS image sensors, Morley M. Blouke, Portland State Univ. (United

States) . . . . . . . . . . . . . . . . . . . . . . . . [8298-36]

1:40 pm: A 176x144 148dB adaptive tone-mapping imager, Sonia Vargas-Sierra, Gustavo Liñán-Cembrano, Ángel B. Rodríguez-Vázquez, Univ. de Sevilla (Spain) . . . . . . . . . . . . . . . . . . . . . [8298-08]

2:00 pm: A high-dynamic range (HDR) back-side illuminated (BSI) CMOS image sensor for extreme UV detection, Xinyang Wang,

CMOSIS nv (Belgium) . . . . . . . . . . . . . . . . . . . [8298-09]

2:20 pm: A low-noise, $15 \mu \mathrm{m}$ pixel-pitch, $640 \times 512$ hybrid InGaAs image sensor for night vision, Fabrice Guellec, Sébastien Dubois, Eric de Borniol, Pierre Castelein, Sébastien Martin, Romain Guiguet, Michaël Tchagaspanian, Anne Rouvie, Philippe Bois, CEA-LETI (France) .[8298-10]

2:40 pm: High-dynamic range, 4 megapixel CMOS image sensor for scientific applications, Paul Vu, Boyd Fowler, Chiao Liu, Steve Mims, Peter Bartkovjak, Hung Do, Wang Li, Jeff Appelbaum, Angel Lopez, BAE Systems Imaging Solutions (United States) . . . . . . . . . . . . [8298-11] Coffee Break . . . . . . . . . . . . . . . . . . 3:00 to 3:30 pm

\section{SESSION 4}

Room: Regency Ballroom A . . . . . . . . . Wed. 3:30 to 5:40 pm

\section{Noise and Characterization}

Session Chair: Kevin J. Matherson, Hewlett-Packard Co. (United States)

3:30 pm: Projecting the rate of in-field pixel defects based on pixel size, sensor area, and ISO, Glenn H. Chapman, Jenny Leung, Ana Namburete, Simon Fraser Univ. (Canada); Israel Koren, Zahava Koren, Univ. of Massachusetts Amherst (United States) . . . . . . . . . . . [8298-12]

3:50 pm: Dynamic CCD pixel depletion edge model and the effects on dark current production, Justin C. Dunlap, Morley M. Blouke, Erik Bodegom, Ralf Widenhorn, Portland State Univ. (United States) .[8298-13]

4:10 pm: Characterizing the response of charge-couple device digital color cameras, Viktor Slavkovikj, Jon Yngve Hardeberg, Gjøvik Univ. College (Norway); Alexander Eichhorn, Simula Research Lab.

(Norway) . . . . . . . . . . . . . . . . . . . . . . . . . [8298-14]

4:30 pm: Implementing and using the EMVA1288 standard, Arnaud Darmont, Jean-François Lemaitre, Jawad Chahiba, Aphesa SPRL

(Belgium) . . . . . . . . . . . . . . . . . . . . . . . [8298-15]

4:50 pm: An overview of the European patent system with particular emphasis on IP issues for imaging devices, M. Boero, A. Cabrita,

European Patent Office (Netherlands). . . . . . . . . . . . . . . . [8298-35]

5:10 pm: Image sensor for defence applications (Invited Paper), Eric Belhaire, Jean-Claude L. Fontanella, Thales Optronique S.A.

(France) . . . . . . . . . . . . . . . . . . . . . . . . [8298-34]

\section{Thursday 26 January \\ SESSION 5}

Room: Regency Ballroom A....... Thurs. 8:30 to 10:10 am

Technological Improvements

Session Chair: Xinyang Wang, CMOSIS nv (Belgium)

8:30 am: Development of high-transmittance, back-illuminated, silicon-on-sapphire substrates thinned below 25 micrometers and bonded to fused silica for high-quantum efficiency and high-resolution avalanche photodiode imaging arrays, Alvin G. Stern, AG Stern, LLC (United States). . . . . . . . . . . . . . . . . . . . . . . . . . .[8298-16]

8:50 am: 29 mp, 35 mm format interline CCD image sensor, Eric J. Meisenzahl, Douglas A. Carpenter, James E. Doran, Robert P. Fabinski, Stephen L. Kosman, John P. McCarten, Eastman Kodak Co. (United States) . . . . . . . . . . . . . . . . . . . . . . . . . . . [8298-17]

9:10 am: Photodiode dopant structure with atomically flat Si surface for high-sensitivity and stability to UV light, Taiki Nakazawa, Rihito Kuroda, Yasumasa Koda, Shigetoshi Sugawa, Tohoku Univ.

(Japan). . . . . . . . . . . . . . . . . . . . . . . . . .[8298-18]

9:30 am: New smart readout technique performing edge detection designed to control vision sensors dataflow, Hawraa Amhaz, Gilles Sicard, TIMA Lab. (France) . . . . . . . . . . . . . . . . . . . [8298-19]

9:50 am: Characterization of orthogonal transfer array CCDs for the WIYN one-degree imager, Michael P. Lesser, David Ouellette, The Univ. of Arizona (United States); Todd Boroson, National Optical Astronomy Observatory (United States); Daniel Harbeck, Pierre Martin, WIYN Observatory (United States); George Jacoby, Carnegie Observatories (United States); John Cavin, Univ. of Wisconsin-Madison (United States); David Sawyer, National Optical Astronomy Observatory (United States); Kasey Boggs, Richard Bredthauer, Semiconductor Technology Associates Inc. (United States) . . . . . . . . . . . . . . . . . . . . . . . . [8298-20] Coffee Break . . . . . . . . . . . . . . . . . 10:10 to 10:50 am

\section{SESSION 6}

Room: Regency Ballroom A . . . . Thurs. 10:50 am to 12:10 pm

\section{Color Imaging}

Session Chair: Erik Bodegom, Portland State Univ. (United States)

10:50 am: Multispectral imaging device for help in diagnosis, Céline Delporte, Mohamed Ben Chouikha, Sylvie Sautrot, Univ. Pierre et Marie Curie (France); Françoise Viénot, Muséum National d'Histoire Naturelle (France); Georges Alquié, Univ. Pierre et Marie Curie (France). . .[8298-21]

11:10 am: Development of a driving method suitable to ultra-highspeed shooting in $\mathbf{2 M}$-fps, 300k-pixel single-chip color camera, Jun Yonai, Toshiki Arai, Japan Broadcasting Corp. (Japan); Tetsuya Hayashida, NHK Engineering Services, Inc. (Japan); Hiroshi Ohtake, Japan Broadcasting Corp. (Japan); Takeharu Goji Etoh, Kinki Univ. (Japan); Tetsuo Yoshida, Jun Namiki, Hitachi Kokusai Electric Inc. (Japan)[8298-22] 11:30 am: Accurate color with increased sensitivity using IR, Amy Enge, Eastman Kodak Co. (United States) . . . . . . . . . . . . . . . [8298-24]

11:50 am: Computational color constancy using chromagenic filters in color filter arrays, Raju Shrestha, Jon Yngve Hardeberg, Gjøvik Univ. College (Norway) . . . . . . . . . . . . . . . . . . . . . . [8298-25] 


\section{Digital Photography VIII}

Conference Chairs: Sebastiano Battiato, Univ. degli Studi di Catania (Italy); Brian G. Rodricks, Fairchild Imaging (United States); Nitin Sampat, Rochester Institute of Technology (United States)

Conference Co-Chairs: Francisco H. Imai, Canon U.S.A., Inc. (United States); Feng Xiao, Vimicro Corp. (United States)

Program Committee: Ajit S. Bopardikar, Samsung Electronics, India Software Operations Ltd. (India); Frédéric Cao, DxO Labs (France); Peter B. Catrysse, Stanford Univ. (United States); Ted J. Cooper, Lens Vector, Inc. (United States); Jeffrey M. DiCarlo, Intuitive Surgical, Inc. (United States); Alexandru F. Drimbarean, Tessera (FotoNation) Ireland Ltd. (Ireland); Joyce E. Farrell, Stanford Univ. (United States); Guotong Feng, Ricoh Innovations, Inc. (United States); Boyd A. Fowler, Fairchild Imaging (United States); Sergio R. Goma, Qualcomm Inc. (United States); Mirko Guarnera, STMicroelectronics (Italy); Xiaoyun Jiang, Qualcomm Inc. (United States); George John, Motorola, Inc. (United States); Michael A. Kriss, Consultant (United States); Jiangtao Kuang, OmniVision Technologies, Inc. (United States); Feng Li, Aptina Imaging Corp. (United States); J. Dylan Li, Lifesize Communications, Inc. (United States); Kevin J. Matherson, Hewlett-Packard Co. (United States); Jon S. McElvain, Dolby Labs., Inc. (United States); Ricardo J. Motta, NVIDIA Corp. (United States); Seishi Ohmori, Nikon Corp. (Japan); Manu Parmar, Qualcomm Inc. (United States); Gloria G. Putnam, Eastman Kodak Co. (United States); John R. Reinert-Nash, Lifetouch, Inc. (United States); Filippo D. Stanco, Univ. degli Studi di Catania (Italy); Qun Sun, Aptina Imaging Corp. (United States); Sabine Süsstrunk, Ecole Polytechnique Fédérale de Lausanne (Switzerland); Touraj Tajbakhsh, Dream Chip Technologies (Germany); Radka Tezaur, Nikon Precision Inc. (United States); Michael Wang, Cisco Systems, Inc. (United States); Dietmar Wüller, Image Engineering Dietmar Wüller (Germany); Weihua Xiong, OmniVision Technologies, Inc. (United States); Alireza Yasan, Foveon Inc. (United States); Lei Zhang, The Hong Kong Polytechnic Univ. (Hong Kong, China)

\section{Monday 23 January SESSION 1}

\section{Room: Regency Ballroom A . . . . . Mon. 8:30 am to 12:10 pm Sensors and Optics \\ Session Chair: Feng Li, Aptina Imaging Corp. (United States)} 8:30 am: An objective protocol for comparing the noise performance of silver halide film and digital sensor, Frédéric Cao, Régis Tessières, Guichard Frédéric, Hervé Hornung, DxO Labs (France) . . . . . . [8299-01] 8:50 am: Sensor defect probability estimation and yield, Honghong Peng, Brian Keelan, Aptina Imaging Corp. (United States). . . . . [8299-02] 9:10 am: Optimum spectral sensitivity functions for single-sensor color imaging, Zahra Sadeghipoor, Ecole Polytechnique Fédérale de Lausanne (Switzerland); Yue Lu, Harvard School of Engineering and Applied Sciences (United States); Sabine Süsstrunk, Ecole Polytechnique Fédérale de Lausanne (Switzerland) . . . . . . . . . . . . . . [8299-03] 9:30 am: A metric for the evaluation of wide dynamic-range cameras, Ping Wah Wong, Pixim Inc. (United States); Yu Hua Lu, Ministry of Public Security (China) . . . . . . . . . . . . . . . . . . . . [8299-04] 9:50 am: Active pixels of transverse field detector based on a charge preamplifier, Giacomo Langfelder, Cesare Buffa, Antonio Francesco Longoni, Alice Pelamatti, Federico Zaraga, Politecnico di Milano (Italy) . . . . . . . . . . [8299. 05] Coffee Break .......................10:10 to 10:50 am 10:50 am: Digital focusing and re-focusing with thin multi-aperture cameras, Alexander Oberdörster, Andreas Brückner, Frank C. Wippermann, Andreas Bräuer, Fraunhofer-Institut für Angewandte Optik und Feinmechanik (Germany); Hendrik P. A. Lensch, Univ. Ulm (Germany) . . . . . . . . . . . . . . . . . . . . . . .8299-06]

11:10 am: The multi-focus plenoptic camera, Todor G. Georgiev, Adobe Systems Inc. (United States); Andrew Lumsdaine, Indiana Univ. (United States) and Adobe Systems Inc. (United States) . . . . . . . . [8299-07]

11:30 am: Spatial domain analysis of discrete plenoptic sampling, Andrew Lumsdaine, Indiana Univ. (United States); Todor G. Georgiev, Adobe Systems Inc. (United States) . . . . . . . . . . . . . . . [8299-08]

11:50 am: Design framework for a spectral mask for a plenoptic camera, Kathrin Berkner, Sapna A. Shroff, Ricoh Innovations, Inc. (United States) . . . . . . . . . . . . . . . . . . . . . . . . .8299-09]

Lunch Break $12: 10$ to $2: 00 \mathrm{pm}$

\section{SESSION 2}

Room: Regency Ballroom A ......... Mon. 2:00 to 5:20 pm

\section{Image Enhancement}

Session Chair: Ajit S. Bopardikar, Samsung Electronics, India Software Operations Ltd. (India)

2:00 pm: Detection thresholds of structured noise in the presence of shot noise, Feng Li, Brian W. Keelan, Alexander Dokoutchaev, Robin Jenkin, Aptina Imaging Corp. (United States) . . . . . . . . . . [8299-10] 2:20 pm: Reduced-reference image quality assessment based on statistics of edge patterns, Yuting Chen, Xuanqin Mou, Xi'an Jiaotong Univ. (China) . . . . . . . . . . . . . . . . . . . . [8299-11] 2:40 pm: Joint chromatic aberration correction and demosaicking, Tripurari Singh, Mritunjay Singh, Image Algorithmics (United States) . . . . . . . . . . . . . . . . . . . . . . [8299-12] 3:00 pm: Optimal defocus estimates from individual images for autofocusing a digital camera, Johannes Burge, Wilson S. Geisler, The Univ. of Texas at Austin (United States) . . . . . . . . . . . [8299-13] Coffee Break . . . . . . . . . . . . . . . . . 3:20 to 4:00 pm 4:00 pm: Quality versus color saturation and noise, Brian W. Keelan, Robin B. Jenkin, Elaine W. Jin, Aptina Imaging Corp. (United States) . . . . . . . . . . . . . . . . . . . . . . . . . . . . [8299-14] 4:20 pm: Bio-inspired framework for automatic image quality enhancement, Francesca Gasparini, Schettini Raimondo, Ceresi Andrea, Marini Fabrizio, Univ. degli Studi di Milano-Bicocca (Italy) . . . . . [8299-15] 4:40 pm: An efficient, multiple-exposure image fusion in JPEG domain, Ramya S. M. Hebbalaguppe, Dublin City Univ. (Ireland); Ramakrishna Kakarala, Nanyang Technological Univ. (Singapore) . . . . . . . . . [8299-16] 5:00 pm: A controllable anti-aliasing filter for digital film cameras, Branko Petljanski, Panavision Inc. (United States) . . . . . . . . . [8299-17] 


\section{Tuesday 24 January}

\section{Room: Grand Peninsula \\ Ballroom A . . . . . . . . . . . . . Tues. 8:20 to 9:30 am \\ Plenary Session and Society Award Presentations}

8:25 am: Computational Photography, William T. Freeman,

Massachusetts Institute of Technology (United States)

\section{SESSION 3}

Room: Regency Ballroom A . . . . . Tues. 9:30 am to 10:30 pm

\section{Image Quality and Mobile Imaging I: Joint Session with Conference 8293}

Session Chairs: Peter D. Burns, Consultant (United States); Sebastiano Battiato, Univ. degli Studi di Catania (Italy)

9:30 am: Development of the I3A CPIQ spatial metrics, Henrik Eliasson, Sony Ericsson Mobile Communications AB (Sweden); Donald Baxter, STMicroelectronics (R\&D) Ltd. (United Kingdom); Frédéric Cao, DxO Labs (France); Jonathan Phillips, Eastman Kodak Co. (United States) .[8293-01] 9:50 am: A functional-design approach to lens shading correction issues on mobile camera system, Seunghun Yoo, SAMSUNG Electronics Co., Ltd. (Korea, Republic of); TaeChan Kim, SAMSUNG Electronics Co., Ltd. (United States) . . . . . . . . . . . . . . . . . . . . . . . . . . . [8299-18]

10:10 am: Rethinking user interfaces for cameraphones, Stephen A. Brewster, Christopher McAdam, Univ. of Glasgow (United Kingdom) . . . . . . . . . . . . . . . . . . . . . . [8299-19] Coffee Break ......................10:30 to $11: 10 \mathrm{am}$

\section{SESSION 4}

Room: Regency Ballroom A . . . . Tues. 11:10 am to 12:30 pm

Image Quality and Mobile Imaging II: Joint Session with Conference 8293

Session Chairs: Peter D. Burns, Consultant (United States); Sebastiano Battiato, Univ. degli Studi di Catania (Italy)

11:10 am: Calibration and adaptation of ISO visual noise for camera phone image quality assessment, Donald J. Baxter, Andrew Murray, STMicroelectronics (R\&D) Ltd. (United Kingdom) . . . . . . . . . [8293-02]

11:30 am: An objective method for evaluating the texture-preserving capability of digital camcorders, Kongfeng Zhu, Shujun Li, Dietmar Saupe, Univ. Konstanz (Germany) . . . . . . . . . . . . . . [8293-03]

11:50 am: Improving texture loss measurement: spatial frequency response based on a colored target, Uwe Artmann, Dietmar Wueller, Image Engineering GmbH \& Co. KG (Germany) . . . . . . . . . . [8293-04]

12:10 pm: On the performances of computer vision algorithms on mobile platforms, Sebastiano Battiato, Giovanni M. Farinella, Enrico Messina, Giovanni Puglisi, Daniele Ravì, Univ. degli Studi di Catania (Italy); Alessandro Capra, Valeria Tomaselli, STMicroelectronics (Italy) .[8299-20]

Lunch Break . . . . . . . . . . . . . . . . . . 12:30 to 2:00 pm

\section{SESSION 5}

Room: Regency Ballroom A..........Tues. 2:00 to 3:00 pm

\section{Multispectral}

Session Chair: Nitin Sampat, Rochester Institute of Technology (United States)

2:00 pm: Spectral sensitivity evaluation considering color constancy, Hideyasu Kuniba, Nikon Corp. (Japan) . . . . . . . . . . . . . . [8299-22] 2:20 pm: Multispectral demosaicking using guided filter, Yusuke Monno, Masayuki Tanaka, Masatoshi Okutomi, Tokyo Institute of Technology (Japan)

2:40 pm: An LED-based lighting system for acquiring multispectral scenes, Joyce E. Farrell, Manu Parmar, Steve Lansel, Stanford Univ. (United States). . .[8299-24]

\section{Interactive Paper and Symposium Demonstration Session}

Room: Grand Peninsula Ballroom E . . Tues. 5:30 to 8:00 pm

Demonstrations. 5:30 to 8:00 pm

A symposium-wide demonstration session will be open to attendees 5:30 to 8:00 pm Tuesday evening. Demonstrators will provide interactive, hands-on demonstrations of a wide-range of products related to Electronic Imaging.

Posters 5:30 to 7:00 pm

Interactive papers will be placed on display after 10:30 am on Tuesday. An interactive paper session, with authors present at their papers, will be held Tuesday evening, 5:30 to 7:00 pm.

Fast in-plane translation and rotation estimation for multi-image registration, Xiaoyun Jiang, Haiyin Wang, Qualcomm Inc. (United States) . . . . . . . . . . . . . . . . . . . . . . . . . . . . . . [8299-25]

Multispectral filter wheel cameras: modeling aberrations for filters in front of lens, Julie Klein, Til Aach, RWTH Aachen (Germany) . . . [8299-26]

Correcting saturated pixels in images, Jun Fu, Wenbo Ji, Xuanqin Mou, Xi'an Jiaotong Univ. (China) . . . . . . . . . . . . . . . . . . [8299-27]

Real-time, multi-directional 2D fast wavelet transform and its denoised sharpening application, ByungJoon Baek, TaeChan Kim, SAMSUNG Electronics Co., Ltd. (Korea, Republic of) . . . . . . . . . [8299-28]

Color transfer using semantic image annotation, Francesca Gasparini, Raimondo Schettini, Claudio Cusano, Univ. degli Studi di Milano-Bicocca (Italy) . . . . . . . . . . . . . . . . . . . . . . [8299-29]

Adaptive directional color image sharpening with overshoot control, Touraj Tajbakhsh, Technische Univ. Hamburg-Harburg (Germany)[8299-30]

\section{Wednesday 25 January}

\section{Room: Grand Peninsula}

Ballroom A . . . . . . . . . . . . Wed. 8:20 to 9:30 am

\section{Plenary Session and Conference Award Presentations}

8:25 am: More Words and Bigger Pictures, David A. Forsyth, Univ. of Illinois at Urbana-Champaign (United States) 


\section{Image Processing: Machine Vision Applications V}

Conference Chairs: Philip R. Bingham, Oak Ridge National Lab. (United States); Edmund Y. Lam, The Univ. of Hong Kong (Hong Kong, China)

Program Committee: Pierrick T. Bourgeat, Australian e-Health Research Ctr. (Australia); Jun Cheng, Chinese Academy of Sciences (China); Michael J. Cree, The Univ. of Waikato (New Zealand); Laurent C. Duval, IFP (France); Ewald Fauster, Montanuniversitaet Loeben (Austria); Steven P. Floeder, 3M Co. (United States); David Fofi, Univ. de Bourgogne (France); Luciano F. Fontoura Da Costa, Univ. de São Paulo (Brazil); Shaun Scott Gleason, Oak Ridge National Lab. (United States); Olivier Laligant, Univ. de Bourgogne (France); Fabrice Meriaudeau, Univ. de Bourgogne (France); Dinesh Nair, National Instruments Corp. (United States); Kurt S. Niel, Fachhochschule Wels (Austria); Arnau Oliver, Univ. de Girona (Spain); Vincent C. Paquit, Oak Ridge National Lab. (United States); Jeffery R. Price, Aldis, Inc. (United States); A. Ravishankar Rao, IBM Thomas J. Watson Research Ctr. (United States); Hamed Sari-Sarraf, Texas Tech Univ. (United States); Peter Schelkens, Vrije Univ. Brussel (Belgium); Ivan W. Selesnick, Polytechnic Institute of NYU (United States); Ralph Seulin, Univ. de Bourgogne (France); Christophe Stolz, Univ. de Bourgogne (France); Yvon Voisin, Univ. de Bourgogne (France); Gerald Zauner, Fachhochschule Wels (Austria)

\section{Tuesday 24 January}

\section{Room: Grand Peninsula \\ Ballroom A . . . . . . . . . . . . Tues. 8:20 to 9:30 am}

\section{Plenary Session and Society Award Presentations}

8:25 am: Computational Photography, William T. Freeman,

Massachusetts Institute of Technology (United States)

\section{Interactive Paper and Symposium Demonstration Session}

Room: Grand Peninsula Ballroom E . .Tues. 5:30 to 8:00 pm

\section{Demonstrations.} 5:30 to $8: 00 \mathrm{pm}$

A symposium-wide demonstration session will be open to attendees $5: 30$ to 8:00 pm Tuesday evening. Demonstrators will provide interactive, hands-on demonstrations of a wide-range of products related to Electronic Imaging.

Posters . . . . . . . . . . . . . . . . . . . 5:30 to 7:00 pm

Interactive papers will be placed on display after 10:30 am on Tuesday. An interactive paper session, with authors present at their papers, will be held Tuesday evening, 5:30 to 7:00 pm.

Efficient local approximation of perceptual color differences for color inspection, Reinhold Huber-Mörk, Austrian Institute of Technology (Austria) . . . . . . . . . . . . . . . . . . . . . . . . [8300-16]

Modified fuzzy c-means applied to a Bragg-grating-based spectral imager for material clustering, Aida Rodríguez, Juan Luis Nieves, Eva Valero, Univ. de Granada (Spain); Estíbaliz Garrote, TECNALIA (Spain); Javier Hernández-Andrés, Javier Romero, Univ. de Granada (Spain) . . . . . . . . . . . . . . . . . . . . . . . . . . [8300-17]

Robust recognition of 1D barcodes using hough transform, John Dwinell, Long Xiang Bian, SICK, Inc. (United States); Peng Bian, Microsoft Corp. (China) . . . . . . . . . . . . . . . . . . . . . . [8300-18]

Estimating the coordinates of pillars and posts in the parking lots for intelligent parking assist system, JaeHyung Choi, Jung Gap Kuk, Nam Ik Cho, Seoul National Univ. (Korea, Republic of). . . . . . . . . . . [8300-19]

Recognizing human gestures using a novel SVM tree, Hitesh Jain, Abhik Chatterjee, Sanjeev Kumar, Balasubramanian Raman, Indian Institute of Technology Roorkee (India).

Fabric defect detection using the wavelet transform in an ARM processor, Jose Armando Fernandez Gallego, Antonio Nariño Univ. (Colombia); Sergio Alejandro Orjuela Vargas, Univ. Gent (Belgium); Jorge Alvarez, Antonio Nariño Univ. (Colombia); Wilfried Philips, Univ. Gent (Belgium) . . . . . . . . . . . . . . . . . . . . . . . . . . . . [8300-22]
Orthophotoplan segmentation based on regions merging for roof detection, Youssef El Merabet, Cyril Meurie, Yassine Ruichek, Univ. de Technologie de Belfort-Montbéliard (France); Abderrahmane Sbihi, Ecole Nationale des Sciences Appliquées de Tanger (Morocco); Rajja Touahni, Univ. Ibn Tofail (Morocco) . . . . . . . . . . . . . . . . . . . [8300-23]

Motion cue analysis for Parkinsonian gait recognition, Taha M. Khan, Jerker Westin, Mark Dougherty, Dalarna Univ. (Sweden) . . . . . . [8300-24]

\section{Wednesday 25 January}

\section{Room: Grand Peninsula}

Ballroom A . . . . . . . . . . . . . . . Wed. 8:20 to 9:30 am

\section{Plenary Session and Conference Award Presentations}

8:25 am: More Words and Bigger Pictures, David A. Forsyth, Univ. of Illinois at Urbana-Champaign (United States)

\section{SESSION 1}

Room: Bayside Room B........... Wed. 9:30 to 10:30 am

\section{Systems}

Session Chair: Edmund Y. Lam, The Univ. of Hong Kong (Hong Kong, China)

9:30 am: An introduction to omnidirectional vision: theory and applications, David Fofi, Saleh Mosaddegh, Abd El Rahman Shabayek, Olivier Morel, Univ. de Bourgogne (France) . . . . . . . . . . [8300-01]

9:50 am: Sensor placement optimization in buildings, Simone Bianco, Raimondo Schettini, Francesco Tisato, Univ. degli Studi di Milano-Bicocca

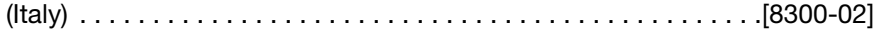

10:10 am: Optical feature extraction with illumination-encoded linear functions, Robin Gruna, Karlsruher Institut für Technologie (Germany); Jürgen Beyerer, Fraunhofer-Institut für Optronik, Systemtechnik und Bildauswertung (Germany) ................... [8300-03] Coffee Break . . . . . . . . . . . . . . . . . . . . . . 10:30 to 11:10 am 


\section{Conference 8300}

\section{SESSION 2}

Room: Bayside Room B. . . . . . . . Wed. 11:10 am to 12:30 pm

\section{Algorithms}

Session Chair: Philip R. Bingham, Oak Ridge National Lab. (United States)

11:10 am: An illumination-invariant phase-shift algorithm in threedimensional profilometry, Fuqin Deng, The Univ. of Hong Kong (Hong Kong, China) and ASM Assembly Automation Ltd. (Hong Kong, China); Edmund Y. Lam, The Univ. of Hong Kong (Hong Kong, China); Wuifung Sze, Jiangwen Deng, Kenneth S.M. Fung, W.H. Leung, Chang Liu, ASM Assembly Automation Ltd. (Hong Kong, China)

11:30 am: Fusing shape and texture features for pose-robust face recognition, Thorsten Gernoth, Rolf-Rainer Grigat, Technische Univ. Hamburg-Harburg (Germany) .

11:50 am: Automated inspection of tubular material based on magnetic particle inspection, Adhiguna Mahendra, Christophe Stolz, Fabrice Meriaudeau, Univ. de Bourgogne (France); Sebastien Petit, Alexandre Noel, Fabien Degoutin, Vallourec S.A. (France) . . . . . [8300-06]

12:10 pm: Intermediate-level segmentation of color images through perception and geometry-based contour completions and shape cuts, Jacopo Grazzini, Lakshman Prasad, Los Alamos National Lab. (United States) . . . . . . . . . . . . . . . . . . . . [8300-07]

Lunch Break . . . . . . . . . . . . . . 12:30 to 2:00 pm

\section{SESSION 3}

Room: Bayside Room B.

Wed. 2:00 to 3:20 pm

\section{Detection and Tracking}

Session Chair: David Fofi, Univ. de Bourgogne (France)

2:00 pm: Runway hazard detection in poor visibility conditions, Bo Jiang, National Institute of Aerospace (United States); Zia-ur Rahman, Old Dominion Univ. (United States) . . . . . . . . . . . . . . . . . . [8300-08]

2:20 pm: Application of image processing to track twin boundary motion in magnetic shape memory alloys, Adrian Rothenbuhler, Elisa $\mathrm{H}$. Barney Smith, Peter Müllner, Boise State Univ. (United States) . [8300-09]

\section{2:40 pm: A new point process model for trajectory-based events} annotation, Nicolas Ballas, CEA LIST (France) and Mines ParisTech (France); Bertrand Delezoide, CEA LIST (France); Françoise Prêteux, Mines ParisTech (France). .[8300-10]

3:00 pm: Face detection and eyeglasses detection for thermal face recognition, Yufeng Zheng, Alcorn State Univ. (United States). .[8300-11] 3:20 to $3: 50 \mathrm{pm}$

\section{SESSION 4}

Room: Bayside Room B. . . . . . . . . . . Wed. 3:50 to 5:30 pm

Applications

Session Chair: Philip R. Bingham, Oak Ridge National Lab. (United States)

3:50 pm: Strain analysis by regularized non-rigid registration, Amir Badshah, Paul L. O’Leary, Matthew J. Harker, Montan Univ. Leoben (Austria) . . . . . . . . . . . . . . . . . . . . . [8300-25]

4:10 pm: Combining spatial and spectral information to improve crop/ weed discrimination algorithms, Gawain Jones, Sylvain Villette, JeanNoel Paoli, Christelle Gée, AgroSup Dijon (France) . . . . . . . . . [8300-12] 4:30 pm: Automated parasite detection in clams by transillumination imaging and pattern classification, Miguel E. Soto, Pablo A. Coelho, Sergio N. Torres, Daniel G. Sbarbaro, Univ. de Concepción

(Chile). . . . . . . . . . . . . . . . . . . . . . [8300-13]

4:50 pm: Vision-based, in-line fabric defect detection using yarnspecific shape features, Dorian Schneider, Til Aach, RWTH Aachen (Germany) . . . . . . . . . . . . . . . . . . . . [8300-14]

5:10 pm: 3D temperature mapping of turboshaft components using thermal paints and color recognition, Samuel Guérin, Turbomeca SA (France) and ONERA, The French Aerospace Lab (France); Christine Lempereur, ONERA, The French Aerospace Lab. (France); Philippe Brevet, Turbomeca SA (France). . . . . . . . . . . . . . . . . . [8300-15] 


\title{
Intelligent Robots and Computer Vision XXIX: Algorithms and Techniques
}

\author{
Conference Chairs: Juha Röning, Univ. of Oulu (Finland); David P. Casasent, Carnegie Mellon Univ. (United States)
}

Program Committee: Norbert Lauinger, CORRSYS 3D Sensors AG (Germany); Dah Jye Lee, Brigham Young Univ. (United States); Charles A. McPherson, Draper Lab. (United States); Kurt S. Niel, Fachhochschule Wels (Austria); Yoshihiko Nomura, Mie Univ. (Japan); Daniel Raviv, Florida Atlantic Univ. (United States); Oliver Sidla, SLR Engineering OG (Austria); Bernard L. Theisen, U.S. Army Tank Automotive Research, Development and Engineering Ctr. (United States); Dili Zhang, Monotype Imaging (United States)

\section{Monday 23 January SESSION 1}

Room: Bayside Room A. ........... Mon. 8:20 to 9:50 am

\section{Invited Papers on Intelligent Robotics \\ Session Chair: Juha Röning, Univ. of Oulu (Finland)}

8:20 am: Software-based, neural-network-assisted movement compensation for nanoresolution piezo actuators (Invited Paper), Juha Röning, Marko Kauppinen, Univ. of Oulu (Finland) . . . . . . . . [8301-01]

8:50 am: Traffic monitoring with distributed smart cameras (Invited Paper), Oliver Sidla, Marcin Rosner, SLR Engineering OG (Austria); Michael Ulm, Austrian Institute of Technology (Austria) . . . . . . . . . [8301-02]

9:20 am: The 19th annual intelligent ground vehicle competition: student-built autonomous ground vehicles (Invited Paper), Bernard L. Theisen, U.S. Army Tank Automotive Research, Development and Engineering Ctr. (United States) . . . . . . . . . . . . . . . . [8301-03]

\section{SESSION 2}

Room: Bayside Room A. . ......... Mon. 9:50 am to 12:10 pm

\section{Stereo Vision and Applications}

Session Chair: Juha Röning, Univ. of Oulu (Finland)

9:50 am: Accurate, dense 3D reconstruction of moving and still objects from dynamic color image and depth image sequences based on temporal modified-RANSAC and feature-cut, Naotomo Tatematsu, Jun Ohya, Waseda Univ. (Japan) . . . . . . . . . . . . . . [8301-04]

10:10 am: Efficient hybrid monocular-stereo approach to on-board, video-based traffic sign detection and tracking, Javier Marinas, Luis Salgado, Jon Arróspide, Massimo Camplani, Univ. Politécnica de Madrid (Spain) . . . . . . . . . . . . . . . . . . . . . . . [8301-05] Coffee Break ......................... 10:30 to 10:50 am 10:50 am: A general model and calibration method for spherical stereoscopic vision, Weijia Feng, Tianjin Univ. (China); Juha Röning, Univ. of Oulu (Finland); Xiaoning Zong, Tianjin Univ. of Technology (China); Baofeng Zhang, Tianjin Univ. (China); Juho Kannala, Univ. of Oulu

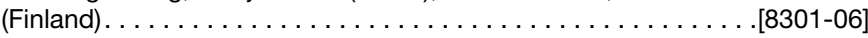
11:10 am: An approach to stereo-point cloud registration using image homographies, Stephen D. Fox, Damian M. Lyons, Fordham Univ. (United States) . . . . . . [8301-07] 11:30 am: Hazardous sign detection for safety applications in traffic monitoring, Wanda Benesova, Slovak Univ. of Technology (Slovakia); Oliver Sidla, SLR Engineering OG (Austria); Michal Kottman, Slovak Univ. of Technology (Slovakia); Elena Sikudova, Zuzana Cernekova, Comenius Univ. in Bratislava (Slovakia) . . . . . . . . . . . . . . . . [8301-08]
11:50 am: PRoViScout: a planetary scouting rover demonstrator, Gerhard M. Paar, JOANNEUM RESEARCH Forschungsgesellschaft $\mathrm{mbH}$ (Austria); Mark Woods, SciSys Ltd. (United Kingdom); Christiane Gimkiewicz, Ctr. Suisse d'Electronique et de Microtechnique SA (Switzerland); Fred Labrosse, Aberystwyth Univ. (United Kingdom); Alberto Medina, GMV S.A. (Spain). . . . . . . . . . . . . . . . . . . [8301-09]

Lunch Break $12: 10$ to $2: 00 \mathrm{pm}$

SESSION 3

Room: Bayside Room A. . . . . . . . . . Mon to 3:40 pm

\section{Novel People and Vehicle Tracking Approaches} Session Chair: Oliver Sidla, SLR Engineering OG (Austria)

2:00 pm: Red-light traffic enforcement at railway crossings, Oliver Sidla, Marcin Rosner, SLR Engineering OG (Austria) . . . . . . . . [8301-10] 2:20 pm: Image projection clues for improved real-time vehicle tracking in tunnels, Vedran Jelaca, Jorge Oswaldo Niño-Castaneda, Aleksandra Pizurica, Wilfried Philips, Univ. Gent (Belgium) .... . [8301-11]

2:40 pm: Decentralized tracking of humans using a camera network, Sebastian Gruenwedel, Vedran Jelaca, Jorge Oswaldo Niño-Castañeda, Peter Van Hese, Dimitri Van Cauwelaert, Peter Veelaert, Wilfried Philips, Univ. Gent (Belgium) . . . . . . . . . . . . . . . . . . .

3:00 pm: Real-time detection of traffic events using smart cameras, Marko M. Macesic, Tehnomobil-Protech (Serbia); Vedran Jelaca, Jorge Oswaldo Niño-Castaneda, Univ. Gent (Belgium); Nenad Prodanovic, Marko Panic, Univ. of Novi Sad (Serbia); Aleksandra Pizurica, Univ. Gent (Belgium); Vladimir Crnojevic, Univ. of Novi Sad (Serbia); Wilfried Philips, Univ. Gent (Belgium) . . . . . . . . . . . . . . . . . [8301-13]

3:20 pm: Mixed road traffic: data acquisition, optical tracking, and microscopic modeling, Robert Schönauer, Technische Univ. Graz (Austria); Yuriy Lypetskyy, SLR Engineering OG (Austria). . . . . . [8301-14] Coffee Break ....................... 3:40 to 4:00 pm

\section{SESSION 4}

Room: Bayside Room A............Mon. 4:00 to 5:00 pm

\section{UAVs and Aerial Applications}

Session Chair: Terrell N. Mundhenk, HRL Labs., LLC (United States)

4:00 pm: AR.Drone: security threat analysis and exemplary attack to track objects or persons, Fred Samland, Jana Fruth, Mario Hildebrandt, Tobias Hoppe, Jana Dittmann, Otto-von-Guericke-Univ. Magdeburg

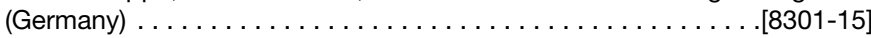

4:20 pm: Detection of unknown targets from aerial camera and extraction of simple object fingerprints for the purpose of target reacquisition, Terrell N. Mundhenk, Kang-Yu Ni, Yang Chen, Kyungnam Kim, Yuri Owechko, HRL Labs., LLC (United States) . . . . . . . . [8301-16]

4:40 pm: Superresolution terrain map enhancement for navigation based on satellite imagery, Jeremy Straub, Jacksonville State Univ. (United States). . . . . . . . . . . . . . . . . . . . . . . . [8301-18] 


\section{Tuesday 24 January}

\section{Room: Grand Peninsula \\ Ballroom A . . . . . . . . . . . . . . Tues. 8:20 to 9:30 am \\ Plenary Session and Society Award Presentations}

8:25 am: Computational Photography, William T. Freeman,

Massachusetts Institute of Technology (United States)

\section{SESSION 5}

Room: Bayside Room A. ........... . Tues. 9:30 to 10:50 am

\section{Robot Manipulation and Application}

Session Chair: David P. Casasent, Carnegie Mellon Univ. (United States)

9:30 am: 3D positional control of magnetic levitation system using adaptive control: improvement of positioning control in horizontal plane, Toshimasa Nishino, Norihiko Kato, Mie Univ. (Japan); Naoaki Tsuda, Wakayama National College of Technology (Japan); Yoshihiko Nomura, Mie Univ. (Japan) . . . . . . . . . . . . . . . [8301-19]

9:50 am: Robots in agriculture: an I-weed robot for a specific spraying, Ghislain Salis, Christelle Gée, Sylvain Villette, Jean-Noel Paoli, Gawain Jones, AgroSup Dijon (France) . . . . . . . . . . . . . . [8301-20]

10:10 am: The magic glove: a gesture-based remote controller for intelligent mobile robots, Chaomin Luo, Yue Chen, Mohan Krishnan, Mark Paulik, Univ. of Detroit Mercy (United States) . . . . . . . . . [8301-21]

10:30 am: Way-point navigation for a skid steer vehicle in unknown environments, Peiyi Chen, Arun Das, Prasenjit Mukherjee, Steven

Waslander, Univ. of Waterloo (Canada) . . . . . . . . . . . . [8301-22]

Coffee Break ..........................10:50 to 11:10 am

\section{SESSION 6}

Room: Bayside Room A. . . . . . . . Tues. 11:10 am to 12:50 pm

\section{Vision Navigation and Activity Recognition}

Session Chair: Charles A. McPherson, Draper Lab. (United States)

11:10 am: Integrated field testing of planetary robotics vision processing: the PRoVisG campaign in Tenerife 2011, Gerhard M. Paar, JOANNEUM RESEARCH Forschungsgesellschaft $\mathrm{mbH}$ (Austria); Lester Waugh, EADS Astrium Ltd. (United Kingdom); David P. Barnes, Aberystwyth Univ. (United Kingdom); Tomas Pajdla, Czech Technical Univ. in Prague (Czech Republic); Mark Woods, SciSys Ltd. (United Kingdom); Hans-Rudolf Graf, Ctr. Suisse d'Electronique et de Microtechnique SA (Switzerland); Yang Gao, Univ. of Surrey (United Kingdom); Konrad Willner, Technische Univ. Berlin (Germany); Jan-Peter A. Muller, Univ. College London (United Kingdom); Rongxing Li, The Ohio State Univ. (United States); Michel Maurette, Ctr. National d'Études Spatiales

(France) . . . . . . . . . . . . . . . . . . . . . . . . . [8301-23]

11:30 am: Hierarchical loop detection for mobile outdoor robots, Dagmar Lang, Christian Winkens, Marcel Häselich, Dietrich W. Paulus, Univ. Koblenz-Landau (Germany) . . . . . . . . . . . . . . . . . [8301-24]

11:50 am: A novel margin-based, linear embedding technique for visual object recognition, Fadi Dornaika, Univ. del País Vasco (Spain) . . . . . . . . . . . . . . . . . . . . . . . . [8301-25]

12:10 pm: Real-time, two-level foreground detection and personsilhouette extraction enhanced by body-parts tracking, Rada Deeb, Élodie Desserée, Saida Bouakaz, Univ. Claude Bernard Lyon 1

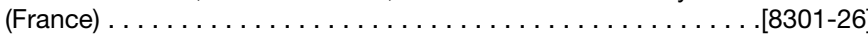

12:30 pm: Activity recognition from video using layered approach, Charles A. McPherson, John M. Irvine, Mon Young, Draper Lab. (United States); Anthony Stefanidis, George Mason Univ. (United States)[8301-27] Lunch Break $12: 50$ to $2: 00 \mathrm{pm}$

\section{SESSION 7}

Room: Bayside Room A............Tues. 2:00 to 3:20 pm

\section{Visual Algorithms}

Session Chairs: David P. Casasent, Carnegie Mellon Univ. (United States); Oliver Sidla, SLR Engineering OG (Austria)

2:00 pm: Method for fast detecting the intersection of a plane and a cube in an octree structure to find point sets within a convex region, Keisuke Fujimoto, Nobutaka Kimura, Toshio Moriya, Hitachi, Ltd.

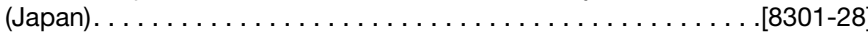

2:20 pm: Lucas-Kanade image registration using camera motions, Sunghyun Cho, Hojin Cho, Pohang Univ. of Science and Technology (Korea, Republic of); Young Su Moon, Junguk Cho, Shihwa Lee, Samsung Electronics Co., Ltd. (Korea, Republic of); Seungyong Lee, Pohang Univ. of Science and Technology (Korea, Republic of) ............ [8301-30]

2:40 pm: Object tracking with adaptive HOG detector and adaptive Rao-Blackwellised particle filter, Stefano Rosa, Marco Paleari, Paolo Ariano, Istituto Italiano di Tecnologia (Italy); Basilio Bona, Politecnico di Torino (Italy) . . . . . . . . . . . . . . . . . . . . . [8301-31]

3:00 pm: A modular real-time vision system for humanoid robots, Alina L. Trifan, António J.R. Neves, Bernardo Cunha, Nuno Lau, Univ. de Aveiro (Portugal) . . . . . . . . . . . . . . . . . . . . . [8301-32]

Coffee Break ..................... 3:20 to 4:00 pm

\section{SESSION 8}

Room: Bayside Room A. ........... Tues. 4:00 to 5:40 pm Intelligent Ground Vehicle Competition

Session Chair: Bernard L. Theisen, U.S. Army Tank Automotive Research, Development and Engineering Ctr. (United States)

4:00 pm: Radial polar histogram approach to obstacle avoidance and path planning for robotic cognition and motion control, Po-Jen Wang, Nicholas R. Keyawa, Craig Euler, C. T. Lin, California State Univ., Northridge (United States). . . . . . . . . . . . . . . . [8301-33]

4:20 pm: Optimising a mobile robot control system with GPU acceleration, Nat Tuck, Michael E. McGuinness, Fred Martin, Univ. of Massachusetts Lowell (United States) . . . . . . . . . . . . . . . [8301-34]

4:40 pm: Design and realization of an intelligent ground vehicle with modular payloads, Mehmet A. Akmanalp, Ryan M. Doherty, Jeffrey Gorges, Peter Kalauskas, Ellen Peterson, Felipe Polido, Stephen S. Nestinger, Taskin Padir, Worcester Polytechnic Institute (United States) . . . . . . . . . . . . . . . . . . . . . . . . . [8301-35]

5:00 pm: Navigating a path delineated by colored flags: an approach for an IGVC 2011 requirement, Alex Szmatula, Matt Parrish, Mohan Krishnan, Mark Paulik, Utayba Mohammad, Chaomin Luo, Univ. of Detroit Mercy (United States) . . . . . . . . . . . . . . . . . . . . . [8301-36]

5:20 pm: Navigating with VFH: a strategy to avoid traps, Chaomin Luo, Mohan Krishnan, Mark Paulik, Utayba Mohammad, Univ. of Detroit Mercy (United States). . . . . . . . . . . . . . . . . . . . . . [8301-37] 


\section{Conference 8301}

\section{Interactive Paper and Symposium Demonstration Session}

\section{Room: Grand Peninsula Ballroom E...Tues. 5:30 to 8:00 pm}

\section{Demonstrations}

5:30 to $8: 00 \mathrm{pm}$

A symposium-wide demonstration session will be open to attendees 5:30 to 8:00 pm Tuesday evening. Demonstrators will provide interactive, hands-on demonstrations of a wide-range of products related to Electronic Imaging.

Posters

\section{5:30 to 7:00 pm}

Interactive papers will be placed on display after 10:30 am on Tuesday. An interactive paper session, with authors present at their papers, will be held Tuesday evening, 5:30 to 7:00 pm.

Measurement of noises and modulation transfer function of cameras used in optical-digital correlators, Nikolay N. Evtikhiev, Sergey N. Starikov, Pavel A. Cheryomkhin, Vitaly V. Krasnov, National Research Nuclear Univ. MEPhl (Russian Federation) . . . . . . . . . . . . . [8301-38]

A phase-space approach for detection and removal of rain in video, Varun Santhaseelan, K. Vijayan Asari, Univ. of Dayton (United States) . . . . . . . . . . . . . . . . . . . . . . . . . . . . . . . .[8301-39]

Intelligence algorithms for autonomous navigation in a ground vehicle, Steve J. Petkovsek, Adam Norton, Trinity College (United States)[8301-40] Hierarchical, multi-level image mosaicing for autonomous navigation of UAV, Sangho Park, Debabrata Ghosh, Naima Kaabouch, Ronald Fevig, William Semke, The Univ. of North Dakota (United States) . . . . [8301-41]

A diffraction-limited 10-mm-aperture adaptive lens, Robert Batchko, Holochip Corp. (United States).

\section{Wednesday 25 January}

\section{Room: Grand Peninsula \\ Ballroom A . . . . . . . . . . . . . . Wed. 8:20 to 9:30 am \\ Plenary Session and Conference Award Presentations}

8:25 am: More Words and Bigger Pictures, David A. Forsyth, Univ. of Illinois at Urbana-Champaign (United States) 


\section{Imaging and Printing in a Web 2.0 World III}

Conference Chairs: Qian Lin, Hewlett-Packard Labs. (United States); Jan P. Allebach, Purdue Univ. (United States); Zhigang Fan, Xerox Corp. (United States)

Program Committee: Patricia Albanese, Rochester Institute of Technology (United States); Kathrin Berkner, Ricoh Innovations, Inc. (United States); Susanne Christine Johanna Boll, Univ. of Oldenburg (Germany); Reiner Fageth, CeWe Color AG \& Co. OHG (Germany); Xiaofan Lin, Vobile, Inc. (United States); Jerry Liu, Hewlett-Packard Labs. (United States); Jiebo Luo, Eastman Kodak Co. (United States); Robert J. Rolleston, Xerox Corp. (United States); David N. Slatter, Hewlett-Packard Labs. (United Kingdom); Yonghong Tian, Peking Univ. (China); Shengjin Wang, Tsinghua Univ. (China); Wiley H. Wang, Shutterfly (United States)

Tuesday 24 January

\section{Room: Grand Peninsula Ballroom A . . . . . . . . . . . . . Tues. 8:20 to 9:30 am Plenary Session and Society Award Presentations 8:25 am: Computational Photography, William T. Freeman, Massachusetts Institute of Technology (United States)}

\section{Wednesday 25 January}

\section{Room: Grand Peninsula}

Ballroom A . . . . . . . . . . . . . . . .Wed. 8:20 to 9:30 am

\section{Plenary Session and Conference Award Presentations}

8:25 am: More Words and Bigger Pictures, David A. Forsyth, Univ. of Illinois at Urbana-Champaign (United States)

\section{SESSION 1}

Room: Bayside Room A. . . . . . . . . . . Wed. 9:30 to 10:30 am

\section{Industrial Applications I}

Session Chair: Qian Lin, Hewlett-Packard Labs. (United States) 9:30 am: Organizing visual moments for sharing and reflections: VisR (Invited Paper), Ramesh C. Jain, Univ. of California, Irvine (United States) . . . . . . . . . [8302-01] 10:00 am: The role of digital presses, Web 2.0, and mobile in enabling the internet of things (Invited Paper), Tony F. Rodriguez, Digimarc Corp. (United States). . . . . . . . . . . . . . . . . . . . . . . . Coffee Break ...................... 10:30 to 11:00 am

\section{SESSION 2}

Room: Bayside Room A. . . . . . . . Wed. 11:00 am to 12:30 pm

\section{Industrial Applications II}

Session Chair: Qian Lin, Hewlett-Packard Labs. (United States) 11:00 am: Mobile image processing for fashion marketplace (Invited Paper), Manish Chandra, Gautam Golwala, Chetan Pungaliya, Poshmark, Inc. (United States) . . . . . . . . . . . . . . . . . . [8302-03] 11:30 am: Mobile capture: the end of the photocopier? (Invited Paper), Michael J. Gormish, Ricoh Innovations, Inc. (United States) . . . [8302-04] 12:00 pm: From scenes to screens: connected digital imaging (Invited Paper), Ziv Gillat, Eye-Fi (United States) . . . . . . . . . . . . . . . . [8302-05] Lunch Break $12: 30$ to $2: 00 \mathrm{pm}$

\section{SESSION 3}

Room: Bayside Room A. . . . . . . . . . . . Wed. 2:00 to 3:00 pm

Web Printing and Analysis

Session Chair: Qian Lin, Hewlett-Packard Labs. (United States)

2:00 pm: Text documents as social networks, Helen Balinsky, HewlettPackard Labs. (United Kingdom); Alexander Balinsky, Cardiff Univ. (United Kingdom); Steven J. Simske, Hewlett-Packard Co. (United

States) . . . . . . . . . . .

2:20 pm: HP2.ME URL shorten service, Hua Zhang, Wei Xiao Wu, Yu Zhang, Can Zheng, Hewlett-Packard China Co., Ltd. (China); Qian Lin, Jerry Liu, Hewlett-Packard Labs. (United States) . . . . . . . . . . .8302-08]

2:40 pm: HP Smartprint, Hua Zhang, Zhen Liu, Yue Yuan, Guo Jia Liao, Hewlett-Packard China Co., Ltd. (China); Qian Lin, Jerry Liu, HewlettPackard Labs. (United States). . . . . . . . . . . . . . . . . . . [8302-09] Coffee Break .................... 3:00 to $3: 40 \mathrm{pm}$

SESSION 4

Room: Bayside Room A. . . . . . . . . . . . . Wed. 3:40 to 5:00 pm

\section{Online Photo Services}

Session Chair: Qian Lin, Hewlett-Packard Labs. (United States)

3:40 pm: Kind of images in printed photo books, Reiner Fageth, Peter Schuetz, Thomas Wagner, CeWe Color AG \& Co. OHG

(Germany) ............................. [8302-10]

4:00 pm: SmartFit: automatic photo fitting for variable data printing, Zachi Karni, Amir Gaash, Hewlett-Packard Labs. Israel Ltd.

(Israel) . . . . . . . . . . . . . . . . . . . . . . . [8302-11]

4:20 pm: All new custom path photo book creation, Wiley $\mathrm{H}$. Wang, Russ Muzzolini, Shutterfly (United States) . . . . . . . . . . . . [8302-12]

4:40 pm: Investigation of the role of aesthetics in differentiating between photographs taken by amateur and professional photographers, Shao-Fu Xue, Purdue Univ. (United States); Qian Lin, Daniel Tretter, Seungyon Lee, Hewlett-Packard Labs. (United States); Zygmunt Pizlo, Jan P. Allebach, Purdue Univ. (United States) . . . [8302-13] 


\section{Thursday 26 January SESSION 5}

\section{Room: Bayside Room A. . . . . . . . . . Thurs. 8:20 to 10:10 am}

\section{Social Media and Mobile Document Applications}

Session Chair: Qian Lin, Hewlett-Packard Labs. (United States)

8:20 am: Learning from user data in Facebook (Invited Paper), Jun Yang, Facebook Inc. (United States) . . . . . . . . . . . . . . . . . . [8302-14]

8:50 am: Measuring engagement effectiveness in social media: a timesensitive methodology, Tong Sun, Lei Li, Wei Peng, Xerox Corp. (United States) . . . . . . . . . . . . . . . . . . . . . . [8302-15]

9:10 am: Building a scalable storage for images on a social network, Jaime Medrano Navarro, Tuenti Technologies (Spain) . . . . . . . .[8302-16]

9:30 am: Color correction of smartphone photos with prior knowledge, Yonghui Zhao, Shen-ge Wang, Xerox Corp. (United States); Jun Jiang, Rochester Institute of Technology (United States) . . . . . . . . . [8302-17] 9:50 am: XML data compression in web publishing, Ruiheng Qiu, Wei $\mathrm{Hu}$, Zhi Tang, Xiaoqing Lu, Peking Univ. (China); Lei Zhang, Peking Univ. Founder Group Corp. (China) . . . . . . . . . . . . . . . . . . . [8302-18]

Coffee Break $10: 10$ to $10: 40 \mathrm{am}$

\section{SESSION 6}

Room: Bayside Room A. . . . . . . Thurs. 10:40 am to 12:20 pm

\section{Layout Analysis and Creation}

Session Chair: Qian Lin, Hewlett-Packard Labs. (United States)

10:40 am: Layout hierarchies for interactive design reuse, Darryl S. Greig, Andrew A. Hunter, David N. Slatter, Hewlett-Packard Labs. (United Kingdom) . . . . . . . . . . . . . . . . . . . . . . . . . . . [8302-19] 11:00 am: Automatic page composition with combined cropping and layout technologies, Andrew A. Hunter, David N. Slatter, Darryl S. Greig, Hewlett-Packard Labs. (United Kingdom). . . . . . . . . . . . . [8302-20]

11:20 am: Psychophysical evaluation of document visual similarity, Aziza Satkhozhina, Ildus Ahmadullin, Purdue Univ. (United States); Seungyon Lee, Hewlett-Packard Co. (United States); Zygmunt Pizlo, Jan P. Allebach, Purdue Univ. (United States) . . . . . . . . . . . . . [8302-21]

11:40 am: Similarity pyramid: browsing a document database with respect to visual similarity, Ildus Ahmadullin, Jan P. Allebach, Purdue Univ. (United States) . . . . . . . . . . . . . . . . . . . . [8302-22]

12:00 pm: Automatic design of magazine covers, Ali Jahanian, Purdue Univ. (United States) and Hewlett-Packard Labs. (United States); Jan P. Allebach, Purdue Univ. (United States); Qian Lin, Jerry Liu, Niranjan Damera-Venkata, Eamonn O'Brien-Strain, Seungyon Lee, Jian Fan, Daniel Tretter, Hewlett-Packard Labs. (United States) ... . . . . . . . . [8302-23] Lunch Break . . . . . . . . . . . . . . . . 12:20 to 2:00 pm

\section{SESSION 7}

Room: Bayside Room A. . . . . . . . . . . Thurs. 2:00 to 5:00 pm

\section{Content Understanding}

Session Chair: Qian Lin, Hewlett-Packard Labs. (United States)

2:00 pm: Sentiment analysis and live customer intelligence from social channels (Invited Paper), Meichun Hsu, Hewlett-Packard Labs. (United States) . . . . . . . . . . [8302-24]

2:30 pm: Automatic content recognition for the next-generation TV experience, Xiaofan Lin, Vobile, Inc. (United States) . . . . . . . . [8302-25]

2:50 pm: Marketing image categorization using hybrid human-machine combinations, Nathan Gnanasambandam, Xerox Corp. (United States) . . . . . . . . . . . . . . . . . . . . . . . . . .

3:10 pm: Practical experiences in analog to digital content transformation, Prakash D. Reddy, Hewlett-Packard Labs. (United States) . . . . . . . . . . . . . . . . . . . . . . . . . .8302-27] Coffee Break . . . . . . . . . . . . . . . . . . . 3:30 to 4:00 pm

4:00 pm: Global image analysis to determine suitability for text-based image personalization, Hengzhou Ding, Raja Bala, Zhigang Fan, Xerox Corp. (United States); Charles A. Bouman, Jan P. Allebach, Purdue Univ. (United States) . . . . . . . . . . . . . . . . . . . . [8302-28]

4:20 pm: Chrominance watermark embed using a full-color visibility model, Alastair M. Reed, Digimarc Corp. (United States) . . . . . [8302-29]

4:40 pm: Document image orientation based on both text and image, Yuejia Sun, Changsong Liu, Xiaoqing Ding, Tsinghua Univ. (China);

Zhigang Fan, Francis Tse, Xerox Corp. (United States) . . . . . . [8302-30] 


\section{Media Watermarking, Security, and Forensics 2012}

Conference Chairs: Nasir D. Memon, Polytechnic Institute of NYU (United States); Adnan M. Alattar, Digimarc Corp. (United States); Edward J. Delp III, Purdue Univ. (United States)

Program Committee: Mauro Barni, Univ. degli Studi di Siena (Italy); Jeffrey A. Bloom, Dialogic Media Labs (United States); Scott A. Craver, Binghamton Univ. (United States); Jana Dittmann, Otto-von-Guericke-Univ. Magdeburg (Germany); Gwenaël Doërr, Technicolor S.A. (France); Jessica Fridrich, Binghamton Univ. (United States); Jiwu Huang, Sun Yat-Sen Univ. (China); Ton Kalker, Hewlett-Packard Co. (United States); Andrew D. Ker, Univ. of Oxford (United Kingdom); Alex Chichung Kot, Nanyang Technological Univ. (Singapore); Bangalore Manjunath, Univ. of California, Santa Barbara (United States); Regunathan Radhakrishnan, Dolby Labs., Inc. (United States); Husrev Taha Sencar, TOBB Ekonomi ve Teknoloji Üniv. (Turkey); Gaurav Sharma, Univ. of Rochester (United States); Claus Vielhauer, Otto-von-Guericke-Univ. Magdeburg (Germany); Svyatoslav V. Voloshynovskiy, Univ. of Geneva (Switzerland); Min Wu, Univ. of Maryland, College Park (United States); Chang D. Yoo, KAIST (Korea, Republic of)

\section{Monday 23 January}

Room: Sandpebble Room C. . . . Mon. 8:20 to 9:20 am
Keynote Presentation I
Session Chair: Adnan M. Alattar, Digimarc Corp. (United States)

8:20 am: Watermarking and fingerprinting for audience measurement (Presentation Only), Arun Ramaswamy, Nielsen Media Research (United States). . . . . . . . . . . . . . . . . . . [8303-28]

\section{SESSION 1}

Room: Sandpebble Room C. . . . . . . . Mon. 9:20 to 10:10 am

\section{Security}

Session Chair: Scott A. Craver, Binghamton Univ. (United States) 9:20 am: Security threat to media security applications based on scale-space feature extraction, Chao-Yong Hsu, Academia Sinica (Taiwan); Chun-Shien Lu, Institute of Information Science (Taiwan); SooChang Pei, National Taiwan Univ. (Taiwan). . . . . . . . . . . [8303-01] 9:45 am: Robust image obfuscation for privacy protection in Web 2.0 applications, Andreas Poller, Martin Steinebach, Huajian Liu, FraunhoferInstitut für Sichere Informations-Technologie (Germany) . . . . . . [8303-02] Coffee Break ...................... 10:10 to $10: 40$ am

\section{SESSION 2}

Room: Sandpebble Room C. . . . . Mon. 10:40 am to 12:20 pm

\section{Watermark}

Session Chair: Gaurav Sharma, Univ. of Rochester (United States) 10:40 am: Improved Fourier domain template and patchwork embedding using spatial masking, Huajian Liu, Martin Steinebach, Fraunhofer-Institut für Sichere Informations-Technologie (Germany) . . . . . . . . . . . . . . . . . . . . . . . [8303-03]

11:05 am: Ranking search for probabilistic fingerprinting codes, Marcel Schäfer, Waldemar Berchtold, Martin Steinebach, Fraunhofer-Institut für Sichere Informations-Technologie (Germany). . . . . . . . . . [8303-04]

11:30 am: Stereoscopic watermarking by horizontal noise mean shifting, Ji-Won Lee, Hee-Dong Kim, Hak-Yeol Choi, Sung-Hee Choi, Heung-Kyu Lee, KAIST (Korea, Republic of). . . . . . . . . . . [8303-05] 11:55 am: Reversible q-ry watermarking with controllable prediction error and location map-free capability, Tatiana Efimushkina, Karen O. Egiazarian, Tampere Univ. of Technology (Finland) . . . . . . . . [8303-06] Lunch Break .................... 12:20 to 2:00 pm
Room: Sandpebble Room C. . . . . . . . . Mon. 2:00 to 2:15 pm

Video 1: Dialogic SESSION 3

Room: Sandpebble Room C. . . . . . . . Mon. 2:15 to 3:30 pm

\section{Steganalysis I}

Session Chair: Jessica Fridrich, Binghamton Univ. (United States) 2:15 pm: Optimizing pixel predictors for steganalysis, Vojtech Holub, Jessica Fridrich, Binghamton Univ. (United States) . . . . . . . . [8303-07] 2:40 pm: Steganalysis of JPEG images using rich models, Jan Kodovsky, Jessica Fridrich, Binghamton Univ. (United States) . . [8303-08] 3:05 pm: Co-occurrence steganalysis in high dimension, Tomas Pevny Czech Technical Univ. in Prague (Czech Republic) . . . . . . . . [8303-09]

Coffee Break . . . . . . . . . . . . . . . . . 3:30 to 4:00 pm

\section{SESSION 4}

Room: Sandpebble Room C. . . . . . . . Mon. 4:00 to 5:00 pm

\section{Guest Speaker 1}

Session Chair: Adnan M. Alattar, Digimarc Corp. (United States) 4:00 pm: Privacy and the social network (Presentation Only), Jessica Staddon, Google Inc. (United States) . . . . . . . . . . . . . . . .88303-18]

\section{Tuesday 24 January}

Room: Grand Peninsula

Ballroom A . . . . . . . . . . . . . . . Tues. 8:20 to 9:30 am

\section{Plenary Session and Society Award Presentations}

8:25 am: Computational Photography, William T. Freeman, Massachusetts Institute of Technology (United States)

Room: Sandpebble Room C. . . . Tues. 9:30 to 10:30 am Keynote Presentation II

Session Chair: Adnan M. Alattar, Digimarc Corp. (United States)

9:30 am: The landscape of mobile payments (Presentation Only), Darko Kirovski, Microsoft Research Cambridge (United Kingdom) . . . . . . . . . . . . . . . . . . $\ldots \ldots$ [8303-29]

Coffee Break ......................10:30 to 10:50 am 


\section{Conference 8303}

\section{SESSION 5}

Room: Sandpebble Room C. . . . Tues. 10:50 am to 12:30 pm

\section{Forensics}

Session Chair: Gwenaël Doërr, Technicolor S.A. (France)

10:50 am: Source camcorder identification with cropped and scaled videos, Dai-Kyung Hyun, Seung-Jin Ryu, Min-Jeong Lee, Jun-Hee Lee, Hae-Yeoun Lee, Heung-Kyu Lee, KAIST (Korea, Republic of) . . [8303-11]

11:15 am: Digital image forensics for photographic copying, Yanmei Fang, Jing Yin, Sun Yat-Sen Univ. (China) . . . . . . . . . . [8303-12]

11:40 am: Forensic audio watermark detection, Martin Steinebach, Sascha Zmudzinski, Fraunhofer-Institut für Sichere Informations-

Technologie (Germany) . . . . . . . . . . . . . . . . . . [8303-13]

12:05 pm: Sensor-fingerprint based identification of images corrected for lens distortion, Miroslav Goljan, Jessica Fridrich, Binghamton Univ. (United States). . . . . . . . . . . . . . . . . . . . . . . [8303-14] Lunch Break ...................... 12:30 to 2:00 pm

Room: Sandpebble Room C . . . . . . . . Tues. 2:00 to 2:08 pm

\section{Video 2: Civolution}

Room: Sandpebble Room C . ........ Tues. 2:08 to 2:15 pm

\section{Video 3: Night Vision Lab}

\section{SESSION 6}

Room: Sandpebble Room C. Tues. 2:15 to $3: 30 \mathrm{pm}$

\section{Authentication}

Session Chair: Ton Kalker, Hewlett-Packard Co. (United States)

2:15 pm: Digital audio authentication by robust feature embedding, Sascha Zmudzinski, Badar Munir, Martin Steinebach, Fraunhofer-Institut für Sichere Informations-Technologie (Germany) . . . . . . . . . [8303-15]

2:40 pm: High-resolution printed amino acid traces: a first-feature extraction approach for fingerprint forgery detection, Mario Hildebrandt, Stefan Kiltz, Jana Dittmann, Otto-von-Guericke-Univ. Magdeburg (Germany) . . . . . . . . . . . . . . . . . [8303-16] 3:05 pm: Image forgery detection by means of no-reference quality metrics, Federica Battisti, Marco Carli, Alessandro Neri, Univ. degli Studi di Roma Tre (Italy) . . . . . . . . . . . . . . . . . . . . . . . [8303-17] Coffee Break $3: 30$ to $4: 00 \mathrm{pm}$

\section{SESSION 7}

Room: Sandpebble Room C.........Tues. 4:00 to 5:00 pm

\section{Guest Speaker 2}

Session Chair: Nasir D. Memon, Polytechnic Institute of NYU (United States)

4:00 pm: Advancing technology: bane and boon for banknotes (Presentation Only), Sara E. Church, Board of Governors of the Federal Reserve System (United States) . . . . . . . . . . . . . . . . [8303-10]
Wednesday 25 January

Room: Grand Peninsula

Ballroom A . . . . . . . . . . . . . . Wed. 8:20 to 9:30 am

\section{Plenary Session and Conference Award Presentations}

8:25 am: More Words and Bigger Pictures, David A. Forsyth, Univ. of Illinois at Urbana-Champaign (United States)

\section{SESSION 8}

Room: Sandpebble Room C........ Wed. 9:30 to 10:20 am

\section{Steganalysis II}

Session Chair: Andrew D. Ker, Univ. of Oxford (United Kingdom) 9:30 am: Going from small to large data in steganalysis, Ivans Lubenko, Andrew D. Ker, Univ. of Oxford (United Kingdom) . . . . . . . . [8303-19]

9:55 am: Identifying a steganographer in realistic and heterogeneous data sets, Andrew D. Ker, Univ. of Oxford (United Kingdom); Tomas Pevny, Czech Technical Univ. in Prague (Czech Republic) . . . . [8303-20]

Coffee Break . . . . . . . . . . . . . . . . . . 10:20 to 10:50 am

\section{SESSION 9}

Room: Sandpebble Room C.....Wed. 10:50 am to 12:30 pm

\section{Fingerprinting}

Session Chair: Regunathan Radhakrishnan, Dolby Labs., Inc. (United States)

10:50 am: Asymmetric robust quantum image hashing, Martin

Steinebach, Huajian Liu, Fraunhofer-Institut für Sichere Informations-

Technologie (Germany) . . . . . . . . . . . . . . . . . . . . [8303-21]

11:15 am: Fast detection of Tardos codes with Boneh-Shaw types, Mathieu Desoubeaux, Gaëtan Le Guelvouit, France Telecom R\&D (France); William Puech, Lab. d'Informatique de Robotique et de Microelectronique de Montpellier (France) . . . . . . . . . . . . . . . . . . [8303-22]

11:40 am: Locatability of modified pixels in steganographic images, Tu-Thach Quach, Sandia National Labs. (United States) . . . . . . [8303-23]

12:05 pm: Forensic characterization of camcorded movies: digital cinema versus celluloid film prints, Xavier Rolland-Neviere, Bertrand Chupeau, Gwenaël Doërr, Laurent Blondé, Technicolor S.A.

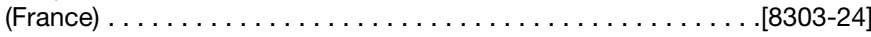

Lunch Break ....................... 12:30 to 2:00 pm

Room: Sandpebble Room C ......... Wed. 2:00 to 2:15 pm

\section{Video 4: MarkAny \\ SESSION 10}

Room: Sandpebble Room C......... Wed. 2:15 to 3:30 pm

\section{Miscellaneous}

Session Chair: Jeffrey A. Bloom, Dialogic Media Labs (United States) 2:15 pm: Extending a context model for microphone forensics, Christian Krätzer, Kun Qian, Jana Dittmann, Otto-von-Guericke-Univ. Magdeburg (Germany) . . . . . . . . . . . . . . . . . [8303-25]

2:40 pm: Simulating large-scale acoustic path benchmarking, Michael Arnold, Peter Baum, Manuel Alonso, Ulrich Gries, Deutsche Thomson oHG (Germany); Gwenaël Doërr, Technicolor S.A. (France) . . . . . . . [8303-26] 3:05 pm: Noise removing in encrypted color image by statistical analysis, Naveed Islam, William Puech, Lab. d'Informatique de Robotique et de Microelectronique de Montpellier (France). . . . . . . . . . . [8303-27] 


\section{Multimedia on Mobile Devices 2012}

Conference Chairs: Reiner Creutzburg, Fachhochschule Brandenburg (Germany); David Akopian, The Univ. of Texas at San Antonio (United States)

Program Committee: Sos S. Agaian, The Univ. of Texas at San Antonio (United States); Nina T. Bhatti, Hewlett-Packard Labs. (United States); Faouzi Alaya Cheikh, Gjøvik Univ. College (Norway); Linda Breitlauch, Mediadesign Hochschule Düsseldorf (Germany); Chang Wen Chen, Univ. at Buffalo (United States); Philip C. L. Chen, The Univ. of Texas at San Antonio (United States); Kenneth J. Crisler, Motorola, Inc. (United States); David Scott Doermann, Univ. of Maryland, College Park (United States); Elizabeth Dykstra-Erickson, Kinoma (United States); Stefan Edlich, Technische Fachhochschule Berlin (Germany); Atanas P. Gotchev, Tampere Univ. of Technology (Finland); Lajos Hanzo, Univ. of Southampton (United Kingdom); Zhihai He, Univ. of Missouri-Columbia (United States); Hendrik O. Knoche, Univ. College London (United Kingdom); Catalin Lacatus, Telcordia Technologies, Inc. (United States); Xin Li, West Virginia Univ. (United States); Manzur M. Murshed, Monash Univ. (Australia); Sethuraman Panchanathan, Arizona State Univ. (United States); Kari A. Pulli, Nokia Research Ctr. (United States); Matthias Rauterberg, Technische Univ. Eindhoven (Netherlands); Phillip A. Regalia, TELECOM \& Management SudParis (France); René Rosenbaum, Univ. of California, Davis (United States); Phanikrishna K. Sagiraju, The Univ. of Texas at San Antonio (United States); Abhay Samant, National Instruments (India); Thomas Schwotzer, FHTW (Germany); Olli Johannes Silvén, Univ. of Oulu (Finland); Jarmo Henrik Takala, Tampere Univ. of Technology (Finland); Haitao Zheng, Univ. of California, Santa Barbara (United States)

\section{Tuesday 24 January}

Room: Grand Peninsula
Ballroom A ............. Tues. 8:20 to 9:30 am

\section{Plenary Session and Society Award Presentations}

8:25 am: Computational Photography, William T. Freeman, Massachusetts Institute of Technology (United States)

\section{Interactive Paper and Symposium Demonstration Session}

Room: Grand Peninsula Ballroom E .. Tues. 5:30 to 8:00 pm

\section{Demonstrations} 5:30 to $8: 00 \mathrm{pm}$

A symposium-wide demonstration session will be open to attendees 5:30 to 8:00 pm Tuesday evening. Demonstrators will provide interactive, hands-on demonstrations of a wide-range of products related to Electronic Imaging.

\section{Posters} 5:30 to $7: 00 \mathrm{pm}$

Interactive papers will be placed on display after 10:30 am on Tuesday. An interactive paper session, with authors present at their papers, will be held Tuesday evening, 5:30 to 7:00 pm.

Low-complexity bit-plane entropy coding for 3D DWT-based video compression, Evgeny A. Belyaev, Karen O. Egiazarian, Moncef Gabbouj, Tampere Univ. of Technology (Finland). . . . . . . . . . . . . . [8304A-16]

Bidirectional probabilistic hyper-graph matching method using Bayes theorem, Wanhyun Cho, Sunworl Kim, Sangcheol Park, Chonnam National Univ. (Korea, Republic of) . . . . . . . . . . . . . . . [8304A-18]

SeamCrop for image retargeting, Johannes Kiess, Benjamin Guthier, Stephan Kopf, Wolfgang Effelsberg, Univ. Mannheim (Germany)[8304A-19]

Collecting fingerprints for recognition using mobile phone cameras, Bian Yang, Xue Li, Christoph Busch, Gjøvik Univ. College (Norway) . . . . . . . . . . . . . . . . . . . . . . . . . . [8304A-20]

Overview of potential forensic analysis of an Android smartphone, Reiner Creutzburg, Knut Kröger, Stefan Sack, Fachhochschule Brandenburg (Germany) . . . . . . . . . . . . . . . . . . . [8304A-21]
Forensics of geodata collected by Apple iOS and Google Android in mobile devices, Knut Kröger, Reiner Creutzburg, Fachhochschule Brandenburg (Germany) . . . . . . . . . . . . . . . . . . . [8304A-22]

Template-based mobile platform image processing training, David Akopian, Santosh Chandana Golagani, Moosa Esfahanian, The Univ. of Texas at San Antonio (United States) . . . . . . . . . . . . . . [8304A-23]

Combining associative computing and distributed arithmetic methods for efficient implementation of multiple inner products, David

Guevorkian, Tampere Univ. of Technology (Finland); Petri Liuha, Timo YliPietilä, Nokia Research Ctr. (Finland); Karen O. Egiazarian, Tampere Univ. of Technology (Finland) . . . . . . . . . . . . . . . . . [8304A-24]

Presentation of forensically interesting Microsoft XBox 360 console features, Silas Luttenberger, Knut Kröger, Reiner Creutzburg, Fachhochschule Brandenburg (Germany). . . . . . . . . . . . . [8304A-25]

Presentation of forensically interesting Sony Playstation 3 console features, Knut Kröger, Gunnar Daugs, Reiner Creutzburg, Fachhochschule Brandenburg (Germany) . . . . . . . . . . . . . . . . . . . . [8304A-26]

A neural network-based approach for recognition of engraved and embossed labels on metallic parts, Amir Shirkhodaie, Vinod K. Bandaru, Tennessee State Univ. (United States) . . . . . . . . . . . . . . [8304A-28]

A fuzzy-logic approach for metallic parts surface defects characterization and shape classification, Amir Shirkhodaie, Fatemeh Vaziribozorg, Tennessee State Univ. (United States) . . . . . . [8304A-30]

Sudoku substitution-permutation image cipher, Yue Wu, Tufts Univ. (United States); Sos Agaian, The Univ. of Texas at San Antonio (United States); Joseph P. Noonan, Tufts Univ. (United States) . . . . . [8304A-31] 


\section{Wednesday 25 January}

\section{Room: Grand Peninsula \\ Ballroom A . . . . . . . . . . . . . . . . Wed. 8:20 to 9:30 am \\ Plenary Session and Conference Award Presentations}

8:25 am: More Words and Bigger Pictures, David A. Forsyth, Univ. of Illinois at Urbana-Champaign (United States)

\section{SESSION 1}

Room: Sandpebble Room B. . . . . . . . . Wed. 9:30 to 10:40 am

\section{Emerging Mobile Applications}

Session Chairs: Reiner Creutzburg, Fachhochschule Brandenburg (Germany); David Akopian, The Univ. of Texas at San Antonio (United States)

9:30 am: Location-aware gang graffiti acquisition and browsing on a mobile device, Albert Parra Pozo, Mireille Boutin, Edward J. Delp III, Purdue Univ. (United States). . . . . . . . . . . . . . . . [8304A-01]

9:50 am: Dietary intake assessment using integrated sensors and software, Junqing Shang, Eric Johnson, Kishore Sundara-Rajan, Ankur Teredesai, Univ. of Washington (United States); Alan Kristal, Fred Hutchinson Cancer Research Ctr. (United States); Alexander V. Mamishev, Univ. of Washington (United States) . . . . . . . . . . . . . [8304A-02]

10:10 am: FCam for multiple cameras (Invited Paper), Alejandro Troccoli, NVIDIA Corp. (United States); Changyin Zhou, Columbia Univ. (United States); Kari Pulli, NVIDIA Corp. (United States) . . . . . . . . . [8304A-03] Coffee Break .................... 10:40 to $11: 00$ am

\section{SESSION 2}

\section{Room: Sandpebble Room B..... Wed. 11:00 am to 12:30 pm}

\section{Processing and Displays for Mobile Applications}

Session Chairs: Atanas P. Gotchev, Tampere Univ. of Technology (Finland); Reiner Creutzburg, Fachhochschule Brandenburg (Germany)

11:00 am: Biosensing mobile display principle for healthcare, Wallen Mphepö, iVorex AB, Borlänge (Sweden) and Beijing Normal Univ. (China) . . . . . . . . . . . . . . . . . . . . . . 11:20 am: Continuously adjustable Pulfrich spectacles for mobile devices, Kenneth M. Jacobs, Binghamton Univ. (United States); Ronald S. Karpf, Consultant (United States) . . . . . . . . . . . . . . [8304A-05]

11:40 am: Parameters of the human 3D gaze while observing portable autostereoscopic display: a model and measurement results, Atanas R. Boev, Marianne Hanhela, Atanas P. Gotchev, Timo Utirainen, Satu Jumisko-Pyykkö, Tampere Univ. of Technology (Finland); Miska Hannuksela, Nokia Research Ctr. (Finland). . . . . . . . . . . [8304A-06] 12:00 pm: Deblocking of mobile stereo video (Invited Paper), Atanas $P$. Gotchev, Lucio Azzari, Karen O. Egiazarian, Tampere Univ. of Technology (Finland) ............................ [8304A-07] Lunch Break ................... 12:30 to 2:00 pm

\section{SESSION 3}

Room: Sandpebble Room B Wed. 2:00 to 3:20 pm

\section{Security, Safety, and Location Technologies}

Session Chairs: David Akopian, The Univ. of Texas at San Antonio (United States); Namho Hur, Electronics and Telecommunications Research Institute (Korea, Republic of)

2:00 pm: SUPL support for mobile devices, Jayanthi M. Narisetty, Arpine Soghoyan, Mohanapriya C. Sundaramurthy, David Akopian, The Univ. of Texas at San Antonio (United States) . . . . . . . . . . . . [8304A-08]

2:20 pm: Measuring ionizing radiation with a mobile device, Matthias Michelsburg, Thomas Fehrenbach, Fernando Puente León, Karlsruher Institut für Technologie (Germany) . . . . . . . . . . . . . [8304A-09]

2:40 pm: Design and evaluation of security multimedia warnings for children's smart phones, Jana Fruth, Sven Tuchscheerer, Otto-vonGuericke-Univ. Magdeburg (Germany) . . . . . . . . . . [8304A-10]

3:00 pm: Using Wi-Fi hotspots as an intrusion vector into corporate networks, Maximilian Scharsich, Friedrich Holl, Fachhochschule

Brandenburg (Germany) . . . . . . . . . . . . . . . [8304A-11] Coffee Break .................... 3:20 to $4: 00$ pm

\section{SESSION 4}

Room: Sandpebble Room B........ Wed. 4:00 to 5:50 pm

\section{Algorithms for Mobile Computing}

Session Chairs: Wanhyun Cho, Chonnam National Univ. (Korea, Republic of); David Akopian, The Univ. of Texas at San Antonio (United States)

4:00 pm: Frame rate up-conversion assisted with camera auto exposure information, Liang Liang, Bob Hung, Gokce Dane, QUALCOMM MEMS Technologies, Inc. (United States). . . . . . . . . . . [8304A-12] 4:20 pm: Fused Fibonacci-like (p,q) sequences with compression and barcoding applications, Sarkis Agaian, Jose Garcia, Salahodeen S. Abdul-Kafi, John T. Gill III, Stanford Univ. (United States) ... . [8304A-13]

4:40 pm: White synthesis with user input for color balancing on mobile camera systems, Satyam Srivastava, Chang Xu, Edward J. Delp III, Purdue Univ. (United States) . . . . . . . . . . . . . . . [8304A-14]

5:00 pm: Detection and segmentation of symmetric shapes on a mobile device with applications to automatic sign interpretation (Invited Paper), Andrew W. Haddad, Mireille Boutin, Edward J. Delp III, Purdue Univ. (United States) . . . . . . . . . . . . . . . [8304A-15]

5:30 pm: Raster image adaptation for mobile devices using profiles, René Rosenbaum, Bernd Hamann, Univ. of California, Davis (United States) . . . . . . . . . . . 


\section{Multimedia Content Access: Algorithms and Systems VI}

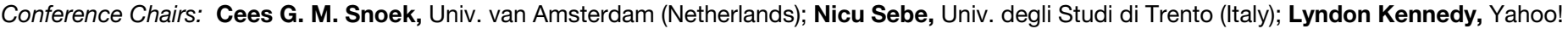
Labs (United States)

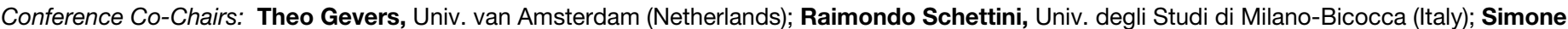
Santini, Univ. Autónoma de Madrid (Spain)

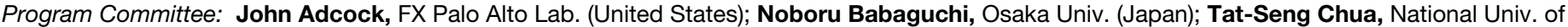

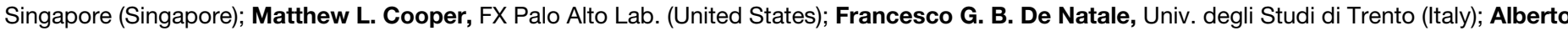

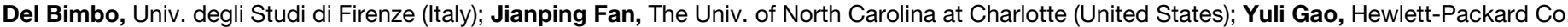

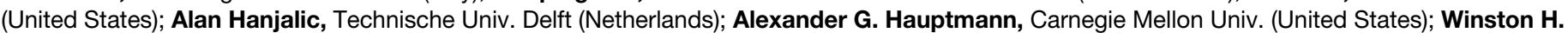

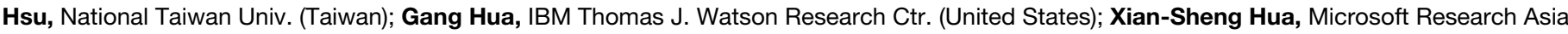

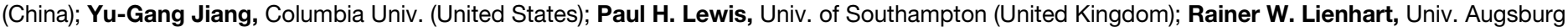

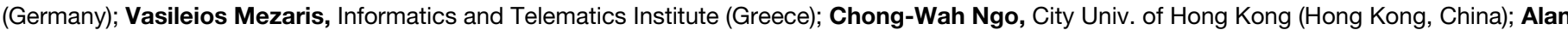

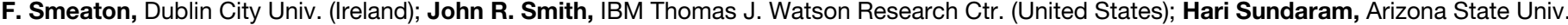

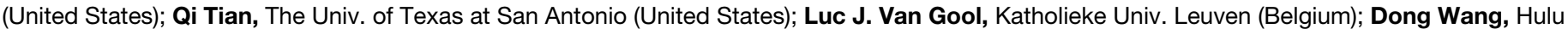

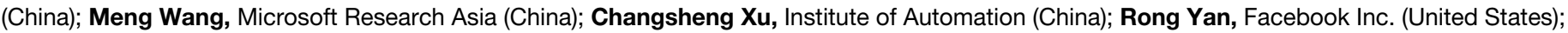
Jun Yang, Facebook Inc. (United States)

\section{Monday 23 January SESSION 5}

Room: Sandpebble Room A. . . . . . . Mon. 8:50 to 10:10 am

\section{Multimedia Content Classification}

Session Chair: Cees G. M. Snoek, Univ. van Amsterdam (Netherlands) 8:50 am: Searching through photographic databases with QuickLook, Claudio Cusano, Gianluigi Ciocca, Raimondo Schettini, Univ. degli Studi d Milano-Bicocca (Italy); Simone Santini, Univ. Autónoma de Madrid (Spain); Andrea De Polo, Francesca Tavanti, Fratelli Alinari (Italy). . . . . [8304B-32]

9:10 am: Large-scale classification of traffic signs under real-world conditions, Lykele Hazelhoff, Ivo M. Creusen, CycloMedia Technology B.V. (Netherlands); Dennis Van de Wouw, Peter H. N. de With, Technische Univ. Eindhoven (Netherlands) . . . . . . . . . . . . . . [8304B-34]

9:30 am: Human action recognition using a Markovian conditional exponential model, Atulya Velivelli, Alexander G. Hauptmann, Carnegie Mellon Univ. (United States) . . . . . . . . . . . . . . . . . . . . . [8304B-35]

9:50 am: Human activity discovery and recognition based on state transitions modeling in persistent surveillance systems, Amir Shirkhodaie, Vinayak Elangovan, Tennessee State Univ. (United

States) . . . . . . . . . . . . . . . . . . . . . . . .

Coffee Break ...................... 10:10 to $10: 50 \mathrm{am}$

\section{Room: Sandpebble Room A. . . Mon. 10:50 to 11:50 am Keynote Presentation I \\ Session Chair: Lyndon S. Kennedy, Yahoo! Inc. (United States)}

10:50 am: Learning to recognize objects despite novel environments and sensors, Trevor Darrell, Univ. of California, Berkeley (United States). [8304B-45]

\section{SESSION 6}

Room: Sandpebble Room A. . . . . Mon. 11:50 am to 12:30 pm

\section{Semantic Multimedia Access}

Session Chair: Nicu Sebe, Univ. degli Studi di Trento (Italy)

11:50 am: Swimmer detection and pose estimation for continuous stroke-rate determination, Dan Zecha, Thomas Greif, Rainer Lienhart, Univ. Augsburg (Germany) . . . . . . . . . . . . . . . . . . [8304B-37]

12:10 pm: Multi-view face detection based on position estimation on multi-camera surveillance system, Ching-Chun Huang, National Kaohsiung Univ. of Applied Sciences (Taiwan); Jay Chou, Jia-Hou Syu, Sheng-Jyh Wang, National Chiao Tung Univ. (Taiwan). . . . . . [8304B-38] Lunch Break ... $12: 30$ to $2: 00 \mathrm{pm}$

Room: Sandpebble Room A . . . . . Mon. 2:00 to 3:00 pm Keynote Presentation II

Session Chair: Cees G. M. Snoek, Univ. van Amsterdam (Netherlands)

2:00 pm: Social media mining at the billion scale: insights, method and practice for analyzing social media in Facebook, Rong Yan, Facebook Inc. (United States). . . . . . . . . . . . . . . . [8304B-46]

\section{SESSION 7}

Room: Sandpebble Room A . Mon. 3:00 to 5:00 pm

\section{Bay Area Multimedia}

Session Chair: Lyndon S. Kennedy, Yahoo! Inc. (United States) 3:00 pm: Mobile visual search, Radek Grzeszczuk, Nokia Research Ctr. (United States) . . . . . . . . . . . . . . . . . . [8304B-39] Coffee Break . . . . . . . . . . . . . . . . . 3:20 to 4:00 pm

4:00 pm: Discriminative tag learning at YouTube, George Toderici, Google Inc. (United States) . . . . . . . . . . . . . . . . . [8304B-40]

4:20 pm: Revisiting K-means quantization and image object retrieval in an industrial context, Roelof van Zwol, Yahoo! Inc. (United

States) . . . . . . . . . . . [8304B-41]

4:40 pm: Multimedia technologies for content creation and consumption (Presentation Only), Qian Lin, Hewlett-Packard Labs. (United

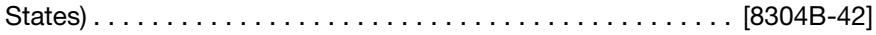




\section{Conference 8304B}

Tuesday 24 January

\section{Room: Grand Peninsula \\ Ballroom A \\ Tues. 8:20 to 9:30 am \\ Plenary Session and Society Award Presentations}

8:25 am: Computational Photography, William T. Freeman,

Massachusetts Institute of Technology (United States) ... [El12SE-101

\section{Interactive Paper and Symposium Demonstration Session}

Room: Grand Peninsula Ballroom E . .Tues. 5:30 to 8:00 pm

\section{Demonstrations}

5:30 to $8: 00 \mathrm{pm}$

A symposium-wide demonstration session will be open to attendees 5:30 to 8:00 pm Tuesday evening. Demonstrators will provide interactive, hands-on demonstrations of a wide-range of products related to Electronic Imaging.

\section{Posters} 5:30 to 7:00 pm

Interactive papers will be placed on display after 10:30 am on Tuesday. An interactive paper session, with authors present at their papers, will be held Tuesday evening, 5:30 to 7:00 pm.

Keyframe generation from cartoon animation using rule-based optical flow, Pakpoom Tanapichet, Nagul Cooharojananone, Rajalida Lipikorn,

Chulalongkorn Univ. (Thailand) . . . . . . . . . . . . . . [8304B-43]

Adaptive characterization, tracking, and semantic labeling of humanvehicle interactions via multimodality data fusion techniques, Amir Shirkhodaie, Vinayak Elangovan, Tennessee State Univ. (United

States)

[8304B-44]

\section{Wednesday 25 January}

\section{Room: Grand Peninsula}

Ballroom A . . . . . . . . . . . . . . Wed. 8:20 to 9:30 am

\section{Plenary Session and Conference Award Presentations}

8:25 am: More Words and Bigger Pictures, David A. Forsyth, Univ. of Illinois at Urbana-Champaign (United States) 


\section{Visual Information Processing and Communication III}

Conference Chairs: Amir Said, Hewlett-Packard Labs. (United States); Onur G. Guleryuz, FutureWei Technologies, Inc. (United States); Robert L. Stevenson, Univ. of Notre Dame (United States)

Program Committee: John G. Apostolopoulos, Hewlett-Packard Labs. (United States); Vasudev Bhaskaran, Qualcomm Inc. (United States); Mireille Boutin, Purdue Univ. (United States); Chang Wen Chen, Univ. at Buffalo (United States); Gerard de Haan, Philips Research Nederland B.V. (Netherlands); Edward J. Delp III, Purdue Univ. (United States); Eric Dubois, Univ. of Ottawa (Canada); Frederic Dufaux, Telecom ParisTech (France); Touradj Ebrahimi, Ecole Polytechnique Fédérale de Lausanne (Switzerland); Keigo Hirakawa, Univ. of Dayton (United States); Marta Karczewicz, Qualcomm Inc. (United States); Janusz Konrad, Boston Univ. (United States); C.-C. Jay Kuo, The Univ. of Southern California (United States); Robert Paul Loce, Xerox Corp. (United States); Ligang Lu, IBM Thomas J. Watson Research Ctr. (United States); Peyman Milanfar, Univ. of California, Santa Cruz (United States); Antonio Ortega, The Univ. of Southern California (United States); Thrasyvoulos N. Pappas, Northwestern Univ. (United States); William A. Pearlman, Rensselaer Polytechnic Institute (United States); Fernando Pereira, Univ. Técnica de Lisboa (Portugal); Béatrice Pesquet-Popescu, Telecom ParisTech (France); Majid Rabbani, Eastman Kodak Co. (United States); Eli Saber, Rochester Institute of Technology (United States); Dan Schonfeld, Univ. of Illinois at Chicago (United States); Gaurav Sharma, Univ. of Rochester (United States); Andrew G. Tescher, AGT Associates (United States); Anthony Vetro, Mitsubishi Electric Research Labs. (United States); John W. Woods, Rensselaer Polytechnic Institute (United States); Xiaolin Wu, McMaster Univ. (Canada)

\section{Tuesday 24 January}

\section{Room: Grand Peninsula}

Ballroom A . . . . . . . . . . . . Tues. 8:20 to 9:30 am

\section{Plenary Session and Society Award Presentations}

8:25 am: Computational Photography, William T. Freeman, Massachusetts Institute of Technology (United States)

Room: Sandpebble Room D. . . . Tues. 9:30 to 10:30 am

\section{Keynote Presentation I}

9:30 am: Developments toward high-efficiency video coding (HEVC), Gary J. Sullivan, Microsoft Corp. (United States) . . . [8305-38]

Coffee Break $10: 30$ to $11: 10 \mathrm{am}$

\section{SESSION 1}

Room: Sandpebble Room D.... . Tues. 11:10 am to 12:30 pm 11:10 am: A novel distortion model for quadtree coding in highefficiency video coding, Bumshik Lee, Sangsoo Ahn, Munchurl Kim, KAIST (Korea, Republic of) . . . . . . . . . . . . . . . . [8305-01] 11:30 am: Weighted prediction for HEVC, Philippe Bordes, Technicolor

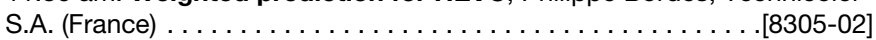
11:50 am: Impact of video parameters on the DCT coefficient distribution for H.264-like video coders, Nejat Kamaci, Ghassan AlRegib, Georgia Institute of Technology (United States) . . . . . . . [8305-03]

12:10 pm: Adaptive loop filter with directional similarity mapping for video coding, PoLin Lai, Felix C. A. Fernandes, SAMSUNG Telecommunications America Inc. (United States) . . . . . . . . . [8305-04] Lunch Break . . . . . . . . . . . . . . . . . . . 12:30 to 2:00 pm

\section{SESSION 2}

Room: Sandpebble Room D..........Tues. 2:00 to 3:20 pm 2:00 pm: Distributed video coding with progressive significance map, William A. Pearlman, Yang Hu, Rensselaer Polytechnic Institute (United

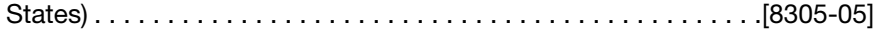

2:20 pm: Improving side information generation using dynamic motion estimation for distributed video coding, Insu Park, David W. Capson, McMaster Univ. (Canada) . . . . . . . . . . . . . . . . . . . . [8305-06]

2:40 pm: Directional frame interpolation for MPEG compressed video, Chang Zhao, Xinwei Gao, Xiaopeng Fan, Debin Zhao, Harbin Institute of Technology (China) . . . . . . . . . . . . . . . . . . . .

3:00 pm: A fast intra-prediction method for high-efficiency video coding using Hadamard transform, Younhee Kim, George Mason Univ. (United States) and Electronics and Telecommunications Research Institute (Korea, Republic of) . . . . . . . . . . . . . . . . . . . . . [8305-08]

Coffee Break $3: 20$ to $4: 00 \mathrm{pm}$

\section{SESSION 3}

Room: Sandpebble Room D. Tues. 4:00 to 5:20 pm

4:00 pm: Lossless description of 3D range models, Neslihan Bayramoglu, A. Aydin Alatan, Middle East Technical Univ. (Turkey) . . . . . . . . . . . . . . . . . . . . . . . .

4:20 pm: Reference frame selection for loss-resilient depth map coding in multiview video conferencing, Bruno Macchiavello, Camilo Dorea, Mintsu Hung, Univ. de Brasília (Brazil) and Hewlett Packard Labs. (United States); Gene Cheung, National Institute of Informatics (Japan); Wai-Tian Tan, Hewlett-Packard Labs. (United States) . . . . . . . [8305-10]

4:40 pm: Low-complexity automated depth-order estimation for 2D-to3D video conversion, Robert Klepko, Communications Research Ctr. Canada (Canada). . . . . . . . . . . . . . . . . . . . [8305-11]

5:00 pm: Block-layer, optimal bit allocation based on constant perceptual quality, Chao Wang, Xuanqin Mou, Xi'an Jiaotong Univ. (China); Lei Zhang, The Hong Kong Polytechnic Univ. (China). . . [8305-12] 


\section{Conference 8305}

Wednesday 25 January

\section{Room: Grand Peninsula \\ Ballroom A . . . . . . . . . . . . . . Wed. 8:20 to 9:30 am \\ Plenary Session and Conference Award Presentations}

8:25 am: More Words and Bigger Pictures, David A. Forsyth, Univ. of Illinois at Urbana-Champaign (United States)

Room: Sandpebble Room D. . . . Wed. 9:30 to 10:30 am Keynote Presentation II

9:30 am: Wavelets on graph: theory and applicaitons to video coding, Antonio Ortega, The Univ. of Southern California (United States) . . . . . . . . . . . . . . . . . . . . [8305-39]

Coffee Break . . . . . . . . . . . . . . . . . . . . 10:30 to 11:10 am

\section{SESSION 4}

Room: Sandpebble Room D. . . . . Wed. 11:10 am to 12:30 pm

11:10 am: Patch-wise ideal stopping time for anisotropic diffusion, Hossein Talebi, Peyman Milanfar, Univ. of California, Santa Cruz (United States) . . . . . . . . . . . . . . . . . . . . . . . [8305-13]

11:30 am: Video attention deviation estimation using inter-frame visual saliency map analysis, Yunlong Feng, Gene Cheung, National Institute of Informatics (Japan); Patrick Le Callet, Polytech' Nantes (France); Yusheng Ji, National Institute of Informatics (Japan). . . . . . . . . . . . [8305-14]

11:50 am: Robust grid registration for non-blind PSF estimation, Jonathan Simpkins, Robert L. Stevenson, Univ. of Notre Dame (United States) . . . . . . . . . . . . . . . . . . . . . . [8305-15]

12:10 pm: Fast pseudo-semantic segmentation for joint region-based hierarchical and multiresolution representation, Rafiq Sekkal, Clement Strauss, François Pasteau, Marie Babel, Olivier Déforges, Institut National des Sciences Appliquées de Rennes (France) . . . . . . . . . . . [8305-16] Lunch Break . . . . . . . . . . . . . . . . 12:30 to 2:00 pm

\section{SESSION 5}

Room: Sandpebble Room D

Wed. 2:00 to 3:20 pm

2:00 pm: Optimal local dimming for LED-backlit LCD displays via linear programming, Xiao Shu, Xiaolin Wu, McMaster Univ. (Canada); Soren Forchhammer, Technical Univ. of Denmark (Denmark) ... . . . . [8305-17]

2:20 pm: Gestures for natural interaction with video, Nesrine Fourati, Emmanuel Marilly, Alcatel-Lucent Bell Labs. Villarceaux (France)[8305-18] 2:40 pm: Improving underwater visibility using vignetting correction, Ken Sooknanan, Anil Kokaram, Trinity College Dublin (Ireland) . .[8305-19] 3:00 pm: Defect pixel interpolation for lossy compression of camera raw data, Michael Schöberl, Friedrich-Alexander-Univ. ErlangenNürnberg (Germany); Joachim Keinert, Fraunhofer-Institut für Integrierte Schaltungen (Germany); Jürgen Seiler, Friedrich-Alexander-Univ. ErlangenNürnberg (Germany); Siegfried Foessel, Fraunhofer-Institut für Integrierte Schaltungen (Germany); André Kaup, Friedrich-Alexander-Univ. ErlangenNürnberg (Germany) . . . . . . . . . . . . . . . . . . . . . . . . . [8305-20] Coffee Break . . . . . . . . . . . . . . . . . . 3:20 to 4:00 pm
SESSION 6

Room: Sandpebble Room D Wed. 4:00 to 4:40 pm

4:00 pm: Cubic-panorama image dataset compression, Saeed Salehi, Eric Dubois, Univ. of Ottawa (Canada) . . .[8305-21]

4:20 pm: Lossless halftone image compression using adaptive context template update, Sung-Bum Park, Dai-Woong Choi, Jae-Won Yoon, Samsung Electronics Co., Ltd. (Korea, Republic of). . . . . . . . . . [8305-22]

\section{Thursday 26 January}

\section{Room: Sandpebble Room D. . . Thurs. 9:00 to 10:00 am}

\section{Keynote Presentation III}

9:00 am: More physics!: The benefits of encorporating near-infrared cues in image processing and computer vision tasks, Sabine Süsstrunk, Ecole Polytechnique Fédérale de Lausanne (Switzerland) . . . . . . . . . . . . . . . . . . . . . . . [8305-40]

Coffee Break . . . . . . . . . . . . . . . . . . . . . 10:00 to 10:40 am

\section{SESSION 7}

Room: Sandpebble Room D. . . Thurs. 10:40 am to 12:20 pm 10:40 am: Recognition of sport players' numbers using fast-color segmentation, Cédric Verleysen, Christophe De Vleeschouwer, Univ. Catholique de Louvain (Belgium). . . . . . . . . . . . . . [8305-33]

11:00 am: On the use of clustering for resource allocation in wireless visual sensor networks, Angeliki V. Katsenou, Lisimachos Paul Kondi, Konstantinos E. Parsopoulos, Univ. of Ioannina (Greece). . . . . . [8305-34]

11:20 am: Kalai-Smorodinsky bargaining solution for optimal resource allocation over wireless DS-CDMA visual sensor networks, Katerina Pandremmenou, Lisimachos Paul Kondi, Konstantinos E. Parsopoulos, Univ. of loannina (Greece) . . . . . . . . . . . . . . . . . . . [8305-35]

11:40 am: State-of-the-art lossy compression of Martian images via the CMA-ES evolution strategy, Frank W. Moore, Brendan Babb, Univ. of Alaska Anchorage (United States); Shawn Aldridge, The Univ. of Southern California (United States); Michael R. Peterson, Univ. of Hawai'i at Hilo (United States). . . . . . . . . . . . . . . . . . . . . [8305-36] 12:00 pm: Spatially adaptive superresolution using the optimal recovery framework, Abdul Jabeer Shaik, Sergio D. Cabrera, The Univ. of Texas at El Paso (United States) . . . . . . . . . . . . . . . . [8305-37] Lunch Break . . . . . . . . . . . . . . . . . . . 12:20 to 2:00 pm 


\section{SESSION 8}

Room: Sandpebble Room D. . . . . . . . . Thurs. 2:00 to 3:20 pm

2:00 pm: Survey of imaging applications used in roadway transportation (Invited Paper), Natesh Manikoth, ACS, A Xerox Co.

(United States); Robert P. Loce, Wencheng Wu, Edgar Bernal, Xerox Corp. (United States). .[8305-31]

2:40 pm: Compression of 2D navigation views with rotational and translational motion, Dominic Springer, Friedrich-Alexander-Univ. Erlangen-Nürnberg (Germany); Franz Simmet, Dieter Niederkorn, Audi AG (Germany); André Kaup, Friedrich-Alexander-Univ. Erlangen-Nürnberg (Germany) .[8305-27]

3:00 pm: A semi-automatic traffic sign detection, classification, and positioning system, Ivo M. Creusen, Lykele Hazelhoff, Peter H. N. de With, CycloMedia Technology B.V. (Netherlands) and Technische Univ. Eindhoven (Netherlands) . . . . . . . . . . . . . . . . [8305-25]

Coffee Break ...................... 3:20 to 4:00 pm

\section{SESSION 9}

\section{Room: Sandpebble Room D........ Thurs. 4:00 to 5:40 pm}

4:00 pm: Image simulation for automatic license plate recognition, Raja Bala, Yonghui Zhao, Aaron Burry, Vladimir Kozitsky, Xerox Corp. (United States); Craig Saunders, Xerox Research Ctr. Europe Grenoble (France) . . . . . . . . . . . . . . . . . . . . . . [8305-32]

4:20 pm: Traffic camera markup language (TCML), Yang Cai, Carnegie Mellon Univ. (United States)

4:40 pm: Passive detection of heavily laden vehicles, Troy McKay, Carl Salvaggio, Philip S. Salvaggio, Jason Faulring, Donald M. McKeown, Rochester Institute of Technology (United States); Alfred J. Garrett, David Coleman, Larry Koffman, Savannah River National Lab. (United

States) . . . . . . . . . . . . . . . . . . . . . . . . . . . . . [8305-29]

5:00 pm: Application of the SNoW machine learning paradigm to a set of transportation imaging problems, Peter Paul, Aaron Burry, Xerox Corp. (United States); Yuheng Wang, Rochester Institute of Technology (United States); Vladimir Kozitsky, Xerox Corp. (United States) . .[8305-30]

5:20 pm: On-board side pedestrian detection for automotive active safety system, Ruzhong Cheng, Yong Zhao, Xin'an Wang, Jiayao Xu, Shaoting Lv, Peking Univ. (China). . . . . . . . . . . . . . [8305-28] 
A

Aach, Til 8295A ProgComm, [8299-26]SIP1, [8300-14]S4

Abbey, Craig K. [8291-24]S6

Abdel-Hameed, Ahmed [8297-06]S3

Abdou, Sherif [8297-06]S3

Abdul-Kafi, Salahodeen S. [8304A-13]S4

Abed, Farhad [8293-15]S5

Abhyankar, Vishwas [8295A43]SIP1

Abidi, Mongi A. 8290 ProgComm

Abram, Gregory [8294-17]S7

Acton, Scott T. [8296-30]S6

Adcock, John 8304B ProgComm

Adhikarla, Vamsi Kiran [828878]SP3

Agaian, Sarkis [8304A-13]S4

Agaian, Sos S. 8295A Chr. 8295A S2 SessChr, 8295A S9 SessChr, 8295A S10 SessChr, [8295A-22]S7, [8295A-25]S7, [8295A36]SIP1, [8295A-38] SIP1, 8304A ProgComm, [8304A-31]SIP

Agam, Gady SC927 Inst, [8293-33]S10, 8297 ProgComm, [8297-05]S2, [8297-30]SIP1

Aguilera, Julieta C. [8289-05]

Ahmadullin, Ildus [8302-21]S6, [8302-22]S6

Ahmed, Toufik [8293-28]S9

Ahn, Sangsoo [8305-01]S1

Ahonen, Timo SC1021 Inst

Ahumada, Albert J. 8291 ProgComm

Aida, Saori [8291-20]S9A [8291-20]S5A

Aigueperse, Antoine [829036]S8

Airieau, Boris [8293-18]S6

Aizenberg, Evgeni [8295A08]S2

Aizenberg, Igor [8295A-27]S8

Akar, Gözde B. 8295A ProgComm

Akmanalp, Mehmet A. [830135]S8

Akopian, Arsen [8304A-27] SIP1

Akopian, David 8304A S1 SessChr, 8304A S3 SessChr, 8304A S4 SessChr, 8304A Chr, [8304A-08]S3, [8304A-23] SIP1

Aksel, Alla [8296-30]S6

Alabi, Femi [8294-08]S3

Alabi, Oluwafemi S. [8294-26] SIP1, [8294-27]SIP1

Alacoque, Laurent [8293-40] SIP1, [8293-41]SIP1

Alatan, A. Aydin [8290-01]S1, [8290-26]S6, [8305-09]S3

Alattar, Adnan M. $8303 \mathrm{Chr}$ 8303 S4 SessChr, 8303 SK2 SessChr, 8303 SK1 SessChr
Alaya Cheikh, Faouzi 8304A ProgComm

Albanese, Patricia 8302 ProgComm

Aldridge, Shawn [8305-36]S7

Aleksakhin, Vladyslav [829420]S10

Aleksic, Milivoje [8292-22]S6, [8293-13]S5

Alers, Hani [8291-29]S7A, [8291-29]S7A

Ali-Bey, Mohamed [8288-72] SP3

Alj, Youssef [8290-04]S

Allebach, Jan P. 8291

ProgComm, 8292

ProgComm, 8292 S7

SessChr, [8292-24]S6

[8292-34]S9, [8292-35]

S9, [8292-36]S9, [8292-37]

S9, [8292-39]S9, [8293-06]

S3, [8293-25]S8, [8293-26]

S8, [8293-27]S8, [8296-31]

S6, $8302 \mathrm{Chr}$, [8302-13]S4,

[8302-21]S6, [8302-22]S6,

[8302-23]S6, [8302-28]S7

Allili, Madjid 8294

ProgComm

Allison, Robert S. [8288-21] S6, [8288-29]S8

Al-Marzouqi, Hasan [8295A14]S4

Alonso, Manuel [8303-26]S10

Alquié, Georges [8298-21]S6

Al-Regib, Ghassan [8290-03] S1, [8295A-14]S4, [830503]S1

Alvarez, Jorge [8300-22]SIP1

Amhaz, Hawraa [8298-19]S5

Amirshahi, Seyed Ali [829153]SP1

Anderson, Hyrum S. [8296-26] S5

Ando, Shigeru [8290-30]S7, [8290-40]SIP1, [8292-25]S7

Andral, Jean-Louis [8291-52] SP1

Andrea, Ceresi [8299-15]S2

Annese, Marco [8298-33]SIP1

Antani, Sameer K. [8297-02] S2

Apostolopoulos, John G. 8305 ProgComm

Appelbaum, Jeff [8298-11]S3

Arai, Kohei [8295A-50]SIP1

Arai, Toshiki [8298-22]S6

Ariano, Paolo [8301-31]S7

Arndt, Christian [8296-06]S1

Arnold, Michael [8303-26]S10

Arróspide, Jon [8301-05]S2

Artmann, Uwe [8293-04]S2, [8293-04]S4

Asari, K. Vijayan [8301-39] SIP 1

Astola, Jaakko T. [8295A-04] S1, [8295A-37]SIP1

Astrom, Anders [8298-07]S2

Atanassov, Kalin [8288-06]S2, [8291-22]S9B, [8291-22] S5B

Atkins, Joshua [8291-18]S4 Aubreton, Olivier [8290-32]S8 Audino, Giuseppe [8292-23] S6

Avci, Aykut [8290-39]S9

Ayiter, Elif E. [8289-11]S3

Azuma, Takeo [8296-34]SIP1

Azzari, Lucio [8304A-07]S2
B

B. S., Raghavendra [8295A34]S10

Baah, Kwame F. [8292-06]S2

Babacan, Derin [8296-41]S6, [8296-42]S6

Babaei, Vahid [8292-07]S3

Babaguchi, Noboru 8304B ProgComm

Babb, Brendan [8305-36]S7

Babel, Marie [8305-16]S4

Badano, Aldo [8292-09]S3

Baden, Scott B. [8294-02]S1

Badihi, Yehuda [8289-02]S1

Badshah, Amir [8300-25]S4

Bae, Kwanghyuk [8290-08]S4

Bae, Sam Youngsam [828894]SP4

Baek, ByungJoon [8299-28] SIP1

Bajorski, Peter SC837 Inst Bakhtiari, Somayeh [8295A22]S7

Bala, Kavita [8291-06]S2

Bala, Raja [8296-31]S6, [830228]S7, [8305-32]S9

Balinsky, Alexander [8302-06] S3

Balinsky, Helen [8302-06]S3

Ballas, Nicolas [8300-10]S3

Bandaru, Vinod K. [8304A-28] SIP1

Bando, Hiroki [8288-98]SP2

Bang, Børre [8295A-11]S3, [8295A-12]S3

Bang, Won-Chul [8289-08]S3

Banks, Martin S. [8288-34] S9A, [8288-34]S5A, [828837]S9B, [8288-37]S5B

Barkowsky, Marcus [828831]S8, [8288-59]SP1, [8291-54]SP2

Barna, Jozef [8289-25]SIP1

Barnes, David P. [8301-23]S6

Barney Smith, Elisa H. 8297 ProgComm, [8300-09]S3

Barni, Mauro 8303 ProgComm

Barrera, Junior 8295A ProgComm

Barrett, Bill 8297 ProgComm

Barth, Erhardt 8291 ProgComm, $8291 \mathrm{~S} 1$ SessChr, [8291-01]S1, [8291-02]S1, [8291-31]S7B Bartkovjak, Peter [8298-11]S3

Baryshev, Alexander [828864]SP2

Baskurt, Atilla M. 8290 Chr, 8290 S6 SessChr

Bass, Steffen A. [8294-08]S3, [8294-26]SIP1, [8294-27] SIP1

Bassham, Diane [8289-04]S2

Basu, Samit 8296 ProgComm

Batchko, Robert [8301-42] SIP1

Battiato, Sebastiano SC1048 Inst, 8293 S1 SessChr 8293 S2 SessChr, 8299 S3 SessChr, 8299 S4 SessChr, 8299 Chr, [8299-20]S2, [8299-20]S4

Battisti, Federica [8295A-06] S2, [8303-17]S6

Batur, Aziz Umit [8288-07]S2, [8288-17]S5

Baum, Peter [8303-26]S10

Baxter, Donald [8293-01]S3, [8293-01]S1, [8293-02]S2, [8293-02]S4

Bay, Thierry [8290-17]S5

Bayramoglu, Neslihan [830509]S3

Bazilevs, Yuri [8289-21]S6

Beernaert, Roel [8290-39]S9

Beghdadi, Azeddine [8293-12] S4, [8295A-26]S8

Belhaire, Eric [8298-34]S

Bellemare, Marc-Emmanuel [8290-17]S5

Belyaev, Evgeny A. [8304A-16] SIP1

Ben Chouikha, Mohamed [8298-21]S6

Benameur, Said [8295A-28]S8

Bender, Walter R. 8291 ProgComm

Benesova, Wanda [8301-08] S2

Bengio, Samy [8297-01]S1

Bengtson, Kurt [8292-39]S9

Bénière, Roseline [8290-21]S5

Benitez Restrepo, Hernan Darío [8295A-47]SIP1

Benois-Pineau, Jenny [829328]S9, 8295A ProgComm

Benoit-Cattin, Hugues 8290 ProgComm

Bentahar, Samir [8288-61]SP1

Beransky, Margarita [8291-16] S4

Berbaum, Kevin S. [8291-27]

Berchtold, Waldemar [830304]S2

Beretta, Giordano B. [829217]S4, [8292-32]S8

Bergeron, R. Daniel [8294-16] S7

Berjón, Daniel [8290-18]S5, [8290-19]S5

Berkner, Kathrin 8297 ProgComm, [8299-09]S1, 8302 ProgComm

Bernabucci, Ivan [8295A-01] S1

Bernal, Edgar [8305-31]S8, [8292-31]S8

Berthoz, Alain [8289-03]S1

Bertini, Enrico [8294-01]S1

Beyerer, Jürgen [8300-03]S1

Bhagavatula, Ramu [8296-05]

Bhargava, Rohit [8296-20]S4

Bhasin, Rajesh [8290-51]SIP1

Bhaskaran, Vasudev 8305 ProgComm

Bhatti, Nina T. 8304A 
Brewster, Stephen A. [829919]S3, [8299-19]S1 Brill, Michael H. 8291 ProgComm

Britt, Florian [8298-33]SIP1

Brousse, Olivier [8298-04]S2

Brown, Geoffrey [8288-13]S4

Brückner, Andreas [8299-06] S1

Brunnström, Kjell [8288-31] S8

Bucha, Victor [8290-10]S4

Bues, Matthias [8288-53]S13

Buffa, Cesare [8299-05]S1

Bui, Huy Q. [8296-42]S6

Bulat, Jaroslaw [8288-31]S8

Bunsch, Eryk [8291-50]SP1

Burge, Johannes [8299-13]S2

Bürger, Kai [8294-22]S11

Burns, Peter D. 8293 Chr,

8293 S2 SessChr, 8293

S1 SessChr, [8293-11]S4,

8299 S3 SessChr, 8299 S4 SessChr

Burry, Aaron [8305-30]S9, [8305-32]S9

Burton, Melissa M. [8291-21] S9A, [8291-21]S5A

Burton, Robert P. [8294-37] SIP1

Busch, Christoph [8304A-20] SIP1

Buytaert, Jan A. N. [8290-28] S7

C

Cabrera, Sergio D. [8305-37]

Cabrita, A. [8298-35]S4

Caceres, Hugo [8292-09]S3

Cai, Yang [8305-26]S9

Calore, Enrico [8288-20]S5

Campbell, P. J. [8289-04]S2

Camplani, Massimo [8290-13] S4, [8301-05]S2

Canosa, Roxanne L. [8295A49]SIP1

Cao, Frédéric [8293-01] S3, [8293-01]S1, 8299 ProgComm, [8299-01]S1

Cao, Lu [8290-15]S5

Capodiferro, Licia [8295A-02] S1, [8295A-16]S5

Capra, Alessandro [8299-20] S2, [8299-20]S4

Capson, David W. [8305-06] S2

Carbon, Claus-Christian [8291-42]S9

Cardoso, Fernando $\mathrm{M}$. [8295A-48]SIP1

Carli, Marco [8295A-01]S1, [8295A-02]S1, [8295A-06] S2, [8303-17]S6

Caron, James [8295A-18]S5

Carpenter, Douglas A. [829817]S5

Casadio, Francesca [8291-52] SP1

Casasent, David P. $8301 \mathrm{Chr}$ 8301 S5 SessChr, 8301 S7 SessChr

Casini, Andrea [8291-43]S9

Castelein, Pierre [8298-10]S3

Castellanos Dominguez,

German [8293-36]S4,

[8295A-47]SIP1
Catregn, Gion-Pol [8298-33] SIP 1

Catrysse, Peter B. 8299 ProgComm

Cavaro-Ménard, Christine [8291-25]S6

Cavin, John [8298-20]S5

Celebi, M. Emre [8295A-45] SIP1, [8295A-46]SIP1

Cernekova, Zuzana [8301-08] s2

Ch.A.V., Vijay [8288-12]S4

Cha, Miriam [8296-18]S3

Chahiba, Jawad [8298-15]S4

Chalupka, Uwe [8290-29]S7

Chamaret, Christel [8288-83] S4, [8291-66]SP2

Chambah, Majed 8293 ProgComm

Chambealland, JeanChristophe [8290-45]SIP1

Chanda, Sukalpa [8297-29] SIP1

Chandra, Manish [8302-03]S2

Chang, Benjamin [8289-01]S1

Chang, Yerin [8293-14]S5

Chang, Yu-Sung [8291-40]S8

Chapman, Glenn H. 8298

ProgComm, [8298-12]S4

Chatterjee, Abhik [8300-21] SIP1

Chau, Dennis [8288-95]SP5

Chaudhuri, Abon [8294-15]S6

Chazalon, Joseph [8297-20]

Chen, Chang Wen 8304A ProgComm, 8305 ProgComm

Chen, Chang-Ying [8288-68] SP2

Chen, Chaomei $8294 \mathrm{Chr}$ 8294 S2 SessChr, 8294 S6 SessChr, [8294-10]S4

Chen, Guoning 8294 ProgComm

Chen, Homer H. [8291-63]SP2

Chen, Jacky [8296-29]S6

Chen, Jhen-Si [8288-46]S12

Chen, Jiansheng 8295B

ProgComm

Chen, Ning [8298-27]SIP1

Chen, Peiyi [8301-22]S5

Chen, Philip C. L. 8304A ProgComm

Chen, Shih-Han [8291-56]SP2

Chen, Wei [8288-59]SP

Chen, Yang [8301-16]S4

Chen, Yue [8301-21]S5

Chen, Yung-Yao [8292-36]S9

Chen, Yuting [8299-11]S2

Chen, Zhuo Wei [8290-17]S5

Cheng, Beibei [8297-02]S2

Cheng, Jun 8300 ProgComm

Cheng, Ruzhong [8305-28]S9

Cheng, Wei-Chung [8292-09]

Cheryomkhin, Pavel A. [830138]SIP1

Chetouani, Aladine [8293-12]

Cheung, Gene [8305-10]S3 [8305-14]S4

Chi, Yi-Chen [8289-16]S5

Chiang, Yi-Jen 8294 ProgComm

Chin, George 8294 ProgComm

Chittar, Naren [8293-19]S6
Cho, Hojin [8296-33]SIP1, [8301-30]S7

Cho, Junguk [8296-33]SIP1, [8301-30]S7

Cho, Nam Ik [8300-19]SIP-

Cho, Sunghyun [8296-33] SIP1, [8301-30]S7

Cho, Wanhyun 8304A S4 SessChr, [8304A-18]SIP1

Cho, Yangho [8288-71]SP3

Choe, Wonhee [8296-35]SIP1

Choi, Dai-Woong [8305-22]S6

Choi, Donchul [8292-48]SIP1

Choi, Hak-Yeol [8303-05]S2

Choi, Hee-Jin [8288-69]SP2

Choi, JaeHyung [8300-19] SIP1

Choi, Ouk [8288-05]S2 [8290-09]S4, [8290-11]S4

Choi, Sung-Hee [8303-05]S2

Chou, Jay [8304B-38]S6

Chou, Tzren-Ru [8292-41]S10

Christopher, Lauren [8290-

$$
\text { 34]S8 }
$$

Chronopoulos, Anthony [8295A-36]SIP1

Chu, Daping [8288-46]S12

Chua, Tat-Seng 8304B ProgComm

Chunev, Georgi N. [8295B-57] S12

Chung, Sung H. [8293-19]S6 Chupeau, Bertrand [8303-24] S9

Church, Sara E. [8303-10]S7

Cigla, Cevahir [8290-01]S1

Ciocca, Gianluigi [8304B-32] S5

Ciurea, Florian 8288 ProgComm

Clausing, Eric [8290-41]SIP1 Clerc, Cedric [8298-04]S2

Coelho, Pablo A. [8300-13]S4

Coetzer, Johannes [8297-18] S7

Cohen, Eliahu [8295A-19]S6

Coleman, David [8305-29]S9

Collar, Bradley T. [8288-58] SP1

Collings, Neil [8288-46]S12

Comba, Joao L. D. [8294-09] S4

Comer, Mary L. [8296-02]S1

Conforto, Silvia [8295A-01]S1

Conover, D. [8291-43]S9

Conze, Pierre-Henri [8288-56] SP1, [8288-86]SP4

Cooharojananone, Nagul [8304B-43]SIP1

Cooper, Matthew L. 8304B ProgComm

Cooper, Ted J. 8299

ProgComm

Cooperstock, Jeremy [829407]S3

Corchs, Silvia [8293-09]S4

Corcoran, Andrew [8294-19] S7

Cornish, Tracy [8289-14]S4

Corso, Nicholas [8296-29]S6

Costantini, Luca [8295A-02]S1

Cottam, Joseph A. [8294-32] SIP1

Coüasnon, Bertrand 8297 ProgComm, [8297-20]S7

Craver, Scott [8293-07]S3, 8303 ProgComm, 8303 S1 SessChr

Cree, Michael J. [8290-20]

S5, [8296-40]SIP1, 8300 ProgComm

Cretu, Ana-Maria [8291-57] SP2

Creusen, Ivo M. [8304B-34] S5, [8305-25]S8

Creutzburg, Reiner 8295A ProgComm, 8304A Chr, 8304A S2 SessChr, 8304A S1 SessChr, [8304A-21] SIP1, [8304A-22]SIP1, [8304A-25]SIP1, [8304A-26] SIP1

Criado, Enrique [8288-41]S11

Crisler, Kenneth J. 8304A ProgComm

Crnojevic, Vladimir [8301-13] S3

Crossno, Patricia J. [8294-11] S5

Cui, Luke C. 8293 ProgComm 8293 S9 SessChr, [829305]S3

Culbertson, Bruce [8288-47] S12

Cunha, Bernardo [8301-32]S7

Cusano, Claudio [8299-29] SIP1, [8304B-32]S5

da Silva, Eduardo 8290 ProgComm

Daher, Hani [8297-31]SIP

Dalal, Edul N. [8293-37]SIP1

D'Alessandro, Stephanie [8291-52]SP1

D'Alessio, Tommaso [8295A01]S1

Dalton, John C. 8291 ProgComm

Daly, Scott J. 8291 ProgComm, 8292 ProgComm, [8292-01]S

Damera-Venkata, Niranjan [8302-23]S6

Dane, Gokce [8304A-12]S4

Daniel, Emmanuel [8288-61] SP1

Daniel, Marc [8290-17]S5

Daoudi, Mohamed 8290 ProgComm, 8290 S5 SessChr, [8290-16]S5

Dark, Veronica J. [8289-18]S5

Darmont, Arnaud SC967 Inst, [8298-15]S4

Darrell, Trevor [8304B-45]SK1

Das, Arun [8301-22]S5 
Dittmann, Jana [8290-33]S8, [8290-41]SIP1, [8295A-31] S9, [8296-06]S1, [8301-15] S4, 8303 ProgComm, [8303-16]S6, [8303-25]S10

Do, Hung [8298-11]S3

Do, Minh N. [8296-20]S4, [8296-41]S6, [8296-42]S6

Do, Quoc Bao [8295A-26]S8

Dobigeon, Nicolas [8296-15]S2

Dodgson, Neil A. 8288 S5 SessChr, 8288 ProgComm

Doermann, David S. 8297 ProgComm, 8304A ProgComm

Doërr, Gwenaël 8303 ProgComm, 8303 S5 SessChr, [8303-24]S9, [8303-26]S10

Doerschuk, Peter C. [8296-08] S1, [8296-09]S1

Doherty, Ryan M. [8301-35]S8

Doherty, Tiarna 8291

ProgComm, 8291 Sg SessChr

Doi, Motonori [8292-25]S7

Dokoutchaev, Alexander [8299-10]S2

Dolinsky, Margaret $8289 \mathrm{Chr}$ 8289 S6 SessChr, 8289 S2 SessChr, [8289-16]S5

Dominguez-Castro, Rafae [8298-02]S1

Doran, James E. [8298-17]S5

Dorea, Camilo [8305-10]S3

Dörk, Marian 8294 ProgComm

Dornaika, Fadi [8301-25]S6

Dorr, Michael [8291-31]S7B, [8291-31]S7B

Dorrington, Adrian A. [829020]S5, [8296-40]SIP-

Dougherty, Daniel [8294-26] SIP1

Dougherty, Mark [8300-24] SIP1

Doyen, Didier [8288-14]S4, [8288-30]S8, [8288-35]S9B, [8288-35]S5B, [8288-54] SP1, [8288-61]SP1

Draper, Geoffrey [8294-33] SIP1

Drazic, Valter [8288-86]SP4

Drimbarean, Alexandru F. 8299 ProgComm

Drummy, Lawrence F. [829603]S1

Dubois, Eric [8288-84]SP4 8305 ProgComm, [8305-21]

Dubois, Sébastien [8298-10]S3

Duchene, Sylvain [8288-15] SP5

Dufaux, Frederic 8305 ProgComm

Dugelay, Jean-Luc E. 8290 ProgComm

Dunlap, Justin C. [8298-13]S4

Dupont, Florent 8290 ProgComm

Dupret, Antoine [8293-40]SIP1, [8293-41]SIP1, $8298 \mathrm{Chr}$, [8298-05]S2

Dürmüller, Martin [8298-33] SIP1

Duval, Laurent C. 8300 ProgComm

Dwinell, John [8300-18]SIP1

Dykstra-Erickson, Elizabeth 8304A ProgComm
Fan, Wei [8295A-29]S9

Fan, Xiaopeng [8305-07]S2

Fan, Zhigang [8292-51]SIP1, [8296-31]S6, $8302 \mathrm{Chr}$, [8302-28]S7, [8302-30]S7

Fandino Toro, Hermes Alexander [8295A-47]SIP1

ProgComm

Eckstein, Miguel [8291-24]S6

Edlich, Stefan 8304A

ProgComm

Effelsberg, Wolfgang [8304A19]SIP1

Efimushkina, Tatiana [830306]S2

Egiazarian, Karen O. 8295A

S3 SessChr, 8295A

S4 SessChr, 8295A

S5 SessChr, 8295A S6

SessChr, 8295A Chr, [8295A-04]S1, [8295A17]S5, [8295A-37]SIP1, [8295A-39]SIP1, [8303-06] S2, [8304A-07]S2, [8304A16]SIP1, [8304A-24]SIP

Eglin, Veronique [8297-31] SIP1

Eichhorn, Alexander [8298-14] S4

Eid, Ahmed Hamad [8295A32]S10

Einakian, Sussan 8294 ProgComm

Eisemann, Elmar [8291-19] S9A, [8291-19]S5A

Eisenbarth, Mattias [8288-22] S6

EL Khoury, Rachid [8290-16]

El Merabet, Youssef [8300-23] SIP1

Elangovan, Vinayak [8304B36]S5, [8304B-44]SIP1

Eliasson, Henrik SC1049 Inst, [8293-01]S3, [8293-01] S1

Eller, Chris [8289-16]S5

Enge, Amy [8298-24]S6

Erbacher, Rob, 8294 S8 SessChr, 8294 S9 SessChr

Eremeev, Oleg [8295A-37] SIP1

Eren, Gonen [8290-32]S8

Ericson, Thomas [8288-55] SP1

Eschbach, Reiner 8292 Chr, 8292 S10 SessChr, 8292 S4 SessChr, 8292 S1 SessChr

Esfahanian, Moosa [8304A23]SIP1

Esser, Daniel [8297-16]S6

Etoh, Takeharu Goji [829822]S6

Euler, Craig [8301-33]S8

Evtikhiev, Nikolay N. [8301-38] SIP1

$\mathbf{F}$

Fabinski, Robert P. [8298-17] S5

Fabrizio, Marini [8299-15]S2

Fageth, Reiner 8302 ProgComm, [8302-10]S4

Fairchild, Mark D. 8293 ProgComm

Fan, Jian [8302-23]S6

Fan, Jianping 8304B

ProgComm [8301-41]SIP1

Fewerda, James 8291 ProgComm

Fickus, Matthew [8296-05]S1

Fiedler, Inge [8291-52]SP1

Filliard, Nicolas [8289-03]S1

Fischer, Fabian [8294-01]S1

Fischer, Mani [8292-35]S9, [8292-36]S9, [8293-06]S3

Fleisher, K. [8291-43]S9

Floeder, Steven P. 8300 ProgComm

Foessel, Siegfried [8305-20] S5 SessChr, [8300-01]S1

Fontanella, Jean-Claude L. [8298-34]S4 8300 ProgComm

Forchhammer, Soren [830517]S5

Forchheimer, Robert [829807]S2 SPLEN2
Fougerolle, Yohan [8290-36] S8

Fourati, Nesrine [8305-18]S5

Fournier, Jérôme [8288-59] SP

Fowler, Boyd [8298-11]S3, 8299 ProgComm

Fox, Stephen D. [8301-07]S2

Fraedrich, Roland [8294-22] S11, [8294-23]S11

Frain, Jonathan [8294-16]S7

Frakes, David H. [8296-12]S2

Frank, Tal [8293-06]S3

Franke, Katrin [8297-29]SIP1

Fredembach, Clement [829321]S7A, [8293-21]S7A

Frédéric, Guichard [8299-01] S1

Freeman, John Craig [828912]S4

Freeman, William T. [El12SE-101]SPLEN1

Frey, Franziska [8293-23]S7B, [8293-23]S7B

Fridrich, Jessica 8303 ProgComm, 8303 S3 SessChr, [8303-07]S3 [8303-08]S3, [8303-14]S5

Frost, Raymond [8298-31] SIP1

Fruth, Jana [8301-15]S4, [8304A-10]S3

Fu, Jun [8299-27]SIP

Fu, ZhenHong [8298-29]SIP1

Fuchs, Philippe [8294-30]SIP1

Führ, Hartmut [8293-36]S4

Fujii, Toshiaki [8288-79]SP3

Fujimoto, Keisuke [8301-28]S7

Fujishiro, Issei [8294-38]SIP1

Fukusaki, Mai [8295A-50]SIP1

Fukuzawa, Masayuki [829042]SIP1, [8290-43]SIP1, [8296-38]SIP1

Fung, Kenneth S.M. [8300-04] S2

Funk, Walter [8288-25]S7

Furuie, Sérgio S. [8295A-48] SIP1

Fischer, Robert [8290-41]SIP1

Fofi, David [8290-36]S8, 8300 ProgComm, 8300 S3

Foi, Alessandro [8291-32]S7B, [8291-32]S7B, [8296-22]S4

Folgieri, Raffaella [8288-20]S5

Fontoura Da Costa, Luciano F.

Forsyth, David A. [El12SE-102]

Gaash, Amir [8302-11]S4

Gabbouj, Moncef [8304A-16] SIP1

Gasparini, Francesca [829309]S4, [8299-15]S2, [829929]SIP1

Gaudreau, Jean-Etienne [8288-70]SP2

Gautier, Gwénaëlle [8291-52] SP1

Gavant, Fabien F. G. [8293-40] SIP1

Gaykema, Frans 8293 Chr, 8293 S8 SessChr

Gedik, Osman S. [8290-26] S6

Gée, Christelle [8300-12]S4, [8301-20]S5

Geisler, Wilson S. [8299-13]S2

Gelautz, Margrit [8288-22]S6

Georgiev, Todor G. [8295B 57]S12, [8296-10]S2, [829907]S1, [8299-08]S1

Gerhardt, Jérémie [8288-66] SP2

Gernoth, Thorsten [8300-05]

Gesquière, Gilles [8290-21]S5, [8290-45]SIP1

Gevers, Theo 8304B CoChr

Ghamisi, Pedram [8299-21]S

Ghosh, Debabrata [8295A-13] S4, [8301-41]SIP1

Ghosh, Dev [8291-03]S

Gilbert, Stephen [8289-20] S6, [8291-21]S9A, [8291-21] S5A, [8291-55]SP2

Gill, John T. [8304A-13]S4

Gillat, Ziv [8302-05]S2

Gille, Jennifer 8291 ProgComm

Gimkiewicz, Christiane [830109]S2

Gleason, Shaun S. 8300 ProgComm

Gnanasambandam, Nathan [8302-26]S7

Godbaz, John P. [8296-40] SIP1

Godil, Afzal 8290 ProgComm 8290 S1 SessChr, 8290 S3 SessChr, [8290-22]S5

Golagani, Santosh Chandana [8304A-23]SIP1 
Gotoda, Hironobu [8288-10] S3

Govindaraju, Venu [8297-24] S8, [8297-25]S8

Graf, Hans-Rudolf [8301-23] S6

Grazzini, Jacopo [8295A-10] S3, [8300-07]S2

Green, Phil J. 8292

ProgComm, [8293-14]S5

Greif, Thomas [8304B-37]S6

Greig, Darryl S. [8302-19]S6, [8302-20]S6

Gries, Ulrich [8303-26]S10

Grigat, Rolf-Rainer [830005]S2

Gröhn, Matti T. 8294 ProgComm

Gromala, Diane [8289-06]S2 Grosicki, Emmanuèle [829727]S8

Groulx, Robert [8298-31]SIP1

Gruenwedel, Sebastian [830112]S3

Gruhn, Stefan [8290-33]S8

Gruna, Robin [8300-03]S1

Grzeszczuk, Radek [8304B39]S7

Guarnera, Mirko 8299 ProgComm

Guastavino, Catherine [829436]SIP1

Guellec, Fabrice [8298-10]S3

Guérin, Samuel [8300-15]S4

Guérin-Dugué, Anne [829341]SIP1

Guevorkian, David [8304A-24] SIP1

Guiguet, Romain [8298-10]S3

Guleryuz, Onur G. 8305 Chr

Gunupudi, Nageswara Rao [8295B-55]S11

Guo, Jia [8291-59]SP2

Gupta, Maya R. 8296 ProgComm, [8296-26]S5

Gurrieri, Luis E. [8288-84] SP4

Gutenev, Alex A. [8295A-35] SIP1

Guthier, Benjamin [8304A-19] SIP1

Guyader, Nathalie [8291-30] S7B, [8291-30]S7B

\section{$\mathrm{H}$}

$\mathrm{Ha}, \mathrm{Ho-Gun}$ [8292-08]S3, [8292-42]S10

$\mathrm{Ha}$, Yeong-Ho [8292-08]S3, [8292-42]S10

Hadar, Ofer [8293-28]S9, [8295A-19]S6

Haddad, Andrew W. [8304A15]S4

Haino, Yasuyuki [8288-09]S3

Hamamoto, Takayuki [828865]SP2

Hamann, Bernd [8294-12]S5, [8294-18]S7, [8304A-17] SIP1

Han, Seong Wook [8292-18] S5

Han, Seung-Ryong [8290 06]S3

Han, Young Seok [8295A-20] S6

Handley, John C. [8293-24]S8, 8295A ProgComm
Hanhela, Marianne [8304A06]S2

Hanjalic, Alan 8304B ProgComm

Hannuksela, Miska [8304A06]S2

Hanrahan, Patrick [8294-42] SK1

Hanzo, Lajos 8304A

ProgComm

Hao, Ming C. 8294 Chr, 8294 SK2 SessChr, [8294-14]S6 Haque, Sufia [8298-31]SIP1

Harbeck, Daniel [8298-20]S5

Hardeberg, Jon [8296-26]S5, [8298-14]S4, [8298-25]S6

Harger, John R. [8294-11]S5

Harker, Matthew J. [8300-25] S4

Hart, John C. [8290-51]SIP1

Harter, Jonathan M. [8294-08] S3, [8294-26]SIP1

Häselich, Marcel [8301-24]S6

Hashimoto, Takanori [828875]SP3

Haug, Lars-Erik [8294-14]S6

Hauptmann, Alexander G. 8304B ProgComm, [8304B-35]S5

Hayashi, Takanori [8293-31]S9

Hayashida, Tetsuya [8298-22] S6

Hazelhoff, Lykele [8304B-34] S5, [8305-25]S8

$\mathrm{He}$, Zhihai 8304A ProgComm

Healey, Christopher G. 8294 S5 SessChr, [8294-08]S3 [8294-27]SIP1

Hebbalaguppe, Ramya S. M [8299-16]S2

Hébert, Mathieu [8292-40]S10 Held, Robin [8288-37]S9B [8288-37]S5B

Helliwell, Jesse [8288-49]S13

Hemami, Sheila S. [8288-03] S2, 8291 ProgComm [8291-14]S3

Hennings Yeomans, Pablo $\mathrm{H}$. [8296-07]S1

Hensley, Justin 8295B ProgComm

Hernández-Andrés, Javier [8300-17]SIP-1

Hero, Alfred O. [8296-15]S2

Herrmann, Enrico [8295A-31] sg

Hersch, Roger D. 8292 ProgComm, [8292-07]S3

Hertel, Dirk W. 8293 ProgComm

Hewage, Chaminda T. E. R. [8288-89]SP4, [8290-48] SIP1

Heynderickx, Ingrid SC1045 Inst, [8291-29]S7A, [829129]S7A, [8291-37]S8

Higuchi, Yuta [8288-79]SP3

Hikima, Rie [8292-27]S7

Hildebrandt, Mario [8290-41]

SIP1, [8296-06]S1, [830115]S4, [8303-16]S6

Hirahara, Masahiro [8288-57] SP1

Hirakawa, Keigo 8305

ProgComm

Hirooka, Kenta [8288-74]SP3

Ho, Yo-Sung SC1046 Inst
Hoarau, Eric [8292-32]S8

Hoberman, Alejandro [829607]S1

Hocke, Jens [8291-01]S1, [8291-31]S7B, [8291-31] S7B

Hogue, Andrew [8288-39]S10, [8288-92]SP4

Holl, Friedrich [8304A-11]S3

Holland, Stephen E. [8298-31] SIP1

Holliman, Nicolas S. 8288 Chr, 8288 S4 SessChr

Holub, Vojtech [8303-07]S3

Holzhüter, Clemens, [8294-21] S10

Hong, Jisoo [8288-27]S7

Ho-Phuoc, Tien [8293-40] SIP1, [8293-41]SIP1

Hoppe, Tobias [8301-15]S4

Horiuchi, Shuma [8295B-61] SIP1

Horiuchi, Takahiko [8292-28] S7

Hornung, Hervé SC1049 Inst, [8299-01]S1

Horton, David M. [8291-16]S4

Hotta, Yoshinobu [8295A-29] S9

Houde, Jean-Christophe [8288-93]SP4

Hrarti, Miryem [8293-30]S9

Hsu, Chao-Yong [8303-01]S1

Hsu, Meichun [8294-14]S6, [8302-24]S7

Hsu, Winston H. 8304B ProgComm

$\mathrm{Hu}$, Jianying 8297 ProgComm

Hu, Sirui [8292-34]S9

$\mathrm{Hu}$, Wei [8302-18]S5

$\mathrm{Hu}$, Xuan [8297-12]S4

Hu, Yang [8295A-43]SIP1

$\mathrm{Hu}$, Yang [8305-05]S2

Hua, Gang 8304B ProgComm

Hua, Hong [8288-52]S13

Hua, Xian-Sheng 8304B ProgComm

Huang, Ching-Chun [8304B38]S6

Huang, Jiwu 8303 ProgComm

Huang, Tai-Hsiang [8291-63] SP2

Huang, Xiaopeng [8295A-52] SIP1

Huang, Xiwei [8298-03]S1

Huber-Mörk, Reinhold [830016]SIP1

Hung, Bob [8304A-12]S4

Hung, Mintsu [8305-10]S3

Hunter, Andrew A. [8302-19] S6, [8302-20]S6

Hur, Namho [8288-36]S9B, [8288-36]S5B, 8304A S3 SessChr

Huynh-Thu, Quan [8288-14] S4, [8288-30]S8, [8288-61] SP1

Hwang, Kyuyoung [8288-71] SP3

Hwang, Yong Seok [8288-67] SP2

Hwang, Youngkyoo [8289-08] S3

Hwu, Wen-Mei 8295B ProgComm

Hylton, Carly [8288-21]S6

Hyun, Dai-Kyung [8303-11]S5

Ichihara, Yasuyo G. [8292-05] S2

Ide-Ektessabi, Ari [8291-45] S9, [8291-48]SP1, [8296 36]SIP1

Ilgner, Justus F. [8288-01]S1

Imai, Francisco H. 8299 CoChr

Inoue, Mitsuteru [8288-64] SP2

Inoue, Naomi [8288-09]S3

Inoue, Takuya [8288-75]SP3

lonescu, Gelu [8291-30]S7B, [8291-30]S7B

Irvine, John M. [8301-27]S6

Isaka, Sae [8290-49]SIP1

Ishwar, Prakash [8288-13]S4

Islam, Atiq [8293-19]S6

Islam, Naveed [8303-27]S10

to, Kei [8292-05]S2

Itti, Laurent 8291 ProgComm

wasawa, Shoichiro [8288-09] S3

$$
\sqrt{ }
$$

Jacobs, Kenneth M. [8304A05]S2

Jacobson, Ralph E. [8293-17] S6

Jacoby, George [8298-20]S5 Jahanian, Ali [8302-23]S6

Jain, Hitesh [8300-21]SIP1

Jain, Ramesh C. [8302-01]S1

Jain, Sunil K. [8288-16]S5

Jamshidi, Mo [8295A-22]S7

Janak, Miroslav [8289-25]SIP1

Janesick, James R. SC504

Inst, SC916 Inst

Janetzko, Halldor 8294

ProgComm, [8294-14]S6

Jang, Won Jun [8290-51]SIP1

Jang, Yulei [8291-26]S6

Janowski, Lucjan [8288-31]S8

Jansen, Reinier J. [8291-41]S8

Jayachandra, Dakala

[8295A-44]SIP1

Je, Minkyu [8298-03]S1

Jelaca, Vedran [8301-11]S3,

[8301-12]S3, [8301-13]S3

Jellinek, Julius [8288-95]SP5

Jenkin, Robin B. 8293

ProgComm, 8293 S3

SessChr, [8299-10]S2, [8299-14]S2

Jeong, Byungil [8294-17]S

Jeong, Kyeong-Min [8288-81] SP3

Ji, Wenbo [8299-27]SIP1 
Katsaggelos, Aggelos [829152]SP1

Katsenou, Angeliki V. [830534]S7

Katsuyama, Yutaka [8295A29]S9

Kauke, Brian [8296-11]S2

Kaup, André [8288-48]S12, [8305-20]S5, [8305-27]S8

Kauppinen, Marko [8301-01] S1

Kawahito, Shoji [8298-06]S2

Kawai, Takashi 8288 ProgComm, 8288 S13 SessChr, [8288-57]SP1, [8288-85]SP4

Kawakita, Masahiro [8288-09]

Kawata, Kazumasa [8290-43] SIP1

Ke, Jun [8296-14]S2

Keefe, Dan 8294 ProgComm

Keelan, Brian [8299-02]S1, [8299-10]S2, [8299-14]S2

Keim, Daniel A. 8294

ProgComm, [8294-14]S6

Keimel, Christian [8293-38] SIP1, [8293-39]SIP1

Keinert, Joachim [8305-20]S5

Kella, Dror [8292-35]S9, [8293-06]S3

Kelly, Jonathan W. [8289-18] S5, [8291-21]S9A, [8291-21] S5A, [8291-55]SP2

Kemeny, Andras [8289-03]S1

Kennedy, Lyndon S. 8304B Chr, 8304B S7 SessChr 8304B SK1 SessChr

Kepplinger, Sara [8293-29]S9

Ker, Andrew D. 8303

ProgComm, 8303 S8

SessChr, [8303-19]S8, [8303-20]S8

Kerby, George [8292-39]S9

Kermorvant, Christopher [8297-07]S3, [8297-33]SIP-

Kerren, Andreas [8294-20]S10

Keyawa, Nicholas R. [830133]S8

Keyser, John [8294-03]S1

Khalfaoui, Souhaiel [829036]S8

Khan, Taha M. [8300-24]SIP1

Khanna, Nitin [8296-24]S4

Khaustova, Darya

Aleksandrovna [8288-30] S8

Khemka, Animesh [8295A23]S7

Kiess, Johannes [8304A-19] SIP1

Kiltz, Stefan [8303-16]S6

Kim, Chang yeong [8296-37] SIP1, [8298-28]SIP1

Kim, Chang-Su [8290-12]S4

Kim, Changyeong [8288-05] S2, [8288-71]SP3, [829635]SIP1, [8289-08]S3 [8290-09]S4, [8290-11]S4

Kim, Chelhwon [8296-28]S6

Kim, Choon-Woo 8292 ProgComm, [8292-43]S10

Kim, Dae-Chul [8292-42]S10

Kim, Dae-Sik [8288-33]S8

Kim, Dong-Hyun [8288-76]

SP3, [8288-77]SP3

Kim, Eun-Soo [8288-67]SP2

Kim, Ga-Hee [8292-43]S10
Kim, Han Suk [8289-21]S6, [8294-02]S1

Kim, Han-Eol [8292-43]S10

Kim, Hee-Dong [8303-05]S2

Kim, Hee-Seung [8288-81] SP3

Kim, Hyun-Eui [8288-81]SP3

Kim, James D. K. [8290-09]

S4, [8290-11]S4, [8296-37]

SIP1, [8288-05]S2, [8289

08]S3, [8298-28]SIP1

Kim, Jongwoo [8297-03]S2

Kim, Joohwan [8288-34]S9A [8288-34]S5A

Kim, Jung-Bae [8289-08]S3

Kim, Kyungnam [8301-16]S4

Kim, Min-Chang [8288-67] SP2

Kim, Munchurl [8305-01]S1

Kim, Sang Ho 8293

ProgComm, [8292-48]SIP1, 8293 S4 SessChr

Kim, Seona [8288-80]SP3

Kim, Seong-Jin [8288-05]S2

Kim, Sunworl [8304A-18]SIP

Kim, TaeChan [8299-18]S3,

[8299-18]S1, [8299-28]SIP1, [8290-08]S4

Kim, Taehyong [8290-24]S6

Kim, Yong Sun [8288-05]S2,

[8290-09]S4, [8290-11]S4

Kim, Yongje [8290-06]S3

Kim, Youngmin [8288-27]S7

Kim, Younhee [8305-08]S2

Kim, Yun-Tae [8288-73]SP3

Kimachi, Akira [8292-25]S7

Kimura, Nobutaka [8301-28] S7

Kinkar, Chhayarani R. [828924]SIP1

Kirovski, Darko [8303-29]SK2

Kisner, Sherman J. [8296-13] S2

Kitaura, Masaki [8292-04]S2 Kitsunezuka, Yoshiki [829043]SIP1

Kleiber, Michael [8288-02]S1

Klein, Julie [8299-26]SIP1

Klein, Stanley A. 8291

ProgComm

Klepko, Robert [8305-11]S3

Knight, Trevor [8294-07]S3

Knoche, Hendrik O. 8304A

ProgComm

Knoll, Aaron [8288-95]SP5

Kobayashi, Fumiya [8293-31] S9

Koch, Michael [8291-53]SP1

Koda, Yasumasa [8298-18]S5

Kodaira, Hiroaki [8288-18]S5

Kodovsky, Jan [8303-08]S3

Koffman, Larry [8305-29]S9

Koh, Kok-Wei [8292-30]S8

Koido, Yoshihisa [8288-85] SP4

Kojima, Michihiro [8291-46]S9

Kojima, Natsuki [8292-05]S2

Kokaram, Anil [8297-28]SIP1, [8305-19]S5

Kolbe, William [8298-31]SIP1

Komiya, Kenji [8290-40]SIP1

Kondi, Lisimachos Paul [8305-

34]S7, [8305-35]S7

Konrad, Janusz [8288-13]S4,

8305 ProgComm

Kopf, Stephan [8304A-19]SIP1

Koren, Israel [8298-12]S4

Koren, Zahava [8298-12]S
Korniski, Ronald [8288-94] SP4

Kosara, Robert 8294 CoChr

Kosman, Stephen L. [8298-17] S5

Kot, Alex C. 8303 ProgComm

Kothandaraman, Sreeni [8288-07]S2

Kothari, Sunil [8292-32]S8

Kottman, Michal [8301-08]S2

Kovacevic, Jelena [8296-05] S1, [8296-07]S1

Kozitsky, Vladimir [8305-30] S9, [8305-32]S9

Kozuka, Masayuki [8288-99] SK

Krasnov, Vitaly V. [8301-38] SIP1

Krätzer, Christian [8303-25] S10

Kreatsoulas, Constantine 8295B ProgComm

Kriener, Florian [8291-02]S1

Krishnan, Mohan [8301-21]S5, [8301-36]S8, [8301-37]S8

Kriss, Michael A. 8292

ProgComm, [8292-14]S4, 8299 ProgComm

Kristal, Alan [8304A-02]S1

Kröger, Knut [8304A-21]SIP1 [8304A-22]SIP1, [8304A-25] SIP1, [8304A-26]SIP1

Krstajic, Milos [8294-01]S1, [8294-04]S2

Kruger, Jens [8294-09]S4

Krupinsky, Elizabeth [829123]S6

Krylov, Vladimir [8296-19]S3

Kua, John [8296-29]S6

Kuang, Jiangtao 8299 ProgComm

Kubacki, Daniel [8296-42]S6

Kubicki, Karol [8290-14]S5

Kuk, Jung Gap [8300-19]SIP1

Kulik, Alexander [8288-32]S8

Kumar, Gaurav [8297-25]S8

Kumar, Sanjeev [8300-21]SIP1

Kunchamwar, Mangesh Kumar [8295B-55]S11

Kuniba, Hideyasu [8299-22]S5

Kunlin, Thomas [8291-30]S7B [8291-30]S7B

Kuo, C.-C. Jay 8305 ProgComm

Kurihara, Toru [8290-30]S7, [8290-40]SIP1

Kurita, Taiichiro [8288-65]SP2

Kuroda, Rihito [8298-18]S5

Kuruvilla, Anupama [8296-07] S1

Kwon, Hyunkyung [8288-69] SP2

Kwon, Ji Yong [8295A-21]S6

Kwon, Junghyun [8296-11]S2

Kwon, Taekyu [8296-32]S6

Kyung, Kyu-Min [8290-08]S4

Kyung, Wang-Jun [8292-08] S3

\section{$\mathbf{L}$}

La Cascia, Marco [8304B-33] S5

Laakso, Mikko [8288-40]S10 Labrosse, Fred [8301-09]S2 Lacatus, Catalin 8304A ProgComm

Ladret, Patricia [8291-30]S7B, [8291-30]S7B

Laforest, Timothé [8298-05] S2

Lafruit, Gauthier [8288-91] SP4

Lai, PoLin [8305-04]S1

Laidler, Paul [8292-38]S9

Lakså, Arne [8295A-11]S3, [8295A-12]S3

Laldin, Sidrah [8288-21]S6

Laligant, Olivier 8300

ProgComm

Lam, Edmund Y. [8296-14] S2, $8300 \mathrm{Chr}, 8300 \mathrm{~S}$ SessChr, [8300-04]S2

Lambers, Martin [8288-15] SP5

Lambert, Peter [8290-39]S9

Lamy, Francis [8291-07]S2

Lang, Dagmar [8301-24]S6

Langfelder, Giacomo [829905]S1

Lanman, Douglas [8288-08] S3

Lansel, Steve [8299-24]S5

Larabi, Chaker 8293

ProgComm, [8291-33]

S7B, [8291-33]S7B, 8293

S6 SessChr, [8293-18]S6, [8293-30]S9, [8293-32]S9

Larkins, Robert [8290-20]S5

Latecki, Longin Jan [8296-32] S6

Lattard, Didier [8298-05]S2

Lau, Nuno [8301-32]S7

Lauinger, Norbert 8301 ProgComm

Lauwereins, Rudy [8288-91] SP4

Lavoie, Frederic [8295A-28]S8

Lawrence, Victor B. [8295A52]SIP1

Le, Daniel X. [8297-03]S2

Le Breton, François [8290-21] S5

Le Callet, Patrick [8288-59] SP1, 8291 ProgComm, 8291 S6 SessChr, [829125]S6, [8291-54]SP2, [8305-14]S4

Le Guelvouit, Gaëtan [830322]S9

LeBourgeois, Frank [8297-04] S2

Lebowsky, Fritz 8292 ProgComm, 8292 S6 SessChr, [8292-10]S3 
Liao, Chris Huei Hung [828890]SP4

Liao, Guo Jia [8302-09]S3

Lienhart, Rainer W. 8304B ProgComm, [8304B-37]S6

Likforman-Sulem, Laurence 8297 ProgComm, [8297-07] S3, [8297-27]S8

Likova, Lora T. 8288 S9B SessChr, 8288 S9A SessChr, 8291 S4 SessChr, 8291 S5B SessChr 8291 S5A SessChr, 8291 ProgComm, [8291-17]S4, [8291-22]S9B, [8291-22] S5B

Lim, Hwasup [8288-05]S2, [8290-09]S4, [8290-11]S4

Lim, JaeGuyn [8296-35]SIP1

Lim, Kyoung-Moon [8288-60] SP1

Lin, C. T. [8301-33]S8

Lin, Christine [8288-91]SP4

Lin, I-Jong [8292-32]S8, 8295B ProgComm, [8295B-56]SK1

Lin, Qian 8302 S4 SessChr, 8302 S1 SessChr, 8302 S2 SessChr, 8302 S3 SessChr, 8302 S5 SessChr, 8302 S6 SessChr, 8302 S7 SessChr, $8302 \mathrm{Chr}$, [8302-08]S3, [8302-09]S3, [8302-13]S4, [8302-23]S6, [8304B-42]S7 Lin, Wei-Ju [8292-41]S10

Lin, Xiaofan 8297 ProgComm, [8297-12]S4, 8302 ProgComm, [8302-25]S7

Lin, Xiaoyan [8297-12]S4

Lin, Xinggang [8295B-58]S12

Liñán-Cembrano, Gustavo [8298-08]S3

Lindstrom, Peter 8294 ProgComm

Linsen, Lars 8294 ProgComm Liou, Jian-Chiun [8288-28]S7 Lipikorn, Rajalida [8304B-43] SIP1

Lipton, Lenny [8288-04]S2 Lister, Kristin [8291-52]SP1 Liu, Chang [8300-04]S2 Liu, Changsong [8297-08]S3, [8302-30]S7

Liu, Chiao [8298-11]S3

Liu, Huajian [8303-02]S1, [8303-03]S2, [8303-21]S9

Liu, Huaping [8292-03]S1

Liu, Jerry 8302 ProgComm, [8302-08]S3, [8302-09]S3, [8302-23]S6

Liu, Lei [8298-27]SIP1

Liu, Zhanping 8294 ProgComm, [8294-24]S11

Liu, Zhen [8302-09]S3

Liu, Zhihao [8296-21]S4

Liuha, Petri [8304A-24]SIP1

Livingston, Mark A. 8294 CoChr, 8294 SK1 SessChr, 8294 S4 SessChr, 8294 S10 SessChr, [8294-13]S5

Liwicki, Marcus 8297 ProgComm

Llebaria, Antoine [8295A03]S1

Loce, Robert P. [8292-31]S8, 8305 ProgComm, [830531]S8

Loewen, Victor [8292-39]S9
Lohou, Christophe [8290-50] SIP1

Lomheim, Terrence S. 8298 ProgComm

Long, Gregory [8289-21]S6

Longoni, Antonio Francesco [8299-05]S1

Lopez, Angel [8298-11]S3

Lopresti, Daniel P. 8297

ProgComm

Louradour, Jérôme [8297-33] SIP1

Lu, Chun-Shien [8303-01]S1

Lu, Ligang 8305 ProgComm

Lu, Xiaoqing [8302-18]S5

Lu, Yu Hua [8299-04]S1

Lu, Yue [8299-03]S1

Lubenko, Ivans [8303-19]S8

Lubniewski, Pawel J. [829050]SIP1

Lue, James [8289-09]S3

Lukin, Vladimir V. 8295A ProgComm, [8295A-04]S1, [8295A-37]SIP1

Lumsdaine, Andrew [8294-32] SIP1, [8295B-57]S12, [8299-07]S1, [8299-08]S1

Lund, William B. [8297-35] SIP1

Luo, Chaomin [8301-21]S5, [8301-36]S8, [8301-37]S8

Luo, Jiebo 8302 ProgComm

Luo, Ronnier [8292-20]S5

Luong, Marie [8295A-26]S8

Luttenberger, Silas [8304A-25] SIP1

Lv, Shaoting [8305-28]S9

Lyons, Damian M. [8301-07] S2

Lypetskyy, Yuriy [8301-14]S3

M

Ma, Cheng [8298-01]S1

Ma, Di [8297-30]SIP1

Macchiavello, Bruno [8305-10] S3

MacDonald, Lindsay W. 8293 ProgComm

Macesic, Marko M. [8301-13] S3

Machizaud, Jacques [829240]S10

MacKenzie, Kevin J. [8288-51] S13

Macq, Benoît M. 8290

ProgComm

Madhukar, Monica [8295A-36] SIP1

Maeda, Yuki [8288-45]S12

Maggioni, Matteo T. [8296-22] S4

Magnan, Pierre 8298 ProgComm

Mahendra, Adhiguna [830006]S2

Makrushin, Andrey [8290-41] SIP1, [8295A-31]S9, [829606]S1

Makur, Anamitra [8295A-44] SIP1

Maloney, Laurence T. [829161]SK1

Maltz, Marty [8292-51]SIP1

Malzbender, Thomas [829443]SK2, 8295B ProgComm

Mamishev, Alexander V. [8304A-02]S1
Man, Hong [8295A-52]SIP1

Manamanni, Noureddine [8288-72]SP3

Mangiatordi, Federica [8295A16]S5

Manikoth, Natesh [8305-31]S8

Manjunath, Bangalore 8303 ProgComm

Manning, Christopher [829715]S5

Manohara, Harish [8288-94] SP4

Manoni, Rachel E. [8295A-49] SIP1

Mansmann, Florian [8294-01] S1

Mantel, Claire [8291-30]S7B, [8291-30]S7B

Marchuk, Vladimir I. [8295A17]S5, [8295A-39]SIP1

Marcu, Gabriel G. 8292 Chr, 8292 S3 SessChr

Margolis, Todd 8289 S4 SessChr, [8289-14]S4, [8289-15]S4

Marilly, Emmanuel [8305-18] S5

Marinas, Javier [8301-05]S2

Marini, Daniele [8288-20]S5

Marini, Fabrizio [8293-09]S4

Marsden, Alison [8289-21]S6

Marsh, William E. [8289-18]S5

Marshall, Stephen 8295A ProgComm

Martin, Fred [8301-34]S8

Martin, Pierre [8298-20]S5

Martin, Sébastien [8298-10]S3

Martinetz, Thomas [8291-01] s1

Martini, Maria G. [8288-89] SP4, [8290-48]SIP1

Masuch, Maic [8288-42]S11, [8288-97]SP5

Masuda, Masataka [8293-31] S9

Matherson, Kevin J. SC1058 Inst, 8298 S4 SessChr, 8298 ProgComm, 8299 ProgComm

Matlin, Erik [8296-27]S5

Maurette, Michel [8301-23]S6

Mayhew, Christopher A. [8291-64]SP2

Mayhew, Craig M. [8291-64] SP2

Mazalov, Vadim [8297-10]S3

McAdam, Christopher [829919]S3, [8299-19]S1

McCann, John J. 8291 ProgComm, [8291-36]S8, [8291-60]SK1, [8292-02]S1

McCann, Michael [8296-05]S1

McCarten, John P. [8298-17] S5

McCourt, Mark E. [8291-15]S4

McDowall, Ian E. 8289 S5

SessChr, 8289 S1 SessChr 8289 S3 SessChr, 8289 Chr

McElvain, Jon S. 8299 ProgComm

McFadden, Lucy A. [8296-16] S3

McFadden, Steven [8293-10] S4

McGinnis, Bradley [8288-95] SP5

McGuinness, Michael E. [8301-34]S8

McKay, Troy [8305-29]S9

McKeown, Donald M. [830529]S9

McLean, Brian [8296-16]S3

McPherson, Charles A.

8301 S6 SessChr, 8301

ProgComm, [8301-27]S6

Medeiro, Fernando [8298-02] S1

Medina, Alberto [8301-09]S2

Medrano Navarro, Jaime [8302-16]S5

Meisenzahl, Eric J. [8298-17] S5

Memarsadeghi, Nargess [8296-16]S3

Memon, Nasir D. 8303 S7 SessChr, $8303 \mathrm{Ch}$

Menasri, Farès [8297-07]S3, [8297-33]SIP1

Mendelowitz, Eitan [8289-15] S4

Meneveaux, Daniel [8293-18] S6

Merhof, Dorit [8294-22]S11

Meriaudeau, Fabrice 8300

ProgComm, [8300-06]S2

Merkel, Ronny [8290-33]S8

Merritt, John O. SC060 Inst, 8288 S9A SessChr, 8288 S8 SessChr, 8288 S9B SessChr, 8291

S5B SessChr, 8291 S5A SessChr

Messina, Enrico [8299-20]S2, [8299-20]S4

Meuret, Youri [8290-39]S9

Meurie, Cyril [8300-23]SIP1

Mezaris, Vasileios 8304B ProgComm

Michelsburg, Matthias [8304A-09]S3

Mignotte, Max [8295A-28]S8

Miguel, Bruno [8290-50]SIP1

Miguet, Serge 8290 ProgComm

Milanfar, Peyman [8296-27] S5, [8296-28]S6, 8305 ProgComm, [8305-13]S4

Miller, Eric L. 8296 ProgComm

Mims, Steve [8298-11]S3

Min, Jongsul [8290-06]S3

Minagawa, Akihiro [8295A29]S9

Mittal, Anish [8291-12]S3

Miyake, Yoichi 8293 ProgComm

Miyata, Kimiyoshi [8291-46] S9, [8293-35]S10 
Nam, Dong-Kyung [8288-73] SP3

Namazi, Nader M. [8295A-18] S5

Namburete, Ana [8298-12]S4

Namiki, Jun [8298-22]S6

Narabu, Tadakuni [8298-32] SIP1

Narayanan, Rangavittal [8295A-34]S10

Narisetty, Jayanthi M. [8304A08]S3

Nauge, Michael [8291-33]S7B, [8291-33]S7B

Navratil, Paul [8294-17]S7

Nelson, Terry [8292-39]S9

Nercessian, Shahan C. [8295A-25]S7

Neri, Alessandro 8295A ProgComm, [8295A-02]S1, [8295A-06]S2, [8303-17]S6

Nestinger, Stephen S. [830135]S8

Netravali, Ravi [8295A-52]SIP1

Neves, António J.R. [8301-32] $\mathrm{S} 7$

Ngo, Chong-Wah 8304B ProgComm

Ngoua, Auguste [8298-04]S2

Nguyen, Tan H. [8296-20]S4

Nguyen, Valérie 8298 S3 SessChr, $8298 \mathrm{Chr}$

$\mathrm{Ni}$, Kang-Yu [8301-16]S4

Nicholson, Didier [8293-32]S9

Niederkorn, Dieter [8305-27]

\section{Niel, Kurt S. 8300}

ProgComm, 8301

ProgComm

Niemelä, Karri [8295B-52]S11

Nieves, Juan Luis [8300-17] SIP1

Niño-Castaneda, Jorge Oswaldo [8301-11]S3, [8301-13]S3, [8301-12]S3

Nishi, Shogo [8292-25]S7

Nishino, Toshimasa [8301-19] S5

Nishiyama, Shusuke [829639]SIP1

Noel, Alexandre [8300-06]S2

Nomura, Kosuke [8288-65] SP2

Nomura, Yoshihiko 8301 ProgComm, [8301-19]S5

Noonan, Joseph P. [8304A-31] SIP1

Norton, Adam [8301-40]SIP1

Novak-Marcincin, Jozef [8289-25]SIP1

Novakova-Marcincinova, Ludmila [8289-25]SIP1

Nowell, Lucille T. 8294 ProgComm

Nyman, Göte S. 8293 ProgComm, 8293 S10 SessChr, [8293-20]S7A [8293-20]S7A

Obafemi-Ajayi, Tayo [8297-05] S2

Oberdörster, Alexander [8299-06]S1

Obermaier, Harald 8294 ProgComm
Obermark, Jerome [8295A18]S5

O'Brien-Strain, Eamonn 8302-23]S6

Ohmori, Seishi 8299 ProgComm

Ohtake, Hiroshi [8298-22]S6

Ohtsuki, Rie [8292-27]S7

Ohya, Jun [8295A-30]S9, [8301-04]S2

Oi, Ryutaro [8288-65]SP2

Okada, Yusuke [8296-34]SIP1

Okoda, Kenta [8288-45]S12

Okumura, Hiroshi [8295A50]SIP1

Okura, Fumio [8292-04]S2

Okutomi, Masatoshi [8299-23] S5

O’Leary, Paul L. [8300-25]S4

Oliver, Arnau 8300 ProgComm

Oliver, James H. [8289-18]S5 Olsson, Roger [8288-55]SP1. [8288-78]SP3, [8290-05] S3, [8290-07]S4

O'Neil-Dunne, Jarlath [8289$15] S 4$

Onural, Levent 8290 ProgComm

Orjuela Vargas, Sergio Alejandro [8293-36]S4, [8295A-47]SIP1, [8300-22]

Ortega, Antonio 8305 ProgComm, [8305-39]SK2

Ortiz Jaramillo, Benhur [8293-36]S4, [8295A-47] SIP1

Ortiz Segovia, Maria V [8292-37]S9, [8293-25]S8

Ostrow, Alan [8294-29]SIP1

O’Sullivan, Joseph A. 8296 ProgComm

Ouellette, David [8298-20]S5

Ouji, Asma [8297-04]S2

Overby, Derek R. [8294-03]S1

Owechko, Yuri [8301-16]S4

Owens, John D. [8295B-59] S12

Oyabu, Umi [8291-46]S9

Ozawa, Noriaki [8295A-29]S9

Ozawa, Seiichiro [8290-42] SIP1

\section{$\mathbf{P}$}

Paar, Gerhard M. [8301-09] S2, [8301-23]S6

Padir, Taskin [8301-35]S8

Pagés, Rafael [8290-18]S5

Pahwa, Ramanpreet S. [829641]S6

Paindavoine, Michel [8298-04] S2

Pajdla, Tomas [8301-23]S6

Pal, Umapada [8297-29]SIP1

Paleari, Marco [8301-31]S7

Paljic, Alexis [8294-30]SIP1

Pallotti, Emiliano [8295A-16]S5

Pan, Danny [8294-10]S4

Pan, Hao [8288-90]SP4

Pan, Tao [8298-27]SIP1

Panchanathan, Sethuraman 8304A ProgComm

Pandremmenou, Katerina [8305-35]S7

Panetta, Karen [8295A-25]S7

Panic, Marko [8301-13]S3
Paoli, Jean-Noel [8300-12]S4, [8301-20]S5

Papka, Michael [8288-95]SP5

Pappas, Thrasyvoulos

N. 8291 Chr, 8291 SK1

SessChr, 8291 S3 SessChr,

[8291-18]S4, [8291-41]S8,

8305 ProgComm

Paquet, Eric 8290 ProgComm, 8290 S4 SessChr, [829023]S6

Paquit, Vincent C. 8300 ProgComm

Pardridge, Robert [8289-09] S3

Park, Byung Kwan [8296-35] SIP1

Park, Dusik [8288-71]SP3, [8288-73]SP3, [8288-87] SP4

Park, Hyun Wook [8288-24]S6

Park, Hyung Jun [8292-18]S5

Park, II-Su [8292-42]S10

Park, Insu [8305-06]S2

Park, Jae-Hyeung [8288-27] S7, [8288-81]SP3

Park, Jae-Young [8293-17]S6

Park, Jinah 8294 CoChr

Park, Ju-Yong [8288-73]SP3

Park, Sangcheol [8304A-18] SIP1

Park, Sangho [8295A-13]S4, [8301-41]SIP1

Park, Se Un [8296-15]S2

Park, Seong Jun [8292-39]S9

Park, Sung W. 8295B ProgComm

Park, Sung-Bum [8305-22]S6

Park, Taesung [8290-06]S3

Parmar, Manu 8299 ProgComm

Parmar, Manu [8299-24]S5

Parra Pozo, Albert [8304A01]S1

Parraman, Carinna E. 8292 ProgComm, 8292 S8 SessChr, [8292-16]S4, [8292-38]S9

Parrish, Matt [8301-36]S8

Parsopoulos, Konstantinos E. [8305-34]S7, [8305-35]S7

Pasteau, François [8305-16] S4

Paul, Peter [8305-30]S9

Paulik, Mark [8301-21]S5, [8301-36]S8, [8301-37]S8

Paulus, Dietrich W. [8290-44] SIP1, [8301-24]S6

Payeur, Pierre [8291-57]SP2

Pearlman, William A. 8305

ProgComm, [8305-05]S2

Pedeboy, Jean-Pierre [8290 38]S9

Pei, Soo-Chang [8303-01]S

Peikert, Silvio [8288-66]SP2

Pekkucuksen, Ibrahim E. [8288-17]S5

Pelah, Adar 8291 ProgComm

Pelamatti, Alice [8299-05]S1

Peli, Eliezer 8291

ProgComm, [8292-13]S4

Pellegrino, Donald A. 8294

ProgComm

Peña Saldarriaga, Sebastian [8297-32]SIP1

Peng, Honghong [8299-02]S1

Peng, Wei [8302-15]S5

Pepion, Romuald [8291-54] SP2

Pepperell, Robert [8291-35]S8

Pereira, Fernando 8305 ProgComm

Persson, Anders [8288-55] SP1

Perwass, Christian [8291-04] S1

Pesquet-Popescu, Béatrice 8305 ProgComm

Peterka, Tom [8288-95]SP5

Petersen, Hannah [8294-08] S3, [8294-26]SIP1, [829427]SIP1

Peterson, Ellen [8301-35]S8

Peterson, Michael R. [8305 36]S7

Petit, Eric [8295A-24]S7

Petit, Sebastien [8300-06]S2

Petkovsek, Steve J. [8301-40] SIP1

Petljanski, Branko [8299-17] S2

Pevny, Tomas [8303-09]S3, [8303-20]S8

Phadke, Madhura N. [8294 08]S3, [8294-26]SIP1, [8294-27]SIP1

Philippe, Robert [8288-56] SP1, [8288-86]SP4

Philips, Wilfried [8293-36]S4, [8295A-47]SIP1, [8295A53]SIP1, [8300-22]SIP1, [8301-11]S3, [8301-12]S3, [8301-13]S3

Phillips, Jonathan B. SC1049 Inst, [8293-01]S3, [8293-01] S1

Phillips, Rhonda [8296-17]S3, [8296-18]S3

Picollo, Marcello [8291-43]S9

Pike, William 8294 ProgComm

Pinho, Márcio Sarroglia [828919]S6

Pinto, Guilherme O. [8291-14]

Pinto, Lifford [8294-08]S3, [8294-26]SIP1, [8294-27] SIP1

Pitrey, Yohann [8291-54]SP2

Pizlo, Zygmunt 8296

ProgComm, [8296-32]S6, [8302-13]S4, [8302-21]S6

Pizurica, Aleksandra [830111]S3, [8301-13]S3, [8295A53]SIP1

Plumlee, Matthew [8294-06] S3

Poggesi, Marco [8291-43]S9 
Ramani, Sathish [8296-21]S4

Ramaswamy, Arun [8303-28] SK1

Ramponi, Gianni 8295A ProgComm

Rao, A. Ravishankar 8300 ProgComm

Rashwan, Abdullah M. [829706]S3

Rashwan, Mohsen A. [829706]S3

Rasmussen, D. René 8293 ProgComm, [8293-16]S6

Rauterberg, Matthias 8304A ProgComm

Ravì, Daniele [8299-20]S2, [8299-20]S4

Raviv, Daniel 8301 ProgComm

Ream, Allen [8288-94]SP4

Recker, John 8295B Chr, [8295B-59]S12

Reddy, Prakash D. [8302-27] S7

Reddy, Rohith K. [8296-20]S4

Redi, Judith A. [8291-29]S7A, [8291-29]S7A, [8291-37]S8

Redies, Christoph [8291-53] SP1

Redl, Arne [8293-38]SIP1, [8293-39]SIP1

Reed, Alastair M. [8302-29]S7

Reeves, Stanley J. 8296 ProgComm

Regalia, Phillip A. 8304A ProgComm

Reibman, Amy R. [8291-11]S3

Reichel, Roman [8288-53]S13

Reiff, Motti [8289-02]S1

Reinert-Nash, John R. 8299 ProgComm

Reinheimer, Alice L. 8298 ProgComm, 8298 S2 SessChr

Renaud, Ron [8288-36]S9B [8288-36]S5B

Restrepo, Alfredo [8295A-15]

Reymond, Gilles [8289-03]S1

Rhyne, Theresa-Marie 8294 ProgComm

Richter, Thomas [8288-48]S12

Riesenfeld, Richard F. [829433]SIP1

Ringger, Eric K. [8297-35]SIP1

Rising, Hawley K. 8291

ProgComm

Ritschel, Tobias [8291-19]S9A [8291-19]S5A

Rivera, Susan M. [8291-16]S4

Rizzi, Alessandro 8292 S5 SessChr, 8292 S2 SessChr 8292 Chr, [8292-23]S6

Ro, Yong Man [8288-24]S6

Roberts, Ian 8294 CoChr

Rodricks, Brian G. 8299 Chr

Rodriguez, Tony F. [8302-02] S1

Rodríguez, Aida [8300-17] SIP1

Rodriguez-Diaz, Eladio [8295A-08]S2

Rodriguez-Pardo, Carlos Eduardo [8292-11]S3, [8292-12]S4

Rodríguez-Vázquez, Ángel B. [8298-02]S1, [8298-08]S3

Roe, Natalie [8298-31]SIP1
Rogowitz, Bernice E. SC1050 Inst, 8291 SK1 SessChr, 8291 S7A SessChr, 8291 S SessChr, 8291 Chr, [829128]S6, 8293 S7A SessChr

Rohrdantz, Christian [8294-14]

Rolland-Neviere, Xavier [8303-24]S9

Rolleston, Robert J. 8302 ProgComm

Romero, Javier [8300-17]SIP1

Röning, Juha $8301 \mathrm{Chr}$, 8301 S1 SessChr, 8301 S2 SessChr, [8301-01]S1, [8301-06]S2

Rosa, Stefano [8301-31]S7

Rosen, Jeffrey [8296-21]S4

Rosenbaum, René [8294-12] S5, [8294-18]S7, 8304A ProgComm, [8304A-17] SIP1

Rosner, Marcin [8301-02]S1, [8301-10]S3

Rossier, Romain [8292-07]S3

Rothe, Hendrik [8290-29]S7

Rothenbuhler, Adrian [8300 09]S3

Roubtsova, Nadejda S [8295A-05]S2

Rouvie, Anne [8298-10]S3

Rowley-Brooke, Róisín F. [8297-28]SIP1

Rubin, Norman 8295B ProgComm

Ruichek, Yassine [8300-23] SIP1

Ruzanka, Silvia P. [8289-13]S4

Ruzic, Tijana [8295A-53]SIP1

Ryan, Louise C. [8288-51]S13

Rychagov, Michael N. [829248]SIP1

Ryu, Seungchul [8288-76] SP3, [8288-77]SP3

Ryu, Seung-Jin [8303-11]S5 S

Saadane, Hakim [8293-30]S9

Saber, Eli 8295A ProgComm, [8295A-43]SIP1, 8305

ProgComm

Sabourin, Robert [8297-18]S7

Sack, Stefan [8304A-21]SIP1

Sacré, Jean-Jacques [828854]SP1

Sadawi, Noureddin M. [829713]S4

Sadeghipoor, Zahra [8299-03] S1

Safaee-Rad, Reza [8292-22] S6, [8293-13]S5

Safonov, Ilia V. [8292-48]SIP1

Sagiraju, Phanikrishna K. 8304A ProgComm

Sahebi, Mahmoud Reza [8299-21]S

Sahyun, Melville R. V. [829151]SP

Said, Amir [8288-47]S12, $8305 \mathrm{Chr}$

Saito, Hideo [8288-75]SP3

Sakai, Masahisa [8288-09]S3

Sako, Hiroshi 8297

ProgComm

Salehi, Saeed [8305-21]S6

Salgado, Luis [8290-13]S4, [8290-18]S5, [8301-05]S2
Salih, Wasil H. M. [8290-28]

S7

Salis, Ghislain [8301-20]S5

Salters, Bart A. [8291-56]SP2

Salvaggio, Carl [8305-29]S9

Salvaggio, Philip S. [8305-29] s9

Samant, Abhay 8304A ProgComm

Samarabandu, Jagath $\mathrm{K}$ 8295A ProgComm

Samland, Fred [8301-15]S4

Sampat, Nitin 8299 Chr, 8299 S5 SessChr

Sanchez, Isaac A. [8295A-38] SIP1

Sankur, Bülent 8290 ProgComm

Santhaseelan, Varun [830139]SIP1

Santini, Simone 8304B CoChr, [8304B-32]S5

Santos-Villalobos, Hector J. [8296-23]S4

Sari-Sarraf, Hamed 8300 ProgComm

Saron, Clifford D. [8291-16]S4

Sastry, Challa Subrahmanya [8295A-51]SIP1

Satkhozhina, Aziza [8302-21] S6

Sato, Masahito [8288-09]S3

Sato, Satoshi [8296-34]SIP1

Saunders, Craig [8305-32]S9

Saupe, Dietmar [8293-03]S2, [8293-03]S4

Sautrot, Sylvie [8298-21]S6

Sauvage, Vincent [8290-50] SIP1

Saveliev, Peter [8295A-09]S3

Sawada, Shimpei [8288-62] SP2

Sawyer, David [8298-20]S5

Saxena, Dhruv [8292-35]S9

Sbarbaro, Daniel G. [8300-13] S4

Sbihi, Abderrahmane [830023]SIP1

Schäfer, Marcel [8303-04]S2

Scharpf, William [8295A-18]S5

Scharsich, Maximilian [8304A11]S3

Scheidegger, Luiz [8294-09] S4

Schelkens, Peter 8290

ProgComm, 8300

ProgComm

Schellenberg, Thomas [829717]S6

Schettini, Raimondo [8299-29] SIP1, [8300-02]S1, 8304B CoChr, [8304B-32]S5

Schild, Jonas [8288-42]S11, [8288-97]SP5

Schill, Alexander [8297-16]S6

Schmalstieg, Dieter [8294-21] S10

Schmid, Maurizio [8295A-01] S1

Schneider, Andrea [8291-16] S4

Schneider, Dorian [8300-14]S4

Schneller, William [8289-04]S2

Schöberl, Michael [8288-48] S12, [8305-20]S5

Schönauer, Robert [8301-14] S3

Schonfeld, Dan 8305

ProgComm

Schreck, Tobias 8294

ProgComm

Schreiber, Falk [8294-20]S10

Schuetz, Peter [8302-10]S4

Schulmerich, Matthew [829620]S4

Schulz, Hans-Jörg [8294-21] S10

Schulze, Jurgen P. [8289-09] S3, [8289-21]S6, [829402]S

Schulze, Yohanna [8295A-24] S7

Schumann, Heidrun [8294-21] S10

Schuster, Daniel [8297-16]S6

Schwartzhaupt, Jorge [828909]S3

Schwarz, Sebastian [828878]SP3, [8290-07]S4

Schwotzer, Thomas 8304A ProgComm

Sebai, Dorsaf [8290-47]SIP1

Sebe, Nicu 8304B Chr, 8304B S6 SessChr

Seele, Sven [8288-42]S11

Seidel, Hans-Peter [8291-19] S9A, [8291-19]S5A

Seiler, Jürgen [8288-48]S12, [8305-20]S5

Seitner, Florian H. [8288-22]S6

Sekkal, Rafiq [8305-16]S4

Sekulovksi, Dragan [8291-56] SP2

Selesnick, Ivan W. 8295A ProgComm, 8300 ProgComm

Semenishchev, Evgeny [8295A-39]SIP1

Semke, William [8295A-13]S4, [8301-41]SIP1

Sencar, Husrev T. 8303 ProgComm

Seo, Jungdong [8288-76] SP3, [8288-77]SP3

Seo, Min-Woong [8298-06]S2

Sepehrband, Farashid [829921]S

Serpico, Sebastiano B. [829619]S3

Sersic, Damir 8295A ProgComm

Setlur Nagesh, Swetadri Vasan [8298-29]SIP

Seulin, Ralph [8290-36]S8, 8300 ProgComm

Seuntiens, Pieter [8291-56] SP2

Sexton, Alan P. [8297-13]S4 
Smeaton, Alan F. 8304B ProgComm

Smith, John R. 8304B ProgComm

Smith, Michael D. [8288-58] SP1

Smith, William [8291-44]S9

Snoek, Cees G. M. 8304B Chr, 8304B SK2 SessChr. 8304B S5 SessChr

Soghoyan, Arpine [8304A08]S3

Soh, Yongseok [8290-12]S4

Sohn, Hosik [8288-24]S6

Sohn, Kwanghoon [8288-76] SP3, [8288-77]SP3

Solh, Mashhour [8290-03]S1

Sonachalam, Sekar [8295B55]S11

Song, In-Yong [8292-08]S3

Song, Ki Sun [8295A-20]S6

Song, Meehae [8289-06]S2

Song, Samuel M. [8296-11]S2

Sooknanan, Ken [8305-19]S5

Sorge, Volker [8297-13]S4

Soto, Miguel E. [8300-13]S4

Spagnuolo, Michela 8290 ProgComm

Speigle, Jon [8292-11]S3

Speranza, Filippo [8288-36] S9B, [8288-36]S5B

Springer, Dominic [8305-27] S8

Srihari, Sargur N. 8297 ProgComm, [8297-19]S7, [8297-26]S8

Srinivasan, Harish [8297-19] S7, [8297-26]S8

Srivastava, Satyam [8304A14]S4

Staddon, Jessica [8303-18]S4

Stanco, Filippo D. 8299 ProgComm

Stanfield, Brodie [8288-39] S10, [8288-92]SP4

Stanley, R. Joe [8297-02]S2

Starikov, Sergey N. [8301-38] SIP1

Stark, Ashley [8291-16]S4

Steed, Chad A. 8294

ProgComm, 8294 S3

SessChr, [8294-05]S2

Stefani, Lorenzo [8291-43]S9

Stefani, Oliver [8288-32]S8, [8288-53]S13

Stefanidis, Anthony [8301-27] S6

Steinebach, Martin [8303-02] S1, [8303-03]S2, [8303-04] S2, [8303-13]S5, [8303-15] S6, [8303-21]S9

Stentiford, Fred W. M. [829134]S7B, [8291-34]S7B

Stern, Alvin G. [8298-16]S5

Stern, John D. 8288 ProgComm, $8288 \mathrm{~S} 6$ SessChr

Steurer, Johannes H. [829105]S1

Stevenson, Robert L. 8305 Chr, [8305-15]S4

Stiller, Peter F. [8295A-07]S2

Stoenescu, Daniel [8288-61] SP1

Stolz, Christophe 8300 ProgComm, [8300-06]S2
Stone, David M. 8291 ProgComm, 8291 S9 SessChr

Stork, David G. SC965 Inst, [8291-40]S8, [8291-44]S9, [8291-47]S9

Straub, Jeremy [8301-18]S4

Strauss, Clement [8305-16]S4

Streit, Marc [8294-21]S10

Strom, Marie [8291-47]S9

Styles, Matthew G. [8294-33] SIP1

Subramaniam, Venkata 8297 ProgComm

Subramanian, Kalpathi R. 8294 ProgComm

Subsol, Gérard [8290-21]S5, [8290-38]S9

Sugawa, Shigetoshi [8298-18] S5

Sullivan, Gary J. [8305-38] SK1

Sumer, Aslihan [8288-95]SP5

Sun, Jun [8295A-29]S9

Sun, Qun 8299 ProgComm

Sun, Tong [8302-15]S5

Sun, Yuejia [8302-30]S7

Sundaram, Hari 8304B ProgComm

Sundaramurthy, Mohanapriya C. [8304A-08]S3

Sundara-Rajan, Kishore [8304A-02]S1

Sung, Gee-Young [8288-73] SP3

Süsstrunk, Sabine 8291

ProgComm, 8299

ProgComm, [8299-03]S1, [8305-40]SK3

Suyama, Shiro [8288-98]SP2

Suzuki, Masahiro [8289-23] SIP1

Swanepoel, Jacques [829718]S7

Symons, Christopher T. [8294-05]S2

Syu, Jia-Hou [8304B-38]S6

Sze, Wuifung [8300-04]S2

Szmatula, Alex [8301-36]S8

\section{$\mathrm{T}$}

Taghva, Kazem 8297 ProgComm

Taguchi, Akira 8295A ProgComm

Tajbakhsh, Touraj [8292-21] S6, 8299 ProgComm, [8299-30]SIP1

Takagi, Hiroyuki [8288-64]SP2

Takahashi, Hideya [8288-74] SP3

Takahashi, Shigeo [8294-38] SIP1

Takahashi, Shohei [8295A30]S9

Takahashi, Taichi [8288-63] SP2

Takaki, Yasuhiro [8288-11]S3, [8288-63]SP2

Takala, Jarmo H. 8304A ProgComm

Takarae, Yukari [8291-16]S4

Takazawa, Keigo [8289-23] SIP1

Takebe, Hiroaki [8295A-29]S9

Takubo, Shoichiro [8295A-50] SIP1
Talandis, Jonas [8288-95]SP5

Talebi, Hossein [8305-13]S4

Tam, Wa James [8288-36]

S9B, [8288-36]S5B, [829120]S9A, [8291-20]S5A

Tamhankar, Mangesh [829721]S7

Tan, Huachun 8295B ProgComm

Tan, Wai-Tian [8305-10]S3

Tanaka, Masayuki [8299-23]

Tanapichet, Pakpoom [8304B-43]SIP1

Tang, Sarah Y. [8290-22]S5

Tang, Yi [8297-26]S8

Tang, Zhi [8297-12]S4, [830218]S5

Tanimoto, Masayuki [8288-79] SP3

Tanimoto, Tetsushi [8292-28] S7

Tastl, Ingeborg [8292-30]S8, [8295B-59]S12

Tatematsu, Naotomo [830104]S2

Tavanti, Francesca [8304B32]S5

Tawadrous, Mina [8288-39] S10, [8288-92]SP4

Taylor, Russell M. [8294-08] S3, [8294-26]SIP1, [829427]SIP1

Tchagaspanian, Michaël [8298-10]S3

Tehrani, Mehrdad Panahpour [8288-79]SP3

Tenedorio, Daniel [8289-09]S3

Teoh, Soon Tee 8294 ProgComm

Teranishi, Nobukazu 8298 ProgComm

Teredesai, Ankur [8304A-02] S1

Tescher, Andrew G. 8305 ProgComm

Tessières, Régis [8299-01]S1

Tezaur, Radka 8299 ProgComm

Thakar, Ani [8294-10]S4

Thalmann, Markus [8298-33] SIP1

Thébault, Cédric [8288-61] SP1, [8288-86]SP4

Theisen, Bernard L. 8301 ProgComm, 8301 S8 SessChr, [8301-03]S1

Thoma, George R. 8297 ProgComm, [8297-02]S2, [8297-03]S2

Thoury, M. [8291-43]S9

Tian, Qi 8304B ProgComm

Tian, Yonghong 8302 ProgComm

Tirilly, Pierre [8294-36]SIP1

Tisato, Francesco [8300-02] S1

Titus, Albert H. [8298-29]SIP1

Toderici, George [8304B-40] S7

Tolstaya, Ekaterina V. [829010]S4, [8292-48]SIP1

Tomaselli, Valeria [8299-20] S2, [8299-20]S4

Tominaga, Shoji 8292

ProgComm, 8292 S9

SessChr, [8292-27]S7,

[8292-28]S7

Tomioka, Satoshi [8296-39] SIP1

Toque, Jay Arre [8291-45]S9, [8291-48]SP1

Torres, Sergio N. [8300-13] S4

Touahni, Rajja [8300-23]SIP1

Tourancheau, Sylvain [828831]S8, [8288-55]SP1, [8290-05]S3

Tournier, Nicolas [8290-38]S9

Tretter, Daniel [8302-13]S4, [8302-23]S6

Treutner, Niklas [8290-02]S1

Triantaphillidou, Sophie 8293 ProgComm, 8293 S5 SessChr, [8293-17]S6

Trifan, Alina L. [8301-32]S7

Trifas, Monica A. [8293-34] $\mathrm{S} 10$

Troccoli, Alejandro SC1021 Inst, [8304A-03]S1

Tröger, Tobias [8288-48]S12

Truchetet, Frederic [829032]S8, 8290 ProgComm 8290 S8 SessChr

Tsaftaris, Sotirios [8291-52] SP 1

Tsai, Chao-Hsu [8288-68]SP2

Tse, Francis [8302-30]S7

Tseng, Kun-Lung [8288-68]

Tsirlin, Inna [8288-29]S8

Tsuda, Naoaki [8301-19]S5

Tsumura, Norimichi [8293-35] S10

Tu, Lien [8298-29]SIP1

Tubaro, Stefano 8290 ProgComm

Tuchscheerer, Sven [8304A10]S3

Tuck, Nat [8301-34]S8

Tumblin, John [8291-03]S

Turner, Eric [8296-18]S3

Tychonievich, Luther A. [829437]SIP1

Tyler, Christopher W. 8288 S9A SessChr, 8288 S9B SessChr, 8291 S5B SessChr, 8291 S9 SessChr 8291 S5A SessChr, 8291 ProgComm, [8291-22]S9B [8291-22]S5B, [8291-44]S9

Tzeng, Di-Yuan [8292-39]S9

U

Uchida, Shigeki [8288-11]S3

Uehira, Kazutake [8289-23] SIP1, [8290-49]SIP1

Uematsu, Yuko [8288-75]SP3

Ulichney, Robert A. [8292-35] 


\section{Index of Authors, Chairs, and Committee Members}

W

Waggoner, Jarrell W. [829604]S1

Wagner, Thomas [8302-10]S4

Walker, Daniel D. [8297-35] SIP1

Wall, James A. [8294-03]S1

Wallace, Glen [8295A-27]S8

Walsh, Michael J. [8296-20]S4

Walworth, Vivian K. 8288 ProgComm

Wang, Albert [8288-03]S2

Wang, An [8298-06]S2

Wang, Chao [8305-12]S3

Wang, Chy-Lin [8288-68]SP2

Wang, Dong 8304B ProgComm

Wang, Guijin 8295B Chr, [8295B-58]S12

Wang, Guobin [8298-31]SIP

Wang, Haiyin [8299-25]SIP1

Wang, Hongqiang [8295A-40] SIP1

Wang, Juan [8292-49]SIP1, [8292-46]SIP1

Wang, Jue [8293-21]S7A, [8293-21]S7A

Wang, Kun [8288-31]S8

Wang, Meng [8288-13]S4

Wang, Meng 8304B ProgComm

Wang, Michael 8299 ProgComm

Wang, Nan [8294-30]SIP1

Wang, Po-Jen [8301-33]S8

Wang, Qiu [8296-08]S1

Wang, Renzhong [8297-02]S2

Wang, Shen-ge [8292-31]S8, [8302-17]S5

Wang, Shengjin 8302 ProgComm

Wang, Sheng-Jyh [8304B38]S6

Wang, Song [8296-04]S1

Wang, Weixing [8292-53]SIP1

Wang, Wiley H. 8302

ProgComm, [8302-12]S4

Wang, Xin'an [8305-28]S9

Wang, Xinyang 8298

ProgComm, 8298 S5

SessChr, [8298-09]S3

Wang, Xusheng [8290-05]S3

Wang, Yanwei [8297-08]S3

Wang, Yuheng [8305-30]S9

Waqas, Mahmood [8293-08] S3

Ward, Chris $8288 \mathrm{~S} 10$

SessChr, 8288 S SessChr, 8288 ProgComm, El12SE S SessChr

Ward, Matthew O. 8294 ProgComm

Ward, Paul A. S. [8293-10]S4

Ward, William S. [8295A-42] SIP1

Ware, Colin [8294-06]S3

Waslander, Steven [8301-22] S5

Watson, Andrew B. 8291 ProgComm

Watt, Simon J. [8288-51]S13

Watt, Stephen M. [8297-10]S3

Waugh, Lester [8301-23]S6

Wei, Xizhang [8295A-40]SIP1

Weigel, Christian [8290-02]S1

Weiß, Denes [8290-44]SIP1
Weissman, Michael A. 8288 ProgComm, 8288 S2 SessChr

Wellner, Mike [8291-02]S1 Wen, Tian Dong [8292-49] SIP1

Wernert, Eric A. [8289-16]S5

West, James E. [8291-18]S4

West, Ruth G. [8289-15]S4

Westermann, Rüdiger [8294 22]S11, [8294-23]S11

Westhofen, Martin [8288-01] S1

Westin, Jerker [8300-24]SIP-

Westland, Stephen 8292

ProgComm

Wey, Hocheon [8288-77]SP3, [8288-76]SP3, [8288-87] SP4

Wichner, Christian [8291-02] S1

Widenhorn, Ralf $8298 \mathrm{Chr}$, [8298-13]S4

Wietzke, Lennart [8291-04]S1

Wijnhoven, Rob [8295A-05]S2

Wilcox, Laurie [8288-21]S6, [8288-29]S8

Wille, Manuel [8291-02]S1

Willems, Pieter [8298-01]S1

Williams, Don [8293-11]S4

Willner, Konrad [8301-23]S6

Winer, Eliot [8289-20]S6,

[8291-21]S9A, [8291-21] S5A

Winkens, Christian [8301-24] S6

Wippermann, Frank C. [829906]S1

Wirtz, Stefan [8290-44]SIP1

Witkowski, Marcin [8289-22] S6, [8290-31]S7

Wolfe, Patrick J. $8296 \mathrm{Chr}$ [8296-25]S5

Wong, Chung M. 8295B ProgComm

Wong, Pak C. 8294 S SessChr, 8294 S1 SessChr, $8294 \mathrm{Chr}$

Wong, Ping Wah [8299-04]S1

Woods, Andrew J. SC060 Inst, $8288 \mathrm{~S}$ SessChr, 8288 S1 SessChr, 8288 S SessChr, 8288 S SessChr, $8288 \mathrm{Chr}$, [8288-49]S13

Woods, John W. 8305 ProgComm

Woods, Mark [8301-09]S2, [8301-23]S6

Woolfe, Geoff [8293-21]S7A, [8293-21]S7A

Wu, Charles Q. [8291-58]SP2

Wu, Min 8303 ProgComm

Wu, Wei Xiao [8302-08]S3

Wu, Wencheng [8293-24]S8, [8293-37]SIP1, [8305-31]S8

Wu, Xiaolin 8305 ProgComm, [8305-17]S5

Wu, Xunlei [8294-08]S3, [8294-26]SIP1, [8294-27] SIP1

Wu, Yingcai 8294 ProgComm

Wu, Yue [8304A-31]SIP1

Wueller, Dietmar [8293-04]S2, [8293-04]S4, SC1058 Inst, 8299 ProgComm

Wurtele, Eve Syrkin [828904]S2
$\mathrm{X}$

Z

Xi, Shikun [8292-50]SIP-

Xiao, Feng 8299 CoChr

Xie, Bingqing [8297-05]S2

Xin, Zhang Yi [8292-49]SIP1

Xing, Weiyong [8292-54]SIP1

Xiong, Weihua 8299

ProgComm

Xu, Beilei [8293-24]S8

Xu, Chang [8296-24]S4, [8304A-14]S4

Xu, Changsheng 8304B

ProgComm

$\mathrm{Xu}$, Chen [8298-03]S1

Xu, Jiayao [8305-28]S9

Xu, Peng [8291-59]SP2

Xue, Haitao [8292-24]S6

Xue, Shao-Fu [8302-13]S4

Xue, Wufeng [8291-65]SP2

Y

Yamada, Kenji [8288-74]SP3

Yamada, Masayoshi [8296-38] SIP1

Yamamoto, Hirotsugu [8288-98]SP2

Yamamoto, Manabu [8295B61]SIP1

Yan, Mei [8298-03]S1

Yan, Rong 8304B ProgComm, [8304B-46]SK2

Yang, Bian [8304A-20]SIP1

Yang, Degui [8295A-40]SIP1

Yang, Jun [8302-14]S5, 8304B ProgComm

Yang, Yongyi 8296 ProgComm

Yanikoglu, Berrin 8297 ProgComm

Yasakethu, Lasith [8288-14]S4

Yasan, Alireza 8299 ProgComm

Yasutomi, Keita [8298-06]S2

Yeh, Chih-Kuo [8294-24]S11

Yeh, Hsiu-Chi [8288-91]SP4

Yendo, Tomohiro [8288-79] SP3

Yeo, Kiatseng [8298-03]S1

Yi, Guanyu [8288-91]SP4

Yi, Hong [8294-25]SIP1

Yin, Jing [8303-12]S5

Yingling, Yaroslava G. [829425]SIP1

Yli-Pietilä, Timo [8304A-24] SIP1

Yokoya, Naokazu [8292-04]S2

Yonai, Jun [8298-22]S6

Yoo, Chang D. 8303

ProgComm

Yoo, Du Sic [8295A-21]S6

Yoo, Seunghun [8299-18]S3, [8299-18]S1

Yoon, Jae-Won [8305-22]S6

Yoshida, Shuhei [8295B-61] SIP1

Yoshida, Tetsuo [8298-22]S6

Young, Mon [8301-27]S6

Youssef, Abdou [8297-34]SIP1

Yu, Hao [8298-03]S1

Yu, Jun [8293-07]S3

Yuan, Bo [8297-17]S6

Yuan, Chang [8288-90]SP4

Yuan, Yue [8302-09]S3

Yun, II Dong [8288-80]SP3
Zakhor, Avideh [8296-29]S6

Zanaty, Peter [8295A-11]S3

Zanibbi, Richard $8297 \mathrm{Chr}$ 8297 S5 SessChr, [8297-17] S6

Zaraga, Federico [8299-05]S1

Zauner, Gerald 8300 ProgComm

Zecha, Dan [8304B-37]S6

Zeffiro, Andrea [8289-06]S2

Zeise, Eric K. 8293 ProgComm

Zelensky, Alexander A. [8295A-04]S1

Zeng, Huan Zhao [8292-20]S5

Zeng, Jun [8292-32]S8

Zerebecki, Chris [8288-39] S10, [8288-92]SP4

Zerubia, Josiane [8296-19]S3

Zhang, Aidong [8290-24]S6

Zhang, Baofeng [8301-06]S2

Zhang, Buyue [8288-07]S2, [8288-17]S5

Zhang, Caixia 8294

ProgComm

Zhang, Dili 8301 ProgComm

Zhang, Heng [8292-03]S1

Zhang, Hongqin 8293

ProgComm

Zhang, Hua [8302-08]S3, [8302-09]S3

Zhang, Jia [8292-34]S9, [8293-27]S8

Zhang, Jian 8294 ProgComm, [8294-10]S4

Zhang, Ke [8288-91]SP4

Zhang, Lei [8291-65]SP2, 8299 ProgComm

Zhang, Lei [8302-18]S5

Zhang, Lei [8305-12]S3

Zhang, Lu [8291-25]S6

Zhang, Song [8290-37]S9

Zhang, Song 8294 ProgComm

Zhang, Xi [8293-33]S10

Zhang, Xiafen [8297-23]S8

Zhang, Xufeng [8295A-40] SIP1

Zhang, Xujie [8292-35]S9, [8293-06]S3

Zhang, Yao [8295B-59]S12

Zhang, Yixin [8292-44]SIP1. [8292-46]SIP1, [8292-50] SIP1

Zhang, Yixin [8292-54]SIP1

Zhang, Yu [8302-08]S3

Zhao, Chang [8305-07]S2

Zhao, Debin [8305-07]S2

Zhao, Xiaojie [8291-59]SP2

Zhao, Yong [8305-28]S9

Zhao, Yonghui [8302-17]S5, [8305-32]S9 
IS\&T/SPIE

Electronic

SCIENCE AND TECHNOLOGY

\section{2-26 January 2012}

Vol\# Title (Editor)

Prepublication Price

8288 Stereoscopic Displays and Applications XXIII (A. J. Woods/N. S. Holliman/G. E. Favalora). . . . . . . \$120

8289 The Engineering Reality of Virtual Reality 2012 (I. E. McDowall/M. Dolinsky) . . . . . . . . . . . . . . \$53

8290 Three-Dimensional Image Processing (3DIP) and

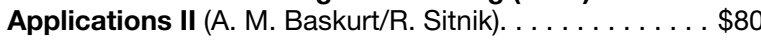

8291 Human Vision and Electronic Imaging XVII (B. E. Rogowitz/T. N. Pappas/H. de Ridder) . . . . . . . . \$ \$100

$\checkmark 8292$ Color Imaging XVII: Displaying, Processing, Hardcopy, and Applications (R. Eschbach/G. G. Marcu/A. Rizzi) . .\$80

8293 Image Quality and System Performance IX (F. Gaykema/P. D. Burns). . . . . . . . . . . . . . \$70

$\checkmark 8294$ Visualization and Data Analysis 2012 (P. C. Wong/ D. L. Kao/M. C. Hao/C. Chen). . . . . . . . . . . . . \$70

8295 Image Processing: Algorithms and Systems X; and Parallel Processing for Imaging Applications II (K. O. Egiazarian/S. S. Agaian/A. P. Gotchev/J. Recker/ G. Wang) . . . . . . . . . . . . . . . . . . . \$90

8296 Computational Imaging X (C. A. Bouman/l. Pollak/ P. J. Wolfe). . . . . . . . . . . . . . . . . . \$60

8297 Document Recognition and Retrieval XIX (C. Viard-Gaudin/R. Zanibbi)

8298 Sensors, Cameras, and Systems for Industrial and Scientific Applications XIII (R. Widenhorn/V. Nguyen/ A. Dupret) . . . . . . . . . . . . . . . . . . \$60

8299 Digital Photography VIII (S. Battiato/B. G. Rodricks/ N. Sampat) . . . . . . . . . . . . . . . . . 660

8300 Image Processing: Machine Vision Applications V

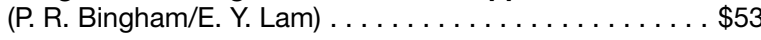

$\checkmark 8301$ Intelligent Robots and Computer Vision XXIX: Algorithms and Techniques (J. Röning/D. P. Casasent). . . . . . . \$70

8302 Imaging and Printing in a Web 2.0 World III (Q. Lin/ J. P. Allebach/Z. Fan). . . . . . . . . . . . . . . \$60

8303 Media Watermarking, Security, and Forensics 2012 (N. D. Memon/A. M. Alattar/E. J. Delp III) . . . . . . . . \$53

8304 Multimedia on Mobile Devices 2012; and Multimedia Content Access: Algorithms and Systems VI (R. Creutzburg/D. Akopian/C. G. Snoek/N. Sebe/ L. Kennedy). .

8305 Visual Information Processing and Communication III (A. Said/O. G. Guleryuz/R. L. Stevenson) . . . . . . . . . \$60

\section{Searchable CD with Multiple Conferences}

CDs are now available within 8 weeks of the meeting.

Full-text papers from all 18 Proceedings volumes.

PC, Macintosh, and Unix compatible.

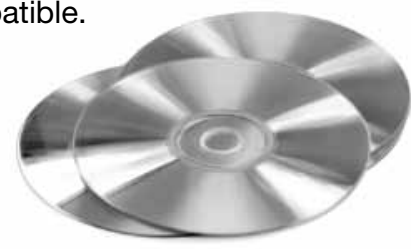

\section{Electronic Imaging 2012}

(Includes Vols. 8288-8305)

Order No. CDS465 • Est. pub. March 2012

Meeting attendee: $\$ 135$

Nonattendee member price: $\$ 890$

Nonattendee nonmember price: $\$ 1170$

\section{Order Proceedings volumes now and receive low prepublication prices.}


First Name

M.I.

Last Name

Title

Company

Address (include Mail Stop)

City

State/Province

Zip/Postal Code

Country other than USA

Phone

Fax

E-Mail Address (SPIE does not sell e-mail addresses)

Date of Birth (Optional)
For Office Use Only

Date

Amt. Recd

CC Cash Check TC

Check \#

P.O. \#

IDN \#

ORD \#

MEMBERSHIP TOTAL

$\$$

SPIE Online Journal Option:

$\square$ Optical Engineering $\square$ Electronic Imaging $\square$ Biomedical Optics $\square$ Microlithography, Microfabrication, and Microsystems $\square$ Applied Remote Sensing $\square$ Nanophotonics

\section{SPIE Digital Library Subscription}

1-year subscription, up to 25 full-article downloads: Regular $\sqcup \$ 145 \quad$ Student/Retired $\sqcup \$ 95 \quad$ Nonmember $\sqcup \$ 250$

1-year subscription, up to 50 full-article downloads: Regular $\sqcup \$ 195 \quad$ Student/Retired $\sqcup \$ 125 \quad$ Nonmember $\sqcup \$ 335$

Once form is submitted and validated, you will receive an email confirmation with instructions for setting up your account. At that point, you may begin using all the features of the Digital Library.

\section{Proceedings and Publications}

Fill in the volume or order number(s) and price(s) of the publications you wish to order below.

\begin{tabular}{|l|l|l|l|}
\hline QTY. & VOL NO. & TITLE & PRICE (USD) \\
\hline & & & \\
\hline & & & \\
\hline & & & \\
\hline & & & \\
\hline & & & \\
\hline
\end{tabular}

CA, FL, WA residents add sales tax; Canadian residents must add GST.

$\$$

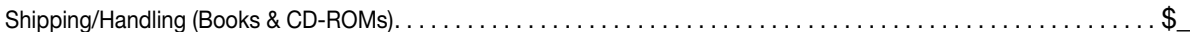

U.S. $5 \%$ of order total [2-3 weeks delivery] Elsewhere $10 \%$ of order total [3-5 weeks delivery]

Express Shipping: U.S. \$15 USD for 1st item; \$10 USD each addl item [2-3 days delivery]

Elsewhere $\$ 30$ USD for 1st item; \$15 USD each addl item [1 week delivery]

\section{Method of Payment}

$\square$ Check enclosed. Payment in U.S. dollars (by draft on a U.S. bank or international money order) is required.

Do not send currency. Wire transfers from banks must include a copy of the transfer order.

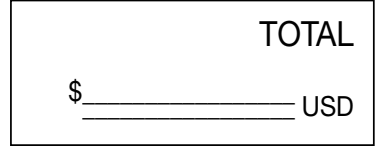
$\sqcup$ Charge to my: $\square$ VISA
$\square$ MasterCard
$\sqcup$ Discover
$\square$ American Express
$\square$ Diners Club

Card Number Security code:

Expiration date

Signature

$\square$ Purchase order enclosed (Purchase orders must be preapproved).

All orders must be PREPAID in U.S. dollars. Prices subject to change without notice. No returns without written authorization of SPIE. ITEMS WILL NOT BE SHIPPED UNLESS PAYMENT IS RECEIVED.
Mail or fax this form to

SPIE, PO Box 10

Bellingham, WA 98227-0010 USA

Phone +1360 6763290

Fax +1360 6471445

spie.org/ei

customerservice@spie.org
SUBTOTAL USD 


\title{
Submit your research to the Journal of Electronic Imaging.
}

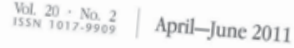

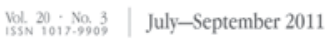

\section{Elecetronic Imaging}

ng
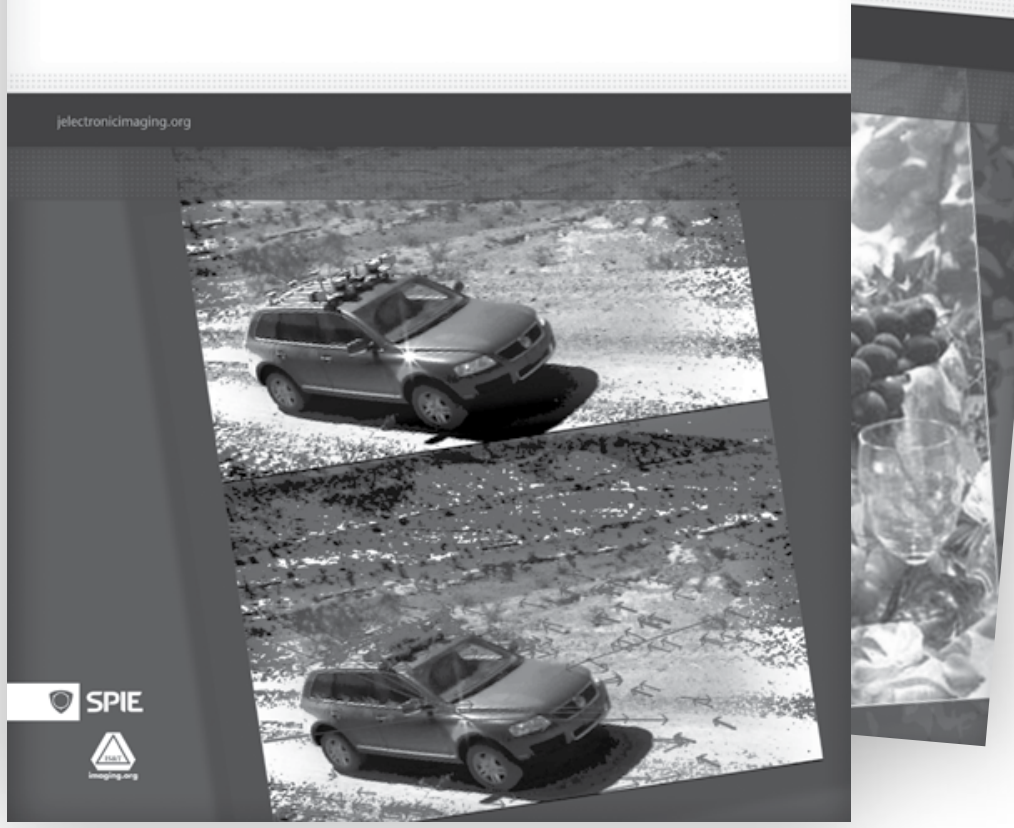

Cin

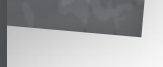

Gaurav Sharma, Editor-in-Chief

\section{spie.org/jei}




\section{About the Symposium Organizers}

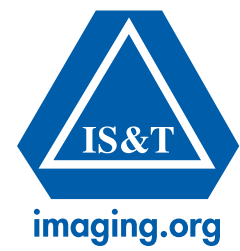

IS\&T, the Society for Imaging Science and Technology, is an international non-profit dedicated to keeping members and others apprised of the latest developments in fields related to imaging science through conferences, educational programs, publications, and its website. IS\&T encompasses all aspects of imaging, with particular emphasis on digital printing, electronic imaging, color science, photofinishing, image preservation, silver halide, pre-press technology, and hybrid imaging systems.

\section{IS\&T offers members:}

- Free, downloadable access to more than 16,000 papers from IS\&T conference proceedings via www.imaging.org

- Complimentary online subscriptions to the Journal of Imaging Science \& Technology or the Journal of Electronic Imaging

- Reduced rates on IS\&T and other publications, including books, conference proceedings, and a second journal subscription.

- Reduced registration fees at all IS\&T sponsored or co-sponsored conferences-a value equal to the difference between member and non-member rates alone-as well as on conference short courses

- Access to the IS\&T member directory

- Networking opportunities through active participation in chapter activities and conference, program, and other committees

- Subscription to the IS\&T The Reporter, a bi-monthly newsletter

- An honors and awards program

Contact IS\&T for more information on these and other benefits.

\section{IS\&T}

7003 Kilworth Lane

Springfield, VA 22151

703/642-9090; 703/642-9094 fax

info@imaging.org

www.imaging.org

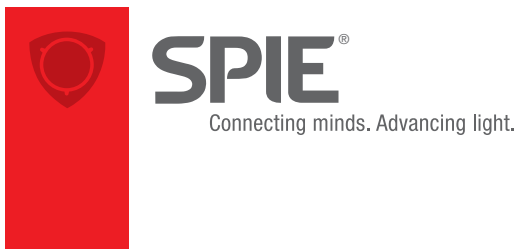

SPIE is an international society advancing an interdisciplinary approach to the science and application of light. SPIE advances the goals of its Members, and the broader scientific community, in a variety of ways:

- SPIE serves the interests of its Members and the broader scientific and technical community who utilize light in their research and application solutions.

- SPIE acts as a catalyst for collaboration among technical disciplines, for information exchange, continuing education, publishing opportunities, patent precedent, and career and professional growth.

- SPIE is a key organizer and sponsor of major conferences, educational programs, and technical exhibitions on emerging technologies around the world. SPIE manages 25 to 30 events in North America, Europe, Asia, and the South Pacific annually; over 40,000 researchers, product developers, and industry representatives participate in presenting, publishing, speaking, learning and networking opportunities.

- The Society spends $\$ 2.3$ million annually in scholarships, grants, and financial support. With more than 160 Student Chapters around the world, SPIE is expanding opportunities for students to develop professional skills and utilize career opportunities, supporting the next generation of scientists and engineers.

- SPIE publishes six scholarly journals and a variety of print media publications. The SPIE Digital Library also publishes the latest research-close to 20,000 proceedings papers each year.

\section{SPIE International Headquarters}

P.O. Box 10, Bellingham, WA 98227-0010 USA

Tel: +1 8885048171 or +13606763290

Fax: +1360 6471445

help@spie.org • SPIE.org

Shipping Address

1000 20th St., Bellingham, WA 98225-6705 USA 


\section{3 Electronic Imaging}

SCEECEC AND TECHNOLOOY 3-7 February 2013

\section{Mark Your Calendar}

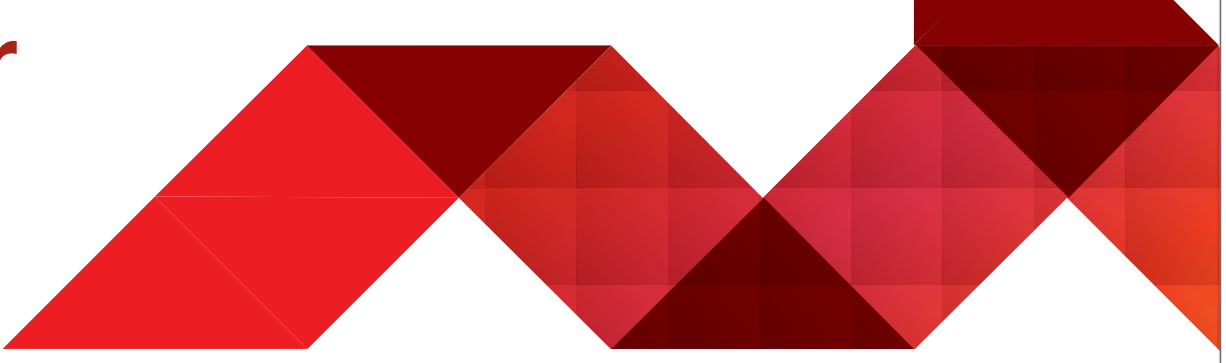

Technologies for digital imaging systems, 3D display, image quality, and optimization

Conference dates

3-7 February 2013

Location

Hyatt Regency San Francisco Airport Hote Burlingame, California, USA

electronicimaging.org
Technologies

- 3D Imaging, Interaction, and Measurement

- Imaging, Visualization, and Perception

- Image Processing

- Digital Imaging Sensors and Applications

- Multimedia Processing and Applications

- Visual Information Processing and Communication

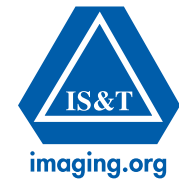

